\title{
MODELLING CHALLENGES OF A HEAT RECOVERY VRF SYSTEM IN A COLD CLIMATE USING A SUSTAINABLE OFFICE CASE STUDY BUILDING
}

\author{
by \\ Cassandra Kani-Sanchez \\ B.Sc. Mechanical Engineering, Queen's University, 2012
}

\author{
A thesis \\ presented to Ryerson University \\ in partial fulfillment of the \\ requirements for the degree of \\ Master of Applied Science \\ in the Program of \\ Building Science
}

Toronto, Ontario, Canada 2015

(C) Cassandra Kani-Sanchez 2015 


\section{AUTHOR'S DECLARATION FOR ELECTRONIC SUBMISSION OF A THESIS}

I hereby declare that I am the sole author of this thesis.

I authorize Ryerson University to lend this thesis to other institutions or individuals for the purpose of scholarly research.

I further authorize Ryerson University to reproduce this thesis by photocopying or by other means, in total, or in part, at the request of other institutions or individuals for the purpose of scholarly research.

I understand that my thesis may be made electronically available to the public. 


\title{
MODELLING CHALLENGES OF A HEAT RECOVERY VRF SYSTEM IN A COLD CLIMATE USING A SUSTAINABLE OFFICE CASE STUDY BUILDING
}

\author{
Master of Applied Science 2015 - Cassandra Kani-Sanchez - Building Science Program \\ Ryerson University
}

\begin{abstract}
There is a need to better understand the performance characteristics of HR VRF systems in a cold climate. This study involved the development of a HR VRF system model in EnergyPlus, using field data from a two-storey case study office building. Using the model, this study investigated calibration with site information, climate variations, VRF indoor terminal unit reconfiguration for heat recovery improvements, right-sizing HR VRF outdoor units to raise part-load ratios, and comparing the HR VRF system to other HVAC systems for system efficiency. Challenges with achieving model calibration led to recommendations for monitoring system design and EnergyPlus modelling improvements.
\end{abstract}




\section{ACKNOWLEDGEMENTS}

Firstly, thank you to my supervisor Dr. Russell Richman for his dedicated guidance and support throughout this thesis research process. I would also like to thank the case study building's building coordinator, systems operator and design team which allowed this research to be executed, through data collection and providing valuable operating information throughout the project. Thank you to Richard Raustad and Karen Walkerman for their invaluable knowledge of modelling in EnergyPlus. I would like to thank Mario Kani and my Building Science peers for entertaining my endless questions and theories and for their advice and support. Finally, I would also like to acknowledge the funding provided by the National Science and Engineering Research Council and Connect Canada in part of the Government of Canada, as well as the Centre for Urban Energy at Ryerson University, which helped initiate this research. 


\section{TABLE OF CONTENTS}

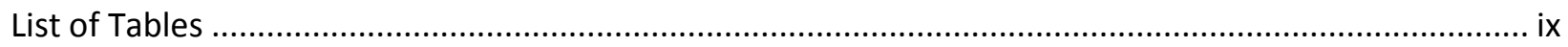

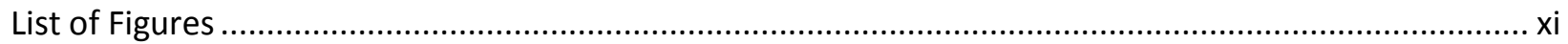

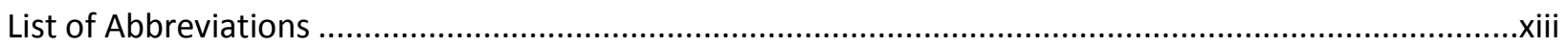

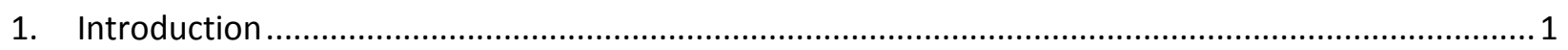

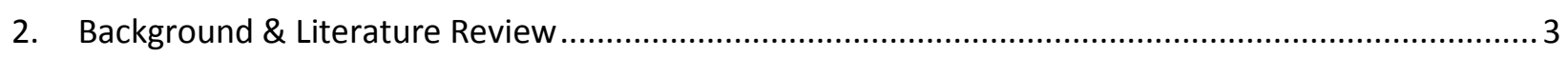

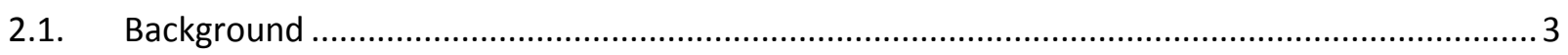

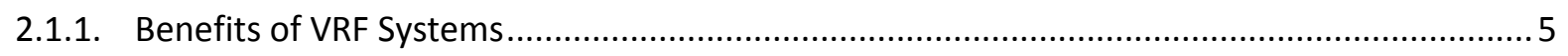

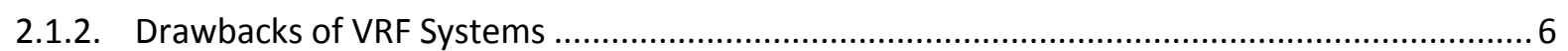

2.1.3. Performance Characteristics ....................................................................................... 7

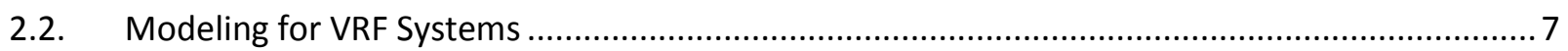

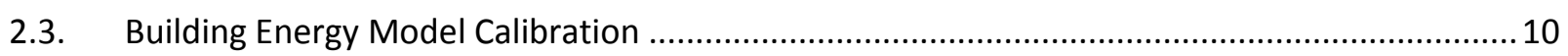

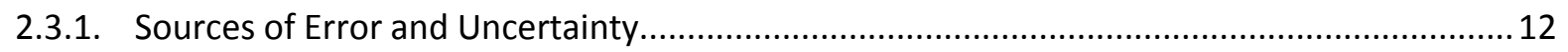

2.3.2. Findings from Previous Calibration Studies ..................................................................... 12

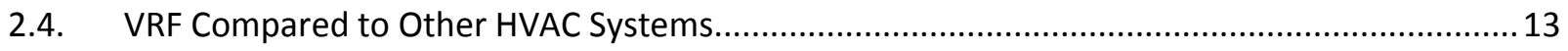

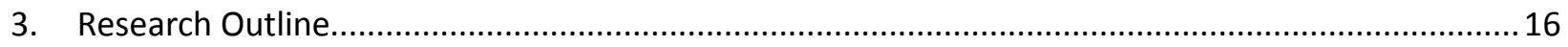

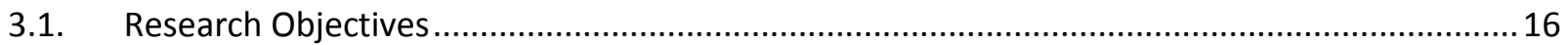

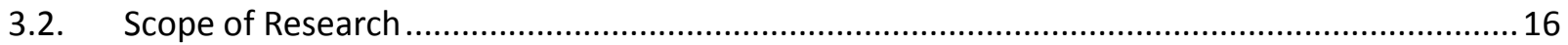

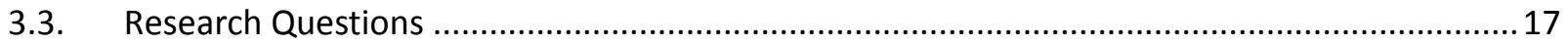

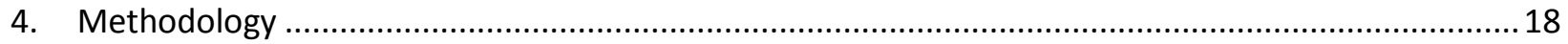

4.1. Determining Building Characteristics................................................................................ 18

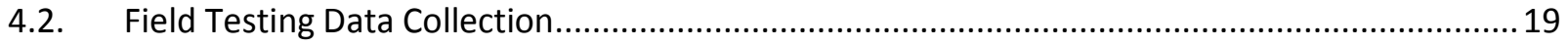

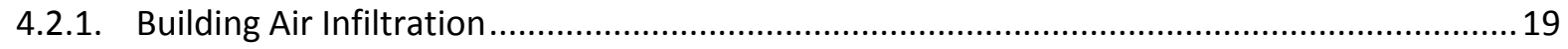

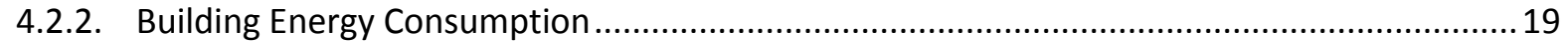

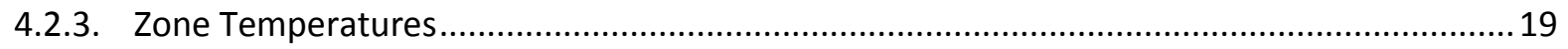

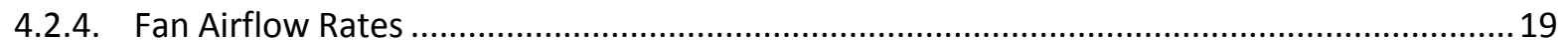

4.3. Developing the EnergyPlus Baseline Model from EE4 ........................................................... 19

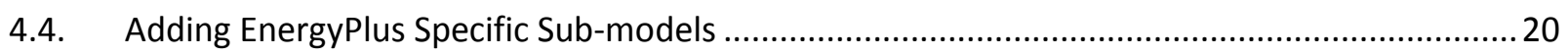

4.5. Developing the EnergyPlus Advanced Model ....................................................................... 20

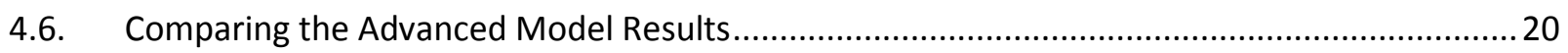

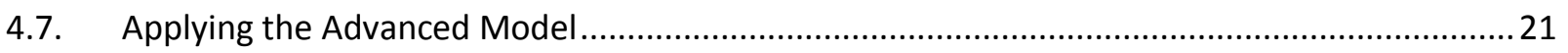

4.7.1. Weather Sensitivity Analysis for VRF Performance ........................................................... 21

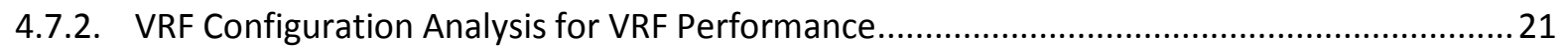

4.7.3. Heating and Cooling Systems Comparison ....................................................................... 21 


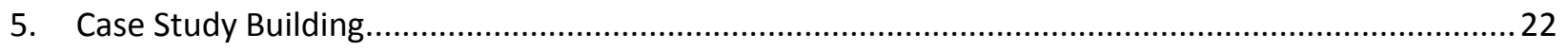

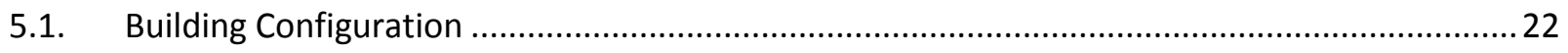

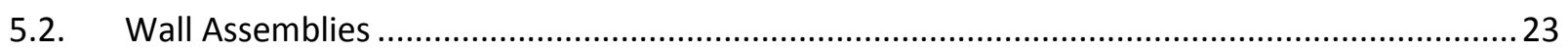

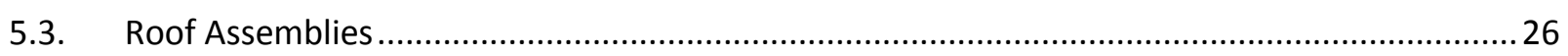

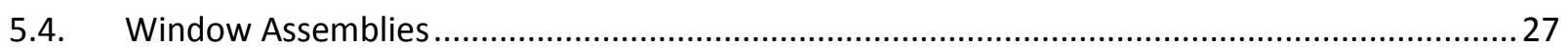

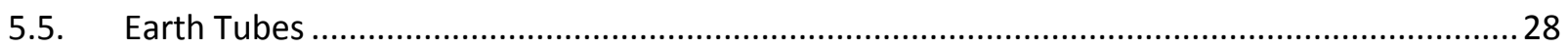

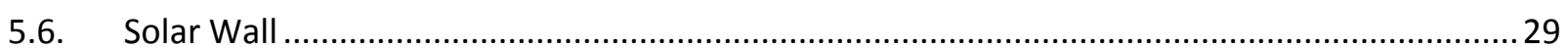

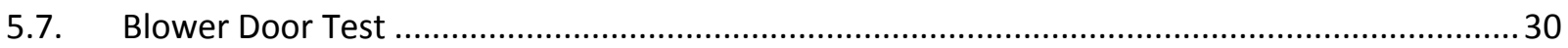

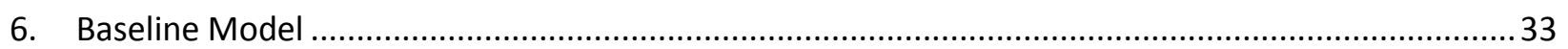

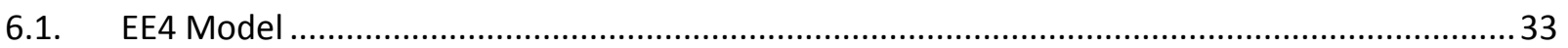

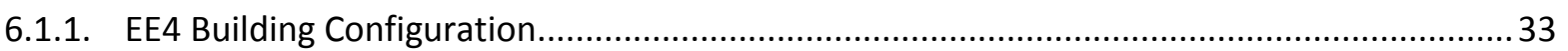

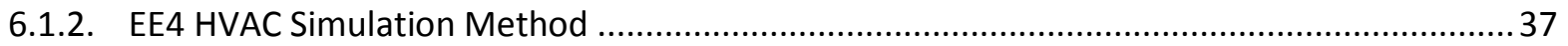

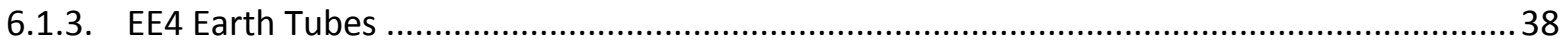

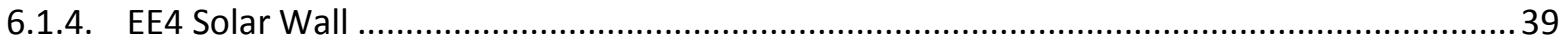

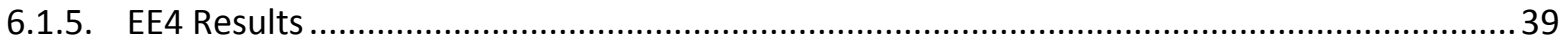

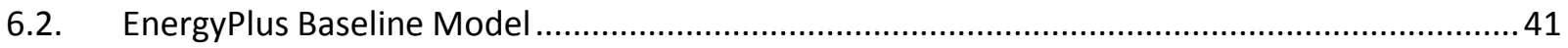

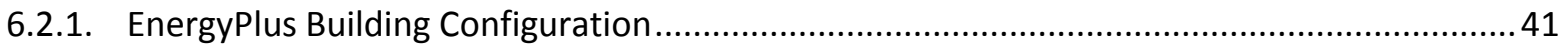

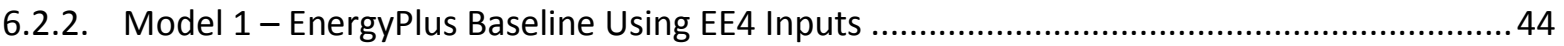

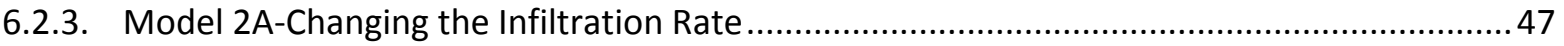

6.2.4. Model 2B - Custom VRF Performance Curves.................................................................... 48

6.2.5. Model 2C \& 2D- Earth Tubes .............................................................................................. 51

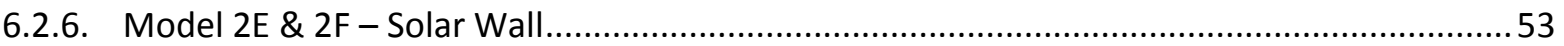

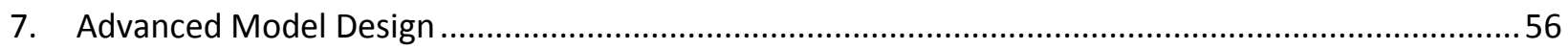

7.1. Advanced Model Development Process Overview ...............................................................56

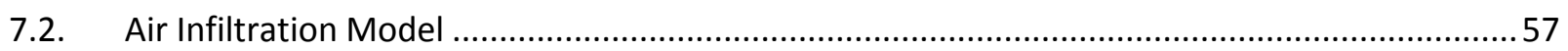

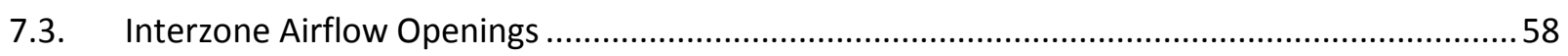

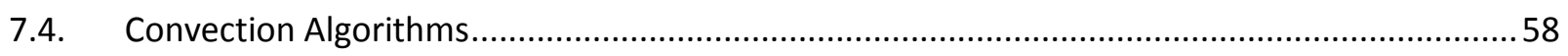

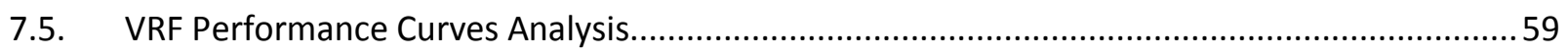

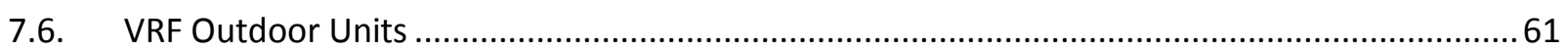

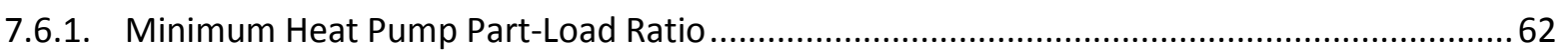

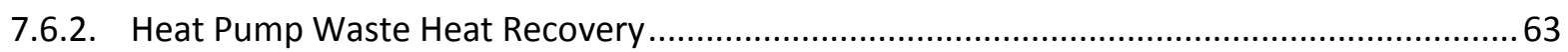

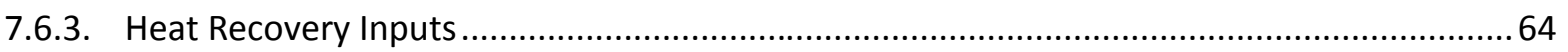

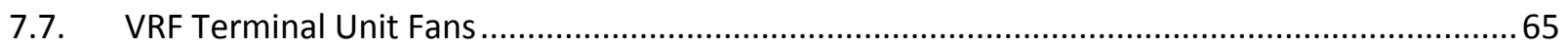

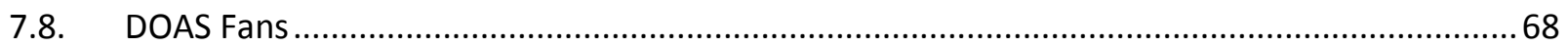

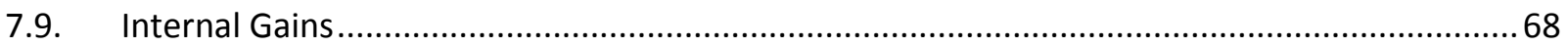




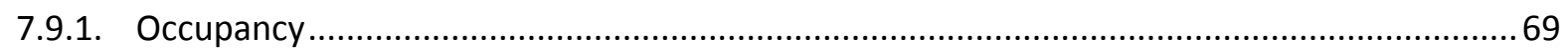

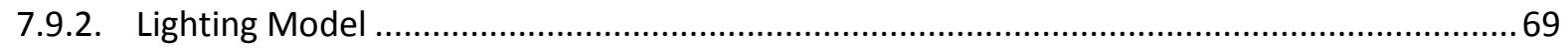

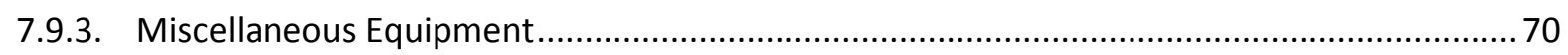

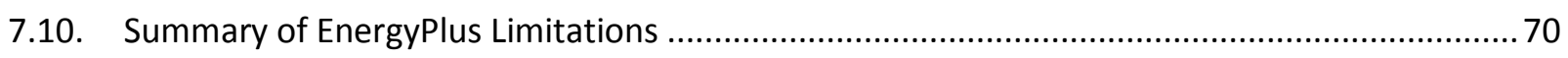

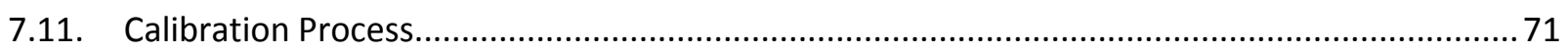

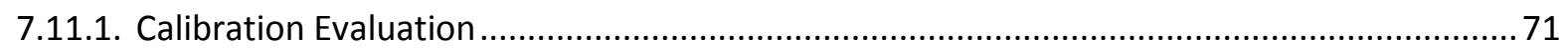

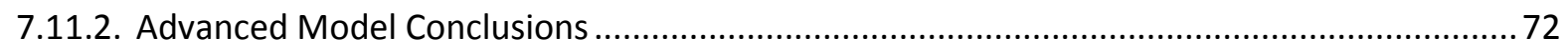

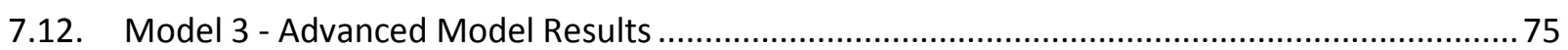

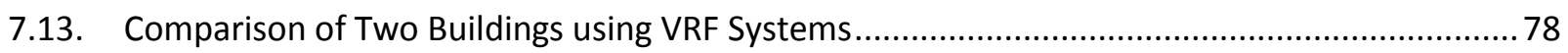

8. Building Performance Based on Varying Weather Conditions ........................................................ 82

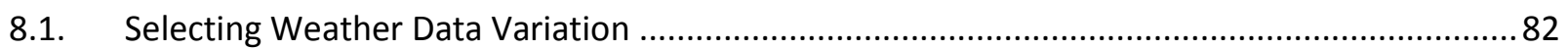

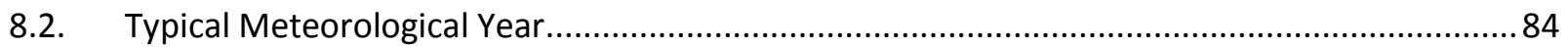

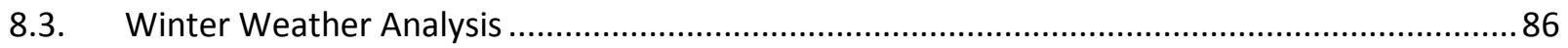

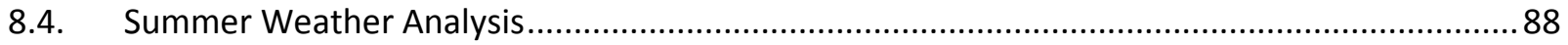

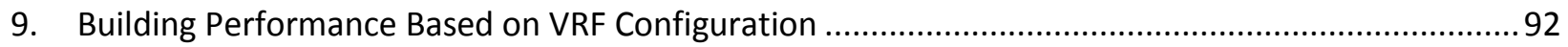

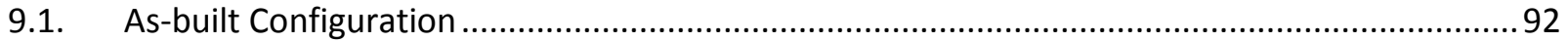

9.2. Balancing Zone Heating \& Cooling Loads Through Indoor Terminal Unit Placements ...............93

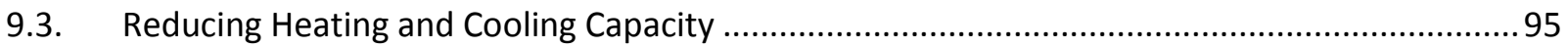

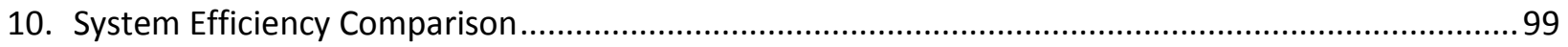

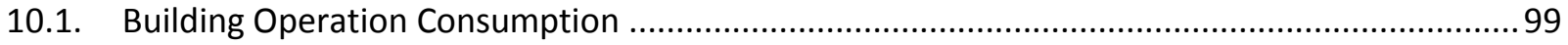

10.1.1. Heat Recovery VRF Heat Pump System ........................................................................ 99

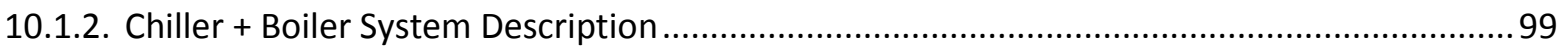

10.1.3. Ground Source Heat Pump System Description .............................................................. 101

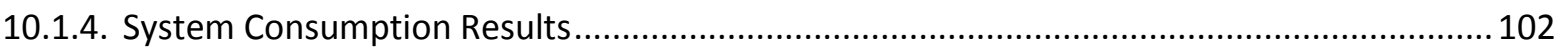

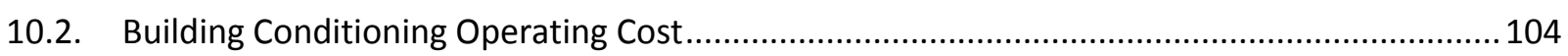

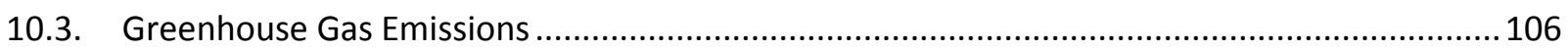

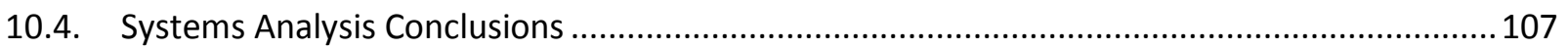

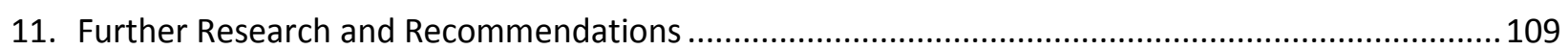

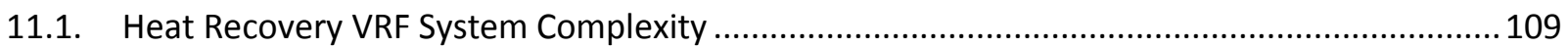

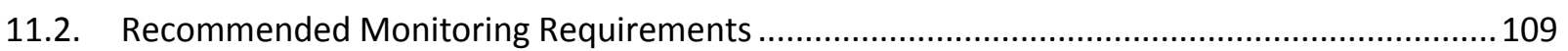

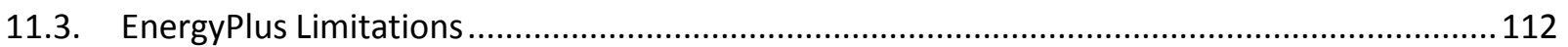

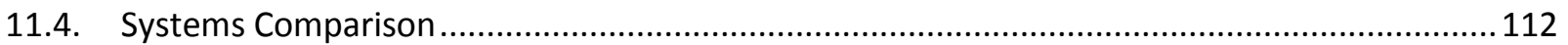

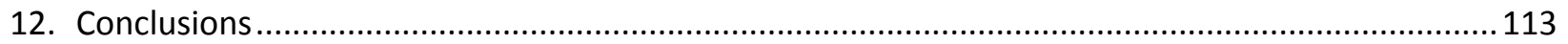

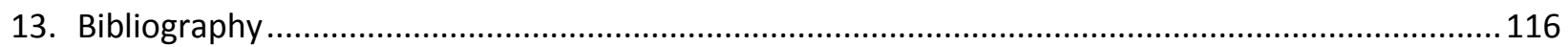

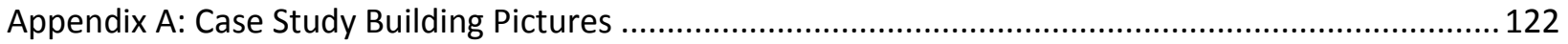




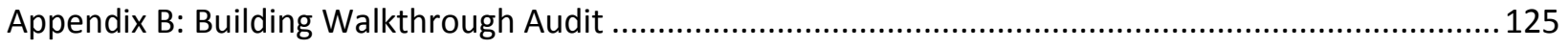

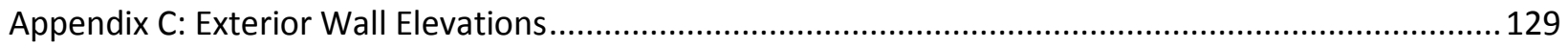

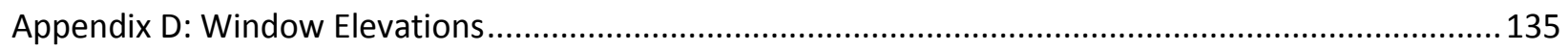

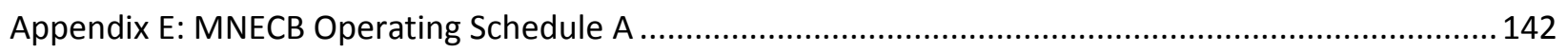

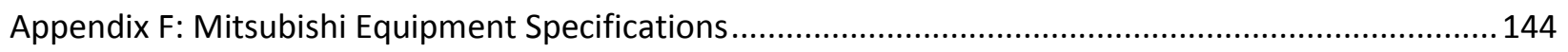

Appendix G: Developed Mitsubishi Performance Curves .................................................................... 146

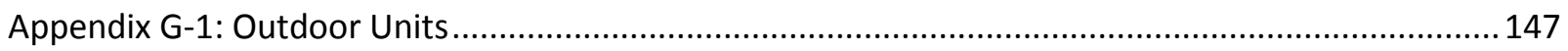

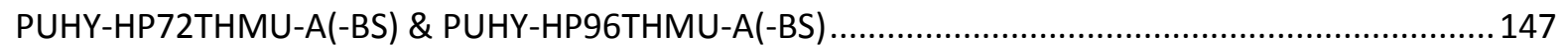

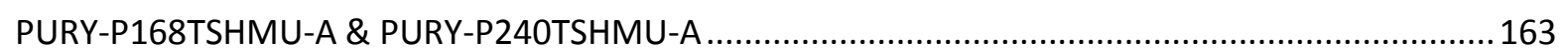

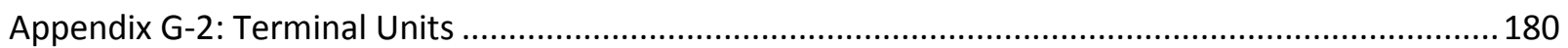

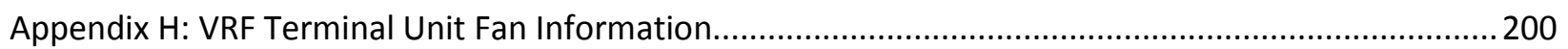

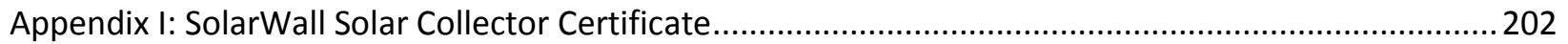




\section{LIST OF TABLES}

Table 1: Blower Door Test Results

Table 2: EE4 Model Building Material Properties (MMM Group Limited, 2012) .................................36

Table 3: EE4 Model Building Glazing Properties (MMM Group Limited, 2012) .................................37

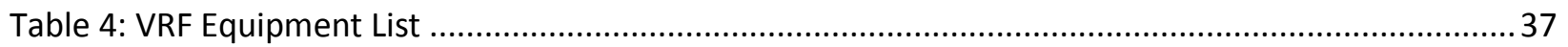

Table 5: UTRCA EE4 Building Loads by Thermal Zone............................................................... 40

Table 6: UTRCA EE4 Annual Modelling Results by Consumption Type..............................................41

Table 7: EnergyPlus Model 1 Modelling Results - Loads Summary by Thermal Zone ..........................45

Table 8: EE4 and EnergyPlus Model 1 Annual Modelling Results by Consumption Type Comparison ...... 46

Table 9: EnergyPlus Model 2A Annual Modelling Results by Consumption Type - Impact of Changing the Infiltration Rate

Table 10: EnergyPlus Model 2B Annual Modelling Results by Consumption Type - Impact of Changing VRF Performance Curves

Table 11: EnergyPlus Model 2C Annual Modelling Results by Consumption Type - Impact of Decreasing ERW Sensible Effectiveness

Table 12: EnergyPlus Model 2D Annual Modelling Results by Consumption Type - Impact of Adding Earth

Tubes. .53

Table 13: Solar Wall Inputs for EnergyPlus. 54

Table 14: EnergyPlus Model 2E Annual Modelling Results by Consumption Type - Impact of Adding a Solar Wall 54

Table 15: EnergyPlus Model 2F Annual Modelling Results by Consumption Type - Impact of Adding a Solar Wall \& Earth Tubes 55

Table 16: Energy Consumption Results for Using Different VRF Performance Curves..... 60

Table 17: Energy Consumption Difference Based on Minimum Heat Pump Part-Load Ratio Input ..... .62

Table 18: VRF Terminal Unit Fan Inputs by Product Tag .66

Table 19: Tested and Simulated Fan Power by Product Tag..... 67

Table 20: Fluorescent Lighting Luminaire Configuration (US Department of Energy, 2014) 69

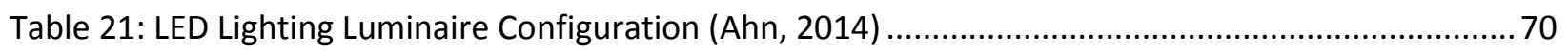

Table 22: EnergyPlus Model 3 Annual Modelling Results by Consumption Type .................................... 75

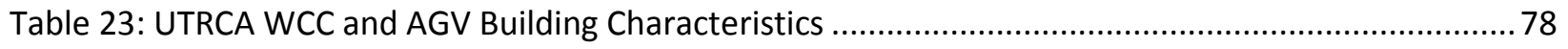

Table 24: Simulated Annual Energy Consumption Comparison for UTRCA WCC and AGV .......................79

Table 25: Monthly Energy Consumption Comparison for UTRCA WCC and AGV ....................................80 
Table 26: Simulated and Metered Electrical Intensities for UTRCA WCC and AGV.....

Table 27: Extreme Winter Years for the Case Study Building Location .

Table 28: Extreme Summer Years for the Case Study Building Location ................................................... 84

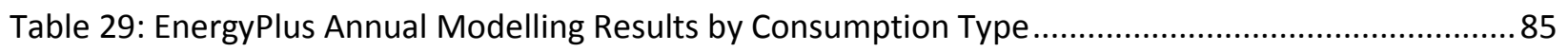

Table 30: EnergyPlus Winter Modelling Results by Consumption Type - Warm Winter: 1123 HDD, Cold

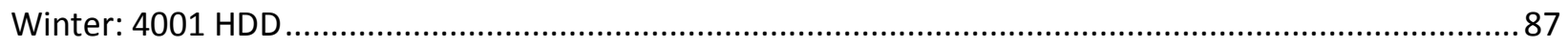

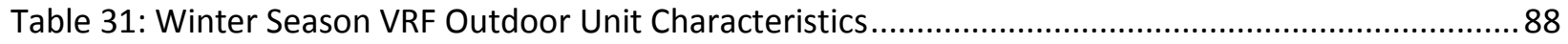

Table 32: EnergyPlus Summer Modelling Results by Consumption Type - Hot Summer: 399 CDD, Cool

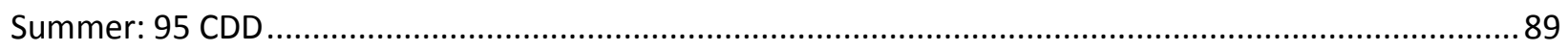

Table 33: Summer VRF Outdoor Unit Characteristics............................................................................ 90

Table 34: Summer Season Cooling and Heating Energy Supply Saved Using Heat Recovery Mode ...........90

Table 35: Capacities and Peak Loads for the VRF Outdoor Units for As-built Configuration .....................93

Table 36: Capacities and Peak Loads for the VRF Outdoor Units (Re-configured - Two Outdoor Units

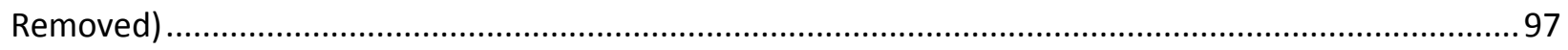

Table 37: VRF Outdoor Units' Capacity Comparison - Outdoor Unit Energy Consumption ......................97

Table 38: EnergyPlus Modelling Results by Consumption Type - Impact of Reducing the VRF Outdoor

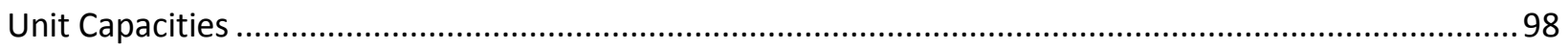

Table 39: Building Equipment Required Output by Season ............................................................... 103

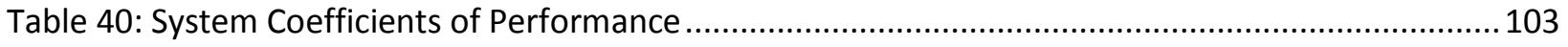

Table 41: System Consumption Comparison for a TMY …................................................................. 103

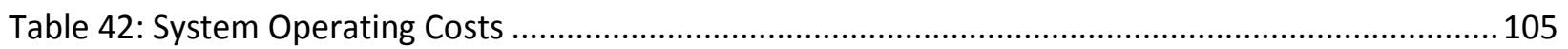

Table 43: System Operating Carbon Dioxide Emissions ................................................................... 107 


\section{LIST OF FIGURES}

Figure 1: Schematic Diagram of a VRF System with One Outdoor Unit and Four Indoor Units (Aynur,

Variable refrigerant flow systems: A review, 2010) .......................................................................... 4

Figure 2: Mitsubishi 2-Pipe Heat Recovery VRF Schematic (Vanderwesten Rutherford Mantecon Inc., 2010) 5

Figure 3: Case Study Building (Upper Thames River Conservation Authority) .......................................22

Figure 4: Exterior Wall Schematics for EW1, EW3 and EW5 (Wilson, 2010) ..........................................23

Figure 5: Foundation Wall Assembly Schematics for FW1 and FW3 (Wilson, 2010)...............................24

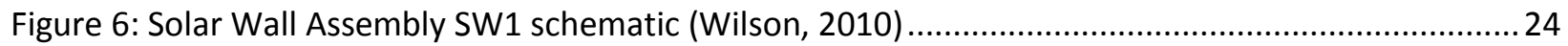

Figure 7: Spandrel Glass Wall Assembly GLA3 Schematic (Wilson, 2010) ..............................................25

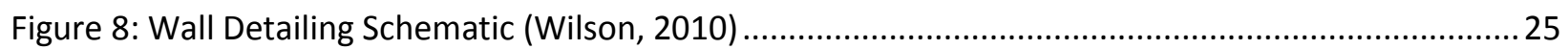

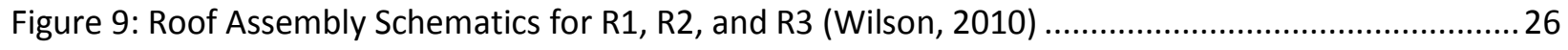

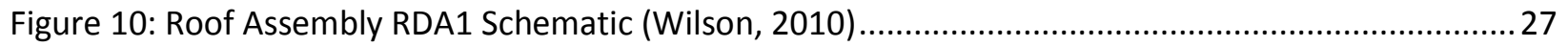

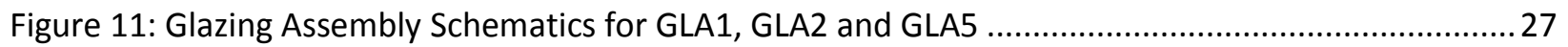

Figure 12: Example Schematic of an EAHE (Peretti, Zarrella, De Carli, \& Zecchin, 2013)......................... 28

Figure 13: SolarWall Typical Construction (left) and Solar Airflow Heating Schematic (right) (Conserval

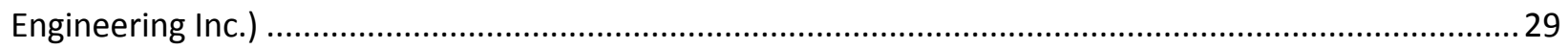

Figure 14: EE4 Zoning Diagram - Lower Floor (MMM Group Limited, 2012) ......................................... 34

Figure 15: EE4 Zoning Diagram - Upper Floor (MMM Group Limited, 2012) ......................................... 35

Figure 16: EnergyPlus Zoning Diagram - Upper Floor ............................................................................ 42

Figure 17: EnergyPlus Zoning Diagram - Lower Floor .......................................................................... 43

Figure 18: Outdoor Units Energy Consumption by Performance Curves ..............................................6 60

Figure 19: Outdoor Units Energy Consumption for Minimum Heat Pump Part-Load Ratio Analysis.........62

Figure 20: Outdoor Units Energy Consumption for Heat Recovery Analysis............................................63

Figure 21: Correlations between COP and PLR for a summer day ...................................................... 74

Figure 22: Whole Building Monthly Energy Consumption for Model 3 and Building Metered Data ......... 75

Figure 23: Outdoor Units Monthly Energy Consumption 2013-2014 .................................................... 76

Figure 24: Indoor Terminal Units Monthly Energy Consumption 2013-2014..........................................77

Figure 25: TMY and AMY Simulated Building Energy Consumption Results .......................................... 85

Figure 26: Winter Weather Building Energy Consumption Results ........................................................ 86

Figure 27: Winter Season Cooling and Heating Energy Supply Saved Using Heat Recovery Mode ............ 88

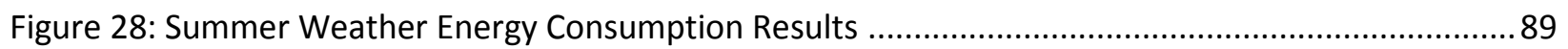


Figure 29: As-built VRF Configuration - Lower Floor (left), Upper Floor (right).

Figure 30: Moving Four Indoor Terminal Unit Reconfiguration - Lower Floor (left), Upper Floor (right) .. 94

Figure 31: North-South VRF Reconfiguration - Lower Floor (left), Upper Floor (right) ........................... 94

Figure 32: Reduced Outdoor Unit Capacity VRF Configuration - Lower Floor (left), Upper Floor (right)...96 


\section{LIST OF ABBREVIATIONS}

AGV - A Grander View

AMY - Actual Metrological Year

ASHRAE - American Society of Heating Refrigeration and Air Conditioning Engineers

CDD - Cooling Degree Days

CV(RMSE) - Coefficient of Variation of Root Mean Square Error

CWEC - Canadian Weather year for Energy Calculation

DOE - Department of Energy (US)

EAHE - Earth-to-Air Heat Exchangers

ERW - Energy Recovery Wheel

FPFA - Fan coil Plus Fresh Air

GHG - Green House Gas emissions

GSHP - Ground Source Heat Pump

HDD - Heating Degree Days

HP- Heat Pump

HR - Heat Recovery

HVAC - Heating Ventilation and Air Conditioning

NMBE - Normalized Mean Bias Error

TARP - Thermal Analysis Research Program

TMY - Typical Metrological Year

UTRCA - Upper Thames River Conservation Authority

VAV - Variable Air Volume

VRF - Variable Refrigerant Flow

WCC - Water Conservation Centre 


\section{INTRODUCTION}

Energy efficient building and system design has become increasingly popular as a result of the decreasing availability of fossil fuels and its rising environmental impacts to the planet. The technologies to aid in the energy reduction process, as well as the knowledge in the industry, have also grown in recent years making implementation easier. Along with minimizing the energy usage in a building, there is a demand for increased thermal comfort as well as healthy living and working environments. The design of the building's HVAC system plays a big role in meeting these demands, therefore critical attention of these systems is needed. There are a variety of system combinations that can be used to satisfy the building's heating, cooling and ventilation needs such as variable air volume (VAV), fan coil plus fresh air (FPFA) and variable refrigerant flow (VRF) systems. The ideal system for any specific building will depend on several building and location factors.

Another contributor to the North American efficient building market was the Leadership in Energy and Environmental Design $\left(\operatorname{LEED}^{\circledR}\right)$ certification program. Although this rating system, like all rating systems, is not perfect, it paved the way for "green building" design to grow in North America. It gave green building design credibility and made the idea become mainstream for people in the industry to aspire to build towards (McLennan, 2011).

Thanks to LEED $^{\circledR}$ and some modifications to building codes, whole building energy modeling has become a more popular step in the design process. Modeling of new buildings has many benefits to the design process which can aid in the determination of the size of mechanical equipment, comparing energy use of different mechanical systems, and optimizing building parameters such as window areas and insulation thicknesses. In Canada there are several programs that are used in industry including EE4 (Natural Resources Canada, 2014), eQuest (Hirsch, 2009), IES (Integrated Environmental Solutions Limited) and HOT2000 (Natural Resources Canada, 2014). Another program, EnergyPlus (US Department of Energy, 2015), is used frequently for research purposes, but is slowly being used more in the design industry.

Accuracy in building energy modeling can be a problem due to many poor operating assumptions, subjective inputs and simplifications, and inadequate algorithms (Reddy, 2006). Calibration of a model is possible but can take a lot time and resources. This is more so when, actual building performance data is not available, as is the case when designing a new building. Once a building has been built and data has been collected, calibration is much easier and one should be able to create a fairly accurate model. This 
new model can aid in energy use management and predictions, as well as optimizing the mechanical system performance in the building.

There have been some experimental and simulation studies done for VRF systems. There have also been some studies done with the equipment installed in a part of a building with artificially simulated indoor heat gains for short periods of time. These studies have primarily focused on cooling aspects of the system, with a couple more recent studies that have focused on some of the heating aspects. The majority of the studies have been done with a Japanese or Chinese context, with a few in Europe and the United States of America, however there have been no published studies of VRF system done in Canada. There have also not been any studies done for continuous long time periods for full postoccupancy buildings.

For this research, a unique opportunity arose with the construction of a small two-storey office building (3345 square meters), in southwestern Ontario. This case study building which was targeting LEED $^{\circledR}$ Platinum certification was completed in December 2012. The building characteristic of interest is the airsource heat recovery variable refrigerant flow heat pump system with indoor terminal units. This system used 5 VRF outdoor units and 57 indoor units for space conditioning. A sixth VRF outdoor unit and an additional indoor terminal unit (make-up air unit) was used for the dedicated outdoor air system. The make-up air unit is connected to a network of ducts to supply the displacement ventilation air throughout the building.

A 12 month building study was undertaken to collect energy consumption and room temperature data for the case study building. An EE4 design model created by the LEED ${ }^{\circledR}$ consultants, along with the collected data, was used to create an advanced building energy model of the case study building in EnergyPlus, which allowed further study of the variable refrigerant flow system parameters used for heating and cooling the building. Using the created EnergyPlus model it was investigated if a heat recovery VRF systems was an efficient system for a cold climate, and if EnergyPlus could accurately model the system. This study is of particular interest as little research has been done on post-occupancy heat recovery VRF system modeling and building performance in a cold Canadian climate. 


\section{BACKGROUND \& LITERATURE REVIEW}

\subsection{BACKGROUND}

Variable Refrigerant Flow (VRF) systems are a type of HVAC technology that were developed in Japan over 25 years ago. They were then introduced to Europe and more recently brought to North America; however the presence of these systems is still small in the United States and Canada. Within recent years there has been a market push as more VRF manufacturers have started to vigorously market their products in North America (Goetzler, 2007).

The VRF system was originally designed as an air conditioning system. The system consists of air-source outdoor compressor unit(s) and multiple indoor terminal evaporator units. The outdoor compressor unit usually has at least two scroll or rotary compressors, where at least one is an inverter-controlled variable speed compressor (Thornton \& Wagner, 2012). It is common to have multiple outdoor units to create an integrated system to serve a building with larger loads. As a ductless system, the heat transfer to or from the zone occurs directly by circulating the refrigerant through the indoor units. The R-410A refrigerant is pushed through the piping based on a pressure differential created by the compressor. Longer piping lengths to circulate the refrigerant in larger buildings will increase the energy generated at the compressor unit (Liu \& Hong, 2010). This refrigerant system has its refrigerant flow rate varied using a variable speed compressor in the outdoor unit and electronic expansion valves (EEVs) in the indoor

units to control the desired indoor air temperature in each zone (Aynur, Variable refrigerant flow systems: A review, 2010).

VRF systems can either be made up of a two-pipe or three-pipe configuration. The two-pipe is used for heating-only or cooling-only modes based upon the season during the year, whereas the three-pipe configuration known as a heat recovery VRF system, allows for simultaneous heating and cooling throughout the year. In the three pipe configuration there is a cooling supply, heating supply, and return pipe. The three pipe system provides five operational modes: cooling-only, cooling-principal, heatingonly, heating-principal, and total heat recovery. In the heat recovery mode the outdoor unit heat exchanger is closed and heat load shifting is done between the indoor units to meet the load demands (Aynur, Variable refrigerant flow systems: A review, 2010). The load shifting is accomplished through an added piece of equipment called the controller. The controller is installed between the outdoor unit and the indoor terminal units, allowing for the refrigerant to be redistributed between the indoor terminal 
units. However, Mitsubishi is able to achieve their heat recovery system using a two-pipe system with a controller (Mitsubishi Electric Canada, 2014).

The indoor terminal units use electronically commutated motors (ECM) which allows for variable-speed control or having a fixed speed and air flow. Without ducts connecting the indoor terminal units, the building's ventilation system works as a separate system with smaller duct sizes. Reduced duct sizes and lengths reduces building height and costs (Goetzler, 2007) (Amarnath \& Blatt, 2008).

As this type of system has the ability to have different operating conditions for each zone, it is ideal for buildings that have multi-purpose/multi-setpoint rooms such as hospitals, office buildings, hotels and conference centers. Figure 1 shows an example of a standard VRF system (no heat recovery) with one outdoor unit and four indoor terminal units. Figure 2 shows an example of Mitsubishi's two-pipe heat recovery system with one outdoor unit, one controller and fourteen indoor terminal units, which is installed in the case study building.

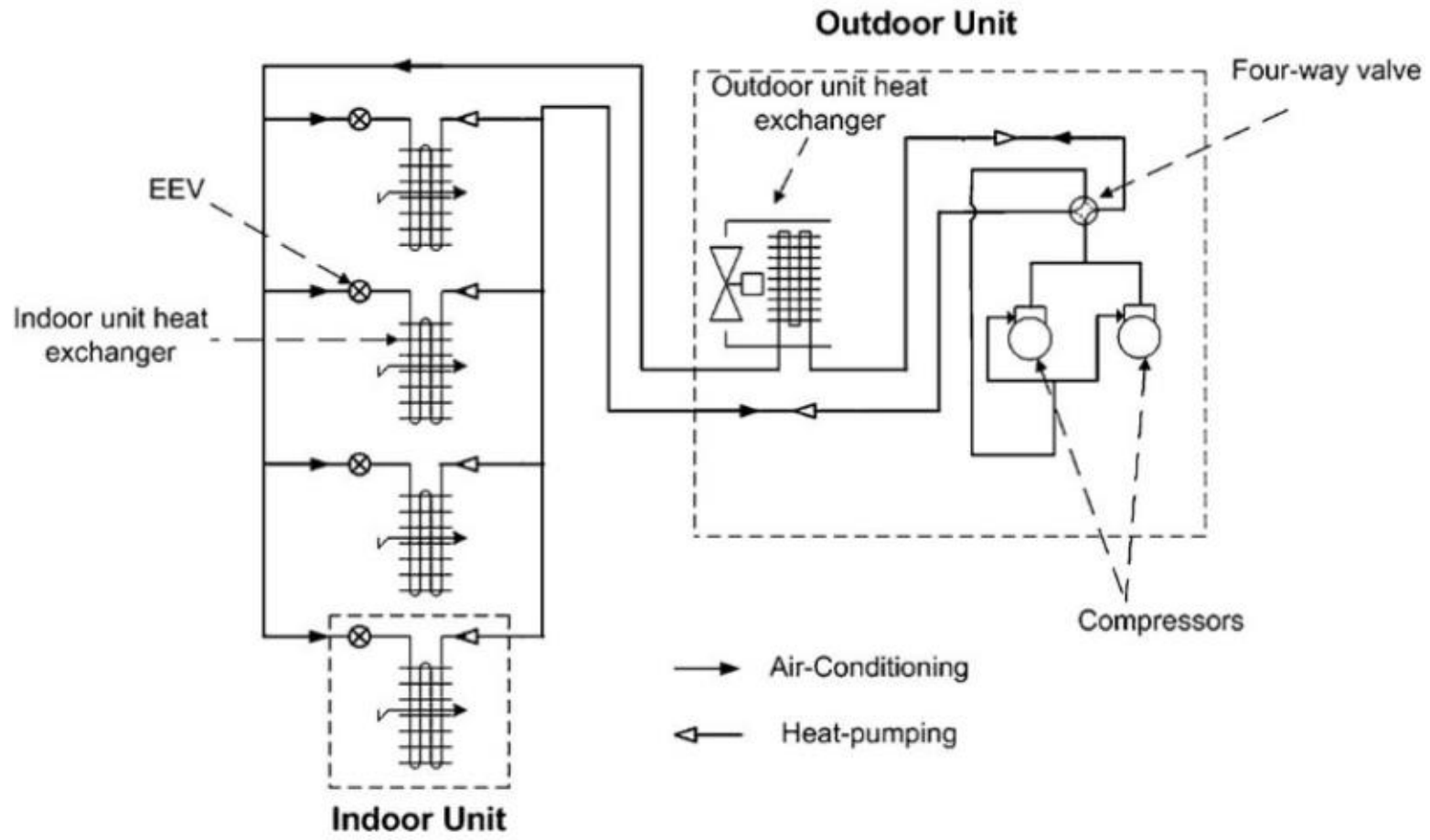

Figure 1: Schematic Diagram of a VRF System with One Outdoor Unit and Four Indoor Units (Aynur, 2010) 


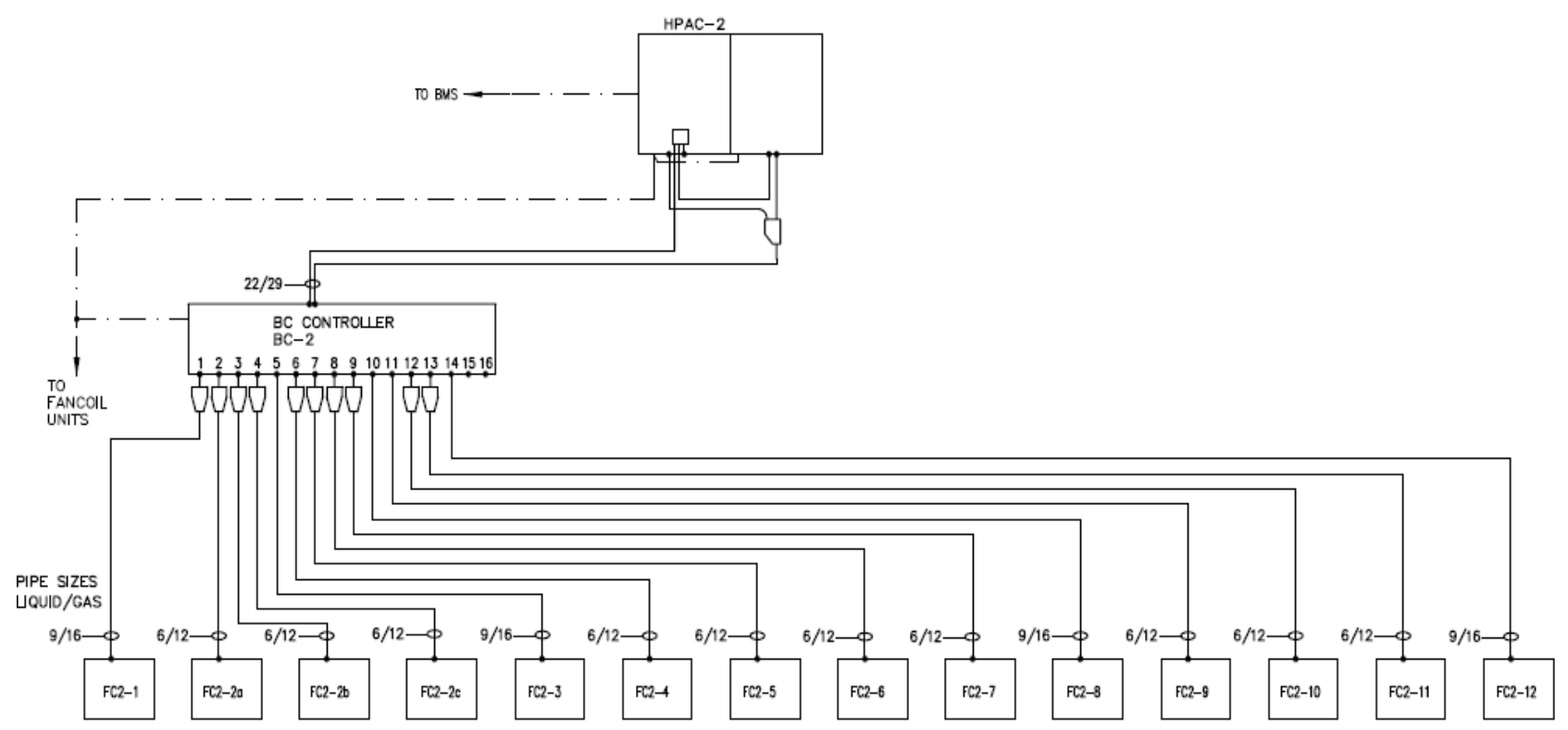

Figure 2: Mitsubishi 2-Pipe Heat Recovery VRF Schematic (Vanderwesten Rutherford Mantecon Inc., 2010)

In Ontario, according to the Ontario Building Code (OBC) SB-10, VRF systems must be designed to meet ASHRAE 90.1 and follow testing procedures under AHRI standard 1230. ASHRAE standard 15-2010 should also be consulted for best practices in refrigerant safety.

\subsubsection{Benefits of VRF Systems}

Due to the design of VRF systems there are many benefits of using this type of system when compared to other common air conditioning and heating systems. The system is modular which allows for easy installation as they are lightweight, fit easily in elevators and can be done in stages as each floor is built, unlike a VAV or FPFA system (Goetzler, 2007). The modularity of the system allows for flexibility in the design as well as making it adaptable for reconfiguration or expansion as the building's use changes over time. The maintenance of VRF systems should be reduced in comparison to systems with water-cooled chillers, as they are direct expansion systems and water treatment issues are not applicable, and mostly consist of changing filters and cleaning the coils (Goetzler, 2007). The zoning of the system enables better comfort control in the building with individual precise zone temperature setpoint controls. VRF systems also allow for smaller ducts to be installed, as they are only used for fresh air ventilation, which can reduce the required building height and ducting costs. Additionally, the energy efficiency of the system is improved with reduced duct losses and fan static pressure as there are no associated ducts with the system (Amarnath \& Blatt, 2008). Due to the multiple compressors, some of which are variable speed compressors, allows for high part-load efficiency of the system resulting in high seasonal energy efficiency (Roth, 2002). 


\subsubsection{Drawbacks of VRF Systems}

VRF systems are not well suited for all types of buildings and the advantages of the systems are best seen in multi-zone buildings using individual and varying zone control such as in office buildings, hospitals, hotels and conference centres. The technology was only recently readily available in North America resulting in minimal knowledge of system performance for the North American context. Without proven studies showing the success of these systems for similar contexts, building owners are skeptical to try new system designs. As the manufacturers of these systems primarily come from Asia, in the past it was difficult to obtain manufacturer support and replacement parts will little presence in the large North American HVAC market (Roth, 2002).

One of the biggest drawbacks is the initial cost for implementation. The associated cost for a VRF system is usually higher than that of a chilled water system, water source heat pump or rooftop direct expansion tank; making it more difficult for building owners to justify spending the extra money when energy saving potentials are unknown (Aynur, 2010). Another concern are long refrigerant piping runs, since contractors consider finding and repairing refrigerant leaks more difficult, as well as a belief of increased liability exposure when large volumes of refrigerant are existing in occupied spaces within the building (Roth, 2002). There is still a lack of awareness of holistic building energy efficiency in North America as industry professionals tend to focus on EER and kW/ton equipment ratings, without considering the impact on the whole building (Goetzler, 2007).

Energy modelling has become more popular as a designing step however the commonly used programs do not incorporate VRF system capabilities and designers are unlikely to move towards using more complex and time consuming programs. The VRF system is known for having high heat pump COP ratings under air conditioning modes. However, heat pump efficiency considerably decreases at low temperatures resulting in the system being less cost effective in heating modes for very cold climates (Goetzler, 2007), as seen in Ontario. An integrated gas heating option could improve the system's efficiency at low temperatures, however this is still currently under development and would also increase the capital cost of the system (Roth, 2002). In addition, codes and standards have only recently started addressing VRF systems (ASHRAE standard 15 implemented in 2010 \& OBC SB-10 implemented in January 2012) which give guidelines to designers for acceptable system practices and performance.

Although VRF systems are very slowly starting to enter the Canadian market, it is unclear how popular they will eventually become. To meet the required peak heating loads, the system may need to be sized 
quite large which results in high comparative capital costs and would also force the system to work at lower part-load ratios for longer periods of the year, making the system less efficient.

\subsubsection{Performance Characteristics}

Each type of HVAC system operates differently making understanding the specific characteristics for that system a critical step for effectively implementing the system and accurately modeling its performance. Experimental analyses have been done to determine performance characteristics for different VRF systems. In (Kang, Joo, Jung, \& Kim, 2008) a heat recovery type system was designed by adding EEVs and a variable speed compressor to the HP-VRF system. By optimizing the control parameters, the EEV opening and varying the compressor speed, the COP increased for the simultaneous heating and cooling modes. In (Hunt et al., 2012) it was determined that the power draw, delivered capacity and EER are dependent on connected load, ratio of cooling to heating, and the net operating mode of the system. This was used to determine the performance of a heat recovery VRF system, with it reaching its highest efficiency when in the net heating mode with some cooling demand. Experimental analysis is performed in a controlled setting, unlike when equipment is used in the field, which leads to the equipment to have varying performance characteristics. It is therefore important to test field equipment for their performance characteristics to determine the variations in results.

\subsection{MODELING FOR VRF SYSTEMS}

Until recently EnergyPlus was the only building energy simulation program that contained a VRF calculation module (Wang et al., 2009). The lack of VRF system modules in simulation tools that are used in the Canadian industry has led to designers using 'workaround' methods, such as zonal air source heat pumps, to try to resemble a VRF system. These workarounds lead to inaccurate prediction of the energy savings for the system (Fang, Heinicke, \& Cooper, 2013). The software packages commonly being used in the Canadian design industry are EE4, eQuest, and HOT2000. Although more advanced programs such as EnergyPlus are technically allowed for compliance to meet local building codes, EnergyPlus is not necessarily a known program in certain districts, which forces the design team/modellers to spend extra time educating the officials and getting the program validated (Pathak M. , 2015). Due to the popular use of eQuest, Daikin created a modelling guide to model VRF systems, using 'workaround' methods, for eQuest (Daikin North America LLC).

VRF system capabilities were introduced to the EnergyPlus software in version 7.2. Due to the complexity and time requirements, EnergyPlus has been primarily used for research in the past and is now only slowing gaining headway into the design industry. Another option is using EnergyPro/DOE 
2.1E which also has fairly extensive VRF modeling capabilities. Its VRF algorithms are similar to the ones used in EnergyPlus with the limitation of only reporting one outside air cut off temperature between the low and high performance curves (Fang, Heinicke, \& Cooper, 2013). In addition, due to the purchasing fee, EnergyPro does not get widely used within the industry.

EnergyPlus is a building simulation engine that uses variable time steps, integrated heat-and-mass balance algorithms for zone simulations, a wide range of HVAC functions, and allows for special module creation or editing through data inputs and outputs, as is needed for each project. The energy performance of the HVAC systems is calculated using performance curves, based on performance data and parameters from manufacturers. Validation work for EnergyPlus has been done with empirical tests; sensitivity and range test suites; as well as studying the energy relationship between the building envelope and the associated HVAC systems (Witte, Henninger, \& Glazer, 2001). This program is more accurate than other programs used in industry as it allows feedback between main HVAC simulation components creating better heat balance responses (Zhou, Wu, Wang, \& Shiochi, 2007).

The VRF system in EnergyPlus is derived from a mathematical model made up of component modules based on the existing model for the air-cooled direct expansion (DX) coil (Zhou, Wu, Wang, \& Shiochi, Energy simulation in the variable refrigerant flow air-conditioning system under cooling conditions, 2007). The project specific VRF input parameters are set in the InputProcess module to simulate the VRF system function. The ManageHVAC module is used in conjunction with InputProcess to bring together all HVAC components and calculate the energy consumption of the entire HVAC system. As the VRF module was created in EnergyPlus source and coding style the module is easily adaptable to any project, allowing for more indoor unit expansion or other equipment add-ons. The completed simulation can create a range of output files including a CSV (spreadsheet) file reporting the selected output parameters. This file allows designers to analyze the system and develop performance optimization practices to create a better suited system for that specific building.

The original VRF system was designed as an air-conditioning system, over time heating mode was added and now simultaneous heating and cooling to different zones is plausible with the heat recovery feature. Yue Ming Li et al. (2010) determined that a HR VRF system when compared to a HP VRF improves thermal comfort, uses less power and is more energy efficient based on an improved HP VRF EnergyPlus model. The generated HR VRF model added capabilities of simultaneously calculating the cooling or heating capacity in the various rooms, as well as determining the main working mode of the system. This model was validated by simulating a typical office building in China indicating that further analysis is 
needed on the HR VRF model for a variety of building types and climates. In particular, it is necessary to examine buildings in cold climates, as are experienced in North America.

Accuracy of the energy modeling programs comes into question quite frequently, as building owners tend to see significantly different results in the built building than what was predicted in the building design energy model. Although various testing utilities are used to assure that each new version of the software continues to perform properly (Witte, Henninger, \& Glazer, 2001), validation work for it is still underway. There is limited performance data available from manufacturers and lab tests dealing with the various heat recovery mode correction factors, leading to the use of constant correction factors instead of heat recovery mode performance curves in the model (Fang, Heinicke, \& Cooper, 2013).

Some studies have evaluated the energy performance of EnergyPlus VRF models through using experimental validation. The validation work of Y.P. Zhou et al. (2008) is an extension of the research in (Zhou, Wu, Wang, \& Shiochi, 2007), in which a VRF a model was created and validated through an experimental test set up in several rooms of an unoccupied office building in China. This allowed a more realistic setup than in a lab, nevertheless it is missing a whole building aspect and occupancy implications, as occupancy loads were mechanically generated. As with other studies this study reiterates the importance of minimizing assumptions and precisely determining the building parameters for the VRF system as well as associated building parameters including equipment operating schedules, construction thermal properties, occupant and ventilation schedules, and weather data. The calibrated VRF module resulted in accurate power consumption and determined that relative error difference between cooling energy and power usage is more important than the relative error itself. It was also noted that the COP at part-load condition was higher than that of the rated condition, as the system ran at part-load conditions for the majority of the testing time.

The importance of acquiring the building occupancy schedules was also seen in the study by Xia Fange et al. (2013), as it caused discrepancies with the model and resulted in unnecessary heating during unoccupied periods. It was also determined that actual COP was significantly lower than the specified COP during the heating mode. Based on the building location and time of year it is likely the building experienced a cold climate adding to the heat pump inefficiencies under cold climates. This also shows the need for gas integrated VRF systems to keep overall system energy efficiency high.

Raustad et al. (2013) performed field testing of two VRF systems. One system was a Mitsubishi VRF-HR in a part of the Electric Power Research Institute (EPRI) lab facility in Knoxville, TN. This system was 
tested for eight months from May-December, and mixed operating mode was minimally experienced. The lab measured parameters were used in the EnergyPlus simulation, as they were deemed to be more realistic than the manufacturer specifications. The simulation results showed similar energy profiles to the measured data, with most of the energy consumption data within a +/-25\% margin, with a CV(RMSE) of $20 \%$ for daily total electric energy consumption, which they determine to be in "good agreement". It was noted that the data starts to diverge with colder outdoor temperatures (heating season).

Although various simulation studies on VRF systems have been done there are not many that have been validated with real-time occupied building and weather data; more specifically for the Canadian context for the heating mode of the VRF system under a cold climate. This has not been done as this requires a lot of sub-metering and testing of equipment which can be time consuming and costly. Also, these systems can be complex to simulate and not all system components can be accounted for in the modelling program. Simultaneous heating and cooling VRF whole building studies should be done with various locations across North America to better understand the performance of these systems under colder climates. This will create a dataset for designers to reference when looking to design new systems. Having a reliable dataset for VRF system will make future designing easier and more enticing as success studies become available. Updating of the model post-occupancy should be done, as it has been seen to be an important step in the commissioning and system optimization process (CIBSE Journal, 2013). It is easier to pin point inefficiencies through the modeling results and will give the building operators indications of how the system parameters should be shifted for better performance.

\subsection{Building Energy Model Calibration}

Creating a calibrated energy model is a process which uses a building simulation program in which a model was created of an existing building and input parameters are tuned so that the simulated results closely match the collected building energy use data. Performing model calibration creates a baseline model which allows for more accurate analysis of future operations at the building by identifying potential energy saving strategies, through improvements of equipment operation and controls, as well as retrofits and added energy efficiency measures. Calibrated model results can also be used as a reference for building monitoring systems and the verification process of the measures and strategies which were implemented. Most of the literature on calibration focuses on commercial buildings. Reddy (Reddy, 2006) has compiled a literature review on calibration of building energy simulation programs.

In the past calibrating an energy model had been dependent on the modeller's knowledge, past experiences, statistical proficiency, engineering judgement, as well as trial and error methods (Reddy, 
2006). First attempts of calibration were taken by using information from utility bills to be compare against. This restricted the accuracy and reliability of the model as there were numerous input field indirectly related to energy consumption. This then led to spot-testing or short-term data collection of particular end-uses in order to improve the accuracy of the inputs. Further advancement was seen when hourly data for a month, season, or even sometimes a year was used to try to better understand and simulate building dynamics, such as in equipment scheduling and controls.

Some of issues with model calibration are that they are labour intensive and time consuming, it also requires the modeller to have high levels of skill and knowledge of both the simulation program as well as actual building operations. Due to personal experiences, each modeller will bring their own judgements into the process therefore making the calibration procedure as more of an art, than a systemic scientific approach, which causes the results to be modeller-specific (Reddy, 2006). Due to the complexity of a calibration process it is most beneficial when applied to medium to large commercial buildings with complex HVAC systems, which can be appropriately modelled in the simulation program (Reddy, Maor, \& Panjapornpon, 2007). Only buildings of this size and complexity will truly benefit from the cost required to perform the analysis. Smaller buildings tend to have less complicated systems and energy efficiency measures can usually be identified through a simple building audit. In addition, smaller buildings tend to have less funds available to put towards lengthy building audits and the monitoring and verification procedures and equipment needed to acquire the appropriate data to be able to perform a model calibration.

Most published studies to date have been based upon the approach of using utility bill data with walkthrough audits, spot-testing and/or short-term monitoring of specific end-uses. Although, it does not provide a methodology, ASHRAE Guideline 14 (American Society of Heating, Refrigerating and AirConditioning Engineers Inc., 2002) provides specific statistical parameters to determine if a model has reached calibration limits. This document suggests that a model can be described as calibrated if the results of the model are within 5\% for the normalized mean bias error (NMBE) and within 15\% for the root mean square error (CV(RMSE)) relative to the monthly consumption data. If hourly consumption data is used the suggested calibration limits for accuracy are $10 \%$ for the NMBE and $30 \%$ for the CV(RMSE). Guideline 14 does not give calibration accuracy limits for daily, seasonal, or yearly consumption data. Additionally, Guideline 14 specifies that the level of uncertainty to be less than $50 \%$ of the annual reported savings at a confidence level of $68 \%$. There have been many published papers of 
different strategies taken to achieve calibration, however no governing body has produced a step-bystep methodology a modeller should use to develop a calibrated model.

\subsubsection{Sources of Error and Uncertainty}

There are four main sources of error or uncertainty in building energy simulation programs. Firstly, incorrect input parameters are used, due to the modeller's inexperience or incorrect material or system properties specifications. Secondly, incorrect assumptions or simplifications are used due to the fundamental physics of the situation or the use of semi-empirical model coefficients. Thirdly, the numerical algorithms in the sub-models may not be robust or accurate enough due to insufficient testing. Lastly, there is a chance there could be errors in the simulation code, again due to insufficient testing, which is out of the modeller's hands to change (Reddy, 2006).

\subsubsection{Findings from Previous Calibration Studies}

Judkoff (Judkoff R. , 1988) compared simulation results for using programs DOE-2.1, BLAST-3.0 and SERIRES-1.0. It was determined that the simulation programs were sensitive to passive solar, and it could drastically influence the zone calculation temperatures and therefore inaccurately predict the energy consumption due to solar over-prediction. He found that the algorithms for cooling loads and temperatures were more sensitive than for the heating context. Therefore accurately trying to predict zone temperatures would not guarantee accurate load and consumption predictions. Furthermore, standard assumptions for conductivity and thermal properties of building materials could create errors in energy consumption predictions of up to $60 \%$.

Zirnhelt (Zirnhelt, 2013) created a calibrated house model in EnergyPlus using a year's worth of electrical consumption data, gas consumption data and interior temperature sensor data. This analysis showed the most influential parameters to be the infiltration model for predicting heating energy consumption, the window model (particularly important when modelling passive solar), changes in internal gains, the interior and exterior convection algorithms, as well as accounting for thermal bridging.

Raferty et al. (2009) present a methodology for calibrating building energy simulation models through the use of an evidence-based approach with detailed simulation modelling. The proposed methodology was then applied to a case study building - a $30,000 \mathrm{~m}^{2}$ office building. They found that even with numerous sensors throughout the building for energy monitoring there were significant gaps in their framework. Many of the electrical panels supplied a combination of very different load types which made it difficult to identify the cause of an unexpected change in the metered energy consumption. It 
was determined that the framework should consist of a building information model, a detailed energy monitoring system and a complete building automation system, so to reduce the time required to calibrate the building energy model and improve its accuracy.

Pan et al. (2006) found that there were limitations in the simulation software for modelling gas boilers. The gas boilers could only be used to supply domestic hot water, however they were using the boiler to supply hot water for space heating as well as laundry and humidification. Due to this limitation they were not able to reach calibration limits for gas consumption. Another limitation in the software created a deviation in the predicted and metered electrical consumption due to not being able to have separate chilled water supply systems for high level zones and low level zones.

O'Neill et al. (2013) used a sensitivity analysis to determine the calibration parameters. Then a metamodel based optimization algorithm was used to determine the values for the parameters. Using this method they were able to reach calibration limits for an office building modelled in the EnergyPlus building simulation program. In a separate study, O'Neill et al. (2011) used quasi-random sampling method to generate calibration parameter samples through the GoSUM software for a LEED ${ }^{\circledR}$ Gold US military building. Using this method they were able to get their EnergyPlus model to be within $4 \%$ of the metered electrical consumption. This study determined that real weather data from on-site weather station was crucial in reducing model error, TMY3 weather data differed too much; local chilled water BTU meter and chiller power measurements were very useful information to have to calibrate the chiller model in EnergyPlus; the common manufacturer's specifications did not supply enough information to create the needed performance curves, and they had to specifically request more data be generated with their proprietary tool; sub-metering of lights and plug loads was essentially in developing electricity schedules in EnergyPlus; nominal as built building envelope construction was used - with high insulation values the sensitivity study showed an insignificant impact on the building energy consumption.

\subsection{VRF COMPARED TO OTHER HVAC SYSTEMS}

Several simulation studies have been done to analyze the performance of different types of VRF systems, as well as in comparison with other traditional HVAC systems. Y.P. Zhou et al. (2007) determined that VRF systems are a more efficient system for a medium-sized office building. That is, 22.2\% more energy efficient under cooling mode than a variable air volume system (VAV) with a variable speed drive fan. It was also determined that the VRF is $11.7 \%$ more efficient under cooling mode than a fan coil plus fresh air (FPFA) system with a variable speed drive loop water pump. The energy efficiency 
experienced by the VRF system was attributed to the cooling medium transportation and range of partload performance.

Aynur et al. (2009) concluded that VRF air conditioning systems can achieve an overall energy consumption reduction between $27 \%-57 \%$ depending on system configuration compared to VAV systems. The secondary VRF system components (terminal units) promise higher energy saving potential than the VAV secondary system components (reheat boxes and supply fan). VRF systems have better thermal comfort, due to the indoor air temperature control. To achieve better temperature control VAV systems need to use reheat boxes which can add up to $65 \%$ more energy consumption.

Liu and Hong (2010) performed a simulation comparison study of a heat recovery air-source VRF system with a heat recovery air-source ground source heat pump (GSHP) system on a simulated small office building. EnergyPro was used to model the building with the VRF system and eQuest was used to model the (same) building with the GSHP system. This simulation work determined the GSHP $9.4 \%$ more energy efficient than the VRF system when located in Miami. When the building was located in Chicago the GSHP system was determined to be $24.1 \%$ more efficient than the VRF system. The results show the GSHP becomes a more efficient system option where greater heating and cooling loads are experienced. Furthermore, the authors determined a $9 \%$ increase in energy consumption with an increase in refrigerant line length of $166 \mathrm{~m}$. A study on the new ASHRAE headquarters building has was completed by ASHRAE members (Southard, Liu, \& Spitler, 2014). The building uses a VRF system to provide heating and cooling to the first floor while a GSHP is used for the second floor. It was determined that the GSHP system was operating at $44 \%$ less energy consumption than the VRF system, after energy use normalization.

In summary, VRF technology is increasingly penetrating the North American market as more studies become available in the North American context, and investigating its performance capabilities. A few studies have focused on performance characterization through lab and limited short-term field testing. The energy modelling programs commonly used in the industry do not have capabilities to model a building with a VRF system. Heat pump and heat recovery variable refrigerant flow system models have been created in EnergyPlus. Limited calibration studies have been done with field-testing data and simulation using EnergyPlus. There have been no VRF calibration studies done on full buildings postoccupancy with field testing data, in a Canadian context. It would be beneficial to know the challenges associated with modelling post-occupancy VRF systems in EnergyPlus, to determine if there are advantages and increased accuracy of using EnergyPlus over industry used modelling programs. 
Performing such a study would also highlight if calibration of a building model with a VRF system can be achieved. Only after a number of post-occupancy studies with extensive monitoring for calibration on various types of buildings have been done in Canada can it be determined if VRF is an efficient HVAC system for cold climates experienced in Canada. 


\section{RESEARCH OUTLINE}

\subsection{RESEARCH OBJECTIVES}

The literature review shows that although there have been a number of studies done on VRF systems, a very limited number have examined VRF system performance after equipment installation in a building, with no VRF study focussing on Canada. This research investigated using EnergyPlus, a whole building simulation program, as a tool for modelling VRF system performance. The objectives of this research were to:

1. Create an advanced EnergyPlus model of the case study building containing a VRF system

2. Identify challenges for predicting post-occupancy building performance, for buildings utilizing VRF systems

3. Show the importance of developing an integrated system design from the beginning of the design process when utilizing VRF systems in a building

4. Compare modelling strategies and results for VRF systems in EE4 and EnergyPlus, as EE4 does not contain a VRF model and workarounds are required

\subsection{SCOPE OF RESEARCH}

Research on post-occupancy modeling of heat recovery VRF systems as well as its applicability for a Canadian climate was completed using EnergyPlus as the main tool, coupled with field data from a case study building located in southwestern Ontario. As-built building characteristics based on the current use and operating regime of the case study building were used to create the model. This included:

- Envelope characteristics: building geometry, window and wall constructions, insulation values

- HVAC system information: air distribution and ventilation schedules, occupancy and equipment schedules, air infiltration, equipment specifications

Specific parameters for the VRF system were analyzed to increase the accuracy of the VRF model and determine system optimization strategies. The VRF modelling parameters which were investigated include:

- Electric energy use

- Air flow rates

- Cooling and heating capacities

- Equipment coefficient of performance (COP)

- Part-load ratio

- Heat recovery mode 


\subsection{RESEARCH QUESTIONS}

The following questions guided this research:

1. Using standard available manufacturer product data, how accurately does EnergyPlus predict energy consumption of a heat recovery VRF system, for a post-occupancy building? What are the challenges in modelling post-occupancy buildings?

2. Using the case study as context, can heat recovery VRF systems be recommended as an efficient system for a Canadian Climate? 


\section{METHODOLOGY}

The methodology for pursuing this research comprised:

- Determining the case study building's characteristics

- Measure specific field testing data

- Developing an EnergyPlus baseline model

- Adding EnergyPlus specific sub-models to the baseline model

- Developing an advanced EnergyPlus model

- Comparing the advanced model results to field testing data

- Applying the advanced model to perform sensitivity analyses

\subsection{Determining BUILDING CHARACTERISTICS}

To start off, the architectural, structural, mechanical and electrical drawings were acquired from the building operator and engineering consultants. An EE4 model and modelling report were obtained from the modelling consultants on the project. The EE4 model was originally used as a design tool and used to apply for LEED ${ }^{\circledR}$ credits, saveONenergy's High Performance New Construction incentives (saveONenergy, 2014), as well as apply for their building permits. Furthermore, a commissioning report was obtained with working equipment settings and setpoint values, as well as some equipment spot testing.

A walkthrough building audit was completed with the building manager to understand the layout and features of the building, to gather operating data and determine the differences between the building drawings and specifications, and what was actually constructed and installed in the building. The discussions with the building manager showed that the building was built to the specification outlined in the drawings with minimal changes. The gathered information is documented in Appendix B: Building Walkthrough Audit.

Discussions with the building operator indicated that energy consumption data was being collected with the Johnson Controls Inc. (JCl) control system (Johnson Controls, 2015). In addition, the building's systems were fairly complex and it showed to be quite a challenge, both logistically and financially, to integrate new instrumentation post completion, therefore it was decided to not add further VRF data collection instrumentation. 


\subsection{Field Testing Data Collection}

\subsubsection{Building Air Infiltration}

Air infiltration rates vary between buildings. It is important to determine the air infiltration rate of a building for modelling purposes, as this can drastically change the predicted heating and cooling consumption of the building. Therefore, a blower door test was conducted to determine the air infiltration rate in the building.

\subsubsection{Building Energy Consumption}

Twelve months of daily energy consumption data, by electrical panel, was collected through the building automation system (BAS) which used the $\mathrm{JCl}$ controls system. A twelve month study allowed the collection of data from all seasons and to fit within the program's timeframe. The energy consumption data was used to create energy profiles to compare the collected versus the predicted energy profiles, including lighting, fresh air ventilation, heating and cooling energy consumption.

\subsubsection{Zone Temperatures}

Omnisense temperature sensors (Omnisense LLC, 2015) were placed throughout the building on cabinets and shelves in representative occupied zones. There were a total of 47 sensors set up in the building for a period of 36 days, from March 18, 2014 - April 22, 2014. The data collected from the Omnisense sensors were used as a validation process for the EnergyPlus model.

\subsubsection{Fan Airflow Rates}

The air balancing report was also acquired which aided in determining the operating fan airflow rates and pressure rises associated will the VRF terminal units and ventilation system.

\subsection{Developing The Energirlus Baseline Model From EE4}

EE4 does not contain capabilities to model VRF systems. It is important to understand what the differences in modelling results will be if someone decides to use workarounds to model a VRF system in EE4, as it under predicts the energy consumption. A baseline model was developed in EnergyPlus using as similar inputs as possible from the inputs from the original EE4 model. This was done to create a model which would be able to be used as a comparison tool to compare modelling strategies and results between the two simulation programs.

The building envelope assemblies, operating schedules, occupancy, lighting intensities and miscellaneous equipment energies were taken from the EE4 model. Any missing information from the EE4 model was supplemented with information obtained through the building audit and communication 
with the building operator and consultants. The HVAC inputs used were obtained from the equipment data specification sheets obtained from Mitsubishi and from the LEED ${ }^{\circledR}$ modelling package.

\subsection{AdDing ENERgyPLUS SPECIFIC SUB-MODELS}

Due to EE4's limitations, certain building aspects were not taken into account accurately in the original model. These features were either updated or specific sub-models were added in EnergyPlus.

- Air infiltration values were updated based on the results of the blower door test.

- The developed Mitsubishi equipment specific VRF performance curves were substituted, based on the FSEC guidelines (Raustad R. , 2012), from the default curves.

- The ZoneEarthTube object was used to model the effectiveness of having an earth tube present as a fresh air intake preconditioning feature throughout the year.

- The SolarCollector:UnglazedTranspired object was used to model the effectiveness of having a solar wall present as a fresh air intake preheat feature during the winter.

\subsection{DeVeloping the EnergyPlus Advanced Model}

An advanced model was created in EnergyPlus working off the baseline model previously created. This model was updated to use more detailed calculation methods and fine tune the HVAC inputs to create a model that would as best as possible represent the building's actual operation and performance. The air infiltration model was updated, interzone airflow and surface heat transfer calculations were addressed, and internal gains and HVAC inputs were fine tuned. The change in inputs was informed through more detailed literature review, further communication with technical specialists and input parameter sensitivity analyses. After each change to the model, the model's results were verified and compare the predicted simulated results to the collected field testing data.

\subsection{Comparing THE AdVAnCEd Model Results}

The initial goal was to calibrate the model to meet ASHRAE Guideline 14's calibration limits. However, due to limitations in building information and modelling inputs, complete calibration was not possible. With the available information and inputs an advanced accurate model was created to be used for further sensitivity analyses of the performance of the VRF system.

The changes were tracked to determine where the biggest impacts to system and building performance lie for a building using a heat recovery VRF system. The challenges in modelling the complex mechanical system were recorded for future research recommendations. 


\subsection{APPlying THE AdVANCED MODEL}

\subsubsection{Weather Sensitivity Analysis for VRF Performance}

The COP of a VRF system is dependent on outdoor temperatures. A couple studies have shown that buildings which are located in climates that have more extreme weather will experience greater energy savings (Raustad, Nigusse, Sharma, Cummings, \& Domitrovic, 2013). Furthermore, heat recovery will be more effective in colder climates, especially if the building experiences a constant cooling load throughout the year (Thornton \& Wagner, 2012).

Using the advanced model, a study was done to determine the impact that varied weather conditions have on the performance of a VRF system for the case study building location. The model was run using four different weather conditions, as well as typical year conditions, for the case study building's location in southwestern Ontario. The four weather conditions used were: (i) a warmer than normal winter, (ii) colder than normal winter, (iii) hotter than normal summer, and (iv) cooler than normal summer.

\subsubsection{VRF Configuration Analysis for VRF Performance}

VRF indoor terminal unit arrangements are important when maximizing the effects of heat recovery. When the VRF system is operating in heat recovery mode the outdoor units do not operate and heat is redistributed through the building via the refrigerant through the VRF controller (heat recovery box) (Hunt et al., 2012). To achieve the most energy savings, the VRF system should arrange the indoor terminal units to have balanced zone heating and cooling loads for each outdoor unit throughout the year.

The advanced model was used to determine the impact of the indoor terminal unit rearrangement on the performance of the VRF system. The purpose of the terminal unit rearrangement was to determine if the designed arrangement allowed for minimal energy consumption and if heat recovery could have been improved. Moreover, it investigated the importance of an integrated systems approach during the design stage.

\subsubsection{Heating and Cooling Systems Comparison}

Using the determined heating and cooling required energy supply from the advanced model, various energy efficient heating and cooling systems were compared against the VRF system to determine if the VRF system was in fact the most efficient system for the case study building. Energy consumption, operating costs and carbon dioxide emissions were used as the performance metrics for comparison. 


\section{CASE STUDY BUILDING}

\subsection{BUILDing CONFIGURATION}

The case study building is located in southwestern (London) Ontario. It is a two-storey, 3345 square meter office building, with LEED ${ }^{\circledR}$ Platinum certification which completed construction in December 2012. The building has a heat pump heat recovery variable refrigerant flow system as their primary heating and cooling system with backup heating through electric duct coils and electric baseboards. The ventilation system is a $100 \%$ dedicated outdoor air system with an energy recovery wheel and displacement ventilation.

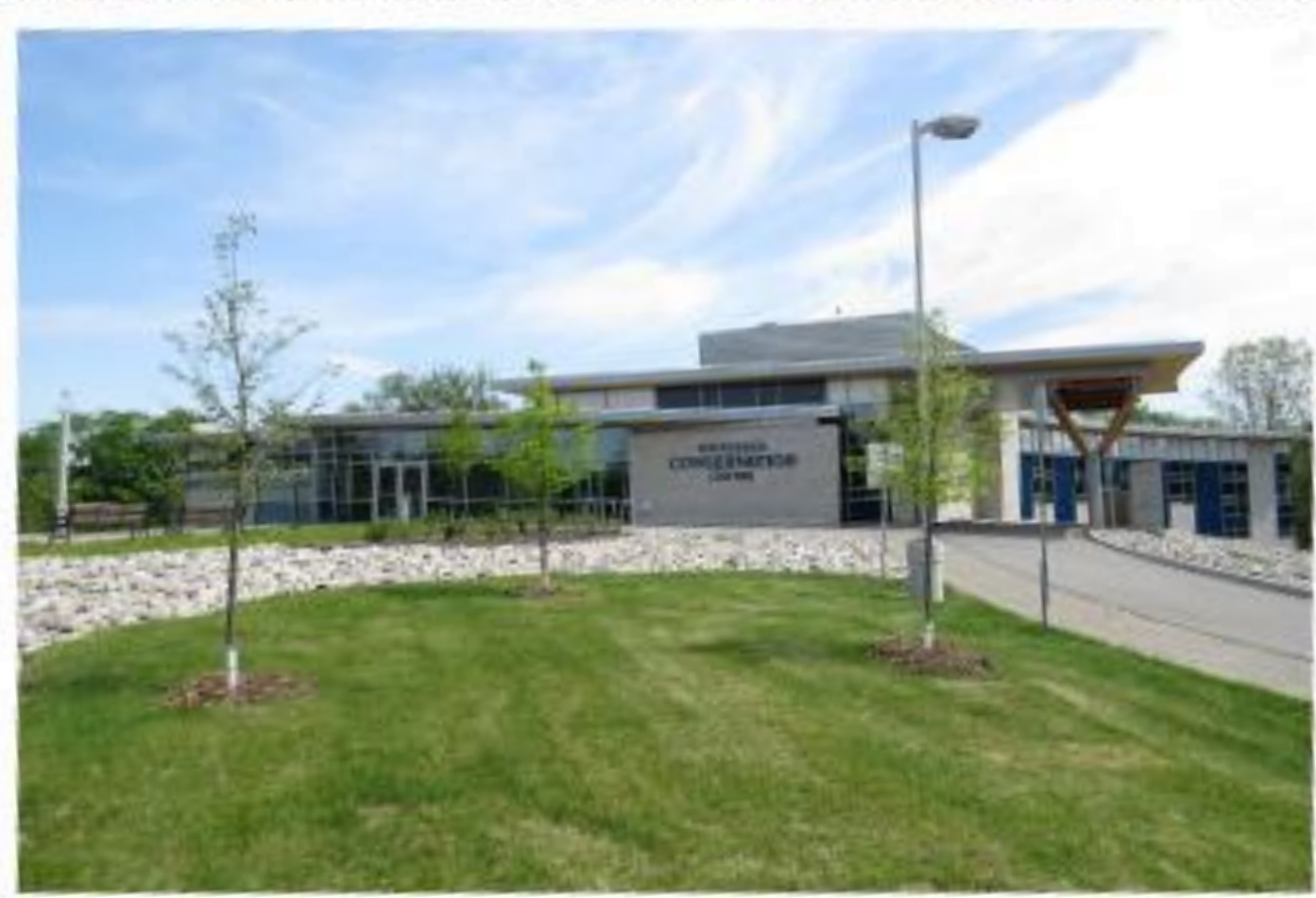

Figure 3: Case Study Building (Upper Thames River Conservation Authority)

Figure 3 is a picture of the case study building, Upper Thames River Conservation Authority's (UTRCA) Watershed Conservation Centre (WCC). More pictures of the case study building are presented in Appendix A: Case Study Building Pictures. 


\subsection{WALL ASSEMBLIES}

The exterior walls comprising the building envelope are generally stone masonry on the outside followed by a drainage plane air space, with spray foam insulation followed by the interior finish. The interior finishes are poured concrete (EW1), concrete blocks (EW3), or metal framing with gypsum board (EW5).

EW1

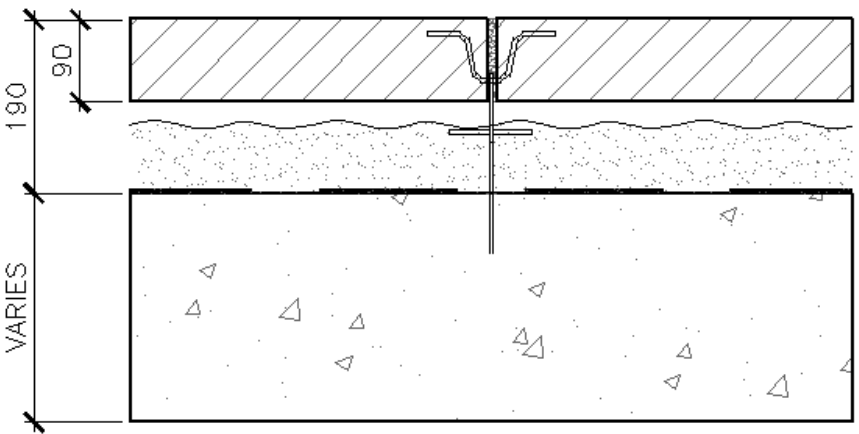

(EW3)

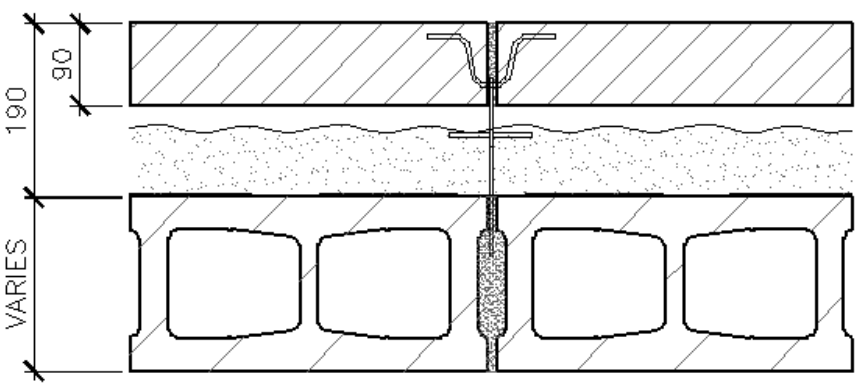

\section{EXTERIOR}

90 STONE MASONRY UNITS

25 AIR SPACE

75 SPRAY APPLIED FOAM INSULATION

AIRNAPOUR BARRIER

CONCRETE BLOCK - REFER TO STRUCTURAL

DRAWINGS FOR THICKNESS

REFER TO DRAWINGS FOR INTERIOR FINISH TYPE TAG

\section{INTERIOR}

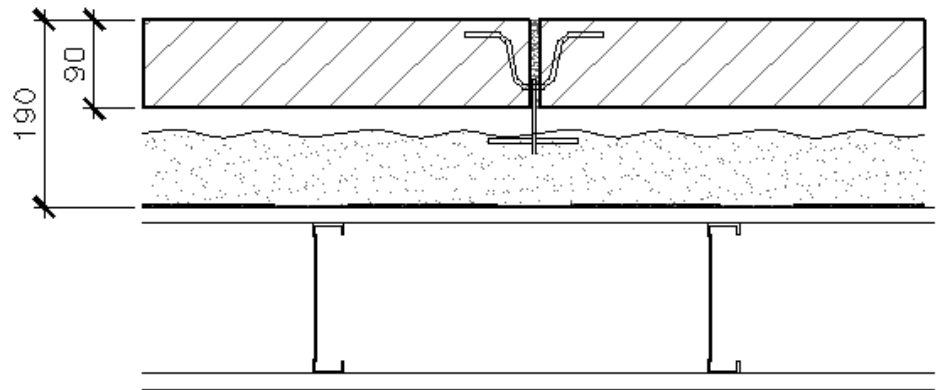

\section{EXTERIOR}

90 STONE MASONRY UNITS

25 AIR SPACE

75 SPRAY APPLIED FOAM INSULATION

AIRNAPOUR BARRIER

16 DENSGLAS GOLD EXTERIOR SHEATHING

152 METAL FRAMING (as Engineered)

16 G.W.B.

\section{INTERIOR}

Figure 4: Exterior Wall Schematics for EW1, EW3 and EW5 (Wilson, 2010)

The above grade foundation wall (FW1) is composed of stone masonry on the outside, followed by sand fill, rigid insulation, a waterproof membrane and concrete for the interior finish The below grade 
foundation wall (FW3) is composed of a drainage layer followed by rigid insulation, a waterproof membrane and poured concrete for the interior finish.

FW1
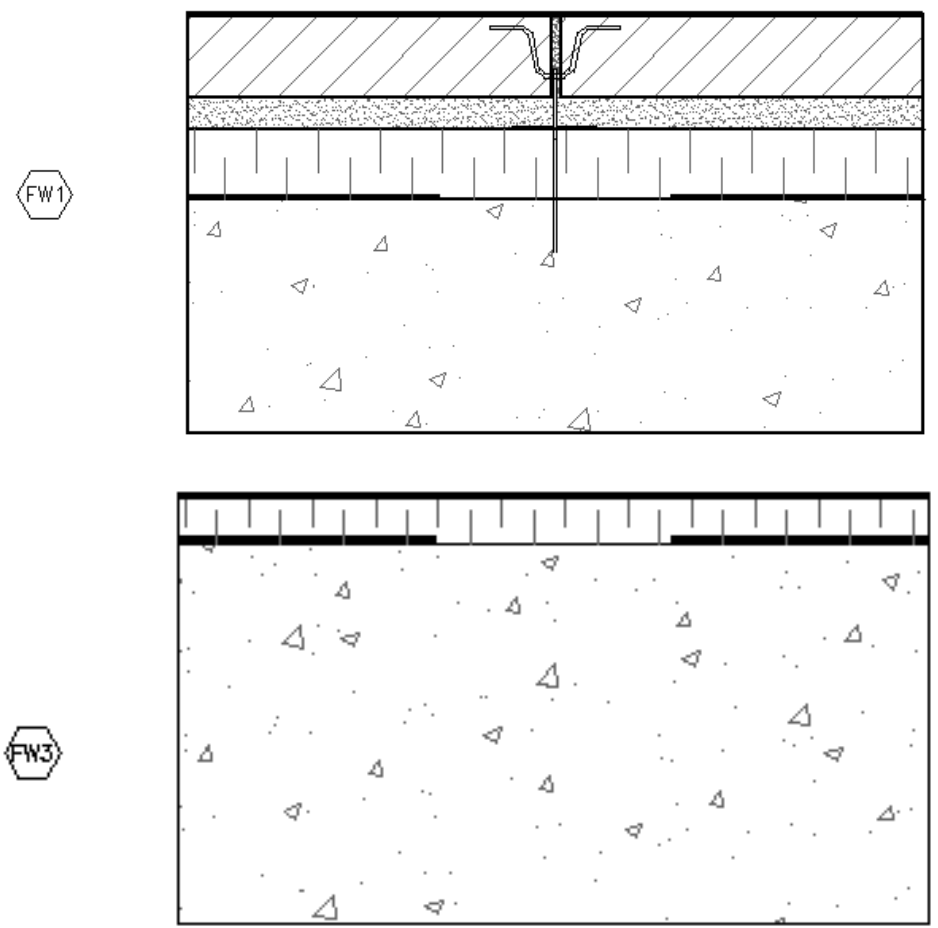

\section{EXTERIOR}

DRAINAGE LAYER @ BELOW GRADE

90 STONE MASONRY UNITS

35 SAND FILL SPACE BETWEEN STONE AND INSULATION 75 RIGID INSULATION WATER PROOF MEMBRANE

REFER TO STRUCTURAL DRAWINGS FOR CONCRETE FOUNDATION THICKNESS.

REFER TO SECTION A FOUNDATION WALL TYPE FOR DRAINAGE LAYER INFORMATION

\section{INTERIOR}

\section{EXTERIOR}

\section{DRAINAGE LAYER}

50 RIGID INSULATION

WATER PROOF MEMBRANE

REFER TO STRUCTURAL DRAWINGS FOR CONCRETE FOUNDATION THICKNESS.

\section{INTERIOR}

Figure 5: Foundation Wall Assembly Schematics for FW1 and FW3 (Wilson, 2010)

On the south side there is also an integrated solar wall (see section 5.6 for explanation on the solar wall). Behind the solar wall cladding there is spray foam insulation, an air/vapour barrier and concrete for the interior finish (SW1).
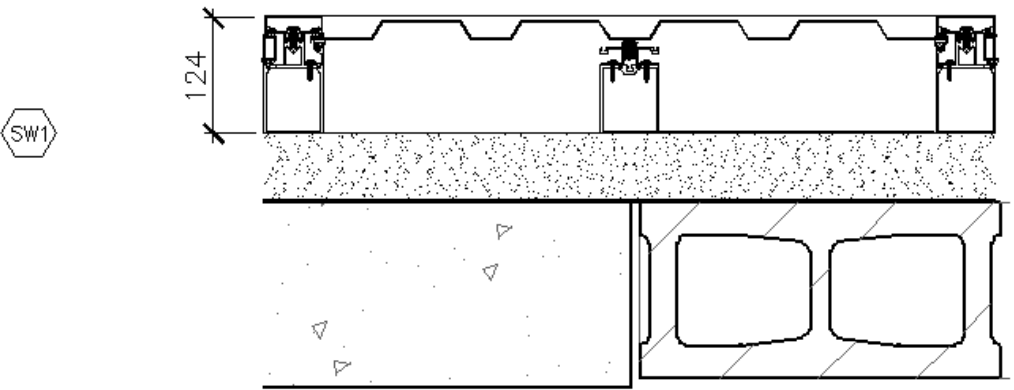

Figure 6: Solar Wall Assembly SW1 schematic (Wilson, 2010)

\section{EXTERIOR}

SOLARWALL METAL PANEL SYSTEM dW BACK OF PANEL SUPPORT SYSTEM FIT INTO GLA3 CURTAINWALL ASSEMBLY 22 GAUGE SHEET METAL BACKPAN 100 Z-GIRTS

75 SPRAY APPLIED FOAM INSULATION AIRVAPOUR BARRIER

REFER TO DRAWINGS FOR CONCRETE WALL AND BLOCK WALL THICKNESS. REFER TO DRAWINGS FOR INTERIOR FINISH TYPE TAG

\section{INTERIOR}


There is also a spandrel glass wall (GLA3) around the building. This is composed of a single pane of spandrel glass with Roxul Semi-Rigid insulation and an aluminum metal back pan to follow on the inside.

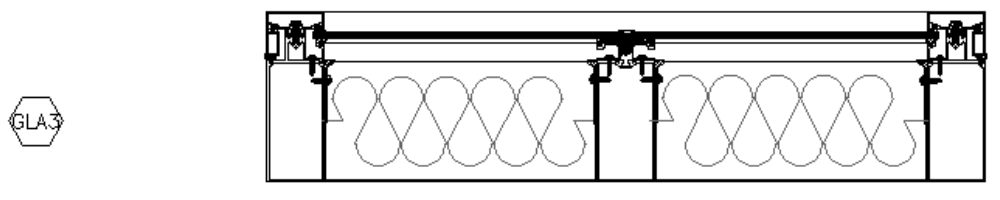

\section{EXTERIOR}

SINGLE GLAZED SPANDREL GLASS

ROXUL SEMI-RIGID INSULATION 100mm IN PRE-FINISHED ALUMINUM BACK PAN

\section{INTERIOR}

Figure 7: Spandrel Glass Wall Assembly GLA3 Schematic (Wilson, 2010)

One detailing example is found below which shows how the different wall assemblies interface with each other.

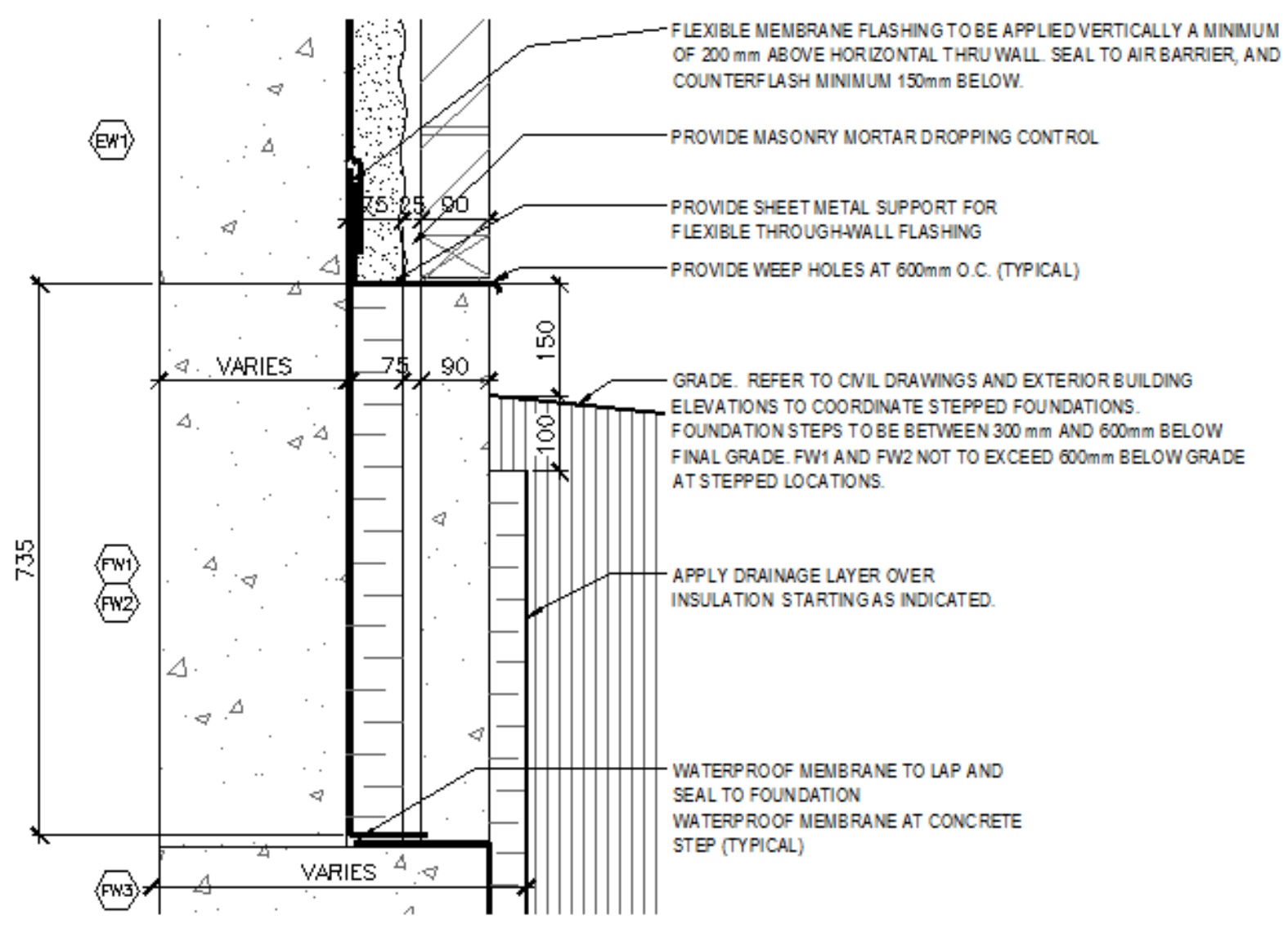

Figure 8: Wall Detailing Schematic (Wilson, 2010) 


\subsection{Roof ASSEMBLIES}

The main roof assemblies are R1, R2, R3 and RDA1.

(R1)
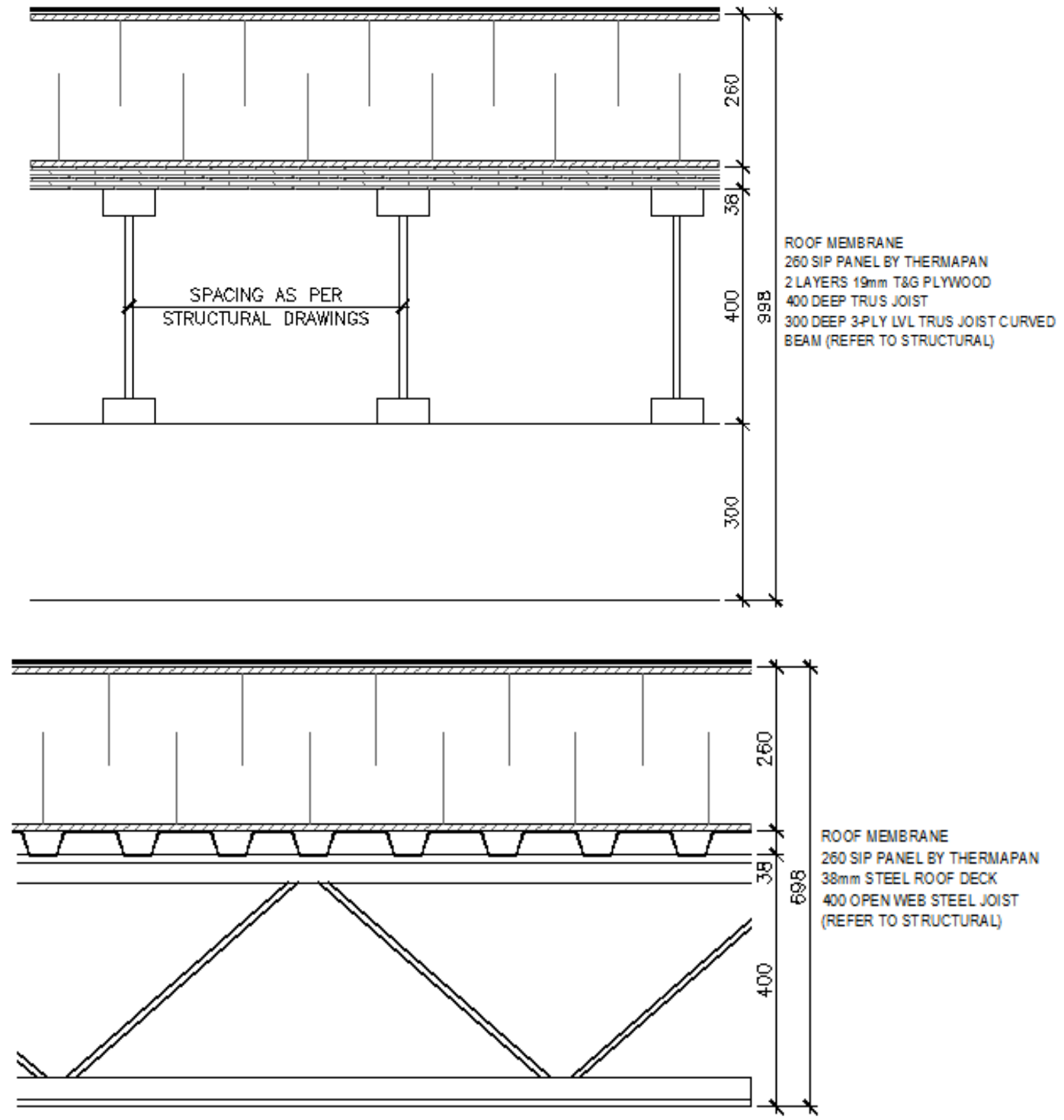

R3

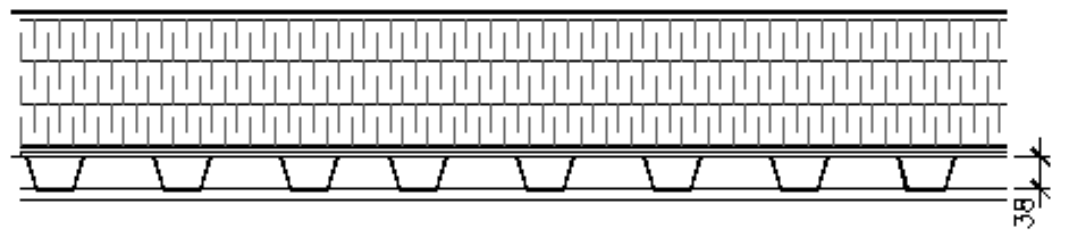




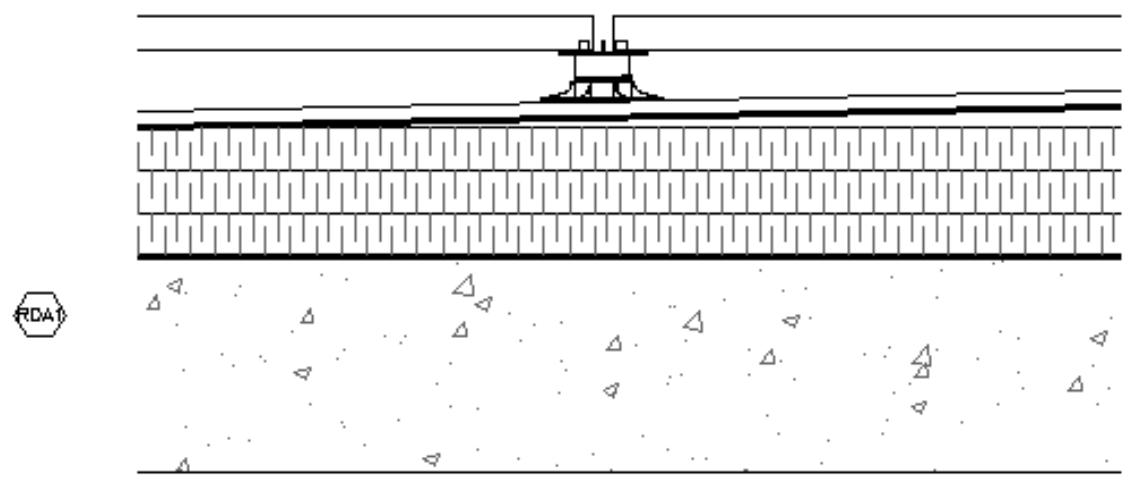

$500 \mathrm{~mm} \times 500 \mathrm{~mm} \times 40 \mathrm{~mm}$ EXPOSED AGGREGATE CONCRETE PAVERS

ADJUSTABLE DECK SUPPORTS FROM $25 \mathrm{~mm}$ HEIGHT AT OUTSIDE PERIMETER TO $125 \mathrm{~mm}$ AT DRAINLOCATIONS

$19 \mathrm{~mm}$ POLYSTYRENE PROTECTION BARRIER ROOF MEMBRANE

SLOPED INSULATION - PERIMETER TO DRAIN MIN. 3 LAYERS $50 \mathrm{~mm}$ RIGIDINSULATIONAT DRAIN AIRNAPOUR BARRIER MEMBRANE

CONCRETE STRUCTURE

(REFER TO STRUCTURAL)

Figure 10: Roof Assembly RDA1 Schematic (Wilson, 2010)

The thermal resistance (RSI) values for the wall and roof assemblies are listed in Table 2, in section

\subsubsection{EE4 Building Configuration}

\subsection{WINDOW ASSEMBLIES}

The main window assemblies are GLA1, GLA2, and GLA5. GLA1 is a double glazed window, GLA2 is a double glazed window with a diffusion interlayer, and GLA5 is a triple glazed unit, all of which have thermally broken window frames. There are both fixed and operable window versions of GLA1 and GLA5.

(GLA)

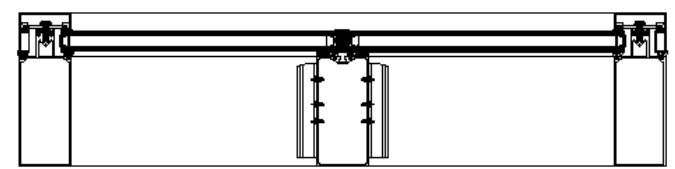

\section{EXTERIOR}

SOLARBAN 70XL DOUBLE GLAZED UNITS IN THERMALLY BROKEN FRAMES INTERIOR

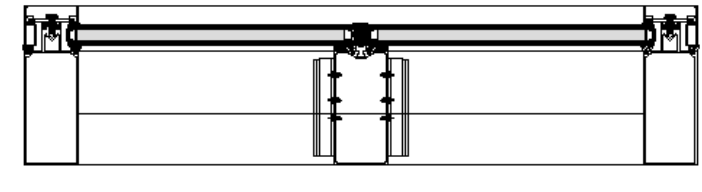

\section{EXTERIOR}

OKALUX DOUBLE GLAZED UNIT S IN THERMALLY BROKEN FRAMES CW DIFFUSION INTERLAYER

GLA2

INTERIOR

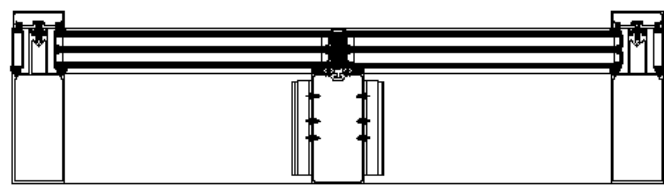

\section{EXTERIOR}

SOLARBAN 70XL TRIPLE GLAZED UNITS IN THERMALLY BROKEN FRAMES

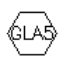

\section{INTERIOR}

Figure 11: Glazing Assembly Schematics for GLA1, GLA2 and GLA5 (Wilson, 2010)

The thermal resistance values (U-values) for the window assemblies are listed in Table 3, in section 6.1.1. 


\subsection{EARTH TUBES}

Earth tubes are earth-to-air heat exchangers (EAHE) (Peretti, Zarrella, De Carli, \& Zecchin, 2013). Below the surface soil temperatures fluctuate much less than air temperatures. The soil will be warmer than air in the winter and cooler than air in the summer. Thus the earth can act as a heat source in the winter and a heat sink in the summer. The pipes are buried a couple meters underground can be made of metal, plastic or concrete. The pipe network is connected to the building's ventilation system along with a fan which draws in the air through the pipes. During the summer the air brought through the pipes is cooled and dehumidified because the soil surrounding the tube is lower than the ambient temperature. During the winter the opposite is true, where the air is preheated since the ambient temperature is colder than the surrounding soil temperature. The energy efficiency of the system depends on the temperature of the earth throughout the year and the surface area of the pipe (Peretti, Zarrella, De Carli, \& Zecchin, 2013). Therefore, in order to get the maximum passive energy benefit it is import for it to be used year round to charge and discharge the heat into the ground.

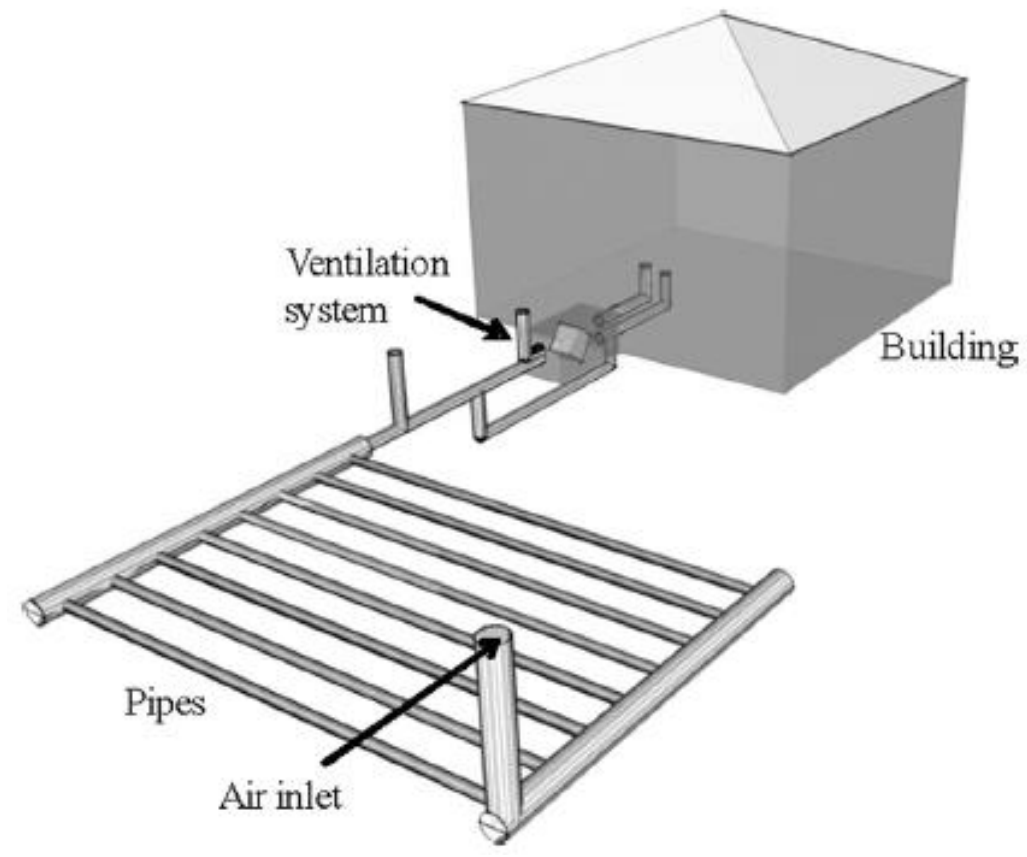

Figure 12: Example Schematic of an EAHE (Peretti, Zarrella, De Carli, \& Zecchin, 2013)

The earth tube system at the case study building consist of two pipes ( $0.6 \mathrm{~m}$ diameter) that are connected to the make-up air unit. During the winter $50 \%$ of $1699 \mathrm{~L} / \mathrm{s}$ of the fresh air is brought in through the earth tubes and $50 \%$ is brought in through the solar wall (see Section 5.6 for a description of 
the solar wall). The rest of the year $1699 \mathrm{~L} / \mathrm{s}$ fresh air is brought in through the earth tubes. The airflow is equally divided between the two pipes year round.

\subsection{SOLAR WALL}

A solar wall is an unglazed transpired solar collector. This technology is fastened to the exterior side of a building on the south, west or east side to take advantage of the solar radiation from the sun. This technology comprises a perforated metal sheet with internal framing which create an air cavity, about $20 \mathrm{~cm}$ wide, between the building and the perforated metal sheet. This cladding system is heated by the sun's solar radiation. The ventilation fan draws in outside air through the perforated metal sheet which is heated as it travels up through the heated cladding system. When the air reaches the top it is ducted into the building, connecting it to the rest of the ventilation system (Conserval Engineering Inc.).
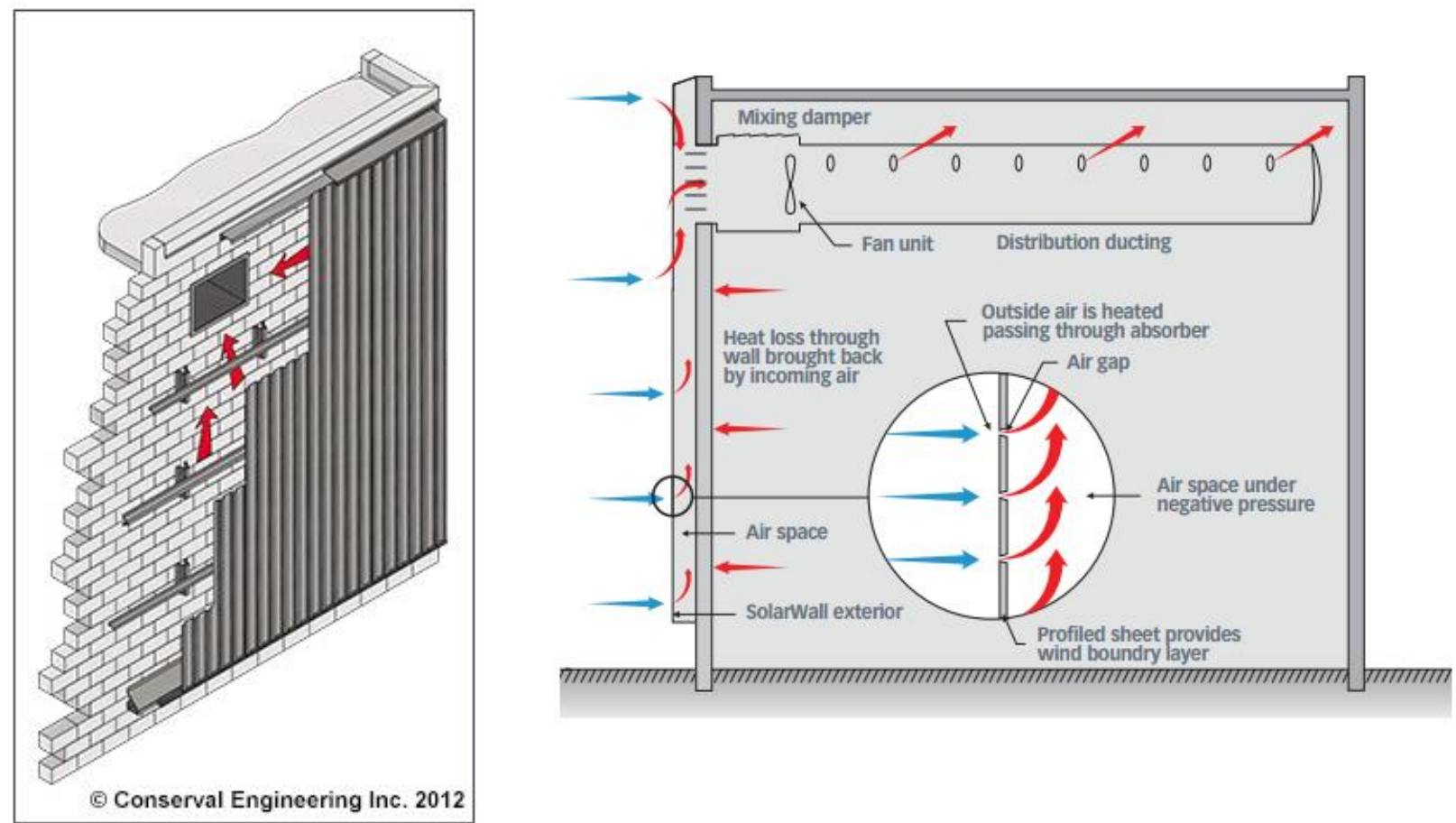

Figure 13: SolarWall Typical Construction (left) and Solar Airflow Heating Schematic (right) (Conserval Engineering Inc.)

The solar wall product used was SolarWall from Conserval Engineering Inc. It was a $58 \mathrm{~m}^{2}$ SolarWall on the building's exterior south wall. The solar wall is used to preheat the outdoor air in the winter before entering into the make-up air unit, where it meets the rest of the ventilation air brought in by the earth tubes. Since the solar wall is only operational during the winter months, the damper is closed between April and September, restricting all the airflow to the earth tubes. 


\subsection{BLOWER DOOR TEST}

Air leakage in buildings can vary for a number of reasons, but trends have shown that it is more related to the detailing of components and workmanship during construction, than the age of the building or type of building construction (Persily, 1998). There is significantly more published literature for residential construction than big and tall commercial buildings, as it is much harder to perform air infiltration testing on large buildings. For large buildings, it is more common to do random component testing to ensure that the installation and construction procedures being used will create an airtight building. For tall buildings it is also important to take wind and stack effects into consideration when performing air leakage calculations.

It is important to determine the level of air tightness in a building, as a leaky building can lead to a lot of conditioned air to escape, impacting the building's energy consumption and indoor air quality. By conducting an air infiltration test one can determine where the building is leaking and make repairs and adjustments to tighten the building's envelope. This is done through pressurization testing, commonly known as a blower-door test. A blower-door test consists of installing a large fan (blower) into a door or window in the building and creating a pressure difference across the building envelope. The airflow at various pressures differentials are measured and recorded, usually ranging from $10-75 \mathrm{~Pa}$. The openings in the building envelope can be described by Equation 5-1, the power law equation, since the openings are usually small enough that the flow does not become fully developed (American Society of Heating, Refrigerating and Air-Conditioning Engineers, Inc., 2005). The air leakage coefficient (C) reflects the size of the hole, the $\Delta P$ is the pressure differential across the hole, and the pressure exponent $(n)$ describes the shape of the hole in the envelope.

$$
Q=c(\Delta P)^{n}
$$

where,

$\mathrm{Q}=$ airflow through the opening, $\mathrm{m} 3 / \mathrm{s}$

$\mathrm{C}=$ air leakage coefficient, $\mathrm{m}^{3} /\left(\mathrm{s} \cdot \mathrm{Pa}^{\mathrm{n}}\right)$

$\Delta \mathrm{P}=$ pressure differential, $\mathrm{Pa}$

$\mathrm{n}=$ pressure exponent, dimensionless

A blower door-test was performed to determine the building's infiltration rate. The test was conducted in collaboration with building performance evaluations experts (BlueGreen Consulting Group Inc., 2015). It was done on a Saturday (October 5, 2014) to ensure that the tests would not interfere with the workers in the office building. Due to the size of the building 2 blower doors were needed to complete 
the test properly. The two doors at the front entrance (vestibule) of the building were used to install the blower doors for the test. Two tests were done. The first test was a depressurization test with all the dampers closed in the building. Then all the dampers in the building were opened and a depressurization test was done. Measurements were taken approximately every $5 \mathrm{~Pa}$, starting around $35 \mathrm{~Pa}$ up to $75 \mathrm{~Pa}$. The test calculations were done by the consultants at BlueGreen Consulting Group, for a building heated volume of $14000 \mathrm{~m}^{3}$ and a building surface area of $5400 \mathrm{~m}^{2}$. Additionally, since the building is only two storeys high, wind and stack effects are not a major concern in the calculations. A summary of the results for the two tests are outlined below. It is important to note that no changes were done to the building during the study period. The results of the tests can be found in Table 1Table 1: Blower Door Test Results.

Table 1: Blower Door Test Results

\begin{tabular}{|l|c|c|}
\cline { 2 - 3 } \multicolumn{1}{c|}{} & With Closed Dampers & With Opened Dampers \\
\cline { 2 - 3 } \multicolumn{1}{c|}{} & 1 - Depressurization & 2 - Depressurization \\
\hline $\mathrm{ACH}_{50}$ & 0.64 & 0.63 \\
\hline $\mathrm{Cdn}$ EqLA @10Pa $\left(\mathrm{cm}^{2}\right)$ & 3996 & 3893 \\
\hline $\mathrm{NLA}\left(\mathrm{cm}^{2} / \mathrm{m}^{2}\right)$ & 0.74 & 0.72 \\
\hline Leakage Curve: $\mathrm{n}$ & 0.571 & 0.576 \\
\hline Leakage Curve: $\mathrm{R}^{2}$ & 0.997 & 0.999 \\
\hline Leakage Curve: Flow $\left(\mathrm{m}^{3} / \mathrm{h}\right)\left[\mathrm{CFM}_{50}\right]$ & $8972[5281]$ & $8816[5189]$ \\
\hline
\end{tabular}

The leakage curve exponent, $n$, is a correlation factor that normally ranges between 0.5 and 1.0 for an acceptable test, with the exponent approaching 1.0 indicating there are many small holes in the building whereas $n$ approaching 0.5 indicating there are few large holes (BlueGreen Consulting Group Inc., 2015). The other important value to note is the value for the correlation coefficient, $R^{2}$, which indicates how well the data collected fits the statistical model, where an acceptable test typically has a value of 0.99 or greater (BlueGreen Consulting Group Inc., 2015). Based on this value it was be noted that the data from Test 1 and Test 2 were statistically acceptable.

Averaging the values for the two depressurization tests, the building has 0.64 air changes per hour at 50 Pascal $\left(\mathrm{ACH}_{50}\right)$, leakage curve exponent value of 0.57 , and a leakage flow of $8894 \mathrm{~m} / \mathrm{h}\left(1.65 \mathrm{~m} / \mathrm{h} \cdot \mathrm{m}^{2}\right)$ at 50 Pascal (5235 CFM50).

To put these values in perspective, Passive House Certification, known for having rigorous airtightness levels, requires the building to have a maximum level of $0.6 \mathrm{ACH}_{50}$ for both pressurization and depressurization tests (Canadian Passive House Institute, 2012). In addition, ASHRAE reports Tamura 
and Shaw's study that non-residential air leakage values per unit of wall area at 75 Pascal are 500, 1500 and $3000 \mathrm{~cm} 3 / \mathrm{s} \cdot \mathrm{m}^{2}$ (equating to $384,1152,2305 \mathrm{~cm} 3 / \mathrm{s} \cdot \mathrm{m}^{2}$ at 50 Pascal) for tight, average and leaky walls, respectively (American Society of Heating, Refrigerating and Air-Conditioning Engineers, Inc., 2005). Persily's comparison study of commercial and institutional buildings found air leakage rates to be between 5.7 to $49.3 \mathrm{~m}^{3} / \mathrm{h} \cdot \mathrm{m}^{2}$ at 75 Pascal (equating to 4.4 to $37.9 \mathrm{~m} / \mathrm{h} \cdot \mathrm{m}^{2}$ at 50 Pascal) (Persily, 1998). From this it can be determined that the building is fairly airtight as it is just above the Passive House level as well as closer to Tamura and Shaw's tight value than their average value.

EnergyPlus requires infiltration to be entered at natural pressure. Equation 5-2 calculates $\mathrm{ACH}$ at natural pressure.

$$
A C H_{\text {natural }}=\frac{A C H_{50}}{\text { LBL Factor }}
$$

LBL factor is determined based on climate region, the number of stories of the building, wind exposure. For climate zone 2, 2 storey building, and a building exposed to wind the LBL Factor is 13.3. (Energy Star, 2001) Using equation 4-2 the building's $\mathrm{ACH}_{\text {natural }}$ was calculated to 0.048 , and a building infiltration flow rate of $0.186 \mathrm{~m}^{3} / \mathrm{s}$. 


\section{BASELINE MODEL}

\subsection{EE4 MODEL}

A series of EE4 energy models where completed as part of the design process and to meet the Model National Energy Code for Buildings (MNECB), saveONenergy's High Performance New Construction (HPNC) program, and Leadership in Energy and Environmental Design Canada New Construction (LEED ${ }^{\circledR}$ NC) requirements. The models were created by one of the building design consultants (Reale, 2013) during the design process, therefore this work was previously completed to the start of this research. The information detailed in this section comes from correspondence with the consultants, their EE4 models, hand calculations and their LEED ${ }^{\circledR}$ energy modelling report.

The MNECB is a prescriptive building code standard used for new medium sized commercial buildings (Natural Resources Canada, 2013). The HPNC program is an incentive program to offset the cost of implementing energy-efficiency measures which achieve lower long-term operating costs, improves the building's marketability and enhances the occupant comfort (saveONenergy, 2014). The LEED ${ }^{\circledR}$ NC is a building rating system, governed by the Canada Green Building Council (CaGBC), that addresses the design and construction for new construction or major renovations of commercial and institutional buildings (buildings which fall under Part 3 of Canada's National Building Code), to produce green buildings by addressing the following six areas: Sustainable Sites, Water Efficiency, Energy and Atmosphere, Materials and Resources, Indoor Environmental Quality, and Innovation and Design Process (Canada Green Building Council).

\subsubsection{EE4 Building Configuration}

The building was modelled as an office building and was separated into 28 thermal zones, with 15 on the upper flower and 13 on the lower floor. The building was separated into thermal zones based on being served by the same HVAC system, having similar operation and function, as well as similar heating and cooling loads (Natural Resources Canada Office of Energy Efficiency \& CANMET Technology Centre, 2008). The zoning layout developed by the consultants is shown below in Figure 14 and Figure 15. 


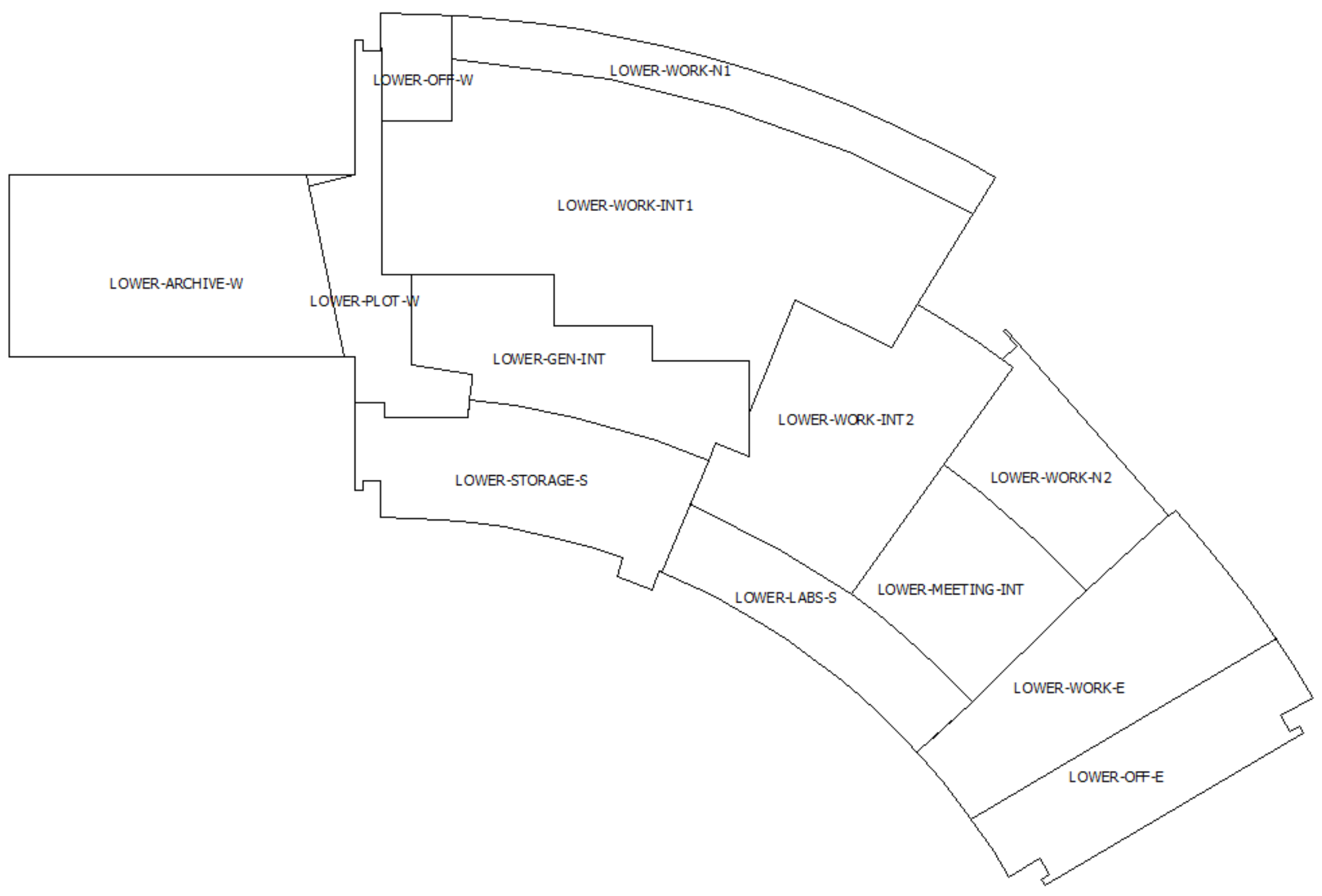

Figure 14: EE4 Zoning Diagram - Lower Floor (MMM Group Limited, 2012) 


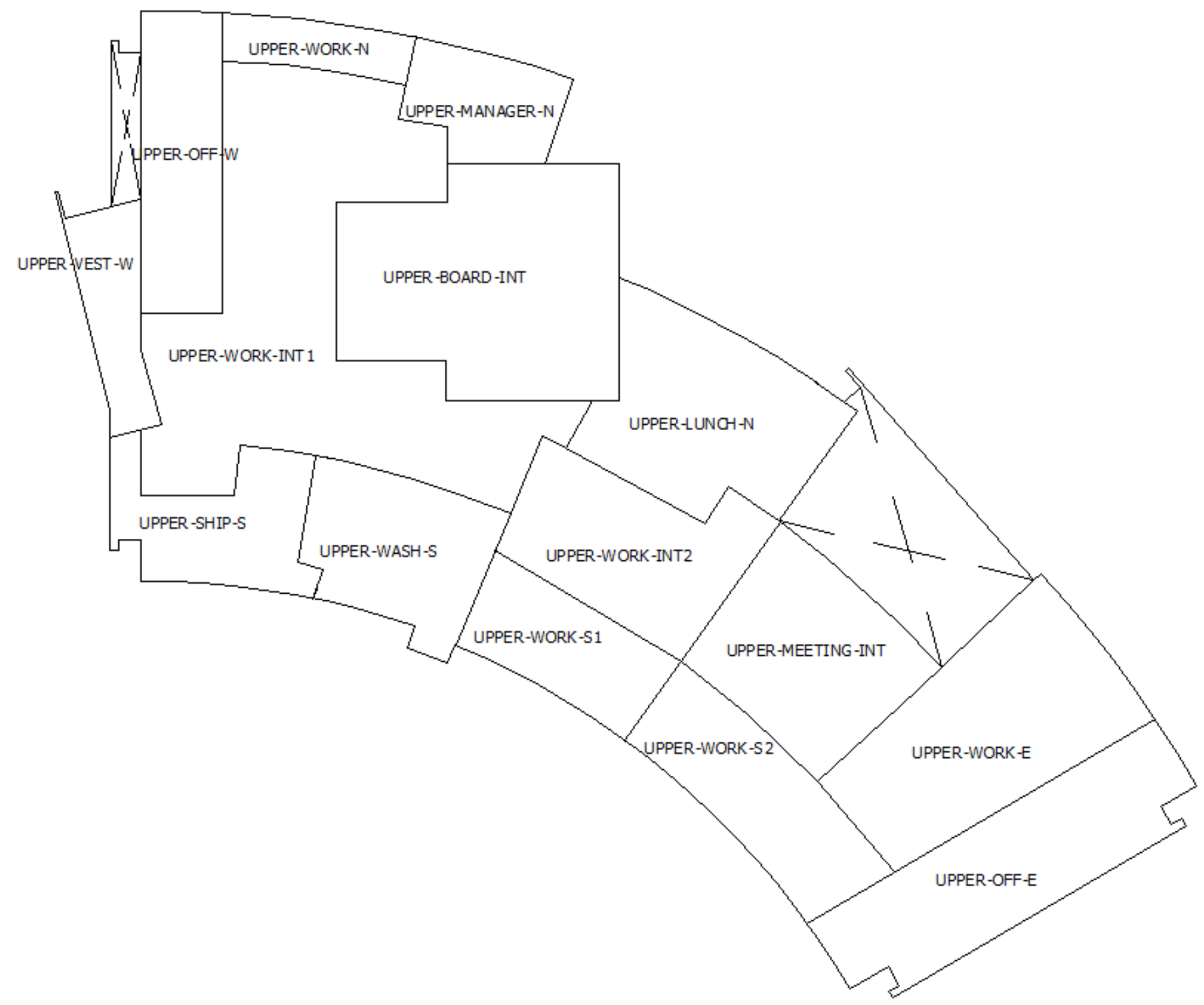

Figure 15: EE4 Zoning Diagram - Upper Floor (MMM Group Limited, 2012) 
The envelope assemblies' locations across the building were determined from architectural drawing $A 300$, and glazing assemblies were determined from drawings $A 1010$ and $A 1011$. Excerpts from A300 for the envelope assemblies' locations can be found in Appendix C: Exterior Wall Elevations. Excerpts from A1010 and A1011 for the glazing assemblies' locations can be found in Appendix D: Window Elevations. The building envelope was mostly made up of curtain wall and spandrel windows, with the remainder being concrete and masonry walls. The roof was constructed using either structurally insulated panels or rigid insulation with either a white roof membrane or stone pavers on the exterior. The wall and roof assembly overall RSI values were determined using the layer assembly construction calculator and material library in EE4. The windows were double-glazed and triple-glazed with a low-e coating, argon filled, along with warm-edge spacers which are secured in thermally broken aluminum frames. The consultants used FRAME ${ }^{\mathrm{TM}}$ plus Online (Enermodal Engineering Ltd.) to calculate the overall U-value and SHGC for the various types of glazing. For more information on the materials and construction of the assemblies see Sections 5.2, 5.3, and 5.4. Table 2 and Table 3 presents the building material properties that were used in the model. GLA-1 OP and GLA-5 OP are operable window versions of fixed windows GLA-1 and GLA-5, respectively, both operable and fixed window values were used in the model.

Table 2: EE4 Model Building Material Properties (MMM Group Limited, 2012)

\begin{tabular}{|l|l|c|c|c|}
\hline \multicolumn{1}{|c|}{ Tag Number } & Component Type & U-Value $\mathbf{( W / \mathbf { m } ^ { \mathbf { 2 } } { } ^ { \circ } \mathbf { C } )}$ & RSI & Absorptivity \\
\hline EW1 & Exterior Wall & 0.279 & 3.6 & 0.7 \\
\hline EW3 & Exterior Wall & 0.284 & 3.5 & 0.7 \\
\hline EW5 & Exterior Wall & 0.263 & 3.8 & 0.7 \\
\hline FW1 & Exterior Wall & 0.340 & 2.9 & 0.7 \\
\hline SW1 & Exterior Wall & 0.608 & 1.6 & 0.7 \\
\hline GLA-3 & $\begin{array}{l}\text { Spandrel Glass Exterior } \\
\text { Wall }\end{array}$ & 1.390 & 0.7 & 0.7 \\
\hline $\begin{array}{l}\text { MNECB Type 1: } \\
\text { Finished }\end{array}$ & Below Grade Wall & 0.417 & 2.4 & 0.7 \\
\hline R1 & Roof & 0.135 & 7.4 & 0.7 \\
\hline R2 & Roof & 0.141 & 7.1 & 0.7 \\
\hline R3 & Roof & 0.156 & 6.4 & 0.7 \\
\hline RDA1 & Roof & 0.139 & 7.2 & 0.7 \\
\hline $\begin{array}{l}\text { MNECB Type 1: } \\
\text { Heated Slab }\end{array}$ & Below Grade Floor & 0.926 & 1.08 & 0.7 \\
\hline
\end{tabular}


Table 3: EE4 Model Building Glazing Properties (MMM Group Limited, 2012)

\begin{tabular}{|l|c|c|c|}
\hline Tag Number & Glazing Type & U-Value $\left(\mathbf{W} / \mathbf{m}^{2} \cdot{ }^{\circ} \mathbf{C}\right)$ & SHGC \\
\hline GLA-1 & Vision & 2.16 & 0.30 \\
\hline GLA-1 OP & Vision & 2.70 & 0.22 \\
\hline GLA-2 & Vision & 2.73 & 0.31 \\
\hline GLA-5 & Vision & 1.53 & 0.27 \\
\hline GLA-5 OP & Vision & 2.32 & 0.20 \\
\hline
\end{tabular}

\subsubsection{EE4 HVAC Simulation Method}

Although heating and cooling for the building is provided through a variable refrigerant flow system, it was modelled using a 4-pipe fan coil system with electric boiler for heating and an electric reciprocating chiller for cooling, as variable refrigerant flow systems are not an available option in EE4.

There are three different models of condensing units used in the building for heating and cooling but to simplify the model only one condensing unit's (PURY-P168-TSJMU-A) efficiency curves were used for all units. The modelling consultants had determined that the efficiency curves for all the condensing units were relatively similar so there would not be a large impact in the results by using the same curves for all the units. The system efficiencies for heating and cooling were calculated based on the input and output capacity of the condensing unit and then adjusted accordingly to its efficiency curves. The breakdown of indoor terminal units to each outdoor unit is listed in the following table.

Table 4: VRF Equipment List

\begin{tabular}{|l|l|l|}
\hline Tag Number & Model Number & Fan Coil Units/Equipment \\
\hline HPAC-1 & PURY-P168TSHMU-A & FC1-1,2,3,4,5,6A,6B,7A,7B,8A,8B,9,10 \\
\hline HPAC-2 & PURY-P240TSHMU-A & FC2-1,2A,2B,2C,3,4,5,6,7,8,9,10,11,12 \\
\hline HPAC-3 & PURY-P240TSHMU-A & FC3-1,2,3,4,5,6,7,8,9,10,11A,11B,12,13; 3-BU2, 3-BU3 \\
\hline HPAC-4 & PURY-P168TSHMU-A & FC4-1,2,3,4A,4B,4C,4D,4E,5,6,7,8,9,10; 4-BU1 \\
\hline HPAC-5 & PUHY-HP72THMU-A & FC5-1A,1B \\
\hline HPAC-6 & PUHY-HP92THMU-A & MAU-1 \\
\hline
\end{tabular}

The building has a dedicated outdoor air system which is composed of a make-up air unit (MAU-1) which tempers the incoming air with coil which uses the refrigerant supplied by the condensing unit HPAC-6. There is also an energy recovery wheel (ERW) with a $76 \%$ effectiveness located in the MAU-1. Since the system is providing tempered outdoor air to the rooms, the supply air temperature was set to $20^{\circ} \mathrm{C}$ and $21^{\circ} \mathrm{C}$, during the heating and cooling seasons, respectively. There is also an electric preheat coil in the make-up air unit, with a temperature setpoint of $-15^{\circ} \mathrm{C}$ to engage the coil. 
The information for lighting was taken from the electrical drawings, E000, E200 and E201. The lighting schedule was cross-referenced with the EE4 default library to determine appropriate wattages for the model.

The operating schedules followed the MNECB defaults for office buildings which correspond to Operating Schedule A. This includes schedules for occupancy, lighting, receptacles, ventilation fans, heating, cooling, and domestic hot water. The schedules are included in Appendix E: MNECB Operating Schedule A.

The fan coil fan power was entered at the system level instead of the zone level because EE4 would overestimate the fan power, as EE4 assumes that the fan coil fans would operate on the same schedule as the ventilation fans instead of only operating when heating or cooling was needed.

\subsubsection{EE4 Earth Tubes}

Since there is no option in EE4 to model earth tubes, the LEED $^{\circledR}$ consultants performed a series of manual calculations. The goal of the calculations was to estimate an average temperature rise and drop between the air entering and leaving the earth tube. Using the temperature rise and drop, an equivalent heat recovery effectiveness was determined to be entered at the system level in EE4. (MMM Group Limited, 2012)

The approach taken by the $\mathrm{LEED}^{\circledR}$ consultants was as follows:

1. Model each earth tube separately under both summer and winter conditions

2. Calculate the convective heat transfer coefficient, $h$, using the Reynolds number, Nusselt number friction factor and air properties $\left(\rho, C_{p}, \mu, k, \operatorname{Pr}\right)$

3. Guess leaving temperature to calculate log mean temperature difference, $\Delta T_{I m}$, between the ground temperature and the air temperature through the pipe

4. Calculate the heat transfer rate from tube wall to inside air using equation 6-1

5. Using calculated heat transfer rate from 6-1, calculate leaving air temperature using equation 6-2. Then compare calculated leaving air temperature to guessed leaving air temperature in step 3

6. Determine the equivalent equipment effectiveness for each season using equation $6-3$, and find an average yearly value to be entered into EE4.

$$
\begin{aligned}
& \dot{q}=h * A_{s} * \Delta T_{\mathrm{lm}} \\
& \dot{q}=\dot{m} * C_{p} *\left(T_{\text {out }}-T_{\text {in }}\right)
\end{aligned}
$$




$$
\text { Effectiveness }=\frac{\text { Actual } \Delta T}{\text { Maximum } \Delta T}
$$

where,

$$
\dot{q}=\text { heat transfer rate, } \mathrm{W}
$$

$\dot{\mathrm{m}}=$ mass flow rate, $\mathrm{kg} / \mathrm{s}$

$\mathrm{h}=$ heat transfer coefficient, $\mathrm{W} / \mathrm{m}^{2} \mathrm{~K}$

$A_{s}=$ surface area of the pipe, $m^{2}$

$\Delta \mathrm{T}_{\mathrm{Im}}=\log$ mean temperature difference between the ground and air travelling through the pipe, ${ }^{\circ} \mathrm{C}$

$\mathrm{C}_{\mathrm{p}}=$ specific heat capacity of air, $\mathrm{J} / \mathrm{kgK}$

$\mathrm{T}_{\text {out }}=$ air temperature leaving the pipe, ${ }^{\circ} \mathrm{C}$

$\mathrm{T}_{\text {in }}=$ air temperature entering the pipe, ${ }^{\circ} \mathrm{C}$

The calculations by the consultants was done to determine an approximate impact for typical summer and winter conditions which resulted in an added $17 \%$ equipment equivalent heat recovery effectiveness. The results of the calculations were accounted for by increasing the modelled HRV heat recovery sensible effectiveness by 17\%, from 76\% to 93\%, in EE4 (MMM Group Limited, 2012).

\subsubsection{EE4 Solar Wall}

The solar wall had an absorptivity of 0.69 and an airflow of $850 \mathrm{~L} / \mathrm{s}$. The solar wall air flow was only $50 \%$ of the total outdoor air intake as the outdoor air tempering was split between the earth tubes and solar wall in the winter.

The LEED ${ }^{\circledR}$ consultants used RETScreen to perform the solar wall Analysis, as there is no option in EE4 to model this system add-on. The RETScreen results suggest that the solar wall should have an energy savings of $3100 \mathrm{kWh}$. Therefore $3100 \mathrm{kWh}$ was deducted from the yearly energy consumption determined by the EE4 model.

\subsubsection{EE4 Results}

Based on the inputs mentioned above the EE4 program performed its calculations and determined the peak building loads for the year to be $110.1 \mathrm{~kW}, 134.5 \mathrm{~kW}$ and $19 \mathrm{~kW}$ for heating, sensible cooling and latent cooling, respectively. A breakdown of the loads by thermal zone can be seen in Table 5 . 
Table 5: UTRCA EE4 Building Loads by Thermal Zone

\begin{tabular}{|l|l|l|l|}
\hline Zones & Heating (kW) & Sensible Cooling $\mathbf{( k W )}$ & Latent Cooling (kW) \\
\hline Upper-Off-W & 3.2 & 3.7 & 0.4 \\
\hline Upper-Meeting-Int & 1.2 & 4 & 0.7 \\
\hline Upper-Off-E & 9.6 & 6.9 & 0.9 \\
\hline Upper-Lunch-N & 5.6 & 5.3 & 1.0 \\
\hline Upper-Board-Int & 7.0 & 12.1 & 2.7 \\
\hline Upper-Work-Int1 & 3.4 & 7.4 & 0.8 \\
\hline Upper-Work-N & 3.0 & 3.2 & 0.3 \\
\hline Upper-Manager-N & 4.1 & 3.7 & 0.3 \\
\hline Upper-Ship-S & 5.2 & 2.7 & 0.4 \\
\hline Upper-Wash-S & 1.4 & 1.7 & 0.2 \\
\hline Upper-Work-Int2 & 0.7 & 2.5 & 0.3 \\
\hline Upper-Work-S2 & 5.1 & 5.0 & 0.5 \\
\hline Upper-Work-S1 & 4.1 & 3.8 & 0.4 \\
\hline Upper-Work-E & 3.5 & 4.5 & 0.6 \\
\hline Upper-Vest-W & 4.7 & 4.8 & 0.5 \\
\hline Lower-Archive-W & 4.4 & 2.9 & 0.7 \\
\hline Lower-Off-W & 1.9 & 2.0 & 0.2 \\
\hline Lower-Plot-W & 2.6 & 2.5 & 0.2 \\
\hline Lower-Gen-Int & 2.2 & 5.7 & 1.2 \\
\hline Lower-Storage-S & 2.5 & 2.7 & 0.2 \\
\hline Lower-Work-N1 & 7.9 & 7.9 & 0.8 \\
\hline Lower-Work-Int1 & 1.9 & 11.2 & 1.5 \\
\hline Lower-Work-Int2 & 1.5 & 5.1 & 0.8 \\
\hline Lower-Work-N2 & 10.1 & 7.1 & 0.8 \\
\hline Lower-Meeting-Int & 1.2 & 4.0 & 0.7 \\
\hline Lower-Labs-S & 2.1 & 2.3 & 0.7 \\
\hline Lower-Work-E & 2.8 & 4.7 & 19 \\
\hline Lower-Off-E & 7.2 & 13.1 & \\
\hline Building Total & 110.1 & & 0.7 \\
\hline
\end{tabular}

Table 6 shows the energy consumption breakdown for the year by consumption type, for the EE4 model created by the LEED ${ }^{\circledR}$ consultants. Using the heating and cooling loads from the EE4 model results the LEED $^{\circledR}$ consultants performed an external spreadsheet analysis was used to estimate the monthly electrical energy input to the heat pump plus fan coil system that would be required to meet the loads. Based on the average monthly outdoor air temperatures adjustment factors were determined to be applied to the heating COP. The estimated COPs account for all the electricity, the outdoor units and the indoor terminal units, used to deliver heat between outside and the interior zones. Based on the 
spreadsheet analysis the heating energy consumption was adjusted. The adjusted energy consumption is displayed in Table 6. Moving forward the EE4 model without adjustments will be used for comparison studies.

Table 6: UTRCA EE4 Annual Modelling Results by Consumption Type

\begin{tabular}{|l|r|r|}
\hline Consumption Type & $\begin{array}{c}\text { EE4 Annual Energy } \\
\text { Consumption (kWh) }\end{array}$ & $\begin{array}{c}\text { Adjusted Annual Energy } \\
\text { Consumption (kWh) }\end{array}$ \\
\hline Area Lights & 72,710 & 72,710 \\
\hline Miscellaneous Equipment & 54,870 & 54,870 \\
\hline Space Heat & 134,640 & 49,720 \\
\hline Space Cool & 21,460 & 21,460 \\
\hline Fans & 22,140 & 22,140 \\
\hline Domestic Hot Water & 9,090 & 9,090 \\
\hline Total & 314,910 & 229,990 \\
\hline
\end{tabular}

\subsection{EnERgyPlus BASELINE Model}

To be able to perform in-depth analysis of the building, a more rigorous energy building simulation program needed to be used. EnergyPlus was chosen as the program to be used, as it is a validated program, has been used in research for other similar types of studies, and allows the user to easily modify almost all the inputs at a very detailed level.

\subsubsection{EnergyPlus Building Configuration}

The building geometry stayed the same for the new series of models created in EnergyPlus. However, due to the way the VRF system is inputted in EnergyPlus, only one VRF terminal unit could be associated for each zone. This caused the thermal zones to be further broken down from 28 to 57 zones, so each zone would have one corresponding VRF terminal unit. The new developed zoning diagram is presented in Figure 16 and Figure 17. 


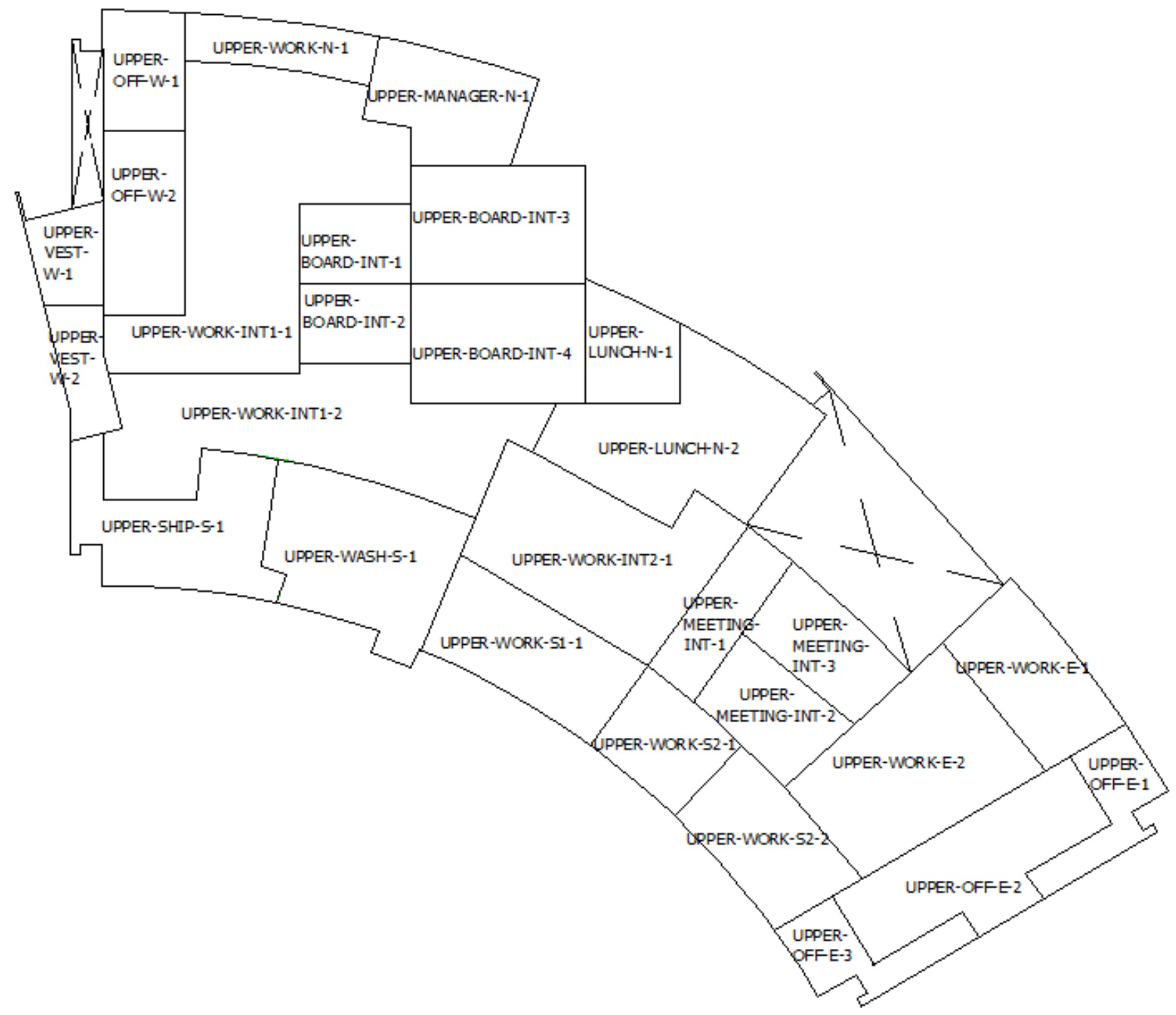

Figure 16: EnergyPlus Zoning Diagram - Upper Floor 


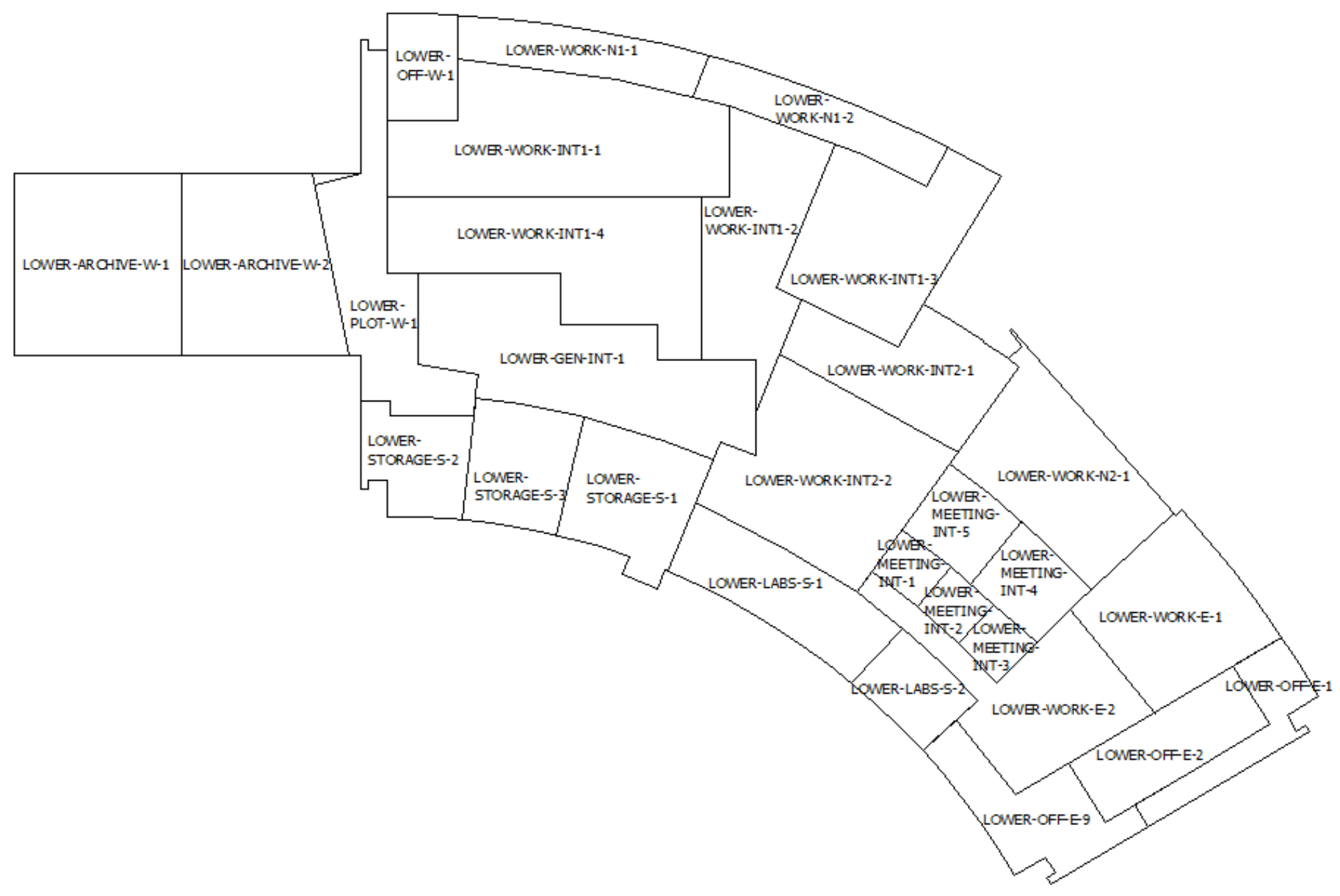

Figure 17: EnergyPlus Zoning Diagram - Lower Floor 


\subsubsection{Model 1 - EnergyPlus Baseline Using EE4 Inputs}

Model 1 was created to showcase the differences in required inputs and how they affected the outcomes of the EE4 and EnergyPlus model. This type of comparison is important to determine if EE4 can be an adequate program for simulating VRF systems at the design stage. As much as possible the EnergyPlus inputs resemble the inputs used in EE4. The first model that was developed was created from using the building drawings, manufacturer specifications and information from the EE4 model.

One major difference is that the EnergyPlus model used the appropriate VRF terminal unit and condenser unit objects. Some of the terminal units have back up electric heaters for days with temperatures below the design day temperature $\left(-18^{\circ} \mathrm{C}\right)$, however at this time EnergyPlus does not allow for a secondary heating coil in the terminal unit therefore an electric baseboard model was added to the associated zones. This EnergyPlus model used default values wherever appropriate for the additional inputs, and used the EnergyPlus default VRF performance Curves. These defaults were kept because these are inputs that require additional investigation and information that is not necessarily readily available through manufacturer data, therefore it is likely modellers would not know what an appropriate value should be assigned to it aside from the default value. Domestic hot water has been left out of this study since this study is primarily focused on space conditioning of the building, as well as there was insufficient information at the time of model creation to accurately be able to include these components in the model.

Both models were run using a Canadian Weather for Energy Calculations (CWEC) weather file for the case study building location.

The energy consumption calculated from the EnergyPlus model is presented in Table 8. It can be seen that EnergyPlus calculated the energy consumption to be $15 \%$ less than EE4 for space heating and $25 \%$ more than EE4 for space cooling, respectively and $12 \%$ less for the fans.

The space heating and cooling were inputted as different systems in the two programs which likely leads to the relatively significant variation in results. The VRF system has many inputs and performance curves which can drastically change the performance of the system. EE4 has many default values that are hidden from the user and which the user is unable to change. For comparison sake of the two programs, the inputs entered in EnergyPlus were entered to as close as possible to resemble the EE4 inputs, therefore certain values requested by EnergyPlus that are not requested in EE4 were left to the default 
values, as it is expected that the designer would not necessarily know to change them to a more fitting input without a lot of extra work being done.

The lighting was entered into EnergyPlus as a lighting power density $\left(\mathrm{W} / \mathrm{m}^{2}\right)$ based on the zone lighting power densities in the EE4 results summary generated by the program. The difference in results can be attributed to slight differences in zone areas.

The fan defaults in EnergyPlus were used for fan total efficiency (0.70), motor efficiency (0.90), and motor in airstream fraction (1.0). Based on these defaults and the fan power (6324 W) inputted in EE4, the pressure rise of the fan was determined $(2605.5 \mathrm{~Pa})$. The difference in values could be attributed to EE4 using a different fan efficiency, which is not a changeable field.

Table 7: EnergyPlus Model 1 Modelling Results - Loads Summary by Thermal Zone

\begin{tabular}{|l|r|r|}
\hline Zones & Sensible Heating (kW) & Sensible Cooling (kW) \\
\hline Upper-Off-W-1 & 2.6 & 1.1 \\
\hline Upper-Off-W-2 & 3.2 & 2.6 \\
\hline Upper-Meeting-Int-1 & 1.6 & 1.8 \\
\hline Upper-Meeting-Int-2 & 2.1 & 1.9 \\
\hline Upper-Meeting-Int-3 & 2.5 & 2.1 \\
\hline Upper-Off-E-1 & 4.4 & 2.3 \\
\hline Upper-Off-E-2 & 5.2 & 3.2 \\
\hline Upper-Off-E-3 & 4.3 & 1.5 \\
\hline Upper-Lunch-N-1 & 2.7 & 1.9 \\
\hline Upper-Lunch-N-2 & 8.0 & 5.3 \\
\hline Upper-Board-Int-1 & 1.6 & 1.4 \\
\hline Upper-Board-Int-2 & 1.6 & 1.3 \\
\hline Upper-Board-Int-3 & 6.3 & 5.3 \\
\hline Upper-Board-Int-4 & 3.4 & 2.9 \\
\hline Upper-Work-Int1-1 & 4.8 & 3.9 \\
\hline Upper-Work-Int1-2 & 6.4 & 3.6 \\
\hline Upper-Work-N-1 & 4.3 & 1.8 \\
\hline Upper-Manager-N-1 & 5.2 & 2.6 \\
\hline Upper-Ship-S-1 & 7.5 & 2.8 \\
\hline Upper-Wash-S-1 & 2.3 & 1.2 \\
\hline Upper-Work-Int2-1 & 4.6 & 3.1 \\
\hline Upper-Work-S2-1 & 5.0 & 3.0 \\
\hline Upper-Work-S2-2 & 3.7 & 1.7 \\
\hline Upper-Work-S1-1 & 5.3 & 3.6 \\
\hline Upper-Work-E-1 & 5.2 & 4.2 \\
\hline Upper-Work-E-2 & & \\
\hline
\end{tabular}




\begin{tabular}{|c|c|c|}
\hline Upper-Vest-W-1 & 3.9 & 2.1 \\
\hline Upper-Vest-W-2 & 3.6 & 3.0 \\
\hline Lower-Archive-W-1 & 2.5 & 0 \\
\hline Lower-Archive-W-2 & 2.5 & 0.7 \\
\hline Lower-Off-W-1 & 2.2 & 1.3 \\
\hline Lower-Plot-W-1 & 4.0 & 1.2 \\
\hline Lower-Gen-Int-1 & 2.3 & 1.6 \\
\hline Lower-Storage-S-1 & 1.9 & 0.4 \\
\hline Lower-Storage-S-2 & 1.2 & 0.2 \\
\hline Lower-Storage-S-3 & 1.3 & 0.3 \\
\hline Lower-Work-N1-1 & 3.4 & 2.0 \\
\hline Lower-Work-N1-2 & 5.2 & 2.8 \\
\hline Lower-Work-Int1-1 & 1.9 & 1.7 \\
\hline Lower-Work-Int1-2 & 1.8 & 1.8 \\
\hline Lower-Work-Int1-3 & 7.0 & 3.1 \\
\hline Lower-Work-Int1-4 & 2.3 & 2.1 \\
\hline Lower-Work-Int2-1 & 2.3 & 1.8 \\
\hline Lower-Work-Int2-2 & 1.4 & 2.3 \\
\hline Lower-Work-N2-1 & 13.1 & 11.8 \\
\hline Lower-Meeting-Int-1 & 0.2 & 0.9 \\
\hline Lower-Meeting-Int-2 & 0.1 & 1.0 \\
\hline Lower-Meeting-Int-3 & 0.2 & 0.9 \\
\hline Lower-Meeting-Int-4 & 0.2 & 1.4 \\
\hline Lower-Meeting-Int-5 & 0.3 & 1.7 \\
\hline Lower-Labs-S-1 & 1.9 & 1.0 \\
\hline Lower-Labs-S-2 & 1.0 & 0.6 \\
\hline Lower-Work-E-1 & 3.2 & 3.3 \\
\hline Lower-Work-E-2 & 1.0 & 2.4 \\
\hline Lower-Off-E-1 & 3.3 & 1.5 \\
\hline Lower-Off-E-2 & 2.7 & 1.9 \\
\hline Lower-Off-E-3 & 3.4 & 1.3 \\
\hline Building Total & 189.3 & 125.9 \\
\hline
\end{tabular}

Table 8: EE4 and EnergyPlus Model 1 Annual Modelling Results by Consumption Type Comparison

\begin{tabular}{|l|r|r|r|}
\hline Energy Consumption Type & $\begin{array}{c}\text { EE4 Model } \\
\text { (kWh)) }\end{array}$ & \multicolumn{1}{c|}{$\begin{array}{c}\text { E+ Model 1 } \\
\text { (kWh) }\end{array}$} & \% Difference \\
\hline Area Lights & 72,710 & 73,800 & $+1.4 \%$ \\
\hline Miscellaneous Equipment & 54,870 & 54,920 & $+0.07 \%$ \\
\hline Space Heat & 134,640 & 117,589 & $-14.5 \%$ \\
\hline Space Cool & 21,460 & 28,500 & $+24.6 \%$ \\
\hline Fans & 22,140 & 19,810 & $-11.9 \%$ \\
\hline ERW Heat Recovery & - & 65 & - \\
\hline
\end{tabular}




\subsubsection{Model 2A-Changing the Infiltration Rate}

Using Model 1, Model 2A was created by only changing the infiltration rate to see the impact of the heating and cooling consumption.

In EE4, the infiltration is fixed at $0.25 \mathrm{~L} / \mathrm{s}$ per $\mathrm{m}^{2}$ of exterior surface area. Model 1 used the Design Flow Rate object with the flow per exterior surface area as the design flow rate calculation method with a value of $0.00025 \mathrm{~m}^{3} / \mathrm{s}$ per $\mathrm{m}^{2}$ of exterior surface area.

The building's infiltration flow rate determined by the blower door test was found to be $0.186 \mathrm{~m}^{3} / \mathrm{s}$ or $0.000061 \mathrm{~m}^{3} / \mathrm{s}$ per $\mathrm{m}^{2}$ of exterior surface area. It can be seen that the default EE4 infiltration rate is four times larger than the building's actual infiltration rate. This is an important variable to be aware of when using EE4 as the modelling program. When the program is used as a comparison tool the infiltration rate does not matter as it is kept the same for both the reference and proposed building. However, this is an important variable when using EE4 to predict the building's energy consumption, especially as building designers are aware of the negative impacts of infiltration and they are designing them to try to achieve minimal air infiltration. This should significantly increase the heating and cooling consumption as more unconditioned air is leaking into the building.

Changing the infiltration rate in the model to $0.000061 \mathrm{~m}^{3} / \mathrm{s}$ per $\mathrm{m}^{2}$ of exterior surface area decreases the heating consumption by $82 \%$, increases the cooling consumption by $18 \%$, and decreases the VRF fan consumption by $12 \%$. The change in infiltration rate did not change the outdoor air ventilation consumption for either the heat recovery unit or the supply and exhaust fan. Although there was an increase in space cooling consumption there was a net decrease in space conditioning for the building by $29 \%$, indicating as expected, that less infiltration decreases the building's energy consumption.

Table 9: EnergyPlus Model 2A Annual Modelling Results by Consumption Type - Impact of Changing the Infiltration Rate

\begin{tabular}{|l|r|r|r|r|}
\hline Energy Consumption Type & $\begin{array}{c}\text { EE4 Model } \\
\text { (kWh)) }\end{array}$ & \multicolumn{1}{c|}{$\begin{array}{c}\text { E+ Model 1 } \\
\text { (kWh) }\end{array}$} & $\begin{array}{c}\text { E+ Model 2A } \\
\text { (kWh) }\end{array}$ & \% Difference \\
\hline Area Lights & 72,710 & 73,800 & 73,800 & $0 \%$ \\
\hline Miscellaneous Equipment & 54,870 & 54,920 & 54,920 & $0 \%$ \\
\hline Space Heat & 134,640 & 117,590 & 64,660 & $-81.8 \%$ \\
\hline Space Cool & 21,460 & 28,500 & 34,850 & $+18.2 \%$ \\
\hline Fans & 22,140 & 19,810 & 17,470 & $-11.8 \%$ \\
\hline ERW Heat Recovery & - & 65 & 65 & $0 \%$ \\
\hline
\end{tabular}




\subsubsection{Model 2B - Custom VRF Performance Curves}

Following Model 2A, Model 2B was created with the sole change of replacing the default VRF performance curves with custom developed curves for the specific equipment which was installed in the building. The procedure that was used in developing the custom performance curves is outlined below, in Section 6.2.4.1.

Based on the manufacturer specifications for the selected equipment the curve minimum and maximum operating temperatures were adjusted, as well as determining the new curve coefficients. The new temperature limits and coefficients are presented in Appendix G: Developed Mitsubishi Performance Curves. Changing the default performance curves to the custom performance curves resulted in an $11 \%$ increase in space heating and a $0.9 \%$ increase in space cooling.

Table 10: EnergyPlus Model 2B Annual Modelling Results by Consumption Type - Impact of Changing VRF Performance Curves

\begin{tabular}{|l|r|r|r|r|r|}
\hline $\begin{array}{l}\text { Energy Consumption } \\
\text { Type }\end{array}$ & $\begin{array}{c}\text { EE4 Model } \\
\mathbf{( k W h ) )}\end{array}$ & $\begin{array}{c}\text { E+ Model 1 } \\
\mathbf{( k W h )}\end{array}$ & $\begin{array}{c}\text { E+ Model 2A } \\
\mathbf{( k W h )}\end{array}$ & $\begin{array}{c}\text { E+ Model 2B } \\
\mathbf{( k W h )}\end{array}$ & $\begin{array}{c}\text { \% } \\
\text { Difference }\end{array}$ \\
\hline Area Lights & 72,710 & 73,800 & 73,800 & 73,800 & $0 \%$ \\
\hline Miscellaneous Equipment & 54,870 & 54,920 & 54,920 & 54,920 & $0 \%$ \\
\hline Space Heat & 134,640 & 117,590 & 64,664 & 73,000 & $+11.4 \%$ \\
\hline Space Cool & 21,460 & 28,500 & 34,850 & 35,160 & $+0.9 \%$ \\
\hline Fans & 22,140 & 19,810 & 17,470 & 17,440 & $-0.1 \%$ \\
\hline ERW Heat Recovery & - & 65 & 65 & 65 & $0 \%$ \\
\hline
\end{tabular}

\subsubsection{Creating Custom VRF Performance Curves}

The VRF equipment used in the building was manufactured by Mitsubishi Electric (Mitsubishi Electric Sales Canada Inc., 2014). Using the Mitsubishi DataBook (Mitsubishi Electric Sales Canada Inc.), equipment specifications were taken to create the performance curves needed for the VRF simulation in EnergyPlus.

EnergyPlus required 22 performance curves for each outdoor unit. In depth information is available in the EnergyPlus Input Output Reference (US Department of Energy, 2014) and the EnergyPlus Engineering Reference (US Department of Energy, 2014). The required curves for each outdoor unit are as follows (with brief descriptions adapted from the EnergyPlus Input Output Reference (US Department of Energy, 2014)): 
- Cooling Capacity Ratio Modifier Function of Low Temperature Curve

- A bi-quadratic equation that uses a weighted average indoor wet-bulb temperature and condenser entering dry-bulb temperature as independent variables to describe the cooling capacity ratio at low outdoor temperatures.

- Cooling Capacity Ratio Boundary Curve

- A linear, quadratic or cubic curve to describe the cooling capacity ratio when cooling capacity changes drastically as outdoor temperature changes as a function of indoor air wet-bulb temperature.

- Cooling Capacity Ratio Modifier Function of High Temperature Curve

- A bi-quadratic equation that uses a weighted average indoor wet-bulb temperature and condenser entering dry-bulb temperature as independent variables to describe the cooling capacity ratio at high outdoor temperatures.

- Cooling Energy Input Ratio Modifier Function of Low Temperature Curve

$\circ \quad \mathrm{A}$ bi-quadratic equation that uses a weighted average indoor wet-bulb temperature and condenser entering dry-bulb temperature as independent variables to describe the cooling energy ratio at low outdoor temperatures.

- Cooling Energy Input Ratio Boundary Curve

- A linear, quadratic or cubic curve to describe the cooling energy ratio when cooling capacity changes drastically as outdoor temperature changes as a function of indoor air wet-bulb temperature.

- Cooling Energy Input Ratio Modifier Function of High Temperature Curve

- A bi-quadratic equation that uses a weighted average indoor wet-bulb temperature and condenser entering dry-bulb temperature as independent variables to describe the cooling energy ratio at high outdoor temperatures.

- Cooling Energy Input Ratio Modifier Function of Low Part-Load Ratio Curve

- A linear, quadratic or cubic equation to describe the behaviour of the cooling energy ratio when the operating part-load ratio is less than or equal to 1.

- Cooling Energy Input Ratio Modifier Function of High Part-Load Ratio Curve

- A linear, quadratic or cubic equation to describe the behaviour of the cooling energy ratio when the operating part-load ratio is greater than 1 .

- Cooling Combination Ratio Correction Factor Curve

- A linear, quadratic or cubic equation to determine a multiplier $(>1)$ that is applied to the heat pump's Gross Rated Total Cooling Capacity for when the part-load ratio is not linearly proportional to the capacity.

- Cooling Part-Load Fraction Correlation Curve

- Defines the cycling losses when the condenser's compressors cycle on and off, when the cooling part-load ratio is less than the Minimum Heat Pump Part-Load Ratio.

- Piping Correction Factor for Length in Cooling Mode Curve

$\circ$ A linear, quadratic or cubic equation to calculate the piping correction factor for lengths in cooling mode, to determine the piping losses.

- Heat Recovery Cooling Capacity Modifier Curve 
- A bi-quadratic equation using weighted average indoor temperature and condenser entering air temperature as the independent variables, or a cubic equation based on part-load ratio. This curve is used to describe the cooling capacity modifier as a constant, as a cooling modifier that varies with either indoor temperature and/or outdoor temperature, or part-load ratio.

- Heat Recovery Cooling Energy Modifier Curve

- A bi-quadratic equation using weighted average indoor temperature and condenser entering air temperature as the independent variables used to describe the cooling energy modifier that varies with indoor and/or outdoor temperatures, or varies with both indoor and outdoor temperatures.

The curves for when the heat pump is operating in heating mode are the same as the 11 cooling mode curves listed above.

The indoor terminal units require four curves under the cooling and heating coil objects. The curves required are as follows (with brief descriptions adapted from the EnergyPlus Input Output Reference (US Department of Energy, 2014)):

- Cooling Capacity Ratio Modifier Function of Temperature Curve

- A linear, quadratic or cubic equation which defines how the cooling capacity changes with changes in indoor wet-bulb temperature

- Cooling Capacity Modifier Curve Function of Flow Fraction Curve

- A linear, quadratic or cubic equation which defines the total cooling capacity variation as a function of the ratio of actual air flow rate across the cooling coil to the coil's rated air flow rate

- Heating Capacity Ratio Modifier Function of Temperature Curve

- A linear, quadratic or cubic equation which defines how the heating capacity changes with changes in indoor wet-bulb temperature

- Heating Capacity Modifier Function of Flow Fraction Curve

- A linear, quadratic or cubic equation which defines the total heating capacity variation as a function of the ratio of actual air flow rate across the heating coil to the coil's rated air flow rate

As can be seen numerous curves need to be created for EnergyPlus modelling. This is an onerous task for a modeller to do, which typically leads to the use of the default curves during the design stage.

The VRF performance curves were created based on the FSEC guidelines for developing VRF heat pump performance curves (Raustad R. , 2012). A considerable amount of the manufacturer data provided was presented in graphical format as opposed to tabular format, which left for some interpolation when reading data points off the graphs. The data taken from the manufacturer specifications is used to fill a table based on the curve's equation. Once this table is filled out a regression analysis is done to 
determine the equation's coefficients. These coefficients are the values needed to fill in the curve objects in EnergyPlus.

To determine if a good curve model is created, it is important to look at the regression statistic value for R-square. R-square values show the curve's goodness of fit and that all changes have been captured by the fundamental equation (Raustad R. , 2012). R-square values near 1 are ideal, however, since data was being read off a graph, in some cases, it was difficult to get an R-square value of 0.99 or higher for the curve. The results of creating the custom curves can be found in Appendix G: Developed Mitsubishi Performance Curves.

Where information was unavailable, the default EnergyPlus performance curves were kept. There was insufficient data to create a custom curves for the Heating Part-Load Fraction Correlation Curve and Cooling Part-Load Fraction Correlation Curve. Additionally, all default heat recovery curves (Heat Recovery Cooling Capacity Modifier Curve, Heat Recovery Cooling Energy Modifier Curve, Heat Recovery Heating Capacity Modifier Curve, and Heat Recovery Heating Energy Modifier Curve) and default inputs were kept as there was no available manufacturer data to allow for appropriate curves or inputs to be created.

\subsubsection{Model 2C \& 2D- Earth Tubes}

The building earth tube network is comprised of two pipes which connect to the DOAS to pre-treat the incoming outdoor air year round. During the summer the full airflow is brought in through the earth tubes to be precooled before entering the building. During the winter half the air flow is brought in through the earth tubes to be preheated before entering the building, while the other half of the airflow is brought in through the solar wall.

The purpose of Model $2 \mathrm{C}$ is to demonstrate the effectiveness of the earth tubes with EnergyPlus in comparison to the manual calculations described in Section 6.1.3. In the previous models, the ERW effectiveness was set to 93\%, based on the consultants' earth tube calculations which determined an additional $17 \%$ heat recovery effectiveness above the manufacturer specification of $76 \%$. In Model $2 \mathrm{C}$ the ERW effectiveness was set to 76\%, as per the manufacturer specifications (Venmar CES Ind., 2011). This resulted in only a slight change in heating and cooling energy associated with conditioning the incoming air. The heating consumption increased by $0.21 \%$ and the cooling consumption increased by $0.95 \%$, from Model 3 . The additional $17 \%$ effectiveness resulted in yearly energy savings of $540 \mathrm{kWh}$. 
Table 11: EnergyPlus Model 2C Annual Modelling Results by Consumption Type - Impact of Decreasing ERW Sensible Effectiveness

\begin{tabular}{|l|r|r|r|r|r|r|}
\hline $\begin{array}{l}\text { Energy Consumption } \\
\text { Type }\end{array}$ & $\begin{array}{c}\text { EE4 } \\
\text { Model } \\
(\mathbf{k W h}) \mathbf{5}\end{array}$ & $\begin{array}{c}\text { E+ Model } \\
\mathbf{1} \\
\mathbf{( k W h )}\end{array}$ & $\begin{array}{c}\text { E+ Model } \\
\text { 2A } \\
\mathbf{( k W h )}\end{array}$ & $\begin{array}{c}\text { E+ Model } \\
\text { 2B } \\
\mathbf{( k W h )}\end{array}$ & $\begin{array}{c}\text { E+ Model } \\
\mathbf{2 C}(\mathbf{k W h})\end{array}$ & $\begin{array}{c}\text { \% } \\
\text { Difference }\end{array}$ \\
\hline Area Lights & 72,710 & 73,800 & 73,800 & 73,800 & 73,800 & $0 \%$ \\
\hline $\begin{array}{l}\text { Miscellaneous } \\
\text { Equipment }\end{array}$ & 54,870 & 54,920 & 54,920 & 54,920 & 54,920 & $0 \%$ \\
\hline Space Heat & 134,640 & 117,590 & 64,664 & 73,000 & 73,160 & $+0.21 \%$ \\
\hline Space Cool & 21,460 & 28,500 & 34,850 & 35,160 & 35,500 & $+0.95 \%$ \\
\hline Fans & 22,140 & 19,810 & 17,470 & 17,440 & 17,480 & $+0.24 \%$ \\
\hline ERW Heat Recovery & - & 65 & 65 & 65 & 65 & $0 \%$ \\
\hline
\end{tabular}

Although an earth tube object (ZoneEarthTube) exists, it could not be implemented as it needs to be directly linked to a zone, and simulates the air entering the zone like an infiltration model. To simulate the actual configuration, the intention was to attach the earth tube to a supply plenum, however, supply plenums can only be positioned on the demand side of the air loop, while the earth tube is needed on the supply side of the air loop, connected to the outdoors.

To work around this limitation, using the ZoneEarthTube object, a standalone modelling test was performed. The test was done to determine the temperature of the air leaving the earth tubes. EnergyPlus uses the following equation 6-4 to calculate the earth tube leaving air temperature ( $\left.T_{\text {zone }}\right)$, where coefficients A, B, C, and D are calculated by the program (US Department of Energy, 2014).

EarthTubeFlowRate $=$

$$
\left(E_{\text {design }}\right)\left(F_{\text {schedule }}\right)\left[A+B\left|T_{\text {zone }}-T_{\text {odb }}\right|+C(\text { WindSpeed })+D\left(\text { WindSpeed }^{2}\right)\right]
$$

where,

$\mathrm{E}_{\text {design }}=$ air mass flow rate

$\mathrm{F}_{\text {schedule }}=$ schedule for when the earth tube damper is open

$\mathrm{T}_{\text {zone }}=$ indoor air temperature

$\mathrm{T}_{\text {odb }}=$ outdoor air dry bulb temperature

For the earth tube to be simulated the average soil surface temperature, the amplitude of soil surface temperature, and the phase constant of soil surface temperature, as well as a weather file, are needed as inputs. The three soil characteristics are determined using one of EnergyPlus's standalone auxiliary programs called CalcSoilSurfTemp. (US Department of Energy, 2014)

Therefore, first the CalcCoilSurfTemp program was simulated to determine the soil characteristics, and then the ZoneEarthTube was simulated to determine the leaving air temperatures. The results from this 
test indicated that the incoming air through the earth tube would result in a $0^{\circ} \mathrm{C}-7^{\circ} \mathrm{C}$ temperature range over the course of a year.

To determine the energy consumption savings of the earth tube a cooling coil (Coil:Cooling:DX:Singlespeed) and heating coil (Coil:Heating:Electric) was added to the front end of the DOAS to simulate the air tempering of the incoming air as the earth tube would do. The energy consumption incurred by the added heating and cooling coil were then subtracted from the total space heating and space cooling amounts.

The results of Model 2D compared to Model 2C show that tempering the air results in a yearly energy savings of $2,260 \mathrm{kWh}$ or a $1.8 \%$ decrease in annual space conditioning energy consumption.

Table 12: EnergyPlus Model 2D Annual Modelling Results by Consumption Type - Impact of Adding Earth Tubes

\begin{tabular}{|l|c|r|r|r|r|r|r|}
\hline $\begin{array}{l}\text { Energy Consumption } \\
\text { Type }\end{array}$ & $\begin{array}{c}\text { EE4 } \\
\text { Model } \\
\mathbf{( k W h ) )}\end{array}$ & $\begin{array}{c}\text { E+ } \\
\text { Model 1 } \\
\mathbf{( k W h )}\end{array}$ & $\begin{array}{c}\text { E+ } \\
\text { Model } \\
\mathbf{2 A} \\
\mathbf{( k W h )}\end{array}$ & $\begin{array}{c}\text { E+ } \\
\text { Model } \\
\mathbf{2 B} \\
\mathbf{( k W h )}\end{array}$ & $\begin{array}{c}\text { E+ } \\
\text { Model } \\
\mathbf{2 C} \\
\mathbf{( k W h )}\end{array}$ & $\begin{array}{c}\text { E+ } \\
\text { Model } \\
\text { 2D } \\
\mathbf{( k W h )}\end{array}$ & $\begin{array}{c}\text { \% } \\
\text { Difference }\end{array}$ \\
\hline Area Lights & 72,710 & 73,800 & 73,800 & 73,800 & 73,800 & 73,800 & $0 \%$ \\
\hline $\begin{array}{l}\text { Miscellaneous } \\
\text { Equipment }\end{array}$ & 54,870 & 54,920 & 54,920 & 54,920 & 54,920 & 54,920 & $0 \%$ \\
\hline Space Heat & 134,640 & 117,590 & 64,664 & 73,000 & 73,160 & 71,840 & $-1.8 \%$ \\
\hline Space Cool & 21,460 & 28,500 & 34,850 & 35,160 & 35,500 & 34,980 & $-1.5 \%$ \\
\hline Fans & 22,140 & 19,810 & 17,470 & 17,440 & 17,480 & 17,060 & $-2.4 \%$ \\
\hline ERW Heat Recovery & - & 65 & 65 & 65 & 65 & 65 & $0 \%$ \\
\hline
\end{tabular}

Based on inputs for the two calculation methods it can be determined that the EnergyPlus methodology should predict the earth tube effectiveness more accurately than the manual calculations down by the consultants. By only changing the ERW effectiveness to account for the earth tubes' air tempering the model will under predict the incoming air's energy savings.

\subsubsection{Model 2E \& 2F - Sollar Wall}

Continuing with the refinement of the building components, Model 2E was adapted from Model 2C, where the solar wall was added to the south wall, which connects to the DOAS to preheat half the incoming outdoor air during the winter months. In the winter, half of the incoming outdoor airflow (i.e. $850 \mathrm{~L} / \mathrm{s}$ ) is brought in through the solar wall to be pre-treated, while in the summer the damper is closed and no air is brought in through the solar wall.

The SolarCollector:UnglazedTranspired object was used in EnergyPlus to model the solar wall. This object allows the modelling of air drawn through perforated absorbers to be heated by the sun as well 
as to recover heat conducted outwards from the building through the main wall behind the collector (US Department of Energy, 2014). The solar wall characteristics used for the model are outlined in the following table. The Certified Solar Collector Certificate (SRCC Certificate) can be found in Appendix I: SolarWall Solar Collector Certificate.

Table 13: Solar Wall Inputs for EnergyPlus

\begin{tabular}{|l|l|}
\hline Perforation Diameter & $1.5 \mathrm{~mm}$ (Hollick, 1998) \\
\hline Distance Between Perforations & $2.54 \mathrm{~cm}$ (Casey, 2015) \\
\hline Thermal Emissivity & 0.88 (Buffalo, NY, USA Patent No. SRCC \\
& $2012054 \mathrm{~A}, 2012)$ \\
\hline Solar Absorptivity & 0.89 (Casey, 2015) \\
\hline Perforation Pattern & Square (Casey, 2015) \\
\hline
\end{tabular}

The controls include a bypass damper. When the damper is set to open, all the ventilation air bypasses the solar wall and goes through the rest of the outdoor air system components. When the damper is closed, all the ventilation air passes through the solar wall before entering the remainder of the outdoor air system components. The bypass damper can only be modelled as completely open or completely closed (US Department of Energy, 2014). EnergyPlus only allows one outdoor air intake stream, however at the building $50 \%$ of the air flow is through the solar wall and $50 \%$ of the air path is through the earth tube, resulting in two outdoor air intake streams. To account for this limitation a similar procedure to the earth tube procedure was done to acquire the leaving air temperatures of the solar wall.

Using the SolarCollector:UnglazedTranspired object the model was simulated to report the leaving air temperatures for the winter months (October 1 - March 31) for each hour. Two models were run by setting the DOAS airflow to $100 \%$ airflow (1699 L/s) and 50\% airflow (850 L/s).

The $100 \%$ DOAS airflow model temperatures were used to determine the effectiveness of only installing a solar wall, with no earth tube. These calculated leaving air temperatures were the new setpoints for the heating coil used to temper the air before entering the DOAS, and the cooling coil was turned off.

To see the effect of only installing a solar wall, the results from Model 2E was compared to Model $2 \mathrm{C}$ (no earth tube). These results show a decrease in both space heating and cooling of $4 \%$ and $2.7 \%$, respectively, with an overall space conditioning decrease of $3910 \mathrm{kWh}$ or $3.1 \%$. A possible explanation for the decrease in cooling is that inputting the solar wall covered part of the exterior wall, which lessened the area available for solar absorption, thus lessened the amount of heat entering the building through the wall assembly. 
Table 14: EnergyPlus Model 2E Annual Modelling Results by Consumption Type - Impact of Adding a Solar Wall

\begin{tabular}{|l|r|r|r|}
\hline Energy Consumption Type & E+ Model 2C (kWh) & E+ Model 2E (kWh) & \% Difference \\
\hline Area Lights & 73,800 & 73,800 & $0 \%$ \\
\hline Miscellaneous Equipment & 54,920 & 54,920 & $0 \%$ \\
\hline Space Heat & 73,160 & 70,360 & $-4.0 \%$ \\
\hline Space Cool & 35,500 & 34,570 & $-2.7 \%$ \\
\hline Fans & 17,480 & 17,300 & $-1.0 \%$ \\
\hline ERW Heat Recovery & 65 & 65 & $0 \%$ \\
\hline
\end{tabular}

To determine how the effectiveness of the solar wall and earth tube working together, the solar wall leaving temperatures at 50\% DOAS airflow were averaged with the earth tube 50\% DOAS airflow for the winter months. These temperatures were then the new setpoints for the cooling and heating coils used to temper the air before entering the DOAS.

To determine the effectiveness of using both the earth tube and solar wall, Model $2 \mathrm{~F}$ was compared to Model $2 \mathrm{C}$. The results show a decrease in space heating and cooling each by $2 \%$, for an overall space conditioning decrease of $1870 \mathrm{kWh}$ or $1.5 \%$.

Table 15: EnergyPlus Model 2F Annual Modelling Results by Consumption Type - Impact of Adding a Solar Wall \& Earth Tubes

\begin{tabular}{|l|r|r|r|}
\hline Energy Consumption Type & E+ Model 2C (kWh) & E+ Model 2F (kWh) & \% Difference \\
\hline Area Lights & 73,800 & 73,800 & $0 \%$ \\
\hline Miscellaneous Equipment & 54,920 & 54,920 & $0 \%$ \\
\hline Space Heat & 73,160 & 71,970 & $-1.6 \%$ \\
\hline Space Cool & 35,500 & 34,960 & $-1.6 \%$ \\
\hline Fans & 17,480 & 17,340 & $-0.8 \%$ \\
\hline ERW Heat Recovery & 65 & 65 & $0 \%$ \\
\hline
\end{tabular}

The RETScreen analysis showed an annual savings of $3100 \mathrm{kWh}$ at 50\% airflow (850 L/s), whereas the solar wall only EnergyPlus simulation showed a result of $3910 \mathrm{kWh}$ in annual savings.

With earth tube only at a 2,260 kWh savings, solar wall only at 3,910 kWh annual savings, and earth tube plus solar wall at 1,870 kWh it can be seen that these components cannot be analyzed individually, when they are actually working together to pre-treat the incoming air. The earth tube air does not reach the high temperatures that the solar wall does, which creates the mixed air stream to be not as warm as with only using the solar wall. This in turn reduces the effectiveness of the air pre-treatment. To achieve greatest energy consumption savings using only a solar wall to pre-treat the incoming air during the winter, and using an earth tube to only pre-treat the incoming air in the summer may have been a better option. 


\section{ADVANCED MODEL DESIGN}

This section describes the refinement process of the baseline model to the advanced model. After each step in the refinement process the simulated data was reference to the measured data from the case study building to determine if the model had reached the calibration limits. The refinement process used measured daily energy consumption data from the case study building from May 2013 to April 2014 and an actual meteorological year (AMY) weather file from Weather Analytics. The AMY Weather Analytics files are based on real collected conditions from close by weather stations and generated climate model data to determine the weather for your exact location (Weather Analytics, 2015). Case study building room temperature data from March and April of 2014 was used as a secondary constraint when adjusting the various parameters, to ensure the model was still meeting the loads.

\subsection{Advanced Model Development Process OVERVieW}

A limited field data calibration was used to create the advanced model. The baseline model, Model $2 \mathrm{~F}$, with all the component add-ons was used as the starting point for the advanced model.

Since the available metered data was at a daily interval, daily comparisons between simulated and metered results was deemed possible. In addition to trying to match the cooling and heating consumption of the building, the simulated zone temperatures were matched with the collected room temperature data. Parametric testing was done on the VRF input parameters to determine their significance. Based on the results of the parametric testing the significant parameters were identified and further tuned. The final inputs for the significant parameters were based on known or measured data. If unknown, assumptions were made based on further literature review.

The major modelling parameters of the case study building were determined from the engineering design documents, manufacturer equipment specifications and the air balancing report. The development process of the advanced model included an iterative process of logically selecting model input parameters that had a significant effect on the heating and cooling energy consumption.

With the Author's current knowledge and due to certain limitations which are discussed below, a fully calibrated model was not achievable. 


\subsection{Air INFILTRATION MODEL}

Few measurements and guidelines have been made available for non-residential building air leakage values and distribution, and the data that has been released does not sufficiently represent the existing building stock in Canada. The size, geometry and function of non-residential buildings varies greatly which makes comparison studies more difficult.

As a detailed blower-door test was completed, there was sufficient information to use the advanced infiltration model in EnergyPlus, Zonelnfiltration:FlowCoefficient. This model uses an empirically tested superposition method to integrate both wind and stack effect, based on the AIM-2 model developed by Walker and Wilson. Although this calculation method is described to be appropriate for the smaller, residential type buildings (US Department of Energy, 2014), it was deemed acceptable to be used for the case study building since it is a small office building and only two storeys high (i.e. not taller than other small residential buildings), therefore the wind and stack effects would be similar as a small residential type building. The wind speeds and directions used in this equation are from the weather file, for the London Airport. Since the case study building is located in a clearing with trees a significant distance away and no adjacent structures to interfere with wind patterns, it can be assumed that both locations would experience similar wind speeds and directions.

The following equation is used to calculate the infiltration for each zone in the building in EnergyPlus (US Department of Energy, 2014).

Infiltration $=F_{\text {Schedule }} \sqrt{\left(c C_{s} \Delta T^{n}\right)^{2}+\left(c C_{w}(s * \text { WindSpeed })^{2 n}\right)^{2}}$

The flow coefficient, $c$, and pressure exponent, $n$, were determined from the results of the blower-door test. Since the blower-door test results are only for the whole building, and not by zone, a weighted average was taken to distribute the infiltration across the building, as was done by Zirnhelt (Zirnhelt, 2013). The weighted average procedure attributes $70 \%$ of the infiltration to a zone percentage of the total window and door frame lengths, with the remaining 30\% proportionally distributed by exposed exterior surface area.

Zone Infiltration Fraction $=$ infiltration rate $*$

$$
\left(\left(\frac{\text { zone glazing length }}{\text { building glazing length }}\right) * 0.7+\left(\frac{\text { zone exposed surface area }}{\text { building exposed surface area }}\right) * 0.3\right)
$$


Replacing the Zonelnfiltration:DesignFlowRate with ZoneInfiltration:FlowCoefficient resulted in a percent decrease of $4.6 \%$, or $17,190 \mathrm{kWh}$, in annual energy consumption.

\subsection{INTERZONE AIRFLOW OPENINGS}

Energy transfer between thermal zones from doorways and stairwells is not accounted for in EnergyPlus. EnergyPlus contains a couple methods for simplified airflow, such as the ZoneCrossMixing object, however there is a limit of only one ZoneCrossMixing object per zone, which in many cases is insufficient. Furthermore, removing a section of a zone connecting surface, such as a wall or floor surface, in the model's building geometry would disregard the heat transfer associated with the given surface (Zirnhelt, 2013). Thus removing stairwells or doorways would not give a good representation of the heat transfer between the zones. To ensure all surface heat transfer was accounted doorways and stairwells were modelled following the same method as Zirnhelt (Zirnhelt, 2013), where the surfaces were modelled as glass surfaces with high transmittance, high emissivity, high long wave transmittance, and very low thermal resistance.

\subsection{CONVECTION Algorithims}

Surface convective heat transfer is an important aspect in releasing stored heat in thermal mass in the building. Since there is a significant amount of concrete, a thermal mass medium, throughout the building, it is important to accurately model the convective heat transfer when predicting the building's overall energy consumption. There are different methods that are available for modelling both inside and outside convective heat transfer. Many of the methods come from previous modelling programs or studies. For both inside and outside calculations, the most in depth model is the Adaptive Convection Algorithm. This model was created for EnergyPlus but borrows concepts from Beausoleil-Morrison, which allows for better control of particular surfaces and selects the most appropriate convection method from a range of methods (US Department of Energy, 2014).

For outside adaptive convection the model takes into consideration the surface classification, wind speed, wind direction and heat flow direction. However, for all methods if the weather file indicates rain, the convective heat transfer coefficient will be set to $1000 \mathrm{~W} / \mathrm{m}^{2} \mathrm{~K}$ for all wind exposed surfaces (US Department of Energy, 2014).

The inside adaptive convection, developed by Beausoleil-Morrison, is similar to the outside adaptive convection algorithm however it has many more options of methods to choose from and is more 
complex. This method takes into consideration zone air flow regime, surface type, surface orientation, and heat flow direction.

In the base case models the Simple Inside Surface Convection Algorithm was selected, since EE4 uses a constant value. Using the TARP algorithm, which is the default option in EnergyPlus, there was a 3.3\% decrease in heating and a $1.9 \%$ increase in cooling energy consumption. Using the Adaptive Convection Algorithm there was a $2.3 \%$ decrease in heating and a $0.6 \%$ increase in cooling energy consumption compared to using the TARP method. This is probably due to a better representation in heat transfer from the thermal mass in the building (Zirnhelt, 2013).

For the Outside Surface Convection Algorithm the base case models used the DOE-2 method since the EE4 program is based on a version of DOE-2. Using the Adaptive Convection Algorithm method there was a $2.3 \%$ increase in heating and a $1.4 \%$ decrease in cooling energy consumption compared to using the DOE- 2 method. This increase is most likely related to the better incorporation of wind parameters in the calculations (Zirnhelt, 2013).

\subsection{VRF PERFORMANCE CURVES ANALYSIS}

The use of custom performance curves was further investigated using a variety of input scenarios in order to gain a better understanding of sensitivity associated with curves. First, all default curves were used. Second, all curves created as part of this research were used (leaving three curves default, as outlined below). Third, only created curves with an R-square value of 0.99 or higher were used, with the rest being reverted to the default curves. Figure 18 presents the results of this analysis. 


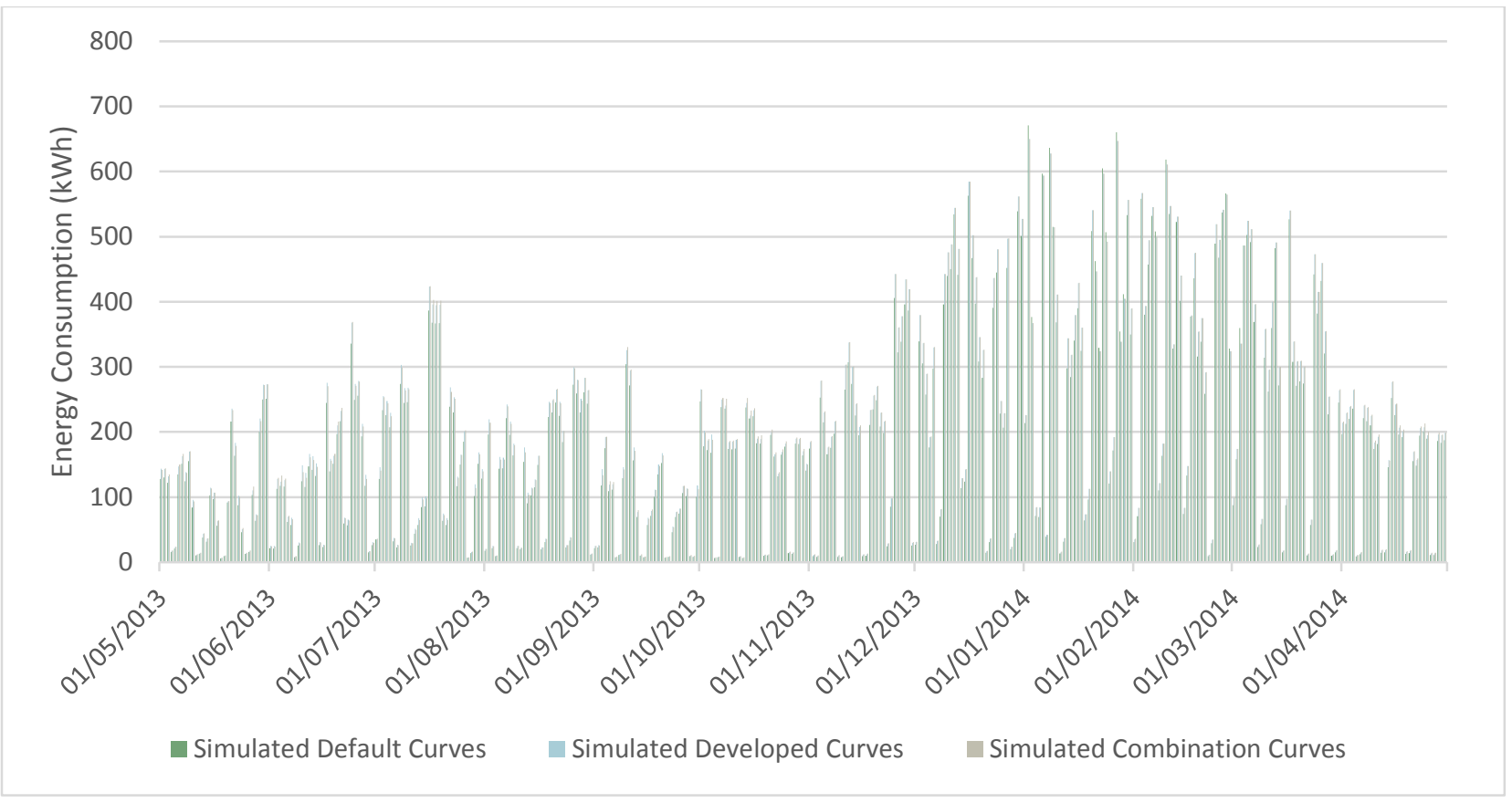

Figure 18: Outdoor Units Energy Consumption by Performance Curves

It can be seen that there was a small energy consumption difference ( $5.4 \%$ increase) in the outdoor units between using the default and developed custom curves, and no difference in the indoor units. The indoor unit's energy consumption comes from the fan's operation and some parasitic energy. Since indoor units are scheduled to only run when there is heating or cooling, it was expected that the change in the outdoor units' performance curves would not greatly change the indoor units, as the frequency of operation did not change. In all cases there is a much higher simulated energy consumption than metered energy consumption for the outdoor units.

The energy consumption for the 12 month period for the three performance curve scenarios are listed in Table 16. There was an overall 5.1\% increase in energy consumption when the developed custom curves were used in comparison to when the default curves were used. The combined curves were selected to be used in the advanced model.

Table 16: Energy Consumption Results for Using Different VRF Performance Curves

\begin{tabular}{|l|c|c|c|}
\hline $\begin{array}{c}\text { Consumption } \\
\text { Type }\end{array}$ & Default (kWh) & $\begin{array}{c}\text { Developed \% Difference from } \\
\text { Default }\end{array}$ & $\begin{array}{c}\text { Combined \% Difference from } \\
\text { Default }\end{array}$ \\
\hline Heating & 52,714 & $+5.4 \%$ & $+5.4 \%$ \\
\hline Cooling & 24,697 & $+9.3 \%$ & $+9.5 \%$ \\
\hline Fans & 22,997 & $0 \%$ & $0 \%$ \\
\hline
\end{tabular}




\subsection{VRF OUTDOOR UNITS}

As previously mentioned, the outdoor unit object in EnergyPlus requires numerous input parameters, including all the performance curves listed in section 6.2.4.1. The other main required input parameters are as follows:

- Cooling \& heating capacity

- Cooling \& heating COP

- Minimum outdoor temperature in cooling mode

- Maximum outdoor temperature in cooling mode

- Minimum outdoor temperature in heating mode

- Maximum outdoor temperature in heating mode

- Minimum heat pump part-load ratio

- Heat pump waste heat recovery

- Crankcase heater power per compressor

- Number of compressors

- Ratio of compressor size to total compressor capacity

- Defrost time period fraction

- Resistive defrost heater capacity

- Initial heat recovery cooling \& heating capacity fraction

- Heat recovery cooling \& heating capacity time constant

- Initial heat recovery cooling \& heating energy fraction

- Heat recovery cooling \& heating energy time constant

The cooling and heating capacities, heating and cooling COPs, minimum and maximum outdoor temperatures for operation, the number of compressors, ratio of compressor size to total compressor capacity and crankcase heater power per compressor were taken from the equipment specifications (Mitsubishi Electric Sales Canada Inc.).

Although not possible during this investigation due to the building being continually occupied, it would have been advantageous to do testing at the case study building to determine the cooling and heating capacities and COPs. Equipment rarely functions at the manufacturer nominal values and changing the capacities and COPs could significantly change the modelling results. Some possible reasons could be attributed to the COP decreasing with an increase in indoor unit capacity and piping length. To show the impact this would have the nominal capacities and COPs were changed to the derated values. The result of changing these values yielded in an increase of $2.7 \%$ and $3.5 \%$ in heating and cooling electrical consumption, respectively, while the fan consumption remained the same. Raustad et al. (2013) found the manufacturer cooling capacity and COP to be higher than the field testing capacity and cooling COP by $12 \%$ and $27 \%$, respectively, as well as a lesser value of $8.5 \%$ and $1.3 \%$ for the manufacturer heating capacity and COP than with the field testing heating capacity and COP, respectively. More studies would 
need to be done to determine if there is a constant factor between manufacturer and measured values with various equipment configurations

\subsubsection{Minimum Heat Pump Part-Load Ratio}

The minimum heat pump part-load ratio input parameter refers to the value that the heat pump's compressor will start cycling in order to meet the cooling and heating demand in the building, whereas above the specified value it will operate the entire time (US Department of Energy, 2014). The default value specified in EnergyPlus for this parameter is 0.15 . The model was run using inputs of $0.15,0.25$, 0.35 and 0.45 . The difference in annual electrical consumption when the minimum heat pump part-load ratio is set to 0.35 and 0.45 is minimal, which leads to believe that the unit's operational ratio is set at 0.35. Further raising this value would not make sense as it would be running constantly due to demand either way. At a part-load ratio of 0.15 the annual outdoor unit consumption was $99,850 \mathrm{kWh}$, at 0.25 part-load ratio the consumption was $90,050 \mathrm{kWh}$ and $83,880 \mathrm{kWh}$ was observed for a minimum partload ratio of 0.35 . Increasing the minimum part-load ratio from 0.15 to 0.35 resulted in an energy consumption decrease of $16 \%$. The results of this sensitivity analysis can be found in Figure 19 and Table 17.

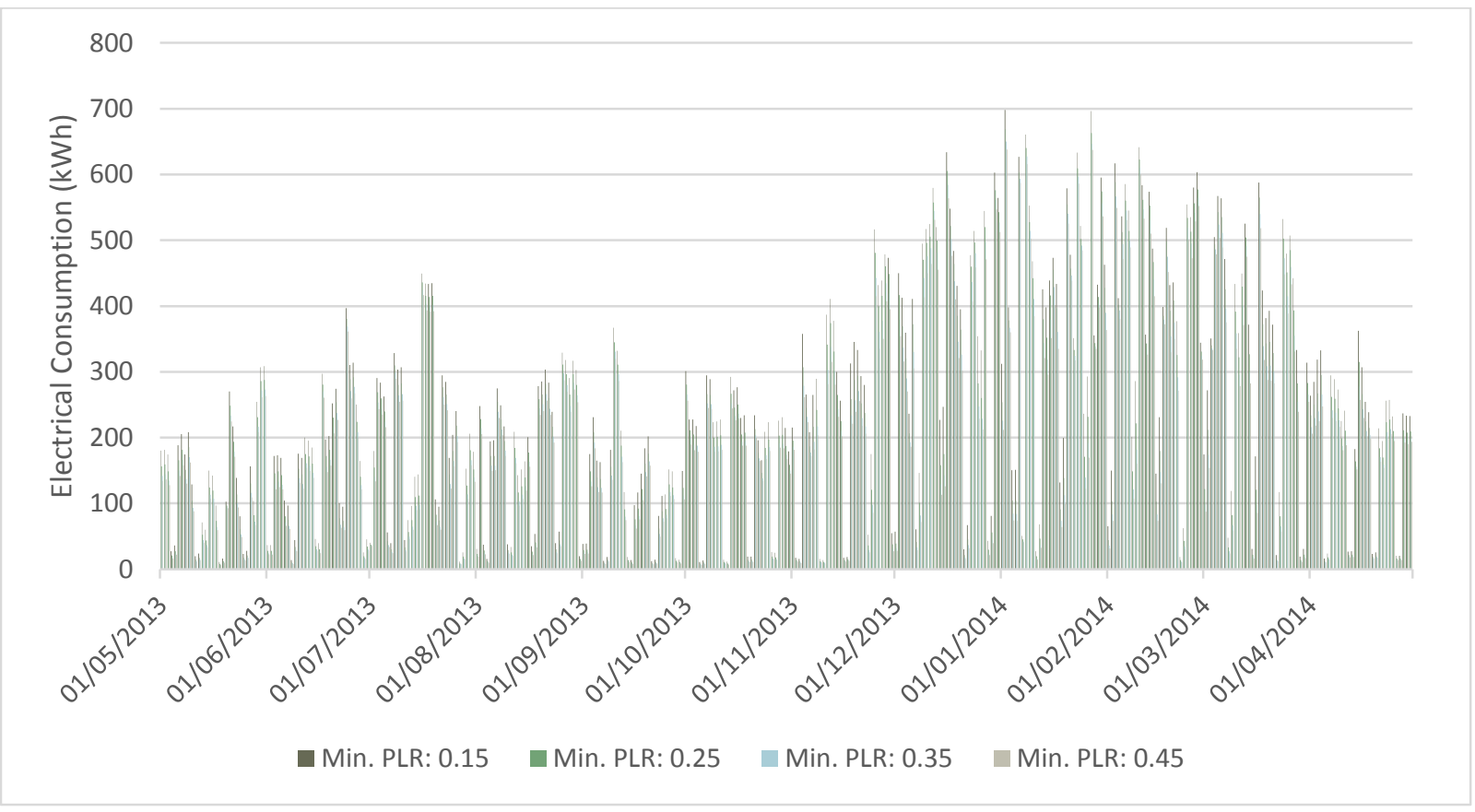

Figure 19: Outdoor Units Energy Consumption for Minimum Heat Pump Part-Load Ratio Analysis

Table 17: Energy Consumption Difference Based on Minimum Heat Pump Part-Load Ratio Input

\begin{tabular}{|l|r|r|r|r|}
\cline { 2 - 5 } \multicolumn{1}{c|}{} & Min. PLR - 0.15 & Min. PLR - 0.25 & Min. PLR - 0.35 & Min. PLR - 0.45 \\
\hline Energy Consumption & $99,850 \mathrm{kWh}$ & $-9.8 \%$ & $-16.0 \%$ & $-19.8 \%$ \\
\hline
\end{tabular}




\subsubsection{Heat Pump Waste Heat Recovery}

The heat pump waste heat recovery defines whether or not the heat recovery system feature is enabled, which allows for independent cooling and heating to different zones to occur simultaneously. The VRF system installed at the case study building was designed with heat recovery. The baseline models did not have heat recovery enabled. It can be seen that there was not a major savings (1,390 kWh or $1.9 \%$ annually) of having the heat recovery mode enabled. Although the temperature setpoints are mostly the same throughout the building, it was expected that there would be a larger energy saving potential. As an example, $\mathrm{Li}$ and $\mathrm{Wu}$ ( $\mathrm{Li} \& \mathrm{Wu}, 2010$ ) determined a 15-17\% decrease in energy consumption when using a heat recovery VRF system over a heat pump VRF system for the same temperature control method for a simplified typical commercial building.

This minimal change leads to three possible issues: the system load balancing was not done as efficiently as possible through the configuration of the terminal units associated with the outdoor units; the building's heating and cooling loads are similar throughout the building so the system doesn't have to move the heat around the building; or since heat recovery is very difficult to quantify as it changes for each building this parameter could be further developed. The results of this sensitivity analysis (i.e. heat recovery on or off) is displayed in Figure 20.

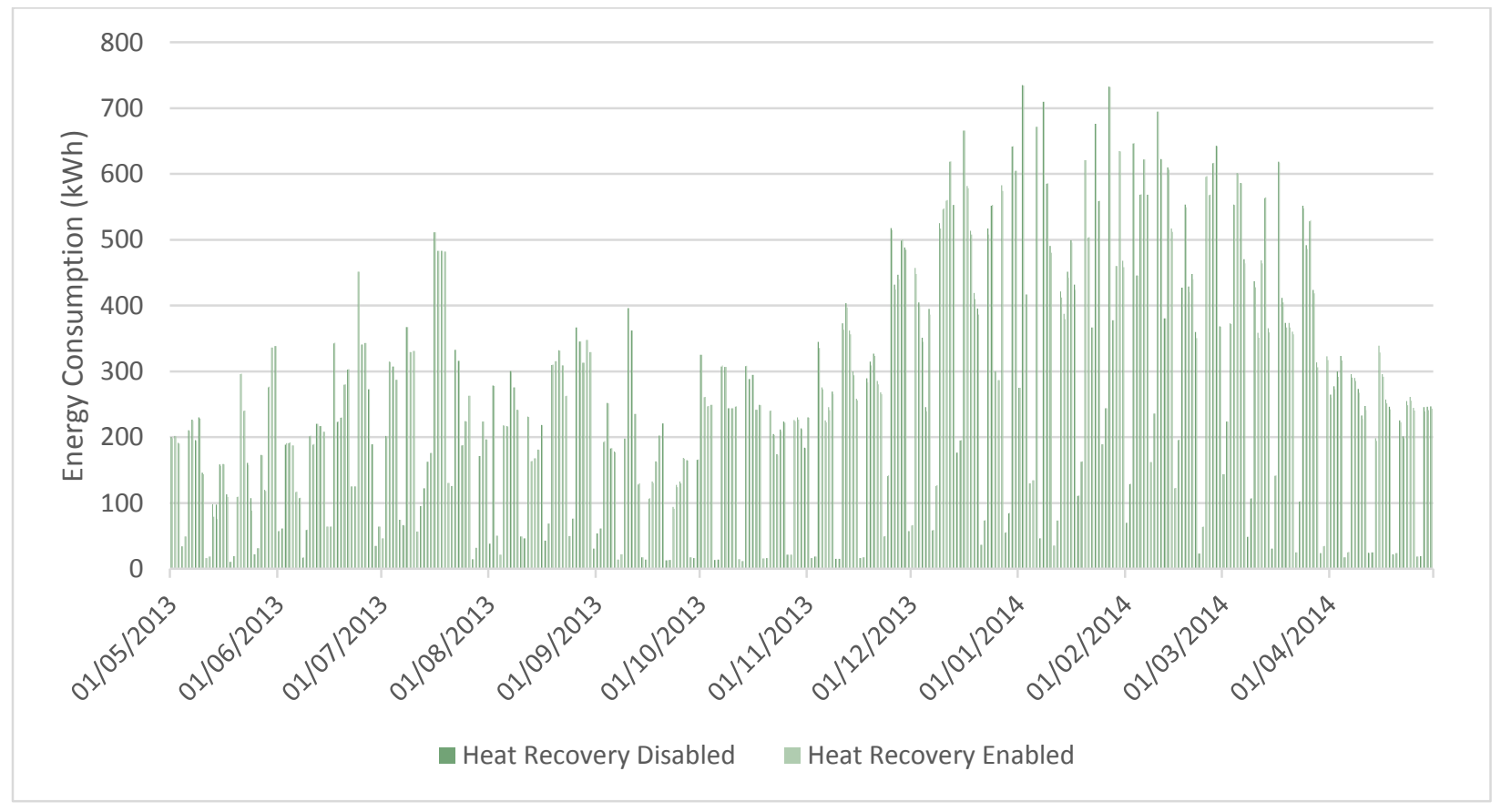

Figure 20: Outdoor Units Energy Consumption for Heat Recovery Analysis 
After input parameters were analyzed the advanced model simulated energy consumption for the outdoor units is still significantly higher than what was recorded at the case study building. This leads to several areas of further study: the data set is flawed; a simulated component is causing the building to require more cooling and heating in the building; the case study building's equipment is performing better than specified by the manufacturer (higher COPs); and/or the case study building is under heat recovery mode more often than predicted by the EnergyPlus simulation.

\subsubsection{Heat Recovery Inputs}

When the heat pump waste heat recovery is enabled, the heat recovery input parameters become active. Heat recovery is a difficult parameter to quantify as it can vary significantly between buildings based on numerous parameters, such as, building type and its usage, temperature setpoints and VRF configuration. Quantifying heat recovery is still in its early stages in EnergyPlus. In general, there is little heat recovery performance data publicly available from manufacturers or published research. Since there is minimal available data the heat recovery default curves and inputs in EnergyPlus are still being refined. Heat recovery performance data was not available through the manufacturer specification for the equipment installed in the case study building. The heat recovery performance curves use biquadratic equations, however due to the minimal amount of data EnergyPlus Engineering Reference recommends only using coefficient "a" (US Department of Energy, 2014). With no additional data available the default performance curves were used.

The EnergyPlus Input Output Reference (US Department of Energy, 2014) states the default values for initial heat recovery cooling capacity fraction and initial heat recovery heating capacity fraction are 0.5 , the initial heat recovery cooling energy fraction is 1 and the initial heating energy fraction is 0.5 . The EnergyPlus Engineering Reference (US Department of Energy, 2014) shows some VRF system laboratory data which indicates that the heat recovery cooling capacity fraction is approximately 0.91 and the heat recovery cooling energy fraction is approximately 1.14 . There is currently no data available for heat recovery heating fractions for capacity or energy. When the capacity fraction and energy fraction were changed to the values determined by the laboratory data listed in the Engineering Reference, there was no change in energy consumption. Therefore, further refinement of these parameters was not undertaken and the default values were kept. The heat recovery cooling and heating capacity time constant have default values of 0.083 and the heat recovery cooling and heating energy time constant have defaults of 0 . It is believed that part of the energy consumption over-prediction is attributed to using the minimal default inputs of the heat recovery model. 


\subsection{VRF TERMINAL UNIT FANS}

Each VRF terminal unit comprises a fan, cooling coil and heating coil. The fan is the main component consuming electricity at the terminal unit level. The energy consumption associated with cooling or heating the refrigerant in the coil is connected to the VRF outdoor units. The fan is used to circulate and condition the air within the zone. The ZoneHVAC:TerminalUnit:VariableRefrigerantFlow model allows two fan model options: Fan:OnOff and Fan:ConstantVolume. Since the operating schedule for the terminal unit fans is set to always available, or runs continuously, Fan:ConstantVolume was the appropriate choice. The Fan:ConstantVolume includes the following input parameters:

- Fan total efficiency

- Motor efficiency

- Pressure rise

- Motor heat gain fraction in airstream

The manufacturer equipment specification sheets contained insufficient information for the terminal unit fans to determine all the input parameters. Based on laboratory tests and simulation work on Mitsubishi VRF equipment by Nigusse et al. (Nigusse, Sharma, Raustad, \& Cummings, 2013), the fans for the terminal units were set to $60 \%$ fan total efficiency and $93 \%$ motor efficiency. Using a $60 \%$ fan total efficiency, a 93\% motor efficiency, along with the airflow rates and shaft power from the equipment specification sheets, the pressure rise was calculated using the following equations from the EnergyPlus Input Output Reference (US Department of Energy, 2014):

Fan Total Efficiency $=$ Motor Efficiency $*$ Impeller Efficiency

Impeller Ef ficiency $=\frac{\text { Power Delivered to the Fluid }}{\text { Shaft Power }}$

Power Delivered to the Fluid $=\frac{\text { Mass Airflow Rate } * \text { Pressure Rise }}{\text { Air Density }}$

It was assumed that $95 \%$ of the motor heat gains are transferred to the airstream with the rest being transferred to the surrounding zone. Since the fan is enclosed in the terminal unit casing it is expected that most of the heat will enter the airstream, with an expected small amount to be transferred to the zone surrounding the fan. The input parameters used in the fan models are listed in Table 18 for each of the terminal units. 
Table 18: VRF Terminal Unit Fan Inputs by Product Tag

\begin{tabular}{|l|c|c|c|c|c|c|}
\hline Product Tag & $\begin{array}{c}\text { Total } \\
\text { Efficiency } \\
(\%)\end{array}$ & $\begin{array}{c}\text { Motor } \\
\text { Efficiency } \\
\mathbf{( \% )}\end{array}$ & $\begin{array}{c}\text { Airflow } \\
\text { Rate } \\
(\mathbf{m 3} / \mathbf{s})\end{array}$ & $\begin{array}{c}\text { Shaft } \\
\text { Power } \\
\mathbf{( k W )}\end{array}$ & $\begin{array}{c}\text { Pressure } \\
\text { Rise } \\
\mathbf{( P a )}\end{array}$ & $\begin{array}{c}\text { Motor Heat } \\
\text { Gain Fraction } \\
\text { in Airstream }\end{array}$ \\
\hline PEFY-P06NMAUE & 0.6 & 0.93 & 0.100 & 85 & 150.0 & 0.95 \\
\hline PEFY-P08NMAUE & 0.6 & 0.93 & 0.142 & 85 & 386.2 & 0.95 \\
\hline PEFY-P12NMAUE & 0.6 & 0.93 & 0.175 & 85 & 313.4 & 0.95 \\
\hline PEFY-P15NMAUE & 0.6 & 0.93 & 0.233 & 85 & 235.4 & 0.95 \\
\hline PEFY-P18NMAUE & 0.6 & 0.93 & 0.283 & 85 & 193.8 & 0.95 \\
\hline PEFY-P24NMAUE & 0.6 & 0.93 & 0.316 & 121 & 247.0 & 0.95 \\
\hline PEFY-P27NMAUE & 0.6 & 0.93 & 0.349 & 121 & 223.7 & 0.95 \\
\hline PEFY-P36NMAUE & 0.6 & 0.93 & 0.550 & 244 & 286.2 & 0.95 \\
\hline PEFY-P48NMAUE & 0.6 & 0.93 & 0.665 & 244 & 236.7 & 0.95 \\
\hline PLFY-P08NCMU-E & 0.6 & 0.93 & 0.133 & 15 & 72.8 & 0.95 \\
\hline PLFY-P12NBMU-E & 0.6 & 0.93 & 0.200 & 50 & 161.3 & 0.95 \\
\hline PLFY-P18NBMU-E & 0.6 & 0.93 & 0.300 & 50 & 107.5 & 0.95 \\
\hline PLFY-P24NBMU-E & 0.6 & 0.93 & 0.333 & 50 & 96.9 & 0.95 \\
\hline PLFY-P30NBMU-E & 0.6 & 0.93 & 0.367 & 50 & 87.9 & 0.95 \\
\hline PKFY-P12NHMU-E & 0.6 & 0.93 & 0.150 & 30 & 129.0 & 0.95 \\
\hline
\end{tabular}

Based on the air balancing report some of the airflows were changed to match with the fan speeds. Some of the airflow rates had to be changed to meet the rated airflow rate range for the heating and cooling coils specified by EnergyPlus (US Department of Energy, 2014): "The rated air volume flow rate should be between $0.00004027 \mathrm{~m}^{3} / \mathrm{s}$ and $0.00006041 \mathrm{~m}^{3} / \mathrm{s}$ per watt of rated total cooling capacity." When the airflow rates are not within this range a "fatal error" occurs and causes EnergyPlus to crash.

The fan power from the simulation was verified with the air balancing report results (not all fan results were available in the report), shown in Table 19. The simulated fan power tended to be lower than the tested values as some of the terminal units had ducts attached to them which could not be accounted for in EnergyPlus. 
Table 19: Tested and Simulated Fan Power by Product Tag

\begin{tabular}{|l|r|r|}
\hline Product Tag & \multicolumn{1}{|c|}{ Tested Fan Power } & EnergyPlus Simulated Fan Power \\
\hline PEFY-P06NMAUE & 94.05 & 91.33 \\
\hline PEFY-P08NMAUE & 94.05 & 91.35 \\
\hline PEFY-P12NMAUE & 114.95 & 91.29 \\
\hline PEFY-P15NMAUE & 117.60 & 91.26 \\
\hline PEFY-P18NMAUE & 137.94 & 91.03 \\
\hline PEFY-P24NMAUE & 194.37 & 130.09 \\
\hline PEFY-P27NMAUE & 195.30 & 129.71 \\
\hline PEFY-P36NMAUE & 291.90 & 262.17 \\
\hline
\end{tabular}

Using the listed fan parameters from Table 18, the simulated energy consumption is much higher than the metered consumption. This lead to further examination of the terminal unit input parameters.

The study done by Raustad et al. (2013) used a pressure rise of $75 \mathrm{~Pa}$ for all their terminal units. Lowering the pressure rise for all the terminal units caused the power to decrease below the findings of the air balancing report. This also caused the simulation to under predict the VRF fan consumption compared to the metered data. In addition, it only minimally lowered the outdoor unit consumption.

Using the other fan object option (Fan:OnOff) was investigated to see if it would create a better energy consumption prediction. However, this created no difference in the terminal unit fan consumption but did increase the heating consumption created by the outdoor units by $440 \mathrm{kWh}$, therefore Fan:ConstantVolume was deemed the better option.

Since the fans are set to run only when heating or cooling is needed and the fan consumption is much greater than the metered consumption, this indicates that the simulation is calling for the building to be conditioned much more than often than in actuality at the case study building. This can be attributed to the deadband not being properly accounted for in EnergyPlus. If the deadband limits were working properly then the fan energy consumption would decrease, as the fan would only run when the system reached the deadband limits and required heating or cooling to meet the setpoint again. 


\subsection{DOAS FANS}

The dedicated outdoor air system (DOAS) includes a VFD supply fan and a VFD exhaust fan, which provides the building's conditioned ventilation air at a maximum flow of $1699 \mathrm{~L} / \mathrm{s}$ throughout the year. The air flow varies based on the occupancy of the building through carbon dioxide sensors located throughout the building. The dedicated outdoor air system (including the fan) is set to be turned off overnight and on weekends and holidays.

Based on the varying airflow, a variable volume fan should be used to simulate the DOAS fan, however, this could not be accomplished in EnergyPlus due to one of its limitations with modelling the ERW. The incoming air must travel through the ERW before passing over the heating and cooling coils. Based on the other outdoor air system components the only fan model which works and was used in the simulation is the Fan:ConstantVolume model.

The fan (Fan:ConstantVolume) model includes the following input parameters:

- Pressure rise

- Motor heat gain fraction in airstream

- Fan total efficiency

- Motor efficiency

To simplify modelling, only one fan object was used, however the pressure rise was doubled to account for both of the fans' consumption. Shim et al. suggest a typical pressure rise for a VFD fan to be $374 \mathrm{~Pa}$ (Shim, Song, \& Wang, 2014). Therefore a pressure rise value of 748 Pa was used. The fans, coils and ERW are enclosed in a make-up air unit, therefore it is assumed that $95 \%$ of the motor heat gains are transferred to the airstream, with some losses to the surrounding mechanical room. The fan specification sheet lists the fan total efficiency at $69.9 \%$ and the impeller efficiency at $63.6 \%$. The motor efficiency is the ratio of fan total efficiency to impeller efficiency. Therefore using Equation 6-6 the motor efficiency was calculated to be $91 \%$.

$$
\text { Motor Efficiency }=\frac{\text { Total Efficiency }}{\text { Impeller Efficiency }}
$$

\subsection{INTERNAL GAINS}

Internal gains are sources of heat apart from the HVAC system. Internal gains are accounted for throughout the building through occupancy, lighting and miscellaneous equipment. 


\subsubsection{Occupancy}

Occupancy was accounted for using the MNECB ' $A$ ' occupants time schedule for all zones, where the number of occupants per zone was determined from the LEED ${ }^{\circledR}$ report. The occupant values are considered average values as the numbers fluctuate depending what type of events are happening at the building. Since most of the building is set up as office space it was assumed most occupants would be using the space as such and an activity level for typing of 117 Watts per person was selected from Table 11 in the Input Output Reference Guide (US Department of Energy, 2014).

\subsubsection{Lighting Model}

In EnergyPlus the lighting inputs were entered using the Lights object based on the lighting drawing as well as how they were entered in EE4. Lighting level was chosen as the design level calculation method which allows the total Watts for lighting for each zone.

The lighting was modelled using a time schedule modified from the MNECB ' $A$ ' lighting schedule that was used in the EE4 model. It was seen that the night/weekend setback ratios were higher than the MNECB lighting setbacks and the day ratios were lower. Therefore the building has numerous lights that are not used very frequently.

The heat gains from the internal lights in the building are calculated based on the following equation (US Department of Energy, 2014):

$$
f_{\text {convected }}=1.0-(\text { Return Air Fraction }+ \text { Fraction Radiant +Fraction Visibile })
$$

The building uses a variety of fluorescent and LED bulbs and configurations. The EnergyPlus Input Output Reference Guide (US Department of Energy, 2014) gives values for fluorescent lighting based on the IESNA Lighting handbook, displayed in Table 20. These values were used in the EnergyPlus model for the different configurations seen throughout the building.

Table 20: Fluorescent Lighting Luminaire Configuration (US Department of Energy, 2014)

\begin{tabular}{|l|l|l|l|}
\hline Field Name & Suspended & Surface Mount & Recessed \\
\hline Return Air Fraction & 0.0 & 0.0 & 0.0 \\
\hline Fraction Radiant & 0.42 & 0.72 & 0.37 \\
\hline Fraction Visible & 0.18 & 0.18 & 0.18 \\
\hline$f_{\text {convected }}$ & 0.40 & 0.10 & 0.45 \\
\hline
\end{tabular}

The values for LEDs will vary depending on the LED efficacy. In an article written by the US department of energy it is reported that LEDs will vary $0.15-.25$ for fraction visible and $0.75-0.85$ for fraction heat 
(conduction + convection) (U.S. Department of Energy: Energy Efficiency and Renewable Energy, 2007). An office "Green Building" simulation study (Ahn, 2014) reported 0.25 for fraction visible and 0.75 for fraction convection, results shown in Table 21. Due to limited available data, it was assumed that the same fractions could be applied to surface mounted LEDs.

Table 21: LED Lighting Luminaire Configuration (Ahn, 2014)

\begin{tabular}{|l|l|}
\hline Field Name & Recessed \\
\hline Return Air Fraction & 0.0 \\
\hline Fraction Radiant & 0.0 \\
\hline Fraction Visible & 0.25 \\
\hline$f_{\text {convected }}$ & 0.75 \\
\hline
\end{tabular}

\subsubsection{Miscellaneous Equipment}

The case study building has numerous sources of miscellaneous electrical equipment such as kitchen appliances, gym equipment, lab equipment and printers. Insufficient data was available for the individual pieces of equipment therefore miscellaneous equipment was modelled as a lump sum based on the available data from the electrical panel and its corresponding collected metered data. It would be beneficial to do spot testing of the electrical equipment to better determine the equipment's actual energy consumption.

\subsection{0. $\quad$ Summary OF ENERgy lus Limitations}

The limitations encountered during this research were:

- More accurate solar distribution algorithms could not be used due to non-convex building geometry. FullExterior solar distribution algorithm was used.

- Only one outdoor air node for the ventilation airstream is allowed, therefore external calculations were required to develop a file with outdoor air inlet node temperatures.

- The ZoneEarthTube object does not connect to an airstream, therefore leaving air temperatures were exported to a file to be used in external calculations to determine the outdoor air inlet node temperature.

- There is a limit of one ZoneCrossMixing object per zone, therefore openings were treated as glazing with high transmittance, high emissivity, high long wave transmittance and very low thermal resistance.

- There is no option to add in electric reheat coils for VRF terminal units, therefore electric baseboards were modelled. 
- There is no option for adding in any ducting to be attached to the VRF terminal units.

- The rated airflow rate across the cooling and heating coils for the VRF terminal units must be between $0.00004027 \mathrm{~m}^{3} / \mathrm{s}$ and $0.00006041 \mathrm{~m}^{3} / \mathrm{s}$ per watt of rated total cooling capacity. Airflow rates were changed to meet the required range.

\subsection{CAlibration Process}

Building simulation calibration involves fine tuning uncertain parameters until an acceptable match is attained between the simulated and metered energy consumption. It is important to vary the parameters across realistic value ranges and not focus on impractical values giving the best result. Then one needs to further analyze the simulation results and parameters to ensure that the results were not by coincidence, although error and uncertainty will always be present to an extent in any simulation work. It is important to measure data at the highest resolution possible; yearly energy consumption is usually not good enough. It is generally more accurate to use monthly data combined with daily or hourly data, along with spot measurements over short periods, since monthly or yearly data can easily miss significant errors which would be captured in an hourly data analysis.

\subsubsection{Calibration Evaluation}

ASHRAE Guideline 14 provides direction for building energy simulation calibration for measuring energy savings (American Society of Heating, Refrigerating and Air-Conditioning Engineers Inc., 2002). The guideline indicates that energy consumption data should be collected for a period of at least one year with corresponding location weather data. This data should be compared at a monthly or hourly basis. To evaluate a model for calibration, Guideline 14 suggests the use of two metrics which compare simulated and metered data: (i) coefficient of variation of the root mean square error (CV(RMSE)) and (ii) the normalized mean bias error (NMBE). For the model to be considered calibrated, the CV(RMSE) should be within $+/-15 \%$ for monthly calibration and $+/-30 \%$ for hourly calibration, and the NMBE value to be within $+/-5 \%$ for monthly calibration and $+/-10 \%$ for hourly calibration. There is no guidance for daily values, therefore it was assumed that an average of monthly and hourly limit values should be used, as was done by Zirnhelt (Zirnhelt, 2013). Thus, for the model to be considered calibrated using daily values the CV(RMSE) should be within +/- $22.5 \%$ and the NMBE should be within $+/-7.5 \%$. The equations used to calculate the CV(RMSE) and NMBE are as follows:

$$
C V(R M S E)=\frac{\sqrt{\frac{\sum\left(y_{i}-\hat{y}_{i}\right)^{2}}{n-1}}}{\bar{y}} * 100
$$


$\quad N M B E=\frac{\sum\left(y_{i}-\hat{y}_{i}\right)}{(n-1) * \bar{y}} * 100$

where,

$y=$ simulated value

$\hat{y}=$ metered value

$\bar{y}=$ mean value of meterd data

$n=$ number of data points

The energy consumption metering at the building is done on a daily basis and is spread across a number of electrical panels. The metered data was collected for 14 months from May 1, 2013 to June 30, 2014, however due to metering software complications two segments of data were lost. The monthly energy bills could not be used to verify the metered data as the bills are for the entire property and not just for the building. As a secondary validation step temperature sensors were installed throughout the building for 5 weeks in March and April 2014. These sensors collected hourly temperature data that was compared to the simulated zone temperatures. The values were compared using the hourly calibration limits. Ideally the model would have been fine-tuned until the statistical calibration limits were achieved.

\subsubsection{Advanced Model Conclusions}

This section describes where the possible sources of differences lay between the metered data and the simulated results. Accurate modelling of buildings is a complex and time intensive task. As building size and system complexity increases, increased uncertainty typically occurs. The case study building includes numerous energy efficiency measures which could not be accurately replicated in the model, or there was a lack of available data to properly calibrate them. As an example, solar wall and earth tube trending performance data was unattainable from the BAS, which would impact the energy consumption of the outdoor air system. A lack of available data, from equipment and metering, did not support the model to reach calibration limits.

A more rigorous and reliable data collection system should be put in place to collect consumption data at smaller time steps (hourly), along with spot measurements to ensure the data collection system is accurately collecting data. Spot measurements of the outdoor units should be done to determine their operating capacities, part-load ratios and COPs. This information could then be verified with the predicted values in EnergyPlus. This would allow the performance curves to be tuned to more accurately predict the actual performance of the units. The accuracy of the performance curves would also increase 
if the manufacturer data was made available in a more user-friendly format, allowing for the creation of accurate performance curves for the installed equipment.

Occupancy was entered based on the design occupancy calculations. Occupancy design calculations are usually done for a maximum number of people in the building for informing system design, however this occupancy intensity is not observable at all times. Meeting rooms are not constantly used throughout the day and the large boardroom is only used for large events a few times per month. Also, there is a lot of field work that is done by the employees which also reduces the number of occupants. To determine the energy consumption impact of decreasing occupancy a simulation was run where occupancy was set to only $50 \%$. This reduction in occupancy decreased the total building consumption by $7 \%$, due to a decrease in internal gains from the occupants in the summer, as well as less ventilation all year due to the lower occupancy. Occupancy should be monitored either through $\mathrm{CO}_{2}$ sensor data collection or detailed occupancy logs. Refining the occupancy would better estimate the actual typical internal gains in the zones which would better predict the cooling and heating loads in the building.

Interior lighting is adjusted by occupancy sensors and daylighting controls. However, the building's occupants were finding the daylighting controls difficult to use especially in the winter due to low light and the reflections from the snow on the ground caused inaccurate lighting levels for the sensors. Lighting should also be monitored on a zone basis to determine a more accurate lighting consumption schedule per zone, as well as which fixtures in the zones are used most frequently. It was assumed task lighting was set to turn on at the same frequency as the overhead lights. The task lighting has a higher radiant fraction which was probably adding extra internal gains into the zones, causing larger cooling loads throughout the building, increasing the energy consumption.

A large portion of the overall building energy consumption relates to miscellaneous equipment. Spot measurements and tracking of plug loads (miscellaneous equipment) for refining inputs would result in a better zone equipment consumption distribution. In the model the miscellaneous equipment loads are roughly evenly distributed throughout the building due to a lack of information. A better equipment zone distribution would more accurately allocate the equipment heat gains and therefore alter the zone heating and cooling loads for the building.

It would also be beneficial to know when the VRF system is in heat recovery mode to verify if the runtime is the same as for the simulated results. Knowing the runtime and which of the zones are 
supplying the heat to other zones would allow for further investigation of the heat recovery function, as well as, informing the heat recovery optimization process.

A part-load ratio investigation of the outdoor units was done, however, further analysis should be done to have a better understanding of its implications. Both Zhou et al. (2007) and (Li, Wu, \& Shiochi, 2009) determined through an EnergyPlus modelling study that the COP increased when the system worked in part-load conditions due to high part-load efficiency. The UTRCA simulation work agreed with the other studies, as shown in Figure 21. This indicates that the simulated system is performing in the model as intended running as intended.

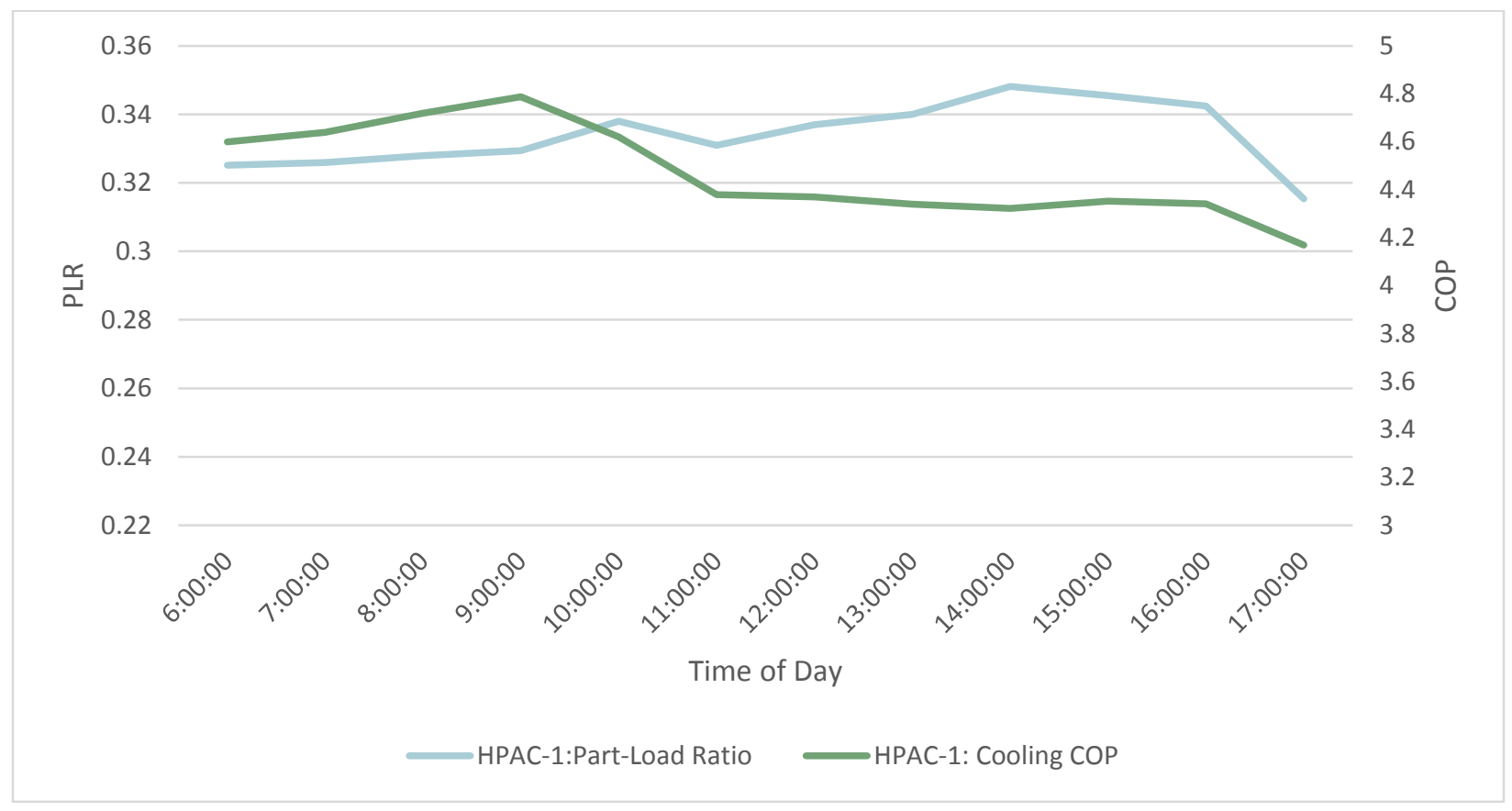

Figure 21: Correlations between COP and PLR for a summer day

Due to the complexity of the energy efficiency measures working with the VRF system it was difficult to pin point the changes in efficiency and performance of the VRF system. Due to the added energy efficiency measures (i.e. solar wall, earth tube, heat rejection to the domestic hot water system), it is possible that the VRF system is operating more efficiently than if these measures had not been installed. It would be beneficial to re-run the VRF parametric analyses without the energy efficiency measures to see the "absolute" changes in performance of the VRF system. 


\subsection{Model 3 - AdVANCEd Model Results}

After addressing all the sub-models listed in Section 7, the advanced model was completed. The simulation was run from May 1, 2013 to April 30, 2014, using the AMY weather file from Weather Analytics. The results of the annual simulation are presented in the following table by energy consumption type.

Table 22: EnergyPlus Model 3 Annual Modelling Results by Consumption Type

\begin{tabular}{|l|c|}
\hline Consumption Type & Electricity (kWh) \\
\hline Lighting & 115,070 \\
\hline Miscellaneous Equipment & 137,140 \\
\hline Electric Duct Heaters & 10,900 \\
\hline Heating & 73,790 \\
\hline Cooling & 33,090 \\
\hline Fans & 23,000 \\
\hline ERW Heat Recovery & 70 \\
\hline Total & 393,060 \\
\hline
\end{tabular}

The monthly energy consumption results of the building for both the EnergyPlus simulation and the collected metered data are shown in Figure 22. Since some of the energy consumption data from the case study building was lost, an estimated consumption based on the consumption trends was allocated to the months with missing data.

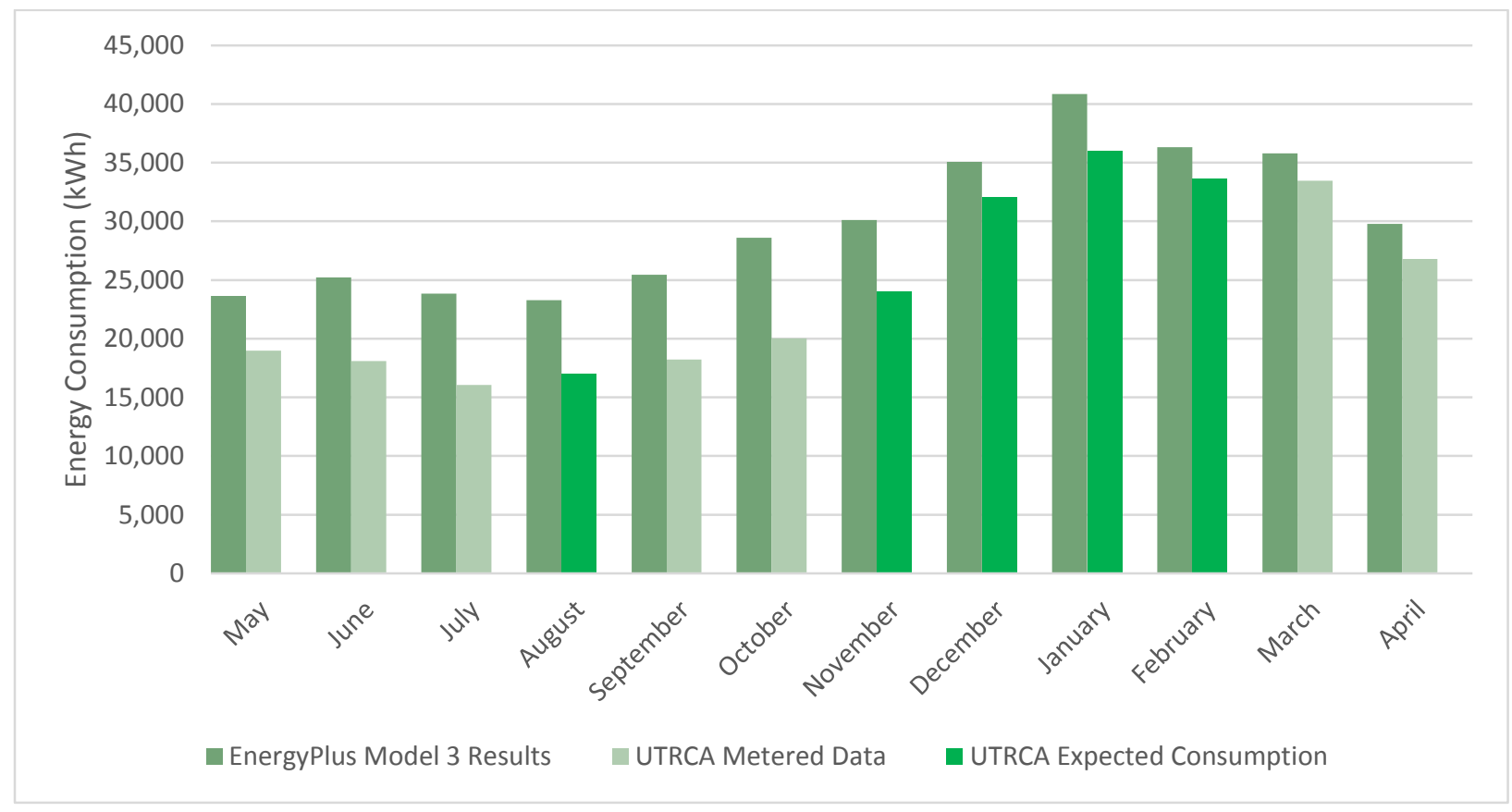

Figure 22: Whole Building Monthly Energy Consumption for Model 3 and Building Metered Data 
The final advanced model energy consumption daily calibration values for the whole building were -29.0\% NMBE and 38.7\% CV(RMSE), which does not meet the ASHRAE calibration limits of $+/-7.5 \%$ NMBE and +/- 22.5\% CV(RMSE). This model did however meet the hourly calibration limits for zone temperatures at a NMBE value of $-6.8 \%$ and $C V(R M S E)$ value of $17.2 \%$.

The differences can be primarily attributed to the over prediction of energy consumption of the indoor terminal units' fans and the outdoor units. There is a lot of concrete throughout the building which acts as thermal mass. It is likely that the energy storage of the mass is not being taken into account adequately. With increased thermal mass the spikes in energy consumption would decrease.

Commissioning of some of the HVAC system equipment and lighting was still underway during the energy consumption data collection period. Therefore the HVAC equipment operation, and lighting consumption and internal gains changed over the course of the data collection period. As an example, in Figure 24 where the metered fan consumption was higher than the simulated data in the first couple months which is quite different than the energy consumption at the end of the data collection period. Real-life variations such as this make model calibration difficult, as building simulation tends to assume similar input values over the whole year.

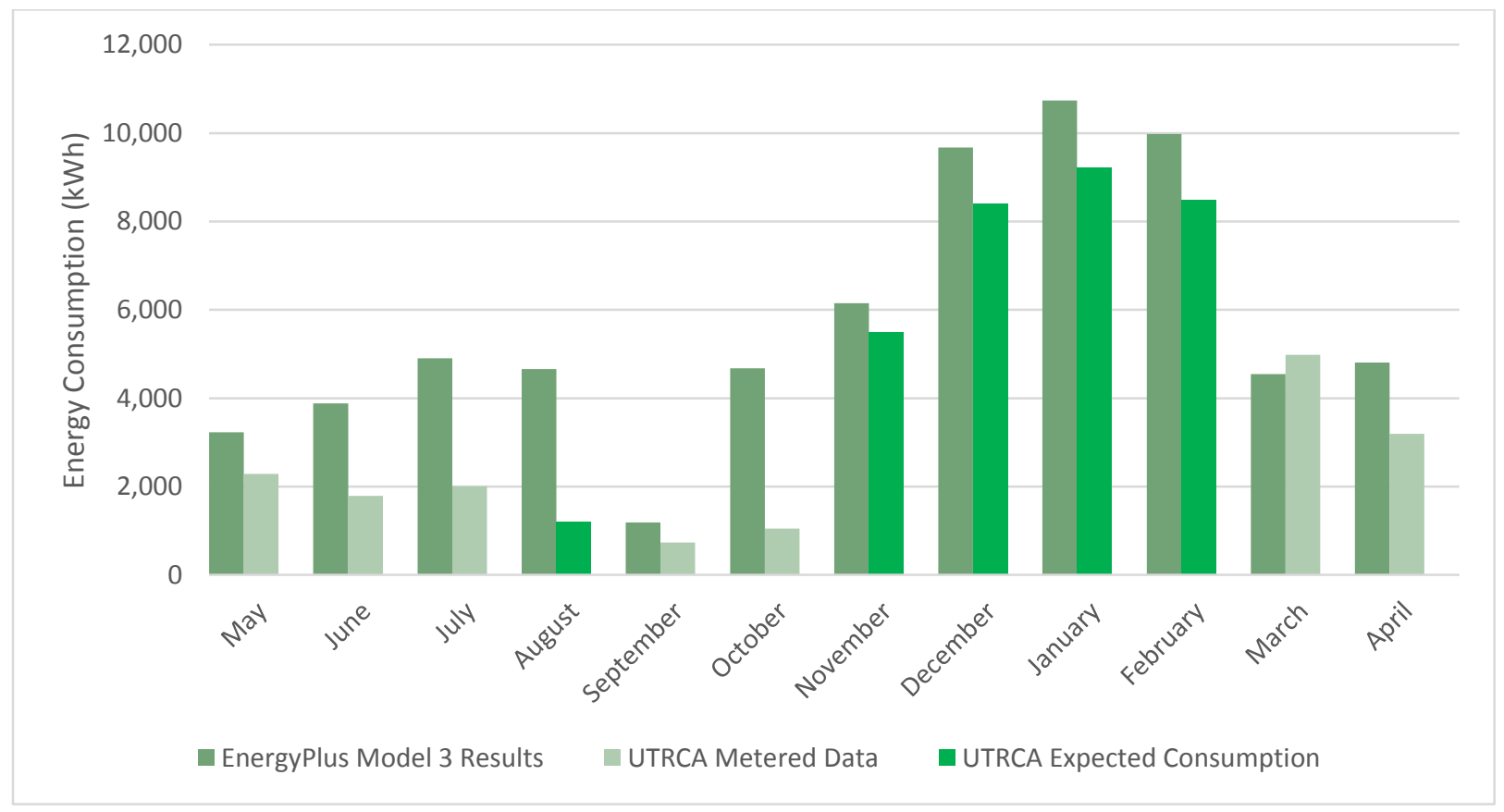

Figure 23: Outdoor Units Monthly Energy Consumption 2013-2014 


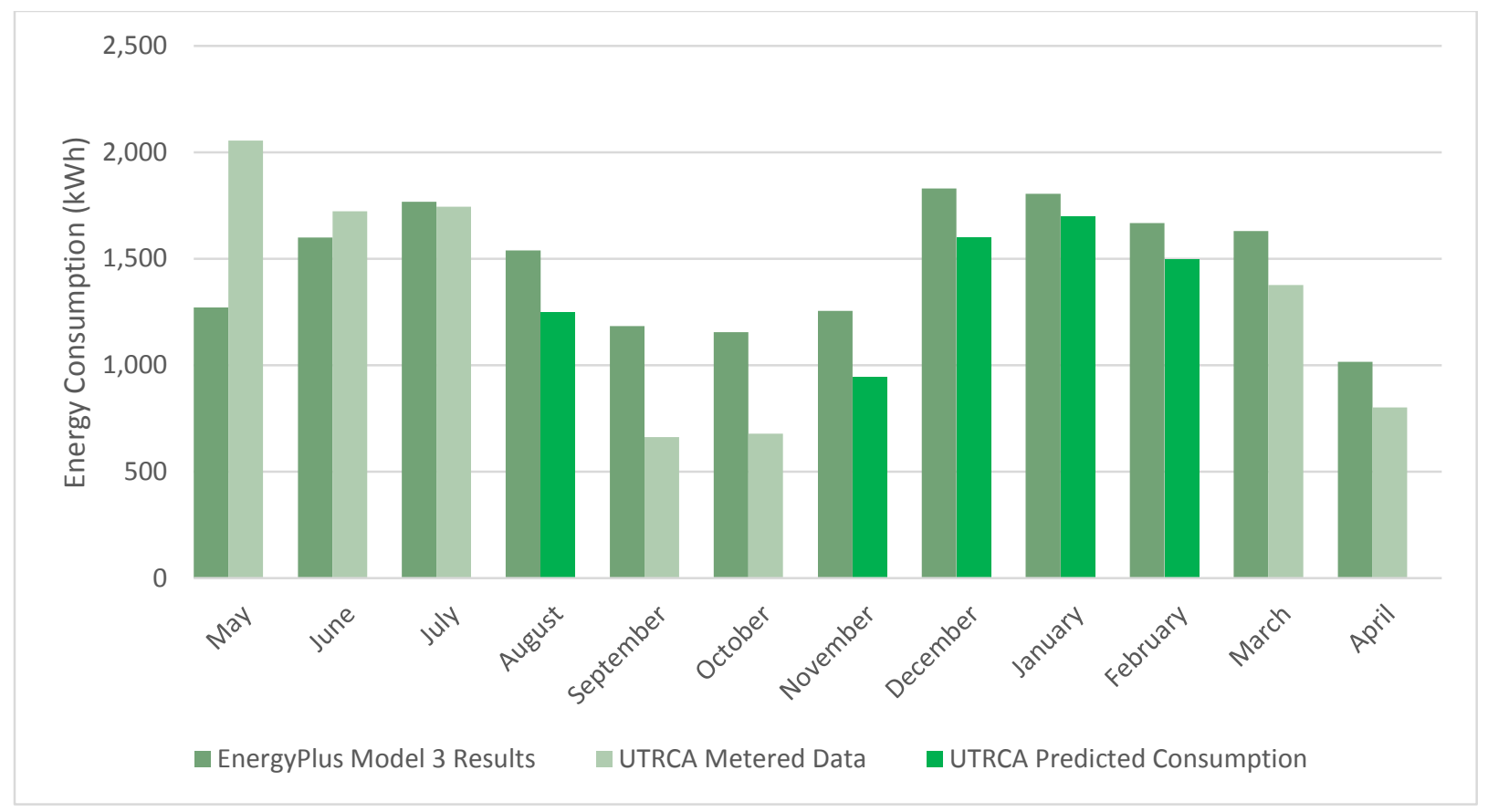

Figure 24: Indoor Terminal Units Monthly Energy Consumption 2013-2014

Building simulation tends to model typical operating practices which are rarely the case of the actual operation in a building. The larger the building and the more complex the systems are, the more likely there will be deviations from ideal practices. Throughout the modelling process, additional operating information was obtained from the building manager which indicated that the building was not operating as initially designed. Some examples are listed as follow:

- The season changeover occurred gradually over a period of time and could vary by floor. Each season shoulder period is also different from year-year. This makes tracking changeover parameters difficult, and therefore difficult to accurately schedule the seasonal changes in the model.

- There is a $3^{\circ} \mathrm{C}$ deadband (1.5C above and below the setpoint). However, this deadband is only applicable to indoor terminal units that are programmed to the "auto" operating setting. There are many units programmed to "heat on" or "cool on" only. Therefore the indoor units which are scheduled to "heat on" or "cool on" only, and associated outdoor units are operating more in the model than in actuality at the case study building, causing the model to over predict the associated energy consumption.

- There are thermostats located throughout the building that allow the employees to change the temperature setpoint if they feel uncomfortable at the predetermined settings. 
It is very difficult to make these adjustments in a model to reflect actual energy consumption when continual operating adjustments are not tracked. Currently the BAS only collects energy consumption data. It does not log when thermostats are changed by the employees, or when the building manager makes adjustments to the temperature setpoints at the BAS, or when indoor terminal units change modes from "auto" to "heat only" or "cool only".

When the BAS system was presented to the research team, it was made to believe that it had a lot of capabilities for measuring and monitoring a large variety of inputs. However, the BAS set up at the building had not been programmed to collect all these different inputs. It was not feasible to have the BAS reprogrammed for this project due to financial and logistical reasons. Furthermore, some of the data was lost due to problems with the BAS and software upgrades, which created the gaps in the dataset.

\subsection{COMPARISON OF TWO BUILDINGS USING VRF SYSTEMS}

A Grander View (AGV) is another building in the Southwestern Ontario area which uses a Mitsubishi VRF system for their building's mechanical system. AGV is a three-storey, $2150 \mathrm{~m}^{2}$, office building designed and used by Enermodal Engineering, now known as MMM Group Limited.

Table 23: UTRCA WCC and AGV Building Characteristics

\begin{tabular}{|l|l|l|}
\hline Building Name & UTRCA WCC & AGV \\
\hline Building Size & $3345 \mathrm{~m}^{2}$ & $2150 \mathrm{~m}^{2}$ \\
\hline Building Type & Two-storey office space & Three-storey office space \\
\hline Location & London, Ontario & Kitchener, Ontario \\
\hline No. of Outdoor Units & 6 & 3 \\
\hline No. of Indoor Units & 58 & 60 \\
\hline
\end{tabular}

The proposed design and adjusted simulation models for both buildings was done using EE4 by MMM Group Limited. The proposed design used the COPs as listed by the manufacturer specifications for rated conditions. The adjusted simulation used adjusted COP values based on more realistic operating conditions, expected outdoor air dry bulb temperatures, and for differences in modelling a standard airsource heat pump system and a VRF system (MMM Group Limited, 2012). The UTRCA solar wall RETScreen Analysis was added in the EE4 adjusted simulation by reducing the space heat by $3100 \mathrm{kWh}$ in Table 24. RETScreen was used to estimate $(7,378 \mathrm{kWh})$ the amount of electricity generated by for the PV system at AGV building (MMM Group Limited, 2010). The PV electricity generated has not been added to this analysis as it does not directly impact the energy consumption of the HVAC system. However, 7,378 kWh should be deducted from the overall building consumption to determine a net 
energy consumption. The UTRCA EnergyPlus advanced model results listed in Table 24 was for a typical meteorological year as previously described in Section 8.2. Although the EnergyPlus model did not model the domestic hot water system, the domestic hot water value of the EE4 model was used as a placeholder value to have a better comparison of the energy intensities between the two buildings.

Table 24 lists the annual energy consumption for a typical year by consumption type for the proposed and adjusted EE4 models for both buildings, as well as, the EnergyPlus model for the UTRCA WACC building. The UTRCA EE4 model under predicted the energy consumption for the lights and miscellaneous equipment, therefore creating a lower building energy intensity compared to the EnergyPlus model. The EnergyPlus model more accurately depicts the actual energy consumption for lights and miscellaneous equipment. Comparing the EE4 adjusted simulations for both buildings it can be seen that the buildings have similar HVAC energy intensities, differing only by $5.7 \mathrm{kWh} / \mathrm{m}^{2} /$ year.

Table 24: Simulated Annual Energy Consumption Comparison for UTRCA WCC and AGV

\begin{tabular}{|c|c|c|c|c|c|}
\hline \multirow[b]{2}{*}{ Consumption Type } & \multicolumn{3}{|c|}{ UTRCA WCC } & \multicolumn{2}{|c|}{$\begin{array}{l}\text { AGV (MMM Group Limited, } \\
\text { 2010) }\end{array}$} \\
\hline & $\begin{array}{l}\text { EE4 } \\
\text { Proposed } \\
\text { Design } \\
\text { Energy } \\
\text { Consumption }\end{array}$ & $\begin{array}{l}\text { EE4 Adjusted } \\
\text { Simulation } \\
\text { Energy } \\
\text { Consumption }\end{array}$ & $\begin{array}{l}\text { EnergyPlus } \\
\text { Advanced } \\
\text { Model } \\
\text { Energy } \\
\text { Consumption }\end{array}$ & $\begin{array}{l}\text { EE4 } \\
\text { Proposed } \\
\text { Design } \\
\text { Energy } \\
\text { Consumption }\end{array}$ & $\begin{array}{l}\text { EE4 Adjusted } \\
\text { Simulation } \\
\text { Energy } \\
\text { Consumption }\end{array}$ \\
\hline Lights (kWh) & 72,710 & 72,710 & 115,070 & 26,370 & 26,370 \\
\hline $\begin{array}{l}\text { Miscellaneous } \\
\text { Equipment (kWh) }\end{array}$ & 54,870 & 54,870 & 137,140 & 59,050 & 59,050 \\
\hline Space Heat (kWh) & 134,640 & 46,120 & 51,450 & 66,220 & 25,490 \\
\hline Space Cool (kWh) & 21,460 & 21,460 & 27,940 & 11,160 & 11,200 \\
\hline Fans (kWh) & 22,140 & 22,140 & 22,410 & 8,780 & 8,780 \\
\hline $\begin{array}{l}\text { Domestic Hot Water } \\
(\mathrm{kWh})\end{array}$ & 9,090 & 9,090 & (9090) & 11,870 & 4,320 \\
\hline Total (kWh) & 314,910 & 226,890 & 354,280 & 183,450 & 135,210 \\
\hline $\begin{array}{l}\text { Mechanical Electrical } \\
\text { Intensity (kWh/m2) }\end{array}$ & 56.0 & 29.5 & 33.2 & 45.7 & 23.1 \\
\hline $\begin{array}{l}\text { Non-Mechanical } \\
\text { Electrical Intensity } \\
(\mathrm{kWh} / \mathrm{m} 2)\end{array}$ & 38.1 & 38.1 & 75.3 & 39.7 & 39.7 \\
\hline $\begin{array}{l}\text { Total Building } \\
\text { Electrical Intensity } \\
(\mathrm{kWh} / \mathrm{m} 2)\end{array}$ & 94.1 & 67.6 & 108.5 & 85.4 & 62.8 \\
\hline
\end{tabular}

The metering period for AGV building took place from October 2009 until September 2010 and for this period Kitchener had 3815 heating degree days and 244 cooling degree days. The building metering 
period for the UTRCA building took place from May 2013 until April 2014 and for this period London had 4450 heating degree days and 254 cooling degree days. Due to software problems with the building automation system at UTRCA, some months of energy consumption data were lost, as well as, the energy consumption data for the domestic hot water system. Table 25 shows the metered monthly energy consumption breakdown for the two buildings. Energy consumption for the UTRCA building was estimated, based on the number of heating and cooling degree days, for the months in which there was missing data. The UTRCA monthly estimated consumption is denoted by the numbers in parentheses. It can be seen that the energy consumption for UTRCA was about double the energy consumption for WCC. The higher energy consumption can be attributed to the fact the UTRCA building was larger building than AGV building and there was a greater non-HVAC energy intensity for the UTRCA system at almost double $\left(78.1 \mathrm{kWh} / \mathrm{m}^{2} /\right.$ year vs. $41.7 \mathrm{kWh} / \mathrm{m}^{2} /$ year) that of the AGV building. During the metering periods London experienced more heating degree days (HDD) and cooling degree days (CDD) (445 HDD, 254 CDD) than the metering period in Kitchener (3815 HDD, 244 CDD). Therefore, more heating and cooling degree days indicated a greater need for space conditioning in the UTRCA building, also increasing its energy consumption.

Table 25: Monthly Energy Consumption Comparison for UTRCA WCC and AGV

\begin{tabular}{|l|l|r|}
\hline Month & UTRCA WCC & AGV (MMM Group Limited, 2010) \\
\hline January & $(37,000)$ & 21,450 \\
\hline February & $(36,000)$ & 17,580 \\
\hline March & 33,460 & 14,690 \\
\hline April & 26,800 & 10,310 \\
\hline May & 18,980 & 9,370 \\
\hline June & 18,100 & 9,540 \\
\hline July & 16,070 & 10,360 \\
\hline August & $(15,000)$ & 9,540 \\
\hline September & 18,220 & 8,250 \\
\hline October & 20,040 & 11,940 \\
\hline November & $(22,000)$ & 15,310 \\
\hline December & $(30,000)$ & 19,880 \\
\hline Total & 291,670 & 138,320 \\
\hline
\end{tabular}

The AGV EE4 adjusted simulated data was close to the metered data for the summer months (AprilSeptember), however the metered data was about $25 \%$ higher than the EE4 adjusted simulated data for the winter months (October-March). This indicates that the higher space heating energy consumption of the EnergyPlus model is probably a better representation than the EE4 adjusted model space heating energy consumption. 
The measured electrical intensity of the mechanical system for AGV building is $38 \mathrm{kWh} / \mathrm{m}^{2}$ and the whole building energy intensity is $69 \mathrm{kWh} / \mathrm{m}^{2}$ (Kemp, 2015). Using the UTRCA WCC metered and estimated data without domestic hot water data, the mechanical electrical intensity was $26.8 \mathrm{kWh} / \mathrm{m}^{2}$ and the total building electrical intensity was $87.2 \mathrm{kWh} / \mathrm{m}^{2}$. Adding in domestic hot water the UTRCA WCC metered mechanical electrical intensity would probably be about $30 \mathrm{kWh} / \mathrm{m}^{2}$ and the total building electrical intensity would be about $91 \mathrm{kWh} / \mathrm{m}^{2}$. The lower mechanical electrical intensity for the UTRCA WCC than the AGV can partly be attributed to the earth tube and solar wall used to pretreat the incoming outdoor air.

Table 26: Simulated and Metered Electrical Intensities for UTRCA WCC and AGV

\begin{tabular}{|l|r|r|r|r|r|}
\cline { 2 - 6 } \multicolumn{1}{c|}{} & \multicolumn{3}{c|}{ UTRCA WCC } & \multicolumn{2}{c|}{ AGV } \\
\cline { 2 - 6 } \multicolumn{1}{c|}{} & EE4 Adjusted & EnergyPlus & Metered & EE4 Adjusted & Metered \\
\hline $\begin{array}{l}\text { Mechanical Electrical } \\
\text { Intensity }\left(\mathrm{kWh} / \mathrm{m}^{2}\right)\end{array}$ & 29.5 & 33.2 & $(26.8)$ & 23.1 & 38.0 \\
\hline $\begin{array}{l}\text { Total Electrical Intensity } \\
\left(\mathrm{kWh} / \mathrm{m}^{2}\right)\end{array}$ & 67.6 & 108.5 & $(87.2)$ & 62.8 & 69.0 \\
\hline
\end{tabular}

Furthermore, it was concluded that EE4 alone is not an adequate software to be used for modelling VRF systems and other complex building and system features as they are not integrated into the modelling software, and mechanical energy consumption will not be accurately predicted, as was demonstrated by the metered data comparison from both the UTRCA WCC and AGV buildings. 


\section{BUILDING PERFORMANCE BASED ON VARYING WEATHER CONDITIONS}

A study was done to determine the impact that varied weather conditions have on the performance of a VRF system for the case study building location. This was accomplished by using the advanced (final) model and simulating it with five weather files for the case study building location: (i) typical meteorological year, (ii) warmer than normal winter, (iii) colder than normal winter, (iv) hotter than normal summer and (v) cooler than normal summer. The purpose was to see if the VRF system's performance differs greatly based on historically based seasonal weather variation as well as determining the ideal climate for a VRF system.

The building was not 'moved' to alternative Canadian locations as the case study building and its VRF system was modelled and designed for the particular location. Moving it to a new location could potentially run the risk of not meeting building code standards or the system sizing to be insufficient for the new climate.

\subsection{Selecting WeATher Data Variation}

Three metrics were used in determining the four extreme weather years for the case study building location: mean minimum temperature, mean daily temperature and heating degree days for the winter periods; and mean maximum temperature, mean daily temperature and cooling degree days for the summer periods. Degree days is a measurement of the time the outdoor temperature differs from the base temperature - "the number of Celsius degrees that the mean temperature is above or below the base temperature" (Government of Canada) - and is typically used to estimate the heating and cooling loads for a building. Ideally the base temperature for a building is the temperature when heating or cooling is needed through the mechanical system of the building. This base temperature will be different for all buildings based on the thermal envelope, air tightness, solar and internal gains, and setpoint temperatures. Based on the Environment Canada data available, the heating degree $\left({ }^{\circ} \mathrm{C}\right)$ days use a balance point temperatures of below $18^{\circ} \mathrm{C}$, and above $18^{\circ} \mathrm{C}$ for cooling degree $\left({ }^{\circ} \mathrm{C}\right)$ days.

To determine the winter periods the data from months from October to April were analyzed. The warmest winter season by Mean Minimum Temperature and Mean Temperature was the 2011-2012 season, followed by the 2001-2002 season. However, the 2001-2002 season had the lowest amount of heating degree $\left({ }^{\circ} \mathrm{C}\right)$ days followed by the $2011-2012$ season. The same pattern was seen with the 19931994 being the coldest winter season followed by 1995-1996, by temperature, and 1995-1996 followed by 1993-1994 with the highest number of heating degree $\left({ }^{\circ} \mathrm{C}\right)$ days (HDD). From this it was decided to 
use 2001-2002 and 1995-1996 as the warmer than normal winter season and colder than normal winter season, respectively. There is a $3.8^{\circ} \mathrm{C}$ and $3.9^{\circ} \mathrm{C}$ average temperature differential between the warm and cold winter periods. The cold winter experiences 2878 more heating degree $\left({ }^{\circ} \mathrm{C}\right)$ days than the warm winter. A summary of the conditions is listed below in Table 27 . Furthermore, there is a $3.8^{\circ} \mathrm{C}$ and $3.9^{\circ} \mathrm{C}$ average temperature differential for the mean minimum temperature and mean daily temperature between the warm and cold winter periods. The cold winter experiences 2878 more heating degree $\left({ }^{\circ} \mathrm{C}\right)$ days than the warm winter.

Table 27: Extreme Winter Years for the Case Study Building Location

\begin{tabular}{|l|c|r|r|r|}
\hline \multicolumn{1}{|c|}{ Season } & Year & Mean Min Temp $\left({ }^{\circ} \mathbf{C}\right)$ & Mean Temp $\left({ }^{\circ} \mathbf{C}\right)$ & Heating Degree $\left({ }^{\circ} \mathbf{C}\right)$ Days \\
\hline \multirow{2}{*}{ Warm } & $2011-2012$ & -0.6 & 3.9 & 2994 \\
\cline { 2 - 5 } Winter & $\mathbf{2 0 0 1 - 2 0 0 2}$ & -1.1 & $\mathbf{3 . 1}$ & $\mathbf{1 1 2 3}$ \\
\hline TMY & - & -3.3 & 0.9 & 3611 \\
\hline Cold & $1993-1994$ & -5.5 & -0.9 & 3976 \\
\cline { 2 - 5 } Winter & $\mathbf{1 9 9 5 - 1 9 9 6}$ & -4.9 & -0.8 & 4001 \\
\hline AMY & $2013-2014$ & -6.4 & -2.1 & 4150 \\
\hline
\end{tabular}

The weather conditions experienced for the warm winter are comparable to the weather normal conditions of Windsor, Ontario having a mean minimum temperature of $-1.1^{\circ} \mathrm{C}$, mean daily temperature of $2.9^{\circ} \mathrm{C}$ and 3215 heating degree $\left({ }^{\circ} \mathrm{C}\right)$ days. The cold winter conditions are comparable to Montreal's winter weather normal conditions, with $-5.5^{\circ} \mathrm{C},-1.1^{\circ} \mathrm{C}$ and 4053 for mean minimum temperature, mean daily temperature and heating degree $\left({ }^{\circ} \mathrm{C}\right)$ days, respectively.

The months from June to September were analyzed to determine the summer periods. The hottest summer season by Mean Maximum Temperature and Mean Temperature was 2002 followed by 2005. Comparing cooling degree $\left({ }^{\circ} \mathrm{C}\right)$ days (CDD) 2005 topped the list for most days in the season, followed by 2002. Looking for the coolest summer season, 1992 topped the list by coolest temperature and fewest cooling degree $\left({ }^{\circ} \mathrm{C}\right)$ days. Based on this analysis 2005 and 1992 were used as the hotter than normal summer season and cooler than normal summer season, respectively. These results obtained from environment Canada are listed in below in Table 28. There was an average temperature differential of $4.9^{\circ} \mathrm{C}$ and $4.3^{\circ} \mathrm{C}$ for mean maximum temperature and mean daily temperature between the hot and cool summer periods. Additionally, the hot summer has 304 more cooling degree $\left({ }^{\circ} \mathrm{C}\right)$ days that the cool summer. 
Table 28: Extreme Summer Years for the Case Study Building Location

\begin{tabular}{|l|c|r|r|r|}
\hline \multicolumn{1}{|c|}{ Season } & Year & Mean Max Temp $\left({ }^{\circ} \mathrm{C}\right)$ & Mean Temp $\left({ }^{\circ} \mathrm{C}\right)$ & \multicolumn{1}{c|}{ Cooling Degree $\left({ }^{\circ} \mathrm{C}\right)$ Days } \\
\hline $\begin{array}{l}\text { Hot } \\
\text { Summer }\end{array}$ & 2002 & 27.2 & 20.9 & 385 \\
\cline { 2 - 5 } & $\mathbf{2 0 0 5}$ & $\mathbf{2 6 . 8}$ & $\mathbf{2 0 . 9}$ & 399 \\
\hline TMY & - & 24.2 & 18.6 & 240 \\
\hline $\begin{array}{l}\text { Cool } \\
\text { Summer }\end{array}$ & 1992 & $\mathbf{2 1 . 9}$ & 16.6 & 95 \\
\hline AMY & 2013 & 23.9 & 18.4 & 230 \\
\hline
\end{tabular}

The conditions for the hot summer can be compared to the summer weather normal conditions for Windsor, Ontario, having a mean maximum temperature of $25.9^{\circ} \mathrm{C}$, a mean daily temperature of $20.9^{\circ} \mathrm{C}$ and 427 cooling degree $\left({ }^{\circ} \mathrm{C}\right)$ days. The cool summer is comparable to normal weather conditions experienced in Halifax, Nova Scotia, with $21.8^{\circ} \mathrm{C}$ for the mean maximum temperature, $16.8^{\circ} \mathrm{C}$ for the mean daily temperature and 113 cooling degree $\left({ }^{\circ} \mathrm{C}\right)$ days.

\subsection{TypicAl METEOROLOGicAl YEAR}

The advanced model was simulated using the CWEC weather file for the case study building location to represent the VRF system's performance for a typical meteorological year. The daily energy consumption for the whole building is displayed in Figure 25, comparing actual weather conditions and typical meteorological conditions for the year. TMY and AMY energy consumption followed the same trends throughout the year with the AMY primarily having higher daily energy consumption. This is especially evident with the high peaks experienced during the winter months, during an extreme cold spell which occurred in January and February of 2014. This is also indicated by the higher number of heating degree $\left({ }^{\circ} \mathrm{C}\right)$ days for the AMY than the TMY. During the AMY energy consumption is less than TMY during a period of the summer, which is to be expected based on the fewer number of cooling degree $\left({ }^{\circ} \mathrm{C}\right)$ days during the summer compared to TMY cooling degree $\left({ }^{\circ} \mathrm{C}\right)$ days. 


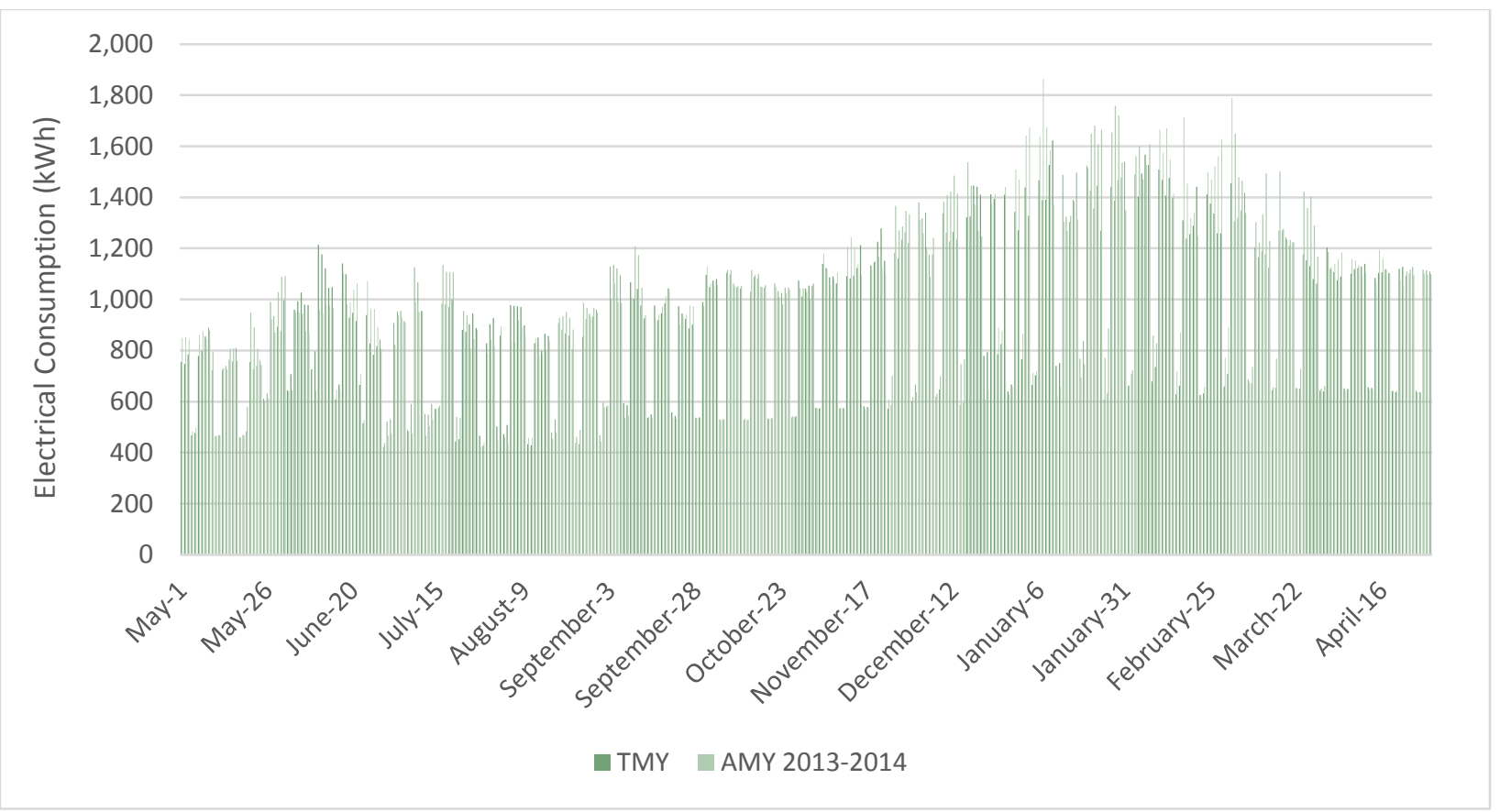

Figure 25: TMY and AMY Simulated Building Energy Consumption Results

The simulation results showed that on average the heating consumption would be lower, cooling consumption would be higher, and fan consumption to be slightly lower than what was experienced during the study period of May 2013 - April 2014. There were also fewer days below $-18^{\circ} \mathrm{C}$ which caused the electric duct heaters to run less. Since less zone conditioning was needed this caused lower fan operation and therefore lower consumption. The results of the simulation are summarized in

Table 29.

Table 29: EnergyPlus Annual Modelling Results by Consumption Type

\begin{tabular}{|l|c|c|}
\hline Consumption Type & AMY Electricity (kWh) & TMY Electricity (kWh) \\
\hline Lighting & 115,070 & 115,070 \\
\hline Miscellaneous Equipment & 137,140 & 137,140 \\
\hline Electric Duct Heaters & 10,900 & 2,270 \\
\hline Heating & 73,790 & 49,180 \\
\hline Cooling & 33,090 & 27,940 \\
\hline Fans & 23,000 & 22,410 \\
\hline ERW Heat Recovery & 70 & 60 \\
\hline Total & 393,060 & 354,070 \\
\hline
\end{tabular}




\subsection{WinTER WEATHER ANALYSIS}

To determine the performance variation of the VRF system in winter, warmer and colder winter climate files were simulated using the advanced model, for the case study building location. Since the temperature differentials between the warm and cold winter was small, a third more extreme winter case was developed. The extreme winter case was developed by using a weather file which was consistently $10^{\circ} \mathrm{C}$ colder than the cold winter. For this analysis, the winter period was defined as November 1 to April 30. The whole building daily energy consumption results for the three winter periods, along with a typical meteorological winter period are displayed in Figure 26.

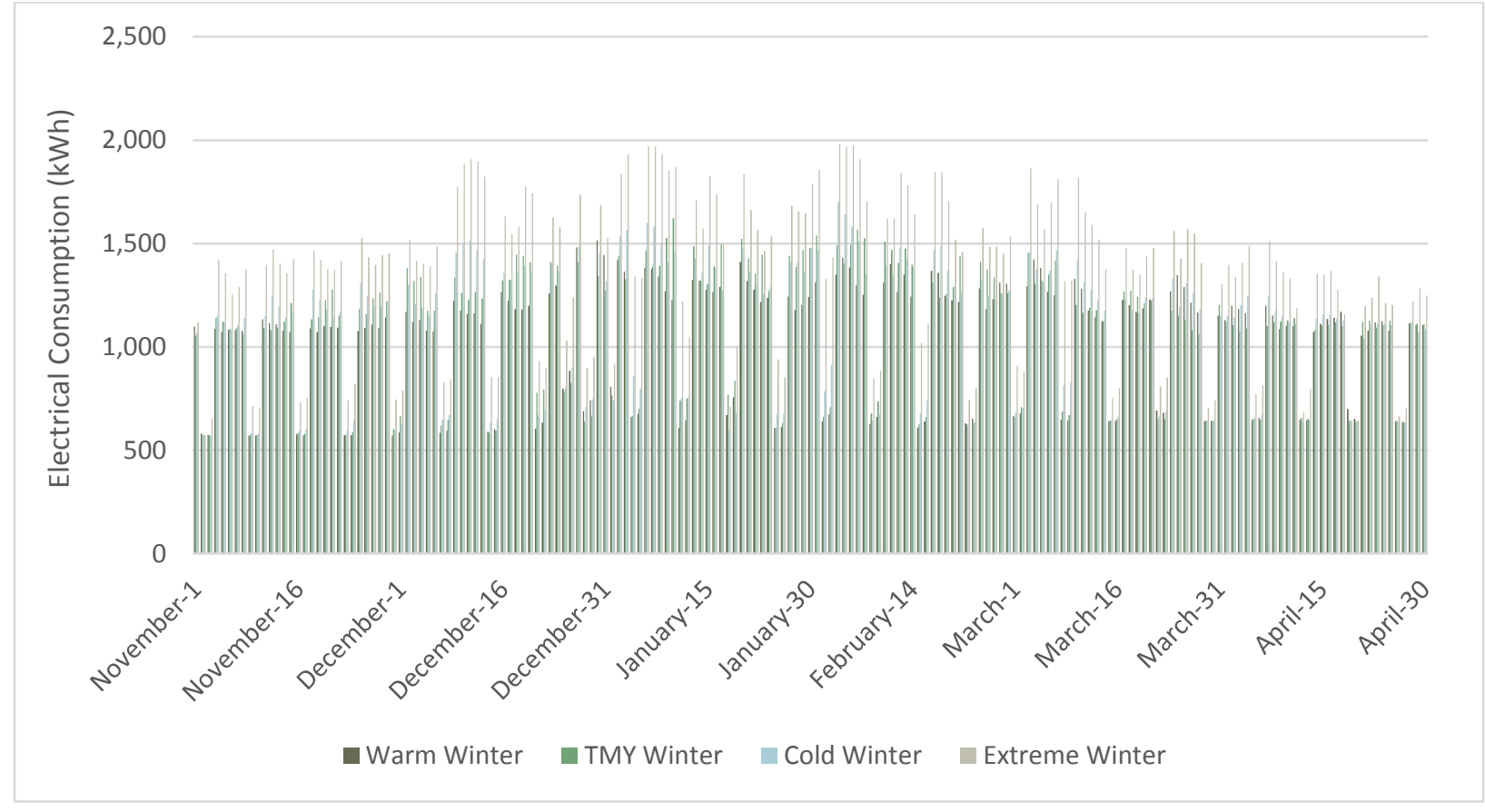

Figure 26: Winter Weather Building Energy Consumption Results

For a warmer winter the electric duct coils may never turn on, if the $-18^{\circ} \mathrm{C}$ outdoor temperature threshold is never reached. The total seasonal energy consumption for the four winter periods is presented in Table 30. 
Table 30: EnergyPlus Winter Modelling Results by Consumption Type - Warm Winter: 1123 HDD, Cold Winter: 4001 HDD

\begin{tabular}{|l|r|r|r|r|}
\hline Consumption Type & $\begin{array}{c}\text { Warm Winter } \\
\text { Electricity (kWh) }\end{array}$ & $\begin{array}{c}\text { TMY Winter } \\
\text { Electricity (kWh) }\end{array}$ & $\begin{array}{c}\text { Cold Winter } \\
\text { Electricity (kWh) }\end{array}$ & $\begin{array}{r}\text { Extreme Winter } \\
\text { Electricity (kWh) }\end{array}$ \\
\hline Lighting & 56,000 & 56,000 & 56,000 & 56,000 \\
\hline $\begin{array}{l}\text { Miscellaneous } \\
\text { Equipment }\end{array}$ & 82,020 & 82,020 & 82,020 & 82,020 \\
\hline Electric Duct Heaters & 1,320 & 2,470 & 2,410 & 33,590 \\
\hline Heating & 37,770 & 45,360 & 49,860 & 64,590 \\
\hline Cooling & 4,280 & 4,690 & 2,500 & 1,030 \\
\hline Fans & 10,580 & 11,220 & 11,990 & 12,540 \\
\hline ERW Heat Recovery & 10 & 0 & 0 & 0 \\
\hline Total & 191,980 & 201,760 & 204,780 & 249,770 \\
\hline
\end{tabular}

Both heating and cooling occurred during the winter months, even with a very cold climate. This can be attributed to the high amount of solar gains as a result of the large amount of glazing throughout the building and an open concept floorplan. The design and orientation of the building was chosen to allow $75 \%$ of the building to take advantage of daylighting (Upper Thames River Conservation Authority). Additionally, it is common for office buildings, to experience cooling loads throughout the building due to heat generated from occupants, lighting and plug loads such as computers, printers and servers. Li et al. (2010) found that the outer zones could have different thermal comfort results than the inner zones. By adding more heating to the colder exterior zones would improve the thermal comfort of those exterior zones but worsen the thermal comfort of the interior zones. Thus, heating and cooling was simultaneously needed throughout the winter in the building.

Analyzing only the zone conditioning outdoor units, with the colder winter temperatures, they experienced lower heating and cooling COPs, with corresponding higher heating consumption and useful heating supply, and lower cooling consumption and useful output. This indicates that the heat pump units work less efficiently in colder outdoor temperatures, although there is only a small difference in the COPs for the various climates. The increase in heating COP for the extreme winter can be attributed to the significant increase in building energy supply due to the very cold climates which would increase the PLR. When there is an increase in PLR there will be an increase in COP. 
Table 31: Winter Season VRF Outdoor Unit Characteristics

\begin{tabular}{|l|r|r|r|r|r|r|}
\hline Climate Type & $\begin{array}{c}\text { Seasonal } \\
\text { Average } \\
\text { Heating } \\
\text { COP }\end{array}$ & $\begin{array}{c}\text { Seasonal } \\
\text { Average } \\
\text { Cooling } \\
\text { COP }\end{array}$ & $\begin{array}{c}\text { Seasonal } \\
\text { Heating } \\
\text { Energy } \\
\text { Consumption } \\
\text { (kWh) }\end{array}$ & $\begin{array}{c}\text { Seasonal } \\
\text { Cooling } \\
\text { Energy } \\
\text { Consumption } \\
\text { (kWh) }\end{array}$ & $\begin{array}{c}\text { Seasonal } \\
\text { Heating } \\
\text { Energy } \\
\text { Supply } \\
\text { (kWh) }\end{array}$ & $\begin{array}{c}\text { Seasonal } \\
\text { Cooling } \\
\text { Energy } \\
\text { Supply } \\
\text { (kWh) }\end{array}$ \\
\hline Warm Winter & $+0.7 \%$ & $-2 \%$ & $-28 \%$ & $+7 \%$ & $-28 \%$ & $+5 \%$ \\
\hline TMY Winter & 2.27 & 3.71 & 29,300 & 2,600 & 66,420 & 9,630 \\
\hline Cold Winter & $-2.0 \%$ & $-3.6 \%$ & $+18 \%$ & $-69 \%$ & $+16 \%$ & $-72 \%$ \\
\hline $\begin{array}{l}\text { Extreme } \\
\text { Winter }\end{array}$ & $-1.8 \%$ & $-3.2 \%$ & $+53 \%$ & $-176 \%$ & $+51 \%$ & $-177 \%$ \\
\hline
\end{tabular}

When heat recovery feature was enabled the building saved an overall $410 \mathrm{kWh}$ of useful seasonal energy supplied by the outdoor units, during the warm winter. For the cold winter, the useful seasonal energy supply was reduced by $200 \mathrm{kWh}$. For the extreme winter, there was no benefit in having the heat recovery mode enabled, since the amount of heating energy supply that was saved was the same amount that the cooling energy supply increased. When heat recovery is enabled the cooling COPs are lower and the heating COPs are slightly higher than when heat recovery is disabled. The largest change in heating COP between having heat recovery enabled and disabled occurred during the warm winter period where the COP decreased from 2.28 to 2.20 .

Figure 27: Winter Season Cooling and Heating Energy Supply Saved Using Heat Recovery Mode

\begin{tabular}{|l|r|r|r|}
\hline Climate Type & $\begin{array}{l}\text { Seasonal Cooling Energy } \\
\text { Supply Difference (kWh) }\end{array}$ & $\begin{array}{l}\text { Seasonal Heating Energy } \\
\text { Supply Difference (kWh) }\end{array}$ & $\begin{array}{l}\text { Seasonal Total Energy } \\
\text { Supply Difference (kWh) }\end{array}$ \\
\hline Warm Winter & 1250 & -840 & 410 \\
\hline Cold Winter & 1040 & -840 & 200 \\
\hline Extreme Winter & 150 & -150 & 0 \\
\hline
\end{tabular}

These results demonstrated that in a warm winter as the heating energy supply decreases and cooling energy supply increases, heat recovery becomes more effective as there is more heat available from the cooling function to be applied to a smaller heating need. Similarly, the reverse is true for extreme cold situations, where minimal amount of heat can be extracted from the cooling process to be applied for heating other zones.

\subsection{SUMimer WEATHER ANALYSIS}

To determine the performance variation of the VRF system in summer, warmer and colder summer climate files were simulated using the advanced (final) model, for the case study building location. Since the temperature amplitude between the cool and hot summer cases was small, an additional third summer case was added by consistently adding $10^{\circ} \mathrm{C}$ to the hot summer weather file. For this analysis, 
the summer period was defined as May 1 to October 31. The daily energy consumption results for the three summer periods, along with typical meteorological summer period are displayed below in Figure 28. The total seasonal energy consumption for the four summer periods is presented in Table 32.

Table 32: EnergyPlus Summer Modelling Results by Consumption Type - Hot Summer: 399 CDD, Cool Summer: 95 CDD

\begin{tabular}{|l|r|r|r|r|}
\hline Consumption Type & $\begin{array}{c}\text { Cool Summer } \\
\text { Electricity } \\
\mathbf{( k W h )}\end{array}$ & $\begin{array}{c}\text { TMY Summer } \\
\text { Electricity } \\
\mathbf{( k W h )}\end{array}$ & $\begin{array}{c}\text { Hot Summer } \\
\text { Electricity } \\
\mathbf{( k W h )}\end{array}$ & $\begin{array}{c}\text { Extreme Summer } \\
\text { Electricity (kWh) }\end{array}$ \\
\hline Lighting & 59,060 & 59,060 & 59,060 & 59,060 \\
\hline Miscellaneous Equipment & 55,120 & 55,120 & 55,120 & 55,120 \\
\hline Electric Duct Heaters & 0 & 0 & 0 & 0 \\
\hline Heating & 3,540 & 3,470 & 3,220 & 2,100 \\
\hline Cooling & 20,580 & 24,220 & 27,560 & 56,900 \\
\hline Fans & 10,250 & 11,230 & 12,130 & 17,080 \\
\hline ERW Heat Recovery & 30 & 60 & 110 & 260 \\
\hline Total & 148,580 & 153,160 & 157,200 & 190,520 \\
\hline
\end{tabular}

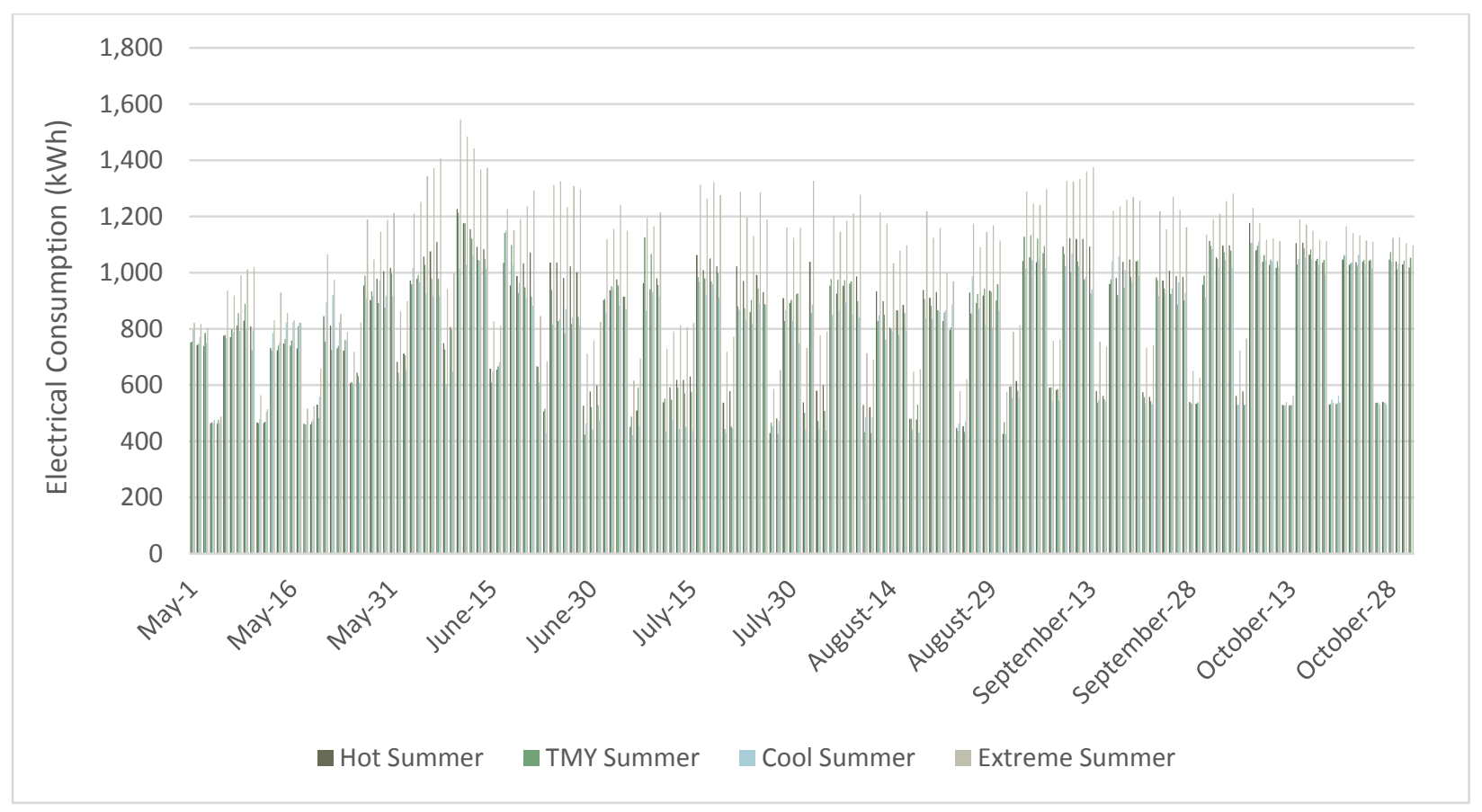

Figure 28: Summer Weather Energy Consumption Results

Analyzing only the outdoor units which provide conditioning to the building's zones, minimal heating occurred during the four core summer months. Both heating and cooling COPs are higher in cooler summer weather. The extreme heat conditions seen in the hot summer climate significantly impact the heating and cooling COP. However, the heating COP did not show a distinct trend with the outdoor 
temperature, as expected. The heat pump COP gradually increases in a linear relationship until it reaches its equilibrium point at which point the linear relationship slope drastically increases. At the same time when the heat pump is working at a higher COP, the part-load ratio will be lower as less power is needed to achieve the required load. These two concepts can counteract the effectiveness of the unit which is probably the reason for the unexpected heating COP results. The results are shown in Table 33.

Table 33: Summer VRF Outdoor Unit Characteristics

\begin{tabular}{|l|r|r|r|r|r|r|}
\hline Climate Type & $\begin{array}{c}\text { Seasonal } \\
\text { Average } \\
\text { Heating } \\
\text { COP }\end{array}$ & $\begin{array}{c}\text { Seasonal } \\
\text { Average } \\
\text { Cooling } \\
\text { COP }\end{array}$ & $\begin{array}{c}\text { Seasonal } \\
\text { Heating } \\
\text { Energy } \\
\text { Consumption } \\
\text { (kWh) }\end{array}$ & $\begin{array}{c}\text { Seasonal } \\
\text { Cooling } \\
\text { Energy } \\
\text { Consumption } \\
\text { (kWh) }\end{array}$ & $\begin{array}{c}\text { Seasonal } \\
\text { Heating } \\
\text { Energy } \\
\text { Supply } \\
\text { (kWh) }\end{array}$ & $\begin{array}{r}\text { Seasonal } \\
\text { Cooling } \\
\text { Energy } \\
\text { Supply } \\
\text { (kWh) }\end{array}$ \\
\hline $\begin{array}{l}\text { Extreme } \\
\text { Summer }\end{array}$ & $+38 \%$ & $-15 \%$ & $-192 \%$ & $+80 \%$ & $-189 \%$ & $+68 \%$ \\
\hline Hot Summer & $+7.2 \%$ & $+0.08 \%$ & $-63 \%$ & $+5 \%$ & $-57 \%$ & $+5 \%$ \\
\hline TMY Summer & 2.65 & 3.85 & 960 & 18,730 & 2,540 & 72,136 \\
\hline Cool Summer & $+10 \%$ & $+4.1 \%$ & $-34 \%$ & $-32 \%$ & $-24 \%$ & $-28 \%$ \\
\hline
\end{tabular}

For the extreme summer period, when the heat recovery mode is enabled the building energy supply will require $40 \mathrm{kWh}$ less in useful seasonal energy supply from the outdoor units. For the hot summer period, there was a useful seasonal energy supply savings of $370 \mathrm{kWh}$. For the cool summer period, the useful seasonal energy supply saved was $410 \mathrm{kWh}$. The heating COPs are higher and cooling COPs are marginally lower with heat recovery enabled than when it is disabled.

Table 34: Summer Season Cooling and Heating Energy Supply Saved Using Heat Recovery Mode

\begin{tabular}{|l|lr|l|l|}
\hline Climate Type & $\begin{array}{l}\text { Seasonal Cooling } \\
\text { Energy Supply } \\
\text { Difference (kWh) }\end{array}$ & $\begin{array}{l}\text { Seasonal Heating } \\
\text { Energy Supply } \\
\text { Difference (kWh) }\end{array}$ & $\begin{array}{l}\text { Seasonal Total Energy } \\
\text { Supply Difference } \\
\text { (kWh) }\end{array}$ \\
\hline Extreme Summer & -5 & 45 & 40 \\
\hline Hot Summer & 40 & 330 & 370 \\
\hline Cool Summer & 70 & 340 & 410 \\
\hline
\end{tabular}

These results demonstrated that in a cooler summer as the heating energy supply increased and cooling energy supply decreased, heat recovery becomes more effective as there is more cooling available from the heating function to be applied to a smaller cooling need. Similarly, the reverse is true for extreme cold situations, where minimal amount of heat can be extracted from the cooling process to be applied for heating other zones. 
Heat recovery mode works better in moderate climates than in extreme climates, more heat was recovered during the warm winter and cool summer than in the cold winter and hot summer, respectively. However, heat recovery had a beneficial impact in all cases of lowering the energy consumption associated with zone conditioning. Therefore it is still beneficial to always have the heat recovery mode enabled to minimize the building energy supply and consumption. 


\section{BUILDING PERFORMANCE BASED ON VRF CONFIGURATION}

\subsection{As-BUilt CONFIGURATION}

In the case study building the VRF system configuration was designed to have four quadrants. The four main outdoor units and their corresponding indoor units partition the building east-west for both floors: upper floor west side corresponds to the HPAC-1; upper floor east side corresponds to HPAC-2; lower floor west side corresponds to HPAC-3; and lower floor east side corresponds to HPAC-4. HPAC-5 corresponds to the two units in the vestibule (main entrance) on the upper floor west end of the building. HPAC- 6 is used for the dedicated outdoor air system. The five VRF outdoor units which do room conditioning will be analyzed in this section.

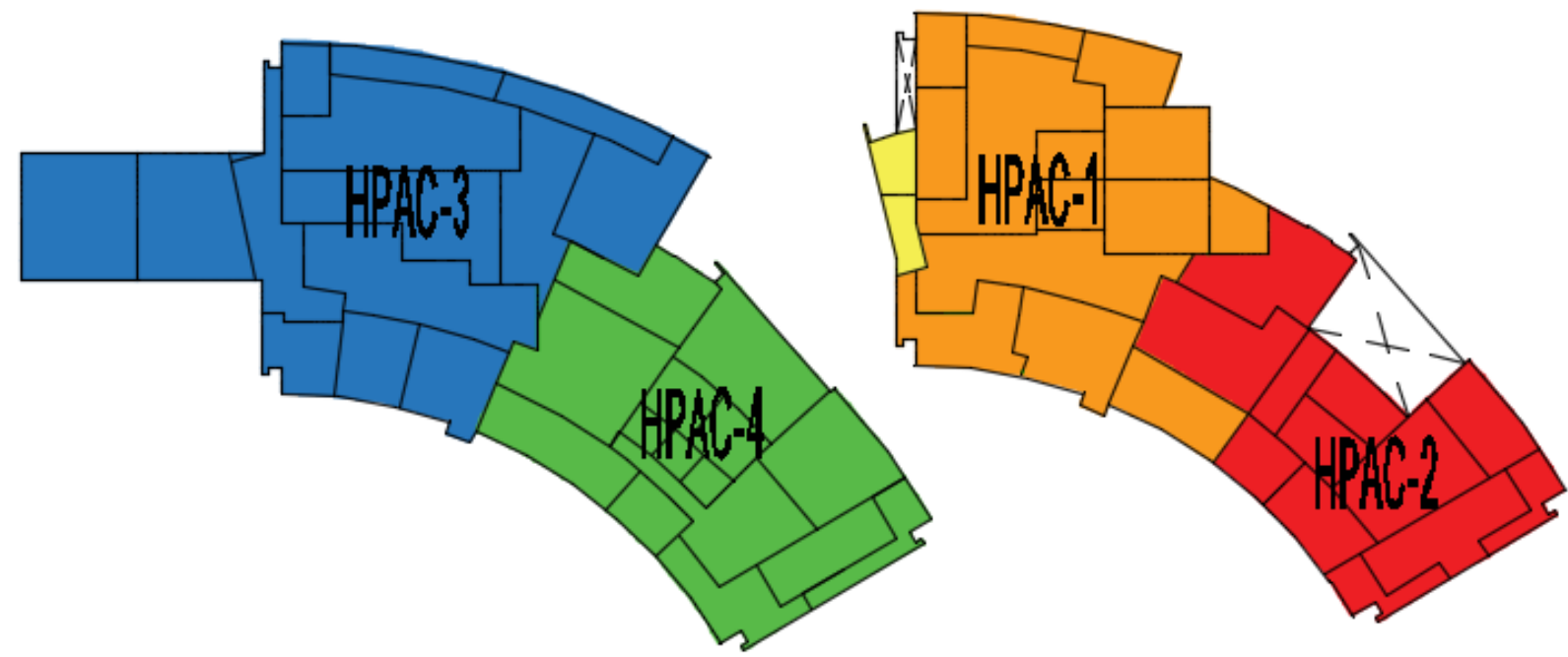

Figure 29: As-built VRF Configuration - Lower Floor (left), Upper Floor (right)

The cooling and heating capacities of the VRF outdoor units as listed in the manufacturer specification are presented in Table 35. Additionally, Table 35 lists the peak modelled cooling and heating loads experienced by each outdoor unit during a typical meteorological year. It can be seen that at peak conditions the main four outdoor units are all working between a 0.31 and 0.73 part load ratio (PLR). In reality the peak loads for HPAC-3 and HPAC-4 could be approximately 5-10\% higher due to the domestic hot water system also being connected to these outdoor units, which was not modelled. These PLR values were lower than expected. Li et al. (2009) found the PLR to range between 0.35 and 0.6 for transitional months and for the PLR to range between 0.5 and 0.9 during the conditioning dominant seasons (winter and summer). The excess heat captured by the VRF system is then transferred through the refrigerant lines to be used to heat the connected domestic hot water system. Using the excess heat 
increases the amount of heat recovery, which therefore makes the system more efficient than what was modelled.

Table 35: Capacities and Peak Loads for the VRF Outdoor Units for As-built Configuration

\begin{tabular}{|c|r|r|r|r|r|r|}
\hline $\begin{array}{c}\text { Outdoor } \\
\text { Units }\end{array}$ & $\begin{array}{c}\text { Cooling } \\
\text { Capacity } \\
\mathbf{( k W )}\end{array}$ & $\begin{array}{c}\text { Heating } \\
\text { Capacity } \\
\mathbf{( k W )}\end{array}$ & $\begin{array}{c}\text { Peak } \\
\text { Cooling } \\
\text { Load (kW) }\end{array}$ & $\begin{array}{c}\text { Peak } \\
\text { Heating } \\
\text { Load (kW) }\end{array}$ & $\begin{array}{c}\text { Peak } \\
\text { Cooling } \\
\text { PLR }\end{array}$ & $\begin{array}{c}\text { Peak } \\
\text { Heating } \\
\text { PLR }\end{array}$ \\
\hline HPAC-1 & 49.2 & 55.1 & 36.1 & 34.7 & 0.73 & 0.63 \\
\hline HPAC-2 & 70.3 & 70.3 & 42.0 & 40.3 & 0.60 & 0.57 \\
\hline HPAC-3 & 70.3 & 70.3 & 32.0 & 29.7 & 0.46 & 0.42 \\
\hline HPAC-4 & 49.2 & 55.1 & 23.8 & 17.0 & 0.48 & 0.31 \\
\hline HPAC-5 & 21.1 & 23.4 & 7.7 & 3.6 & 0.36 & 0.15 \\
\hline
\end{tabular}

Using the heat recovery mode for the as-built configuration reduced the required useful energy supply from the outdoor units by only $80 \mathrm{kWh}$, for a typical meteorological year. Therefore, this configuration is not achieving a significant amount of heat recovery.

\subsection{Balancing Zone Heating \& Cooling Loads Through Indoor TeRminal Unit Placements}

Heat recovery is the process of taking excess heat from one zone and applying to another in need of heat. This is accomplished through the redistribution of refrigerant through the system's controller to the zones requiring conditioning. To achieve the highest efficiency of a heat recovery VRF system, it is believed, that it is important to appropriately balance the heating and cooling loads of the zones associated with each outdoor unit (Nigusse, Sharma, Raustad, \& Cummings, 2013). If the VRF controller is able to redistribute the refrigerant to meet the cooling and heating loads, at that particular point in time, the outdoor units will not operate. Minimizing the runtime of the outdoor units will lower the energy consumption of the VRF system.

Analyzing the cooling and heating rates of the outdoor units (of the as-built configuration), HPAC-4 had the lowest heating rate and HPAC-2 and HPAC-3 had the highest heating rates. Therefore, four indoor terminal units, FC-2-5, FC-2-9, FC-3-3, and FC-3-8, with high heating and low cooling rates were transferred from HPAC-2 and HPAC-3, respectively, to HPAC-4. This new configuration is depicted in Figure 30. This resulted in a $493 \mathrm{kWh}$ decrease in annual useful energy supply from the VRF outdoor units and $1050 \mathrm{kWh}$ (or 2.1\%) energy consumption reduction. An energy consumption savings of 920 kWh was experienced in this configuration due to heat redistribution through the heat recovery mode. 


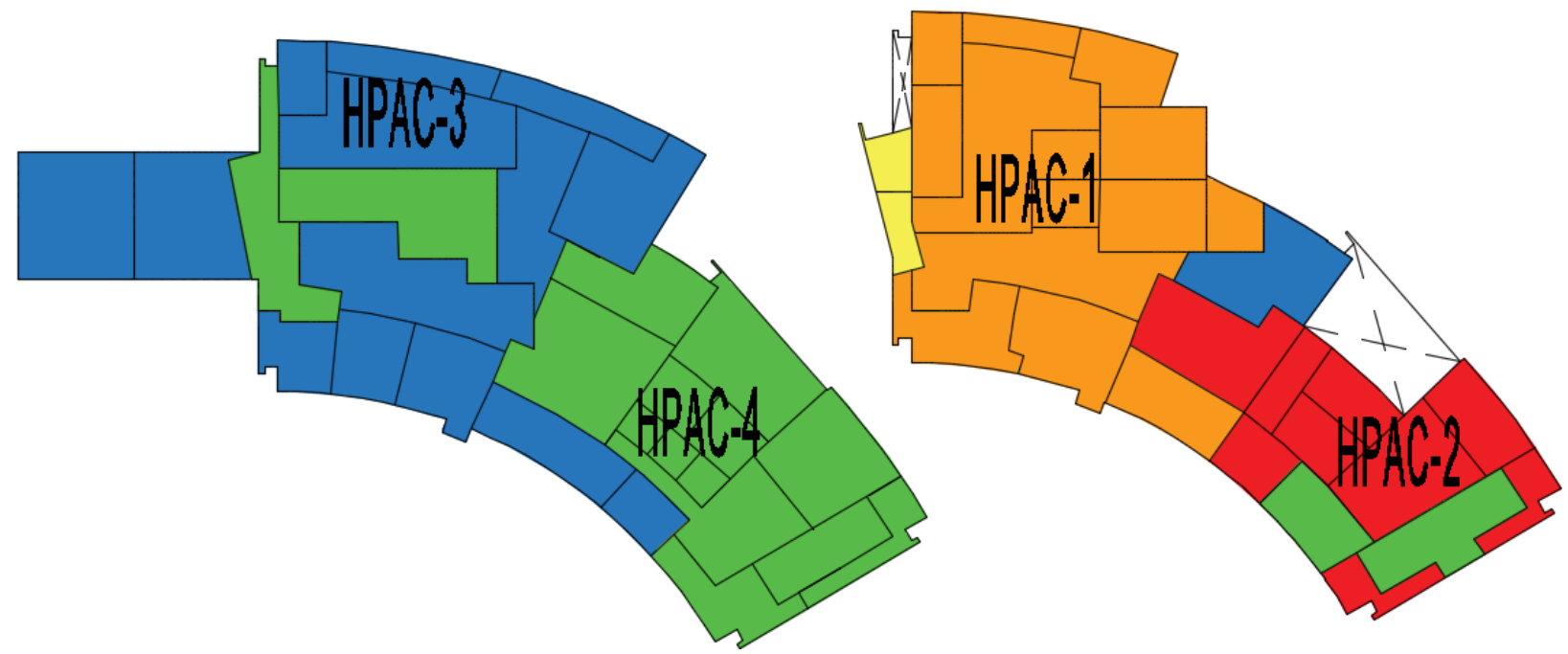

Figure 30: Moving Four Indoor Terminal Unit Reconfiguration - Lower Floor (left), Upper Floor (right)

Another analysis that was done was to divide the building in a north-south configuration, with HPAC-1 dedicated to the upper-south zone, HPAC-2 upper-north zones, HPAC-3 for the lower-south zones, and HPAC-4 for the lower-north zones, as depicted in Figure 31. This configuration decreased the annual useful energy supply from the VRF outdoor units by $940 \mathrm{kWh}$ and decreased the VRF outdoor units' energy consumption by $1460 \mathrm{kWh}$ (or 3\%). Using the heat recovery mode for this configuration reduced the required useful energy supply from the outdoor units by $1470 \mathrm{kWh}$. This is most likely attributed to the increased part-load ratio from the increase in zone loads associated with HPAC-1 and HPAC-4.

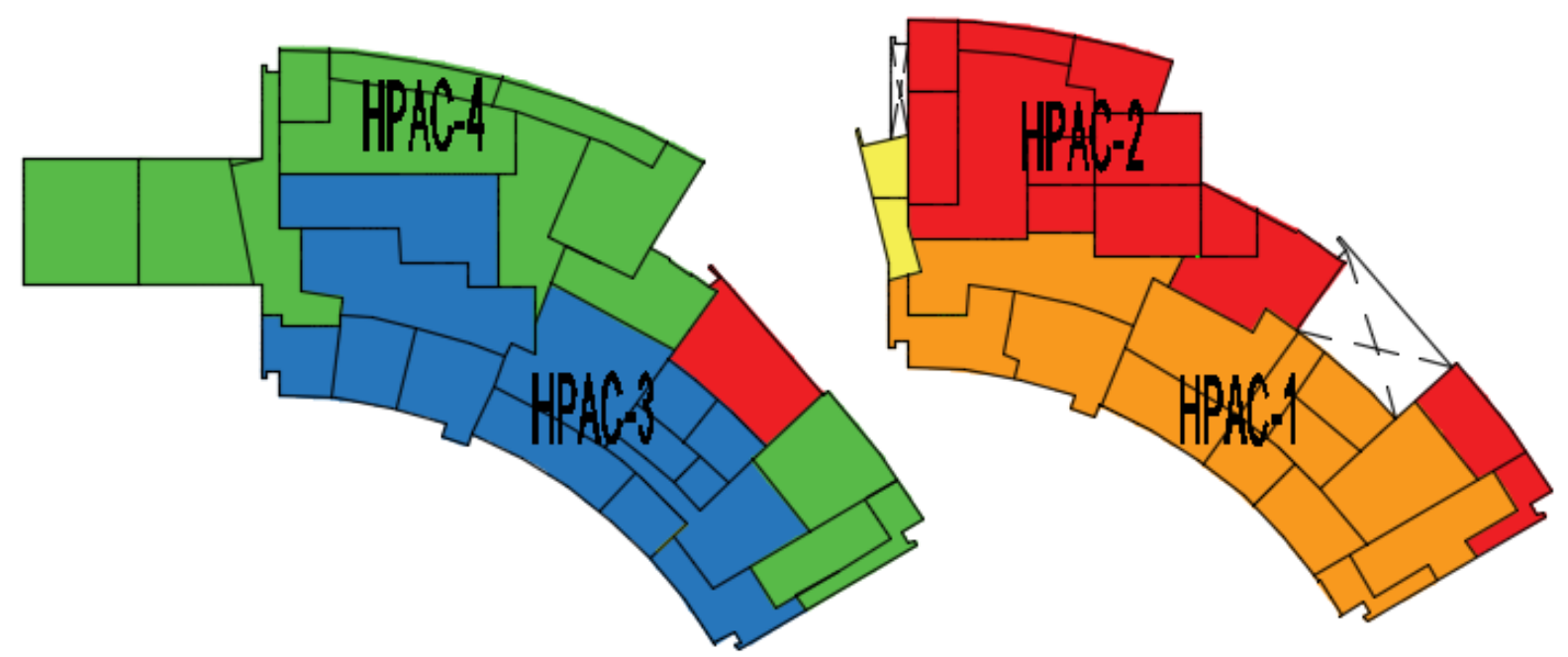

Figure 31: North-South VRF Reconfiguration - Lower Floor (left), Upper Floor (right)

The study by Nigusse et al (2013) experienced minimal energy savings from simultaneous heating and cooling operation. They attributed these results to the studied buildings not having substantial cooling 
and heating diversity and/or that the VRF terminal units were not properly zoned to achieve its maximum benefit. Li et al. (2010) determined through simulation work that the heat recovery mode could save $15-17 \%$ energy consumption over the regular heat pump VRF system depending on the selected zone temperature control strategy.

Both of the above configuration analyses provide insight into the heat recovery function. Further analysis could be done to determine the parameters leading to ideal configurations based on matching cooling and heating loads for optimum heat recovery, however the outdoor units' capacities are much larger than the cooling and heating rates which cause the units to run at a low part-load ratio. Without increasing the part-load ratio, reconfiguring the indoor terminal units with the outdoor units will not have a major impact on energy savings.

It is import to increase the required energy supply from the outdoor units or decrease the outdoor unit's capacity to ensure a higher average part-load ratio on the outdoor unit, as this would lower the energy consumption. By carefully selecting indoor terminal unit combinations where the outdoor units can match the heating and cooling loads, this would increase the heat recovery effectiveness which requires the outdoor units to run less frequently, in turn reducing the energy consumption. Further detailed investigation is warranted to better understand the heat recovery function and how it impacts the partload ratio.

\subsection{Reducing Heating and Cooling Capacity}

In the as-built configuration the peak loads are significantly less than the specified capacities, therefore it can be said that the system was oversized. If the capacity of the outdoor units was decreased the equipment would have been running at higher part-load ratios throughout the year. This could have been achieved by removing HPAC- 1 and HPAC-4 and allocating their indoor terminal units to HPAC-2 and HPAC-3. Another option would be to downsize all four of the outdoor units to smaller capacity units. The original design methodology and reasoning of the as-built VRF configuration is unknown to the author at this time. The system performance varies based on the number of indoor terminal units attached to each outdoor unit, as well as the amount of ducting attached to the indoor terminal units, the length of the refrigerant piping between the outdoor unit and its indoor terminal units, and each of the indoor terminal unit's loading conditions (Thornton \& Wagner, 2012) (Liu \& Hong, 2010). Based on these factors, the performance of the system could worsen on the picked arrangement. 
In addition, there is a tendency for designers to oversize mechanical equipment to ensure system reliability in the future, so the building will be able to meet the loads due to more extreme weather or changes in the usage of the building (Mitchell-Jackson, Koomey, Nordman, \& Blazek, 2003). To ensure reliability safety factors will be added and the system will be oversized. Furthermore, energy efficiency of mechanical systems is still a relatively new concept to some designers and they may not take that as one of their priorities when designing their systems. It would be more beneficial to size a heating and cooling system to $80 \%$ or $90 \%$ of the loads and use a less-efficient secondary system to meet infrequent occurring peak loads (Allen, 2015). Although the secondary system is less efficient it would only be operating potentially $5 \%$ of the year, therefore overall creating a more efficient system due to longer operation in higher part-load ratio ranges. Designing the VRF system to $80 \%$ peak loads and having electric resistance baseboards or additional electric re-heat coils would allow the VRF system to run at higher part-load ratios throughout the year and having the baseboard heaters or electric coils to come on only a few times a year. The cost of installing additional baseboard heaters would be much less than the extra capital cost for the VRF outdoor units needed to meet $100 \%$ of the heating loads (Allen, 2015).

As an example to show the increased efficiency of the VRF system when operating at higher part-load ratios, a building simulation was done where HPAC-1 and HPAC-4 were removed, the indoor terminal units from HPAC-1 and HPAC-3 were linked to HPAC-3 and the indoor terminal units from HPAC-2 and HPAC-4 were linked to HPAC-2. The new VRF configuration is depicted in Figure 32. The new peak loads from this reconfigured system are displayed in Table 36.

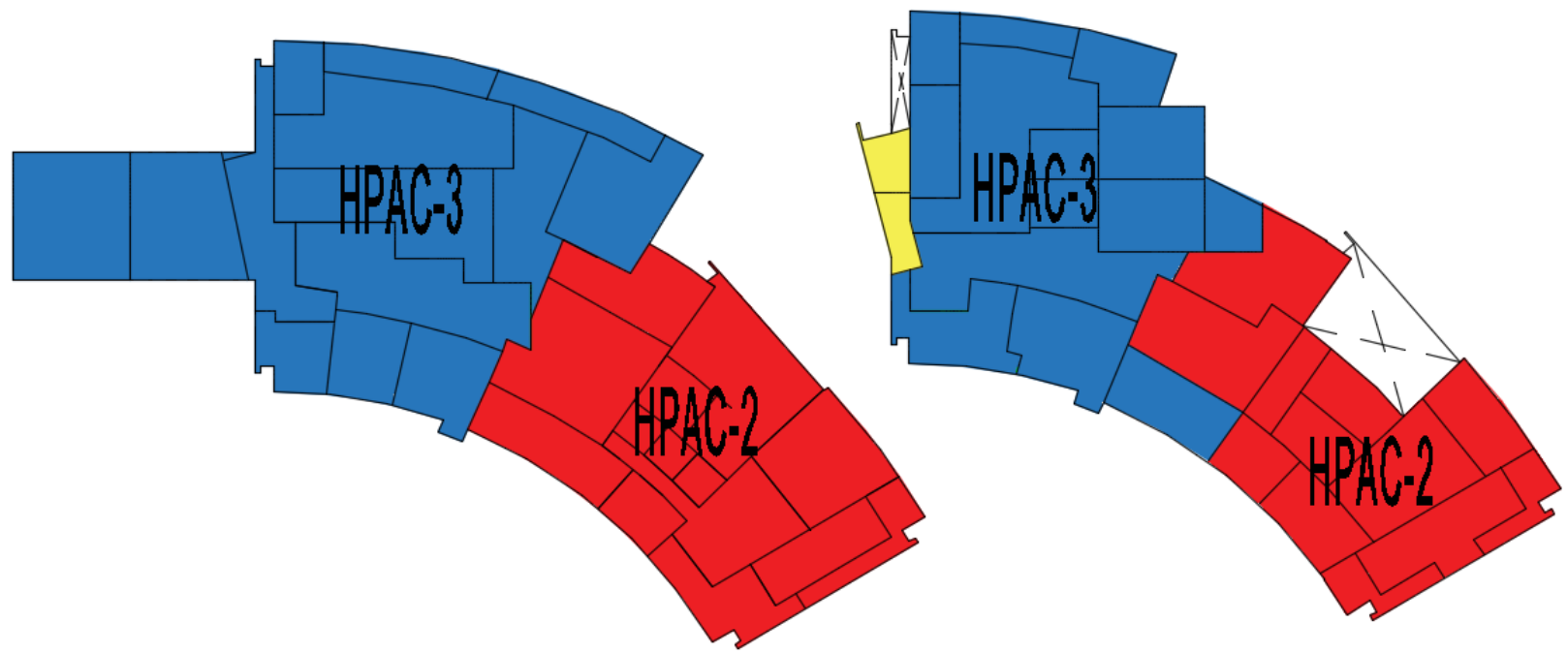

Figure 32: Reduced Outdoor Unit Capacity VRF Configuration - Lower Floor (left), Upper Floor (right) 
It can be seen that the peak loads are still below the manufacturer specifications but now HPAC-2 reaches 0.85 and 0.77 cooling and heating part-load ratios, and HPAC-3 reaches 0.86 and 0.89 part-load ratios for cooling and heating, respectively.

Table 36: Capacities and Peak Loads for the VRF Outdoor Units (Re-configured - Two Outdoor Units Removed)

\begin{tabular}{|c|r|r|r|r|r|r|}
\hline $\begin{array}{c}\text { Outdoor } \\
\text { Units }\end{array}$ & $\begin{array}{c}\text { Cooling } \\
\text { Capacity (kW) }\end{array}$ & $\begin{array}{c}\text { Heating } \\
\text { Capacity (kW) }\end{array}$ & $\begin{array}{c}\text { Peak Cooling } \\
\text { Load (kW) }\end{array}$ & $\begin{array}{c}\text { Peak } \\
\text { Heating Load } \\
\text { (kW) }\end{array}$ & $\begin{array}{c}\text { Peak } \\
\text { Cooling } \\
\text { PLR }\end{array}$ & $\begin{array}{c}\text { Peak } \\
\text { Heating } \\
\text { PLR }\end{array}$ \\
\hline HPAC-2 & 70.3 & 70.3 & 59.7 & 54.2 & 0.85 & 0.77 \\
\hline HPAC-3 & 70.3 & 70.3 & 60.2 & 62.7 & 0.86 & 0.89 \\
\hline HPAC-5 & 21.1 & 23.4 & 7.7 & 3.6 & 0.36 & 0.15 \\
\hline
\end{tabular}

The reduced capacity configuration decreased the cooling and heating rates required by the outdoor unit, it also increased the cooling and heating COPs, therefore decreasing the total cooling and heating consumptions. The reduced capacity configuration resulted in a reduction of 3,070 kWh of cooling consumption and $11,360 \mathrm{kWh}$ of heating consumption, resulting in $29 \%$ annual energy savings for space conditioning. The energy consumption of the outdoor units used for space conditioning of the two configurations is summarized in Table 37. This energy consumption does not include heating or cooling energy consumption associated with parasitic energy or the DOAS system, as is included in Table 38.

Table 37: VRF Outdoor Units' Capacity Comparison - Outdoor Unit Energy Consumption

\begin{tabular}{|l|r|r|}
\cline { 2 - 3 } \multicolumn{1}{c|}{} & Cooling Consumption (kWh) & Heating Consumption (kWh) \\
\hline As-built Configuration & 19,680 & 30,450 \\
\hline Decreased Capacity Configuration & 16,610 & 19,090 \\
\hline Energy Savings & 3,070 & 11,360 \\
\hline
\end{tabular}

Furthermore, in the as-built configuration the cooling and heating rate was decreased by $80 \mathrm{kWh}$ due to heat recovery, but in the reduced capacity configuration there was a decrease of $800 \mathrm{kWh}$. This indicates that the new configuration had better zone conditioning balancing which increased the amount of heat recovery seen throughout the year.

Adding in the domestic hot water loads would also increase the heating loads which would help to further balance the loads, especially in the summer months when minimal heating is required. The overall higher loads would increase the overall part-load ratios throughout the year. Higher part-load ratios result in a higher COPs and therefore a more efficient building. The energy consumption broken down by consumption type is listed in Table 38 for both the as-built configuration and the reduced capacity configuration, removing HPAC-1 and HPAC-4. 
Table 38: EnergyPlus Modelling Results by Consumption Type - Impact of Reducing the VRF Outdoor Unit Capacities

\begin{tabular}{|l|c|c|}
\hline Consumption Type & $\begin{array}{c}\text { As-built Configuration Electricity } \\
\text { Consumption (kWh) }\end{array}$ & $\begin{array}{c}\text { New Configuration Electricity } \\
\text { Consumption (kWh) }\end{array}$ \\
\hline Lighting & 115,070 & 115,070 \\
\hline Miscellaneous Equipment & 137,140 & 137,140 \\
\hline Electric Duct Heaters & 2,270 & 2,270 \\
\hline Heating & 49,180 & 37,850 \\
\hline Cooling & 27,940 & 24,590 \\
\hline Fans & 22,410 & 22,420 \\
\hline ERW Heat Recovery & 60 & 60 \\
\hline Total & 354,070 & 339,400 \\
\hline
\end{tabular}




\section{SYSTEM EFFICIENCY COMPARISON}

There are a number of different factors that can be used to evaluate a system's efficiency. The comparison done in this section used system operating consumption, system operating fuel costs and generated system operating carbon dioxide emissions as the metrics. The case study building's efficient HVAC system, an electric Mitsubishi heat recovery variable refrigerant flow system, will be compared to a two other potential efficient systems which could have been installed in the building. This comparison used a fully condensing hydronic boiler (Cleaver-Brooks, 2012) and an air-cooled chiller (Trane, 2015) along with hydronic fan coil units for zone conditioning distribution, as one of the potential systems. The second system used for comparison was a ground source heat pump (ClimateMaster, 2013) along with hydronic fan coil units for zone conditioning distribution. This comparison will look at the plant equipment used to deliver the heat to the fan coil units for zone conditioning. Fan energy at the fan coil will not be analyzed as it is assumed that it would be similar for all cases. For this comparison summer months (primary cooling season) are considered to be May 1 to September 30, and winter months (primary heating season) to be October 1 to April 30.

\subsection{BUILDING OPERATION CONSUMPTION}

\subsubsection{Heat Recovery VRF Heat Pump System}

VRF system efficiency is measured by the coefficient of performance (COP). COP is a dimensionless ratio of the system's output to the system's input. Using the simulated cooling and heating building consumption and building cooling and heating effects, average COP values were determined using equation 10-1. During the winter the average COP for cooling and heating was 3.71 and 2.27, respectively. For the summer COP values of 3.85 and 2.61 were determined for cooling and heating, respectively. It is important to note that the refrigerant pumping consumption from the compressor and fan energy in the outdoor unit is assumed to be captured in the COP and total energy consumption for the outdoor units.

$$
\text { COP }=\frac{\text { Useful Cooling or Heating Effect }(k W h)}{\text { Cooling or Heating Consumption }(k W h)}
$$

\subsubsection{Chiller + Boiler System Description}

A chiller is a piece of equipment which removes heat from a liquid through the absorption refrigeration cycle. The liquid is then circulated through a heat exchanger to cool the air that passes through it. The cold liquid travels through the coils in the hydronic fan coils and the fan circulates air over the coils to 
cool the air in the zone. This refrigeration process creates waste heat which is exhausted to the outdoor air, adding to the warming of the earth.

Chillers' system efficiency is usually measured through the energy efficiency ratio (EER). EER is a ratio of the system's output cooling energy to input electrical energy at the rating point, see equation 10-2, with a unit of BTU/W/h. The VRF system was sized for $260.1 \mathrm{~kW}$ of cooling (887498 BTU/h or 74 refrigeration tons), therefore a similarly sized chiller was selected. The Trane air-cooled scroll chiller 70 ton (model CGAM) unit, which has a capacity of 79.8 tons. During the summer it is assumed the average daytime outdoor temperature would be 21C (70F) (Government of Canada, 2014), however the Trane specifications are ratings start at $85 \mathrm{~F}$ for condenser ambient temperature. Aermec suggests a fan coil unit leaving temperature of 7C (5OF) (AERMEC). For these parameters, this chiller would have a summer EER of 12.6 (Trane, 2015), which translates to a COP of 3.96. Trane does not allow extrapolation of their specification values, therefore the same COP value of 3.96 is used for the winter cooling, although it is noted that the chiller would work significantly better at colder. The internal fan and any pump energy on the heat rejection side is assumed to be included in the chiller EER.

$$
\begin{aligned}
& E E R=\frac{\text { output Cooling Energy }(B T U)}{\text { Input Electrical Energy }(W h)} \\
& E E R=C O P * 3.413
\end{aligned}
$$

A condensing boiler is essentially a water heater which uses natural gas, propane or oil as the energy source. These boilers can achieve a high efficiency by using the waste heat incurred by the flue gases to preheat the cold water entering the boiler, which reduces the total required energy to heat the water as it goes through the boiler.

The VRF system heating capacity in the case study building was $274.2 \mathrm{~kW}$ (935 $610 \mathrm{BTU} / \mathrm{h}$ ), therefore a comparable boiler capacity was chosen. The unit chosen for this comparison was the $1 \mathrm{MMBTU} / \mathrm{h}$ unit fully condensing boiler from Cleaver-Brooks (Cleaver-Brooks, 2012), which can be either gas-fired or propane-fired. The efficiency of the boiler is a ratio of the system consumption to the system's capacity, as per equation 10-4. This condensing boiler has a combustion efficiency of 96\% (Cleaver-Brooks, 2012). To be conservative and account for part load operation, a 91\% efficiency was used for this comparative study, which translates to a heating COP of 0.91. The reduction in efficiency was based on the findings from Butcher's study that the steady state thermal efficiency of a natural gas condensing boiler was about $5 \%$ less than the rated combustion efficiency (Butcher, 2007). 


$$
\text { Boiler Efficiency }(\%)=\frac{\text { Firing Output }(B T U / h)}{\text { Maximum Input Capacity }(B T U / h)} * 100
$$

It is assumed that building side pumping energy is not accounted for in the chiller and boiler. Kavanaugh et al. suggests an average value of $17 \mathrm{~W} / \mathrm{kW}$ for building side loop pumping to fan coils (Kavanaugh \& Rafferty, 1997). This pumping consumption would be for the fluid being delivered to the fan coil units in the zones.

\subsubsection{Ground Source Heat Pump System Description}

Another potential efficient HVAC system which could have been installed in the case study building is a ground source heat pump (GSHP) with hydronic fan coil units for zone conditioning distribution. A ground source heat pump is heat exchanger connected to a series of pipes in the ground. The ground acts as a heat source in heating mode and a heat sink in cooling mode. The heat from the ground is absorbed or released into the fluid in the pipes which is carried to the heat exchanger. The ground has more moderate temperatures than the air which increases the heat pump's efficiency, in turn reducing the energy consumption of operating the building. There are four sources of energy consumption for a GSHP: heating, cooling, fan, and pump.

An example of a ground source heat pump company is ClimateMaster. Since heating and cooling occur simultaneously throughout the year two ClimateMaster Tranquility Modular Water-to-Water TMW600 (50 ton) units were chosen, to coincide with the capacity of the VRF system. The next size down in equipment would not have had a large enough capacity.

Summer cooling design parameters were chosen from the Climate Master specifications. An average soil temperature of $12.6{ }^{\circ} \mathrm{C}$ was determined by the EnergyPlus auxiliary program CalcSoilSurfTemp, therefore a seasonal average entering water source temperature of $15.5^{\circ} \mathrm{C}\left(60^{\circ} \mathrm{F}\right)$ (the lowest available temperature on the ClimateMaster specification) (ClimateMaster, 2013). Aermec fan coil units (FCX P) recommend a $7^{\circ} \mathrm{C}$ entering fan coil temperature with a $5^{\circ} \mathrm{C}$ temperature differential (AERMEC). Using the medium flow rate (113 GPM) on both sides of the heat pump, the heat pump EER is 23.3 or a COP of 6.83, based on equation 10-3.

For winter cooling it is assumed that the average source entering water temperature would approach $10^{\circ} \mathrm{C}$, since the CalcSoilSurfTemp reports an average winter ground temperature of $8^{\circ} \mathrm{C}$. However, the performance tables do not give data for such low temperatures in cooling mode. Since the 
ClimateMaster specifications state the extrapolation is not permissible the same COP of 6.83 was used. It is noted that it is likely that the SEER would be higher due to better operating conditions.

For winter ground temperature of $8^{\circ} \mathrm{C}$ it is assumed that the water could reach an average source entering water temperature of $4^{\circ} \mathrm{C}\left(40^{\circ} \mathrm{F}\right)$. Aermec suggests a $50^{\circ} \mathrm{C}$ fan coil inlet temperature with a temperature differential of $10^{\circ} \mathrm{C}$ (AERMEC) for heating. Based on these temperatures and again selecting the medium flow rate (113 GPM) the heat pump COP is rated at 5.0 (ClimateMaster, 2013).

For summer heating an average source and fan coil entering water temperatures of $15.5 \mathrm{C}\left(60^{\circ} \mathrm{F}\right)$ and $38^{\circ} \mathrm{C}(100 \mathrm{~F})$, respectively were chosen, for a flow rate of $113 \mathrm{GPM}$. For these parameters the heat pump units had a corresponding COP of 4.8 (ClimateMaster, 2013).

It is assumed that the heat pump efficiencies do not take into account pumping losses. The pumping pressure drop for the source loop was determined based on the calculations in the Engineering Manual for the Design and Installation of Ground and Water Source Heat Pump Systems (Geddes, 1990). For 3/4" pipe $140 \mathrm{ft}$. borehole depth with elbows and fittings would incur a pressure drop of $11.53 \mathrm{ft}$. The selected heat pump has a pressure drop of $8.3 \mathrm{ft}$. Therefore a pump with a head of $20 \mathrm{ft}$. was selected. Furthermore, as per the design guidelines a flow rate of $3 \mathrm{GPM} /$ ton was suggested for a total of 222 GPM. Using the Grundfos pump sizing selector for 222 GPM and $20 \mathrm{ft}$. of head, the pump power was 2.2 kW or 8.5 W/kW (Grundfos). Additionally, Kavanaugh et al. (1997) suggests an average 17W/kW for building loop pumping power.

\subsubsection{System Consumption Results}

For a typical year to meet the case study building's space conditioning loads the 5 main VRF outdoor units required a useful cooling and heating supply of 9,630 kWh and 66,420 kWh for the winter. For the summer the building required useful outputs of 72,140 kWh and 2,540 kWh for cooling and heating, respectively, for the summer. These values were determined through the modelling of a typical meteorological year in EnergyPlus, as presented in Section 8.2. These values do not include the fan and parasitic energy required to operate the VRF indoor terminal units or the equipment required to operate the dedicated outdoor air system. For this analysis it is assumed that these excluded values would remain the same for any of the systems analyzed. These useful outputs required to meet the building's loads were used for each system to determine their annual energy consumption. 
Table 39: Building Equipment Required Output by Season

\begin{tabular}{|l|r|r|}
\hline Season & Cooling (kWh) & \multicolumn{1}{|c|}{ Heating (kWh) } \\
\hline Winter & 9,630 & 66,420 \\
\hline Summer & 72,140 & 2,500 \\
\hline
\end{tabular}

Table 40 summarizes the system equipment efficiencies using coefficient of performance, of the selected equipment, described in the previous sections.

Table 40: System Coefficients of Performance

\begin{tabular}{|l|c|c|c|c|c|c|}
\cline { 2 - 7 } \multicolumn{1}{c|}{} & \multicolumn{2}{c|}{ HR VRF HP } & \multicolumn{2}{c|}{ Chiller + Boiler } & \multicolumn{2}{c|}{ Ground Source HP } \\
\cline { 2 - 7 } \multicolumn{1}{c|}{} & Cooling COP & Heating COP & Cooling COP & Heating COP & Cooling COP & Heating COP \\
\hline Winter & 3.71 & 2.27 & 3.69 & 0.91 & 6.83 & 3.0 \\
\hline Summer & 3.85 & 2.61 & 3.69 & 0.91 & 6.83 & 3.7 \\
\hline
\end{tabular}

Table 41 summarizes the energy consumption for each system. The ground source heat pump was determined to have the least amount of energy consumption at $38,640 \mathrm{kWh}$. The ground source heat pump system consumed $29 \%$ less energy than the heat recovery VRF system. The chiller plus boiler system consumed $86 \%$ more energy than the heat recovery VRF system.

Table 41: System Consumption Comparison for a TMY

\begin{tabular}{|c|c|c|c|c|c|c|}
\hline \multirow[t]{2}{*}{ Consumption (kWh) } & \multicolumn{2}{|c|}{ HR VRF HP } & \multicolumn{2}{|c|}{ Chiller + Boiler } & \multicolumn{2}{|c|}{ Ground Source HP } \\
\hline & Winter & Summer & Winter & Summer & Winter & Summer \\
\hline Cooling & 2,600 & 18,730 & 2,610 & 19,540 & 1,410 & 10,570 \\
\hline Heating & 29,300 & 960 & 72,990 & 2,750 & 22,140 & 680 \\
\hline Pumping & - & - & 1,290 & 1,270 & 1,940 & 1,900 \\
\hline Electric Duct Coils & 2,470 & - & - & - & - & 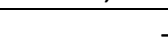 \\
\hline Electrical Total & \multicolumn{2}{|c|}{54,060} & \multicolumn{2}{|c|}{24,710} & \multicolumn{2}{|c|}{38,640} \\
\hline Elec. Equivalent Total & \multicolumn{2}{|c|}{-} & \multicolumn{2}{|c|}{75,740} & \multicolumn{2}{|c|}{-} \\
\hline Total & \multicolumn{2}{|c|}{54,060} & \multicolumn{2}{|c|}{100,450} & \multicolumn{2}{|c|}{38,640} \\
\hline
\end{tabular}

For a typical meteorological year, the building's annual energy consumption was simulated in EnergyPlus to be $230,670 \mathrm{kWh}$, plus energy consumption required to run the domestic hot water system. For office buildings the energy consumption of running a domestic hot water system is usually not more than an additional 5-10\% energy consumption. Therefore, allocating an additional $5 \%$ for the domestic hot water system the total building energy consumption would be around 242, $200 \mathrm{kWh}$. The modelling floor area (i.e. mechanical room was not modelled) for the case study building was $3167 \mathrm{~m}^{2}$. Thus, the case study building had an annual whole building energy intensity of $76 \mathrm{kWh} / \mathrm{m}^{2}\left(0.27 \mathrm{GJ} / \mathrm{m}^{2}\right)$, where the space conditioning (5 main VRF outdoor units) energy intensity was $17 \mathrm{kWh} / \mathrm{m}^{2}\left(0.061 \mathrm{GJ} / \mathrm{m}^{2}\right)$. 
Assuming all aspects of the building had remained the same, expect for the external equipment producing the cooling and heating for space conditioning, the building with the chiller plus boiler system would have had an annual whole building energy intensity of $91 \mathrm{kWh} / \mathrm{m} 2\left(0.33 \mathrm{GJ} / \mathrm{m}^{2}\right)$., where the space conditioning energy intensity was $32 \mathrm{kWh} / \mathrm{m} 2\left(0.12 \mathrm{GJ} / \mathrm{m}^{2}\right)$. Similarly, the ground source heat pump would have had an annual whole building energy intensity of $71 \mathrm{kwh} / \mathrm{m} 2\left(0.26 \mathrm{GJ} / \mathrm{m}^{2}\right)$, where the space conditioning energy intensity was $12 \mathrm{kwh} / \mathrm{m} 2\left(0.043 \mathrm{GJ} / \mathrm{m}^{2}\right)$.

Natural Resources Canada released a study in 2012 titled Survey of Commercial and Institutional Energy Use - Buildings 2009. This study surveyed a large diversity of building types, sizes, climate zone, and construction dates (before 1920 up to 2009). For the Great Lakes region and for a building having a floor area between $930 \mathrm{~m}^{2}$ to $4645 \mathrm{~m}^{2} 57,478$ buildings were surveyed. The survey determined the average energy intensity for these buildings was $0.99 \mathrm{GJ} / \mathrm{m}^{2}$ (Natural Resources Canada Office of Energy Efficiency, 2012). It can be concluded that the case study building is an energy efficient building since its total energy intensity is less than $30 \%$ of the region's typical energy intensity.

\subsection{Building Conditioning OPERATing Cost}

The installed Mitsubishi system at the case study building runs solely on electrical energy. For a small commercial building which uses RPP tiered pricing from Hydro One, the electricity cost is $\$ 0.088 / \mathrm{kWh}$ for the first $750 \mathrm{kWh}$, and afterwards the electricity is charged at $\$ 0.103 / \mathrm{kWh}$ (Hydro One Inc., 2015). This translates to an annual VRF system operating consumption cost of $\$ 4750$, plus additional fees and taxes.

If the boiler-chiller-hydronic fan coil system had been installed using natural gas for the boiler and electricity for the chiller and pumps, the annual system operating consumption would have been around $\$ 3,480$, plus additional fees and taxes. This is based on the electrical consumption again being charged at $\$ 0.088 / \mathrm{kWh}$ and $\$ 0.103 / \mathrm{kWh}$, and natural gas being charged out at $\$ 0.190 / \mathrm{m}^{3}$ (Ontario Energy Board, 2015), by Union Gas Limited, which provides natural gas to the region in which the case study building is located. However, if this building was located in an area where natural gas lines were not readily available, propane could be the other fuel choice to fire the boiler. The propane consumption cost for the boiler operation was calculated to be $\$ 6,990$ at a rate of $\$ 0.675 / L$ (Pathak M. , 2015), an average price for the heating months of 2013 from Superior Propane. The use of a propane fired boiler with an electric chiller would have cost roughly $\$ 9160$ annually for a typical year. The ground source heat pump system is an all-electric system that would have cost $\$ 3,400$ to run for a typical year. The system operation costs are summarized in Table 42. On an annual basis the gas boiler plus chiller would cost 
$27 \%$ less to operate than the heat recovery system. The propane boiler plus chiller would cost $93 \%$ more to operate than the heat recovery VRF system. The ground source heat pump system would cost $28 \%$ less to operate than the heat recovery VRF system.

Table 42: System Operating Costs

\begin{tabular}{|l|r|r|r|r|r|}
\cline { 2 - 6 } \multicolumn{1}{c|}{} & Price & HR VRF HP & $\begin{array}{c}\text { Gas Boiler } \\
+ \text { Chiller }\end{array}$ & $\begin{array}{c}\text { Propane Boiler } \\
+ \text { Chiller }\end{array}$ & $\begin{array}{c}\text { Ground Source } \\
\text { HP }\end{array}$ \\
\hline \multirow{2}{*}{ Electricity (\$/kWh) } & $\$ 0.088$ & $\$ 790$ & $\$ 790$ & $\$ 790$ & $\$ 790$ \\
\cline { 2 - 6 } & $\$ 0.103$ & $\$ 3,960$ & $\$ 1,380$ & $\$ 1,380$ & $\$ 2,610$ \\
\hline Natural Gas (\$/m3) & $\$ 0.190$ & - & $\$ 1,310$ & - & - \\
\hline Propane (\$/L) & $\$ 0.675$ & - & - & $\$ 6,990$ & - \\
\hline \multicolumn{2}{r|}{ Total $(\$):$} & $\$ 4,750$ & $\$ 3,480$ & $\$ 9,160$ & $\$ 3,400$ \\
\hline
\end{tabular}

The case study building is owned and on the land of the Upper Thames River Conservation Authority. The building overlooks the Upper Thames River, where a flood control dam, Fanshawe Dam, is present. Fanshawe Dam is a small hydroelectric generating plant, which has the capability to produce 2,860 MWh per year, and provides this electricity to the buildings on the conservation area (Upper Thames River Conservation Authority). Excess energy generated by the dam is sold to the grid, and when the dam is offline (due to maintenance), electricity is purchased from London Hydro. Therefore, the case study building does not incur costs due to HVAC operating electrical consumption. Thus, the VRF and Ground Source HP systems, as well as the chiller, would essentially have no electrical consumption operating costs, if installed at the case study building. However, the gas boiler would cost $\$ 1,310$ and the propane boiler would cost $\$ 6,990$ in operation consumption.

To determine the overall cost efficiency of the systems capital costs should also be considered. Thornton and Wagner (2012) compiled capital costs for VRF systems in the US. The costs ranged between US\$177.60/ $\mathrm{m}^{2}$ and US\$355.21/ $\mathrm{m}^{2}\left(\$ 16.50 / \mathrm{ft}^{2}\right.$ to $\left.\$ 33.00 / \mathrm{ft}^{2}\right)$. The total cost for the mechanical system at A Grander View building in Kitchener, Ontario was $\$ 430 / \mathrm{m}^{2}\left(\$ 40 / \mathrm{ft}^{2}\right)$ (Carpenter, 2010). The cost of materials and labour for installing the VRF system at the case study building was \$925,000 CAD (Curney Mechanical Inc., 2010) or $\$ 276 / \mathrm{m}^{2}$. The system cost for the case study building falls within Thornton and Wagner's systems capital costs range.

A study done by department of Civil Engineering of the University of Toronto and Toronto and Region Conservation for the Living City studied alternative energy technologies in Ontario. They determined a GSHP on average would cost CAD $\$ 46.6 / \mathrm{m}^{2}$ for commercial and institutional buildings (Bristow, 2003). The Metrus Building $\left(3250 \mathrm{~m}^{2}\right)$ in Concord, Ontario had a capital cost of $\$ 380,000$ for their ground 
source heat pump system (Natural Resources Canada, 2002). This results in a capital cost of $\$ 117 / \mathrm{m} 2$ $\left(\$ 10.86 / \mathrm{ft}^{2}\right)$. From these costing numbers, it is evident that the cost for GSHP varies significantly. To get an accurate cost for the case study building (or any other building) a number of manufacturers and installers should be consulted.

Comparing the capital system costs of the UTRCA WCC (the case study building) for a VRF system at $\$ 276 / \mathrm{m} 2$ and the Metrus Building for a ground source heat pump at $\$ 117 / \mathrm{m} 2$, as they are of similar size and function, as well as both buildings being located in southern Ontario, a ground source heat pump would be both cheaper to install and operate than a VRF system. However, depending on the ground conditions at the case study building site, digging the boreholes could be difficult which could incur significantly higher capital costs than were seen at the Metrus Building. The above calculations were rough estimations and further research would need to be done to determine realistic values for any building.

\subsection{GREENHOUSE GAS EMISSIONS}

Greenhouse gases absorb energy causing the earth to slow down the rate at which it is able to release heat to space, which is causing the earth to warm up. Human based activities started to significantly contribute to the greenhouse gas emissions since the beginning of the industrial revolution. The warming of the earth is causing climate change such as more extreme storms and glaciers melting. Humans need to become more aware of the damages we are creating to the earth by generating these greenhouse gas emissions.

The main gases that make up the greenhouse gases in the earth's atmosphere are water vapour $\left(\mathrm{H}_{2} \mathrm{O}\right)$, carbon dioxide $\left(\mathrm{CO}_{2}\right)$, methane $\left(\mathrm{CH}_{4}\right)$, nitrous oxide $\left(\mathrm{N}_{2} \mathrm{O}\right)$, and ozone $\left(\mathrm{O}_{3}\right)$. Carbon dioxide is a naturally occurring element in the atmosphere, however due to human related processes the amount of carbon dioxide has significantly increase which is harming the environment. Carbon dioxide is considered to be the primary greenhouse gas, at $82 \%$, from human related activities which mostly comes from the generation of fossil fuels for energy and transportation (United States Environmental Protection Agency).

Electricity created by renewal sources, such as nuclear, hydro, wind and solar, are said to have no GHG emissions (0 g/kWh) generated during power generation (Frommann \& DiValentino, 2012), nevertheless this does not take into account the manufacturing or delivery emissions. However, in most cases the electricity from the grid is generated through multiple sources. In 2011, the Ontario electricity grid had a 
carbon dioxide intensity of $92 \mathrm{~g} / \mathrm{Kwh}$ (Environment Canada, 2014), mainly from the electricity produced from combustion plants. Since then, there has been a phase-out of coal plants for the Ontario electricity grid, as well as other combustion plants have reduced generation. In 2014, the Ontario electricity grid was generated using nuclear, hydro, wind, natural gas, oil, solar, biofuel and coal for an overall carbon dioxide intensity of $38.15 \mathrm{~g} / \mathrm{kWh}$ (Ontario Energy Board, 2015). Natural gas produces $215.31 \mathrm{~g} / \mathrm{kWh}$ (53.1 kg/MMBTU) of carbon dioxide and propane produces $181.18 \mathrm{~g} / \mathrm{kWh}(63.1 \mathrm{~kg} / \mathrm{MMBTU})$ (U.S. Energy Information Admisitration). The electric heat recovery VRF system would generate 2,060 $\mathrm{kg}$ of carbon dioxide. The natural gas and propane plus chiller systems would generate 17,250 and 14,660 kg of carbon dioxide, respectively. That results in $737 \%$ more carbon dioxide emissions for the gas boiler plus chiller and $612 \%$ more carbon dioxide emissions for the propane boiler and chiller, than the heat recovery VRF system. The ground source heat pump is the least damaging to the earth, coming in at $1,470 \mathrm{~kg}$ of carbon dioxide emissions generated on an annual basis, or $29 \%$ less carbon dioxide emissions than the heat recovery VRF system.

Table 43: System Operating Carbon Dioxide Emissions

\begin{tabular}{|c|c|c|c|c|c|}
\hline Fuel Type & $\begin{array}{c}\text { CO2 Intensity } \\
\text { (g/kWh) }\end{array}$ & $\begin{array}{c}\text { HR VRF HP } \\
\text { (kg) }\end{array}$ & $\begin{array}{c}\text { Gas Boiler } \\
+ \text { Chiller (kg) }\end{array}$ & $\begin{array}{l}\text { Propane Boiler } \\
+ \text { Chiller (kg) }\end{array}$ & $\begin{array}{c}\text { Ground } \\
\text { Source HP (kg) }\end{array}$ \\
\hline Electricity & 38.15 & 2,060 & 940 & 940 & 1,470 \\
\hline Natural Gas & 215.31 & - & 16,310 & - & - \\
\hline Propane & 181.18 & - & - & 13,720 & - \\
\hline & Total $(\mathrm{kg}):$ & 2,060 & 17,250 & 14,660 & 1,470 \\
\hline
\end{tabular}

Any electrical system installed at the case study building would have a much lower $\mathrm{CO}_{2}$ intensity as they use the electricity generated by the dam on the river next to the building. The energy generated by the dam would essentially have a $\mathrm{CO}_{2}$ intensity of $0 \mathrm{~g} / \mathrm{kWh}$. However it should be noted that the dam does go offline at times for maintenance and then the building would have to use electricity from the grid.

\subsection{SySTEMS ANALYSIS CONCLUSIONS}

The ground source heat pump system has the highest equipment efficiency which results in the lowest energy consumption and the lowest generated carbon dioxide emissions of the three systems. If the building was located in a core part of a city it is possible that building restrictions would not allow for the boreholes to be dug. However, since the building is not located in the core, a ground source heat pump system should have been a feasible option. Another consideration would be the capital cost of both systems. The drilling of the boreholes and installation of the piping can be a costly endeavour which may not have seemed feasible with the VRF system being a comparable system. VRF and GSHP have similar 
outcomes since they both run on electricity and have similar consumptions and greenhouse gas emissions. A more detailed modelling analysis of a ground source heat pump would need to be done to confirm calculated consumptions, and local contractors and GSHP companies should be consulted for capital cost comparisons. Thus, either the VRF system or ground source heat pump system would have been an efficient system to be used in the case study building. 


\section{FURTHER RESEARCH AND RECOMMENDATIONS}

The results of this research supplement information on influential input parameters in modelling heat recovery VRF systems in EnergyPlus, as well as, the applicability of heat recovery VRF systems for a Canadian Climate. Several additional areas remain to be investigated that would help in understanding the implications of EnergyPlus heat recovery VRF system input parameters, appropriate metering and data collection for model calibration, and improving EnergyPlus objects to reduce encounter software limitations.

\subsection{HEAT RECOVERY VRF SYSTEM COMPLEXITY}

Heat recovery VRF systems are very complex systems. To be able to fully understand the efficiency and performance characteristics of heat recovery VRF systems, they should be studied in buildings in which they are the sole HVAC component. In the case study building there were a number of energy efficiency measures which were installed to operate with the heat recovery VRF system. This created a rather complex mechanical system which created difficulties in modelling the building in EnergyPlus. Due to the energy efficiency measure it is possible that the VRF system is operating more efficiently than if these measures had not been installed. It would be beneficial to re-run the VRF parametric analyses without the energy efficiency measures to see the "absolute" changes in performance of the heat recovery VRF system.

\subsection{RECOMIMENDED MONITORING REQUIREMENTS}

While this work discussed the steps taken to create the advanced energy model, the model was not able to be calibrated with the site information available at the time of this research. The research process showed that further more detailed data collection was needed to increase the accuracy of the model inputs to reach calibration limits.

Since this project developed after the fact, the information needed for calibration was not always readily available and data from various equipment was grouped together. Changing the wiring or adding extra instrumentation and equipment later was determined to be unfeasible. Better grouping of equipment for electrical consumption data collection would have made for easier pinpointing of consumption fluctuations and differences and allowed for better calibration. It would have been beneficial to know the indoor terminal unit fan speed and air flow rate to calibrate the indoor terminal units. Also, having recorded data of entering and leaving temperatures of the solar wall and earth tube would have allowed for more accurate performance characterization of the two components. In 
addition, numerous spot check throughout the study period would ensure the continuity and accuracy of the data being collected. Utility metering would also add as another method of double checking the collected energy consumption data. Utility bills could not be used during this study as there was only one meter for the whole site which included much more than just the case study building.

The indoor terminal units can be set to either operate in auto, heat only or cool only modes. Due to scheduling issues in EnergyPlus all indoor terminal units were set to operate in auto mode. Having all the units set to auto increased the energy consumption. It would be beneficial to know which mode each indoor terminal unit is working in and when the modes are changed.

The airflow of the indoor terminal units was set based on the engineering design specifications and the air balancing report. These are not necessarily representative of the continuous operating conditions of the fan in the indoor terminal unit. It would be beneficial for the metering system to track the fan speed and airflows of the indoor terminal units to improve the indoor terminal unit inputs and increase the accuracy of the energy model.

The VRF indoor terminal units in the meeting rooms were only activated when an occupant decided to turn on the unit. Since there was no logging of when the meeting rooms were used or when the units were turned on, it was difficult to predict their usage. Future logging of when these units are turned on and off would help to increase the accuracy of the energy model.

Heat recovery is a difficult parameter to quantify. There are numerous input parameters for the heat recovery mode, however due to insufficient data from the manufacturer to create the required inputs, default values and curves had to be used. It would be interesting to be able to monitor the heat recovery controller to know when the controller is receiving conditioned refrigerant from the outdoor unit and when the controller is able to load balance. This would allow one to determine the heat recovery capacity fractions, energy fractions and time constants.

Field testing of heating and cooling consumption, and power inputs to determine COPs would better estimate the performance of the outdoor units. It would be beneficial to know if the outdoor units' COPs constantly differ from the manufacturer specifications COPs. If a constant margin can be determine this margin could be translated into modelling values to better predict energy consumption by the VRF system. 
The occupancy used in the simulation work was based on the predicted building usage. Occupancy is a difficult variable to predict as it can be constantly changing. Occupants may work in different rooms of the building depending on their tasks for that day, or may even out of the building doing field work. There was also a large board room typical used for large events, such as conferences, which only happen a few times per month. There was no occupancy logging in place at the building to better aid in occupancy scheduling. The only way of possibly determining the occupancy was through the building's carbon dioxide sensors, however during the study data was not being collected through those sensors. The carbon dioxide levels were being used for the DOAS to determine the amount of fresh air intake needed at any given point throughout the day. Having known the occupancy values could have aided in better predicting the DOAS and VRF system performance and their energy consumption.

For another research study like this one to be successful, the stakeholders of the building project need to be informed early of the intent of the research so as to be able incorporate the required measurement protocol during construction. It is also important to carefully log the equipment that is assigned to each sensor or electrical panel and equipment location in the building. The dataset needs to be frequently downloaded, backed up and analyzed to ensure the data that is being collected is producing a good dataset.

The minimum requirements for modelling a heat recovery VRF system in EnergyPlus are:

- At least 12 months of continuous (preferably hourly) collected energy consumption data

- Utility metering for cross checking values

- Indoor terminal unit operation mode - heat only, cool only, auto

- Logging of indoor terminal unit operation for units with manual on/off switch

- Indoor terminal units' fan speeds and airflow rates

- Sensor on the heat recovery controller to determine when the outdoor units are operating in heat recovery mode

- Power sensors on the outdoor units to be able to calculate operating COPs

- Sensor/submetering for energy consumption of each VRF outdoor unit

- Sensor/sub metering, spot testing, and equipment locations of plug loads

- $\mathrm{CO}_{2}$ sensors to determine occupancy for internal gains and required ventilation rates 


\subsection{EnERgyPlus Limitations}

There were a number of limitations with the EnergyPlus software which led to difficulties and inaccuracies in modelling the relatively complex case study building. It would be beneficial for EnergyPlus to allow for multiple outdoor air intake streams that feed into the same outdoor air loop system. The ZoneEarthTube module should be updated to be able to be connected to the HVAC air loop, as opposed to how now it must be associated to a zone and the air flows into that zone as air infiltration would. These two changes in the outdoor air system air loop would allow for proper integration of both the solar wall and earth tube for pre-treating the outdoor air for building ventilation.

In cold climates it is necessary to include a supplemental heating system to the heat recovery VRF system for when the outdoor temperature drops below the operating threshold of the outdoor units. In many cases this is accomplished through additional electric duct heaters which are added to the ducts attached to the indoor terminal units. At this time the VRF Indoor terminal units only have the ability to contain a fan, and a direct expansion heating and cooling coil. A reheat option or additional coil should be added to allow for more realistic modelling in cold climates.

At this time the VRF system in EnergyPlus only allows for indoor terminal units to be attached to the outdoor units. Some buildings have other equipment integrated into the refrigerant system, such as a domestic hot water system. In cooling dominated buildings having an added heat load allows for better heat recovery and can increase the part-load ratio which, in turn reduces the total energy consumption. Again, it would be beneficial if the VRF module were expanded to allow for other equipment, besides the terminal units, to be added to the refrigerant loops.

\subsection{SYSTEMS COMPARISON}

Determining the efficiency and impact of a system goes beyond analyzing the operational consumption and costs. Energy modelling, lifecycle cost analysis, as well as lifecycle operational and embodied total greenhouse gas emissions analyses should be carried out for the four studied systems to determine the system for the case study building with the least lifecycle cost and impact. These procedures should also be done for several new buildings built in different locations as energy and material costs will differ. 


\section{CONCLUSIONS}

Heat recovery variable refrigerant flow systems are slowly being introduced into the Canadian market. They have been marketed as energy efficient systems with increased thermal comfort control over other conventional HVAC systems used in Canada. There is not a lot of data to understand the efficiency of heat recovery VRF systems in the Canadian climate which can experience very cold winters and hot summers.

The goal of this research was to determine if a heat recovery variable refrigerant flow system was an efficient system for a cold climate using a LEED ${ }^{\circledR}$ Platinum case study building located in London, Ontario. This was done through a comparison of field data with simulation results from an advanced model created in EnergyPlus, and outlining the challenges of modelling the complex heat recovery variable refrigerant flow system.

The contributions of this research was presenting the importance of integrated system design in minimizing energy consumption through right sizing of equipment and optimizing VRF heat recovery; identifying the minimum requirements needed for heat recovery VRF system simplicity and monitoring system installation for more accurate modelling and model calibration achievement for a case study building; identifying the importance of developing VRF equipment specific performance curves and determining the minimum heat pump part-load ratio for more accurate energy consumption model prediction.

An advanced energy model was created using standard available manufacturer data of the UTRCA WCC building with a heat recovery VRF system based on the available data and objects in EnergyPlus. However, with a NMBE of $-29.0 \%$ and a (CV) RMSE of $38.7 \%$ for total building energy consumption, the advanced model did not meet the ASHRAE Guideline 14 calibration limits. The EnergyPlus model predicted higher energy consumption for the outdoor units and indoor terminal units. The UTRCA WCC building uses advanced energy efficiency measures, such as earth tubes and a solar wall, which could not be modeled in EnergyPlus the same as they are in operation at the building. The domestic hot water system and the dedicated outdoor air system (DOAS) are incorporated into the VRF network system at the building but could not be modeled as such due to limitations in the EnergyPlus software. Currently the EnergyPlus VRF system does not allow for the refrigerant to be used to heat (or cool) additional equipment such as that for the domestic hot water system. Due to the domestic hot water model limitation, the modelled required loads on the outdoor units was lower, which caused the outdoor units 
to operate at lower part-load ratios, in turn increasing their energy consumption. However, in commercial buildings the domestic hot water consumption is quite small, usually limited to hand washing in washrooms. Additionally, the VRF terminal units need to be associated with a zone, not an airstream, as is the case for the DOAS, therefore the DOAS heating and cooling coils were modelled as regular direct expansion refrigerant coils.

Custom performance curves were needed to be created for the specific equipment which was installed in the case study building, Based on manufacturer data this was not always possible and EnergyPlus default VRF performance curves were used in those cases. Using a combination of developed and default VRF performance curves instead of only default VRF performance curves, resulted in a $5 \%$ energy consumption increase for the VRF outdoor units.

The input for the minimum heat pump part-load ratio parameter had a significant impact on the outdoor units' energy consumption. Raising the value from the default of 0.15 to 0.35 decreased the outdoor units' annual energy consumption by $16 \%$.

Balancing zone heating and cooling loads by reconfiguring the indoor terminal units with the outdoor units did reduce the energy consumption. However, since the case study building did not have diverse heating and cooling loads and the outdoor units were working at low part-load ratios, there was only a $3 \%$ reduction in space conditioning energy consumption.

Appropriately sizing the outdoor units' capacities was determined to be very important for the outdoor units to operate at higher part-load ratios throughout the year, in turn reducing energy consumption. Reducing the total outdoor units' cooling capacity by $98 \mathrm{~kW}$ and heating capacity by $110 \mathrm{~kW}$ resulted in a $29 \%$ space conditioning energy consumption decrease.

Through a climate analysis for the case study building location (London, Ontario), it was determined that the seasonal average COPs for the outdoor units for both heating and cooling will be higher during more moderate climates (warm winter, cool summer) than for extreme climates (cold winter, hot summer), as expected. In addition to the higher COPs, more heat recovery occurred through load balancing for moderate climates.

The conclusions of this study are based on only one relatively small office building. Nevertheless, it is a common experience that modelling programs do not keep up with design features that mechanical designers use. To deal with this issue and specifically addressing the complexity of heat recovery VRF 
systems which require numerous modelling inputs by EnergyPlus, modelling guidelines need to be created.

The metrics used to determine system efficiency in this study were annual system operating energy consumption, annual operating energy costs and generated system operating carbon dioxide emissions. The heat recovery VRF system was compared against a chiller plus boiler and hydronic fan coil system as well as a ground source heat pump plus hydronic fan coil system. It was determined that a comparative high-efficiency propane or gas boiler plus electric chiller and hydronic fan coil system would consume $86 \%$ more energy and $612 \%-737 \%$ more carbon dioxide emissions than the heat recovery VRF system. However, a comparative ground source heat pump and hydronic fan coil system had $28 \%$ lower energy consumption and $29 \%$ lower carbon dioxide emissions than the heat recovery VRF system. Considering the different fuels costs the heat recovery VRF system was the most expensive to operate in an urban setting where natural gas is readily available, at $28 \%$ more than the ground source heat pump, which was the cheapest to operate. In the country, similar to the case study building location, where only electricity and propane are typically available, the high efficiency propane boiler plus chiller and hydronic fan coil system was the most expensive to operate, at $93 \%$ more than the heat recovery VRF system. The energy costs of operating a ground source heat pump for the case study building would have been an option with lower annual energy consumption costs and lower carbon dioxide emissions than the heat recovery VRF system. 


\section{BIBLIOGRAPHY}

AERMEC. FCX. Retrieved April 1, 2015, from

http://download.aermec.com/support/docs/schede/fcx_p_en.pdf

Ahn, B.-L. e. (2014). Effect of LED lighting on the cooling and heating loads in office buildings. Applied Energy(113), 1484-1489.

Allen, G. (2015, February 24). Designing Efficient Mechanical Systems.

Amarnath, A., \& Blatt, M. (2008). Variable Refrigerant Flow: An Emerging Air Conditioner and Heat Pump Technology. American Council for an Energy Efficient Economy Summer Study on Energy Efficiency in Buildings. Pacific Grove, CA.

American Society of Heating, Refrigerating and Air-Conditioning Engineers Inc. (2002). Guideline 14: Measurement of Energy and Demand Savings. Atlanta, GA: American Society of Heating, Refrigerating and Air-Conditioning Engineers Inc.

American Society of Heating, Refrigerating and Air-Conditioning Engineers, Inc. (2005). 2005 ASHRAE Handbook: Fundamentals. In Chapter 27: Ventilation and Infiltration. Atlanta: ASHRAE.

Aplin, S. (2015). Ontario Power Stats. (Canadian Energy Issues) Retrieved February 26, 2015, from http://canadianenergyissues.com/ontario-power-stats/

Aynur, T. N. (2010). Variable refrigerant flow systems: A review. Energy and Buildings, 42(7), 1106-1112.

Aynur, T. N., Hwang, Y., \& Radermacher, R. (2009). Simulation compariosn of VAV and VRF air conditioning systems in an existing building for the cooling season. Energy and Buildings, 41(11), 11431150.

BlueGreen Consulting Group Inc. (2015). BlueGreen Consulting Group. (BlueGreen Consulting Group Inc.) Retrieved March 18, 2015, from http://www.bluegreengroup.ca/

Bristow, D. (2003). The Buisness Case for Alternative Eneryg Technologies in Ontario. Toronto: University of Toronto \& Toronto and Region Conservation Authority.

Butcher, T. A. (2007). Performance of Integrated Hydronic Systems. Upton, NY: Brookhaven National Laboratory.

Canada Green Building Council. New Construction. (Canada Green Building Council) Retrieved September 9, 2014, from http://www.cagbc.org/AM/Template.cfm?Section=LEED_Canada_NC_1_0

Canadian Passive House Institute. (2012). Building Certification. (Canadian Passive House Institute) Retrieved September 22, 2014, from http://www.passivehouse.ca/building-certification/

Carpenter, S. (2010, July 7). Variable-flow refrigerant systems: Ground source heat pumps without the ground? Retrieved from Energy Manager: www.energy-manager.ca/feature-articles/variable-flowrefrigerant-systems-ground-source-heat-pumps-without-the-ground.html

Carrier Corporation. (2013). Variable Refrigerant Flow (VRF) Systems: Flexible Solutions for Comfort. Syracuse, NY: Carrier Corporation.

Casey, R. (2015, January). SolarWall Information.

CIBSE Journal. (2013). Simulation Gets Real. CIBSE Journal, 2013(January), 64-66. 
Cleaver-Brooks. (2012, February). ClearFire-C. Retrieved March 1, 2015, from http://www.cleaverbrooks.com/Products-and-Solutions/Boilers/Commercial-Condensing/ClearFire-C/Index.aspx

ClimateMaster. (2013, February 27). Tranquility ${ }^{\circledR}$ Large Water-to-Water Series Submittal Data. Retrieved March 3, 2015, from http://www.climatemaster.com/downloads/Ic975-climatemaster-commercialtranquility-large-water-to-water-tmw-series-water-source-heat-pump-submittal-set.pdf

Conserval Engineering Inc. (2012, October 12). Buffalo, NY, USA Patent No. SRCC 2012054A.

Conserval Engineering Inc. How the SolarWall Technology Provides Fresh Air \& Free Heat. (SolarWall) Retrieved February 13, 2015, from http://solarwall.com/en/products/solarwall-air-heating/howsolarwall-works.php

Curney Mechanical Inc. (2010). Invoice \# 10-837-01 Revised. UTRCA Costs Breakdown. London, Ontario, Canada: Curney Mechanical Inc.

Daikin North America LLC. VRV Modelling With eQuest. Retrieved March 12, 2015, from http://www.daikinac.com/content/assets/Energy-Modeling-Files/DaikineQuest.pdf

Energy Star. (2001). Energy Star Home Sealing Specification.

Enermodal Engineering Ltd. FRAME ${ }^{T M}$ plus Online. (Enermodal Engineering Ltd.) Retrieved March 24, 2015, from http://tools.enermodal.com/webframeplus/

Environment Canada. (2014). National Inventory Report. Gatineau, QC: Environement Canada.

Fang, X., Heinicke, D., \& Cooper, M. (2013). Modeling Comparison and Field Validation Studies on Variable Flow Refrigerant Systems. Denver. Retrieved 2011 йил November from http://www.dripirrigation.ca/

Frommann, K., \& DiValentino, E. (2012). Calculation and Application of Hourly Emission Factors for Increased Accuracy in Scope Two Emission Calculations. Canadian Society for Mechanical Engineering, 36(2), 143-148.

Geddes, D. (1990). Engineering Manual for the Design and Installation of Ground and Water Source Heat Pump Systems. Dunrobin, ON: The Canadian Earth Energy Association.

Goetzler, W. (2007). Variable Refrigerant Flow Systems. ASHRAE Journal, 49(4), 24-29.

Government of Canada. (2014, 07 09). Engineering Climate Datasets. (Government of Canada) Retrieved 08 13, 2014, from http://climate.weather.gc.ca/prods_servs/engineering_e.html

Government of Canada. Climate: Glossary. (Government of Canada) Retrieved March 30, 2015, from http://climate.weather.gc.ca/glossary_e.html

Grundfos. NB 65-160/177 A-F-A-BAQE - On Request +. Retrieved April 1, 2015, from https://productselection.grundfos.com/product-

detail.html pumpsystemid $=22229996 \&$ qcid $=22229980 \&$ scenario=Quick\%2BSizing\&application=HEATIN G\&area=\&installation=\&family=\&type=\&subtype=\&step=1\#/Quick\%20sizing/Sizing\%20result/NB\%2065160\%2F177\%20A-F-A-BAQE?qci

Hirsch, J. J. (2009). eQUEST: The Quick Energy Simulation Tool. (DOE2) Retrieved March 23, 2015, from http://www.doe2.com/equest/

Hollick, J. (1998). Solar Cogeneration Panel. Renewable Energy(15), 195-200.

Hunt et al., W. (2012). Variable Refrigerant Flow-Heat Recovery Performance Characterization. ACEEE Summer Study on Energy Efficiency in Buildings. Pacific Grove, CA. 
Hydro One Inc. (2015). Small Business Delivery - KWH. (Hydro One Inc.) Retrieved February 27, 2015, from http://www.hydroone.com/RegulatoryAffairs/RatesPrices/Pages/SmallBusinessDeliveryRates.aspx

Integrated Environmental Solutions Limited. Software. (Integrated Environmental Solutions Limited) Retrieved March 23, 2015, from http://www.iesve.com/

Johnson Controls. (2015). METASYS Building Automation System. (Johnson Controls) Retrieved March 23, 2015, from http://www.johnsoncontrols.com/content/us/en/products/building_efficiency/productsand-systems/building_management/metasys.html

Judkoff, R. (1988). Validation of the Building Energy Analysis Simulation Programs at the Solar Energy Research Institute. Energy and Buildings(10), 221-239.

Judkoff, R., \& Neymark, J. (2006). Model Validation and Testing: The Methodological Foundation of ASHRAE standard 140. ASHRAE Transactions(112), 367-376.

Kang, H., Joo, Y., Jung, H., \& Kim, Y. (2008). Performance Characterization and Optimization of a Simultaneous Heating and Cooling Multi Heat Pump. International Refrigeration and Air Conditioning Conference. Purdue.

Kavanaugh, P., \& Rafferty, K. (1997). Ground-source Heat Pumps - Design Geothermal Systems for Commercial and Institutional Buildings. Atlanta, GA: American Society of Heating, Refrigerating and AirConditioning Engineers, Inc.

Kemp, S. (2015, April 24). A Grander View.

Li, Y. M., \& Wu, J. Y. (2010). Energy simulation and analysis of the heat recovery variable refrigerant flow system in winter. Energy and Buildings, 42(7), 1093-1099.

Li, Y., Wu, J., \& Shiochi, S. (2009). Modeling and energy simulation of the variable refrigerant flow air conditioning system with water-cooled condenser under cooling conditions. Energgy and Buildings(41), 949-957.

Liu, X., \& Hong, T. (2010). Comparison of Energy Efficiency Between Variable Refrigerant Flow Systems and Ground Source Heat Pump Systems. Energy and Buildings(42), 584-589.

McLennan, J. F. (2011 йил Spring). Defending LEED. Trim Tab, pp. 69-73.

Mitchell-Jackson, J., Koomey, J., Nordman, B., \& Blazek, M. (2003). Data center power requirements: measurements from Silicon Valley. Elsevier Energy(28), 837-850.

Mitsubishi Electric Canada. (2014). Mitsubishi Electric Canada. Retrieved from City Multi Features: http://www.mitsubishielectric.ca/en/hvac/city_multi/simultaneous_heating_and_cooling.html

Mitsubishi Electric Sales Canada Inc. (2014). City Multi: VRF Technology. (Mitsubishi Electic Sales Canada Inc.) Retrieved March 24, 2015, from

http://www.mitsubishielectric.ca/en/hvac/city_multi/vrf_technology.html

Mitsubishi Electric Sales Canada Inc. Mitsubishi Electric Technical Info Centre: City Multi Databooks. (Mitsubishi Electric Sales Canada Inc.) Retrieved May 14, 2013, from http://www.mitsubishielectric.ca/HVAC_Info/City_Multi/CM-Databook.htm

MMM Group Limited. (2010). A Grander View EE4 Modelling. Kitchener, Ontario: MMM Group Limited. MMM Group Limited. (2012). UTRCA EE4 Model. London: MMM Group Limited.

Morwood, E. (2011). The OGA's response to Ontario' Long Term Energy Plan. Ontario Geothermal Association. 
National Renewable Energy Laboratoy (NREL). (2008, August 20). National Solar Radiation Data Base. (NREL) Retrieved August 13, 2014, from http://rredc.nrel.gov/solar/old_data/nsrdb/1991-2005/tmy3/

Natural Resources Canada. (2002). Ground-source heat pumps produce savings for commercial building. Ottawa: Natural Resources Canada.

Natural Resources Canada. (2005). Ground-Source Heat Pump Project Analysis. In Clean Energy Project Analysis: RETScreen Engineering \& Cases Textbook (pp. GSHP 1-70). Ottawa: Minister of Natural Resources Canada.

Natural Resources Canada. (2013, November 16). Energy Efficiency Measures - Commercial - Model National Energy Code for Buildings (MNECB). (Government of Canada) Retrieved September 9, 2014, from http://www.retscreen.net/ang/templates_model_national_energy_code_for_buildings.php

Natural Resources Canada. (2014, November 20). EE4. (Government of Canada) Retrieved March 23, 2015, from https://www.nrcan.gc.ca/energy/software-tools/7453

Natural Resources Canada. (2014, December 5). HOT2000. (Government of Canada) Retrieved March 23, 2015, from https://www.nrcan.gc.ca/energy/software-tools/7421

Natural Resources Canada Office of Energy Efficiency \& CANMET Technology Centre. (2008). EE4 Software Version 1.7 Modelling Guide. Ottawa: Natural Resources Canada.

Natural Resources Canada Office of Energy Efficiency. (2012). Survey of Commercial and Institutional Energy Use - Buildings 2009: Detailed Statistical Report. Ottawa: Natural Resources Canada.

Nigusse, B., Sharma, C., Raustad, R., \& Cummings, J. (2013). Technical Subtopic 2.1:Modeling Variable Refrigerant Flow Heat Pump and Heat Recovery Equipment in EnergyPlus: Task 9.0 - Parametric Analysis using the EnergyPlus VRF AC System Model. Cocoa, FL.: FLorida Solar Energy Center.

Oliva, R. (2003). Model Calibration as a esting Strategy for System Dynamics Models. European Journal of Operational Research(151), 552-5568.

Omnisense LLC. (2015). Top Wireless Sensors S-900-1 Wireless T, \%RH, WME Sensor. (Omnisense LLC) Retrieved March 23, 2015, from http://shop.omnisense.com/p/53/s-900-1-wireless-t-rh-wme-sensor

O'Neill, Z., \& Eisenhower, B. (2013). Leveraging the analysis of parametric uncertainty for building energy calibration. Building Simulation, 6(4), 365-377.

O'Neill, Z., Eisenhower, B., Yuan, S., Bailey, T., Narayanan, S., \& Fonoberov, V. (2011). Modeling and Calibration of Energy Models for a DoD Building. ASHRAE Transactions, 358-365.

Ontario Energy Board. (2015, January 1). Natural Gas Rate Updates. (Ontario Energy Board) Retrieved February 26, 2015, from

http://www.ontarioenergyboard.ca/OEB/Consumers/Natural+Gas/Natural+Gas+Rates

Pan, Y., Huang, Z., Wu, G., \& Chen, C. (2006). The application of building energy simulation and calibration in two high-rise commercial buildings in Shanghai. Second National IBPSA-USA Conference. Cambridge, MA.

Pathak, M. (2015, March 27). Energy Modelling Programs to Meet Building Codes.

Pathak, M. (2015, March 3). Superior Propane Price for 2013.

Peretti, C., Zarrella, A., De Carli, M., \& Zecchin, R. (2013). The design and environmental evaluation of earth-to-air heat exchangers (EAHE). A literature review. Renewable and Sustainble Energy Reviews(28), 107-116. 
Persily, A. K. (1998). Airtightness of Commercial Buildings: Blowing Holes in the Myth of Tight Buildings. ASHRAE Thermal Envelopes VII - Airtightness and Airflow in Buildings. Clearwater, FL.

Raferty, P., Keane, M., \& Costa, A. (2009). Calibration of a Detailed Simulation Model to Energy Monitoring System Data: A Methodology and Case Study. Eleventh International IBPSA Conference. Glasgow, Scotland.

Raferty, P., Keane, M., \& O'Donnell, J. (2011). Calibrating whole building energy models: An evidence based methodology. Energy and Buildings(43), 2356-2364.

Raustad, R. (2012). Creating Performance Curves for Variable Refrigerant Flow Heat Pumps in EnergyPlus. Cocoa: Florida Solar Energy Center.

Raustad, R., Nigusse, B., Sharma, C., Cummings, J., \& Domitrovic, R. (2013). Technical Subtopic 2.1: Modeling Variable Refrigerant Flow Heat Pump and Heat Recovery Equipment in EnergyPlus. Cocoa, FL.: Florida Solar Energy Center.

Reale, G. (2013). UTRCA Energy Modelling. MMM Group Limited.

Reddy, T. A. (2006). Literature Review on Calibration of Building Energy Simulation Programs: Uses, Problems, Procedures, Uncertainty, and Tools. ProQuest Science Jounrals: ASHRAE Transactions(112), 226-240.

Reddy, T. A., Maor, I., \& Panjapornpon, C. (2007). Calibrating Detailed Building Energy Simulation Programs with Measured Data. ASHRAE: HVAC\&R Research, 13(2), 221-241.

Roth, K. W. (2002). Energy Consumption Characteristics of Commercial Building HVAC Systems III: Energy Savings Potential. Springfield, VA: National Technical Information Service - US Department of Commerce.

saveONenergy. (2014). High Performance New Construction. (Ontario Power Authority) Retrieved September 12, 2014, from https://saveonenergy.ca/Business/Program-Overviews/NewConstruction.aspx

Shim, G., Song, L., \& Wang, G. (2014). Comparison of different fan control strategies on a variable air volume system through simulations and experiments. Building and Environment(72), 212-222.

Southard, L., Liu, X., \& Spitler, J. (2014, Sepetember). Performance of HVAC Systems at ASHRAE HQ, Part 1. ASHRAE Journal, 56(9).

Thornton, B., \& Wagner, A. (2012). Variable Refrigerant Flow Systems. Richland, WA: Pacific Northwest National Laboratory.

Trane. (2015, February). Scroll Chiller Model CGAM. Retrieved March 1, 2015, from http://www.trane.com/content/dam/Trane/Commercial/global/products-

systems/equipment/chillers/air-cooled/CG-PRC017H-EN_02232015.pdf

U.S. Department of Energy: Energy Efficiency and Renewable Energy. (2007). Thermal Management of White LEDs. U.S. Department of Energy: Energy Efficiency and Renewable Energy: Washington, DC.

U.S. Energy Information Admisitration. Carbon Dioxide Emissions Coefficients. (U.S. Energy Information Admisitration) Retrieved February 27, 2015, from

http://www.eia.gov/environment/emissions/co2_vol_mass.cfm

United States Environmental Protection Agency. Overview of Greenhouse Gases. (United States

Environmental Protection Agency) Retrieved February 27, 2015, from

http://www.epa.gov/climatechange/ghgemissions/gases/co2.html 
Upper Thames River Conservation Authority. (2012). UTRCA Watershed Conservation Centre. (Upper Thames River Conservation Authority) Retrieved 2013 йил March from http://www.thamesriver.on.ca/About_Us/wcc.htm

Upper Thames River Conservation Authority. Energy \& Atmosphere. (Upper Thames River Conservation Authority) Retrieved March 27, 2015, from http://thamesriver.on.ca/watershed-conservationcentre/energy-and-atmosphere/

Upper Thames River Conservation Authority. Watershed Conservation Centre. (Upper Thames River Conservation Authority) Retrieved March 24, 2015, from http://thamesriver.on.ca/watershedconservation-centre/

US Department of Energy. (2014). Engineering Reference. Orlando: US Department of Energy.

US Department of Energy. (2014). Input Output Reference. Orlando: US Department of Energy.

US Department of Energy. (2015, February 12). EnergyPlus Enery Simulation Software. (Energy Efficiency \& Renewable Energy: Energy Efficiency \& Renewable Energy) Retrieved March 23, 2015, from http://apps1.eere.energy.gov/buildings/energyplus/

Vanderwesten Rutherford Mantecon Inc. (2010, July 13). M600. Piping and H.V.A.C. Schematic. London, Ontario, Canada: Vanderwesten Rutherford Mantecon Inc.

Venmar CES Ind. (2011). Submittal Documents. St-Leonard-d'Aston, QC: Venmar CES Inc.

Wang et al., X. (2009). Modeling and Experiment Analysis of Variable Refrigerant Flow Air-conditioning Systems. Elevanth International IBPSA Conference. Glasgow, Scotland.

Weather Analytics. (2014). FAQ. (Weatehr Analytics) Retrieved August 13, 2014, from http://www.weatheranalytics.com/wa/company/faq/

Weather Analytics. (2015). How We Do It. (Weather Analytics) Retrieved February 17, 2015, from http://www.weatheranalytics.com/wa/company/how-we-do-it/

Wilson, R. R. (2010). Building Elements - A051. London, ON: Randy Wilson Architect Incorporated.

Witte, M. J., Henninger, R. H., \& Glazer, J. (2001). Testing and Validation of a New Building Energy Simulation Program. Seventh International IBPSA Conference. Rio de Janeiro.

Zhou, Y., Wu, J., Wang, R., \& Shiochi, S. (2007). Energy simulation in the variable refrigerant flow airconditioning system under cooling conditions. Energy and Buildings, 39(2), 212-220.

Zhou, Y., Wu, J., Wang, R., Shiochi, S., \& Li, Y. (2008). Simulation and experimental validation of the variable-refrigerant-volume (VRV) air-conditioning system in EnergyPlus. Energy and Buildings, 40(6), 1041-1047.

Zirnhelt, H. (2013). Using calibrated simulation to quantify the energy savings from residential passive solar design in Canada. Toronto, Canada. 
APPENDIX A: CASE STUDY BUILDING PICTURES 
The following pictures of the case study building, Upper Thames River Conservation Authority Watershed Conservation Centre, are from the building's website (Upper Thames River Conservation Authority).
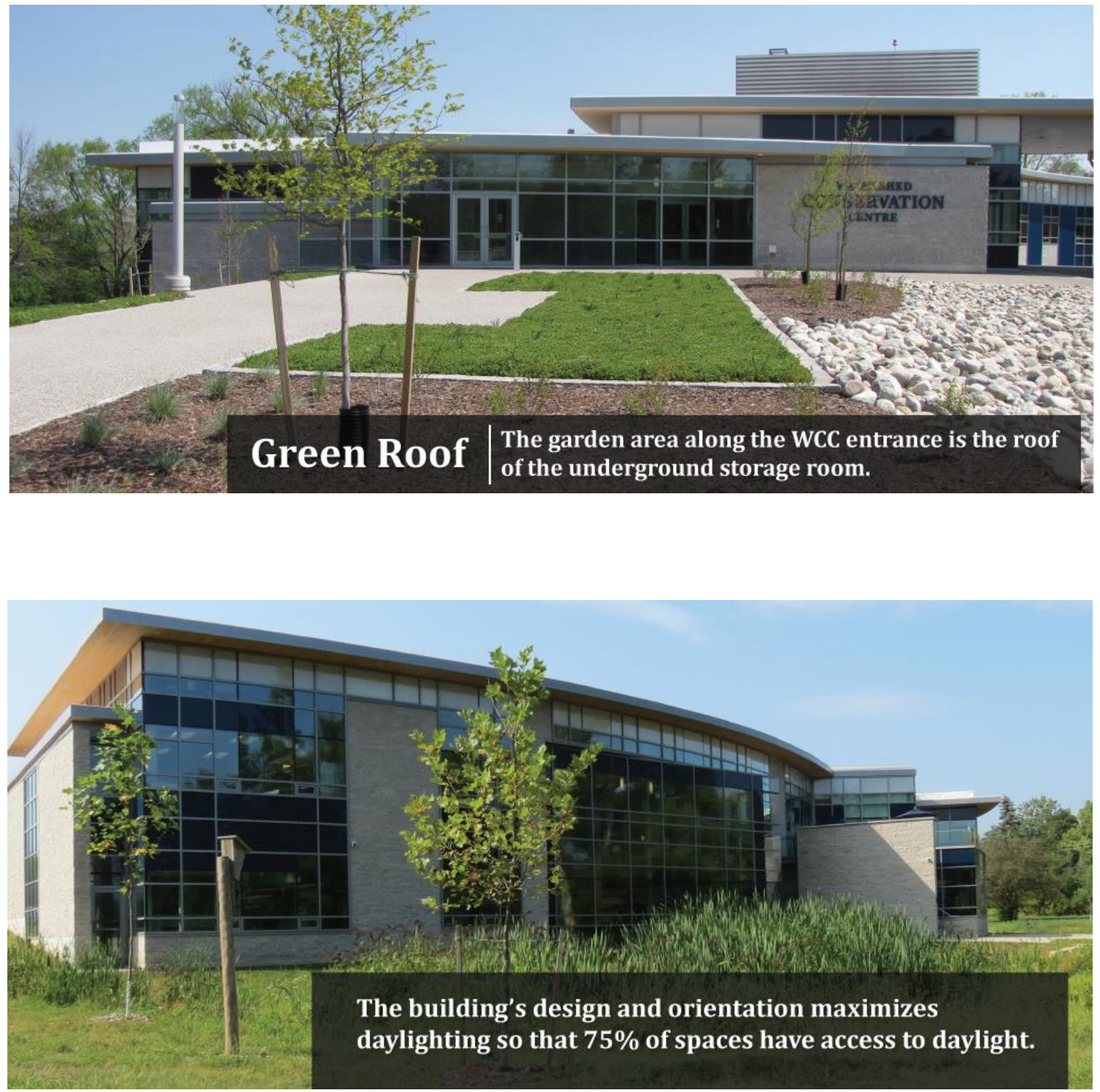

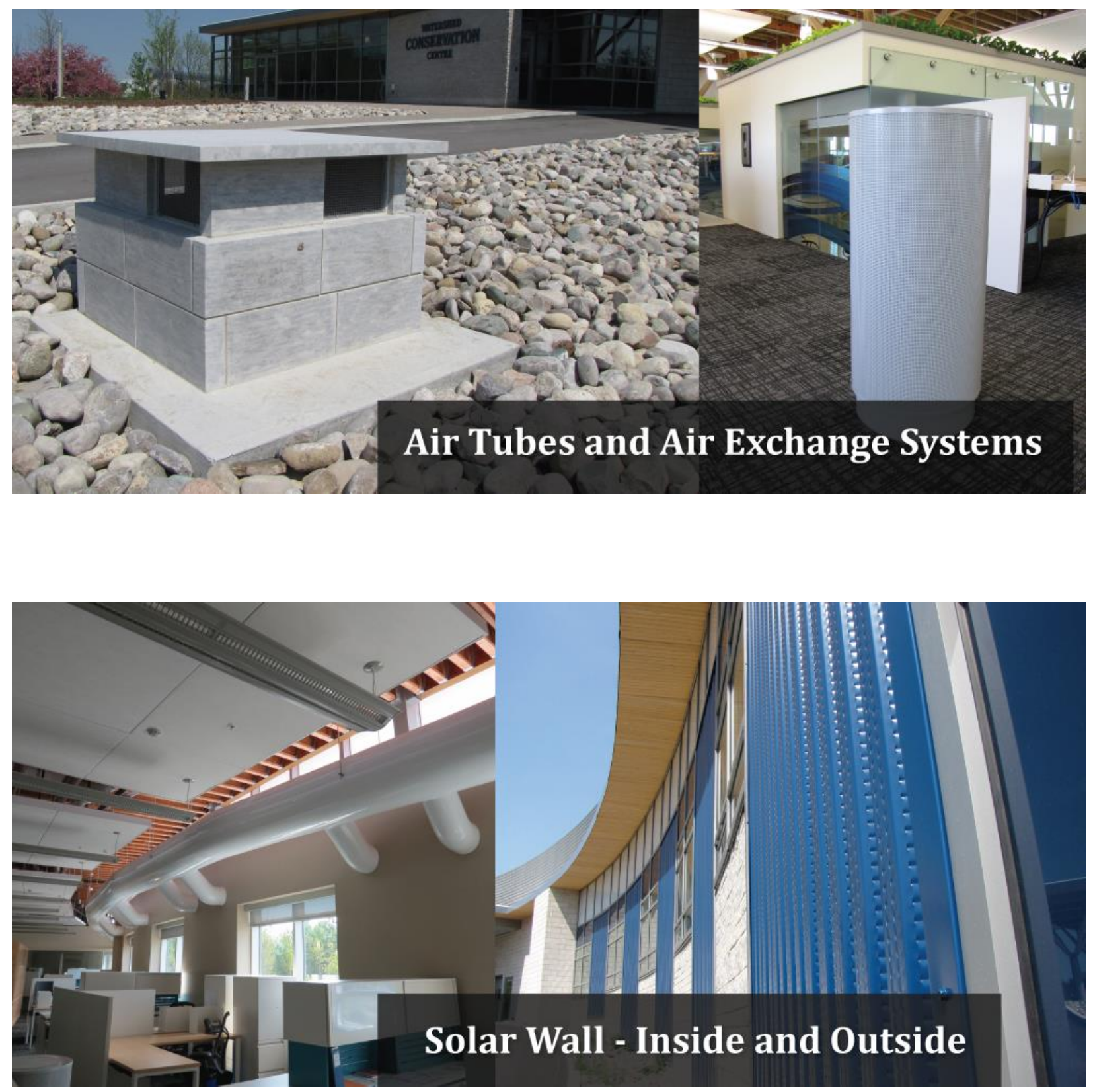
APPENDIX B: BUILDING WALKTHROUGH AUDIT 
Below is a list of information compiled through a few site visit to the case study building along with continuous correspondence with the building manager and system installer.

- $\quad$ There are 5 VRF outdoor units that serve the conditioning of the building

- A separate VRF outdoor unit serves the DOAS.

- DOAS supply \& exhaust fans are operated by VFD's controlled by the Johnson BAS to maintain the airflow necessary to satisfy the $\mathrm{CO}_{2}$ sensors located throughout the building. The air volume is controlled by VAV terminal dampers that modulate to maintain the $\mathrm{CO}_{2}$ setpoint in each area. Pressure controls measure the duct static, and adjust the fan VFD to maintain a setpoint. Flow measuring stations report the actual air volume in the supply and exhaust and display the air volume on the BAS front end. Ventilation air is dispersed through high volume - low velocity air diffusers

- SolarWall pre-treats air during winter months. Trending data not available.

- Earth tube pre-treats air all year - 50\% during winter, $100 \%$ rest of the year. Trending data not available.

- No major changes were done during construction -> architectural and design drawings are a very good representation what was constructed/installed.

- All rooms in correct locations as identified on the plans.

- All doors are installed as identified on the plans.

- Windows are installed as identified on the plans.

- Summer Months (generally May to October) FCU set points are 24C starting at 5 AM setting back to $28 \mathrm{C}$ at 6 PM Monday to Friday and remain at 28C for Saturday and Sunday.

- Winter Months (generally November to April) FCU set points are 23C starting at 5 AM setting back to $15 \mathrm{C}$ at 6 PM Monday to Friday and remain at $15 \mathrm{C}$ for Saturday and Sunday. A few units along north face wall at set to come on at 4 AM (FC-1-1, FC-1-4, FC-1-5)

- There is a $3 \mathrm{C}$ deadband $-1.5 \mathrm{C}$ above and below the temperature setpoint. However this is only applicable to FCUs that are programmed to "auto" I have many of the units programmed to "heat on" or "cool on" only. For example in the winter if the set point is 23 and the temperature rises to $25 \mathrm{C}$ in an office the AC will not come on. Staff prefer not to have cool air blowing on them in the winter or warm air in the summer. The FCUs can change settings 2 to 3 times per year. During the winter months the following FCUs are usually set to the "heat only" setting: FC-1-1, FC-1-2, FC-1-3, FC-1-4, FC-1-7a, FC-1-7b, FC-1-9, FC-2-1, FC-2-2, FC-2-3, FC-2-4, FC-2-5, FC-2-6, FC-2-7, FC-2-8, FC-3-1, FC3-2, FC-3-3, FC-3-4, FC-3-5, FC-3-6, FC-3-7, FC-3-8, FC-3-9, FC-3-10, FC-4-1, FC-4-2, FC-4-3, FC-4-5, 
FC-4-6, FC-4-7, FC-4-8, FC-4-9, FC-5-1a, FC-5-1b. These units will probably be set to the "cool only" setting in the summer. During the winter/summer months the following units are set to the "auto on" setting: FC-1-5, FC-1-6a, FC-1-6b, FC1-8a, FC-1-8b, FC-1-10, FC-2-11, FC-2-12, FC-3-11a, FC-3-11b, FC-3-12, FC-3-13, FC-4-4a, FC-4-4b, FC-4-4c, FC-4-4,d, FC-4-4e, FC-4-10a, FC-4-10b, FC-4-10c.

- The changeover is usually done gradually over a period of time and is even different from floor to floor. Each season shoulder period is also different from year-to-year. The AG150 allows for 5 different schedules but I have stayed with one and make small adjustments weekly.

- Meeting rooms (11) remain off unless someone turns them on. Some days all meeting rooms are in use and other days only a few. Best guess would be 3 small meeting rooms used daily on average and boardroom used 3-4 times per week. Employees turn the units on when required but haven't got into the habit of turning them off when meeting is over

- Some (22) of the indoor terminal units that are equipped with electric duct heaters controlled by the Mitsubishi indoor units. If the setpoint cannot be maintained by the heat pump and temperature in the space drops approximately 1.8 degrees $F$ below the setpoint, the auxiliary heat output is turned on and the electric heater operates. This heater control was originally disabled until the outdoor temperature reached design conditions, but late last winter we removed the heater lockout to allow the heater to operate at warmer outdoor temperatures. The electric coils are usually enabled at $-18^{\circ} \mathrm{C}$. This was changed to $-10^{\circ} \mathrm{C}$ during very cold spells.

- Baseboard heaters are located at east end of building one on each floor custodial rooms (never turn them on) and one on upper floor east end hallway leading to exit stairs (on only when extremely cold) Electric heaters ( 3 - located at both east end exit doors and mudroom staff door) and turn on partially during winter months as the stairwell air can be cold some-days....all have built-in thermostats).

- Hot water circulation pumps are all in the mechanical room, and only operate when there is a call for hot water. There is a small recirculation pump on the domestic loop. Electric water heaters (one small at each end of building to supply hot water to the 3 custodial rooms. Energy consumption data for domestic hot water is not yet available.

- There is some incorrect tagging on the electrical panels. Some of the electric duct coils were missing. $B C-1, B B C-2, B C-3, B C-4$ refer to the indoor terminal units associated with those $B C$ controllers and outdoor units. Johnson numbers relate to Johnson Controls which is separate from the FCUs. The control \#s are marked on the circuits as a reminder to me not to turn off these three 
circuits. The controls are wired into the same circuits...not deliberately. Additional controls energy consumption tied to Panel HD.

- $\quad$ MMM Group (Enermodal) did the air balancing testing and report.

- Daylighting sensors are installed but difficult to manage especially in the winter when the sun is low and there is snow on the ground.

- Lighting consumption is higher than expected. Measures are being taken to reduce the amount of lighting being used through scheduling and controls issues. Most of the lighting is on occupancy sensors.

- Hydroelectric dam on the river next to the building produces the electricity to run the building.

- Heat recovery wheel in the makeup air unit.

- Thermostats are located throughout the building to allow the employees to adjust the temperatures accordingly.

- The bunker roof is a "green roof" - actually grass and garden next to the entrance way

- HVAC equipment was so quiet that white noise makers had to be installed.

- All wastewater is treated on-site with a septic tank and Waterloo Biofilter. 
APPENDIX C: EXTERIOR WALL ELEVATIONS 
The following excerpts were taken from the Architectural Drawing A300.

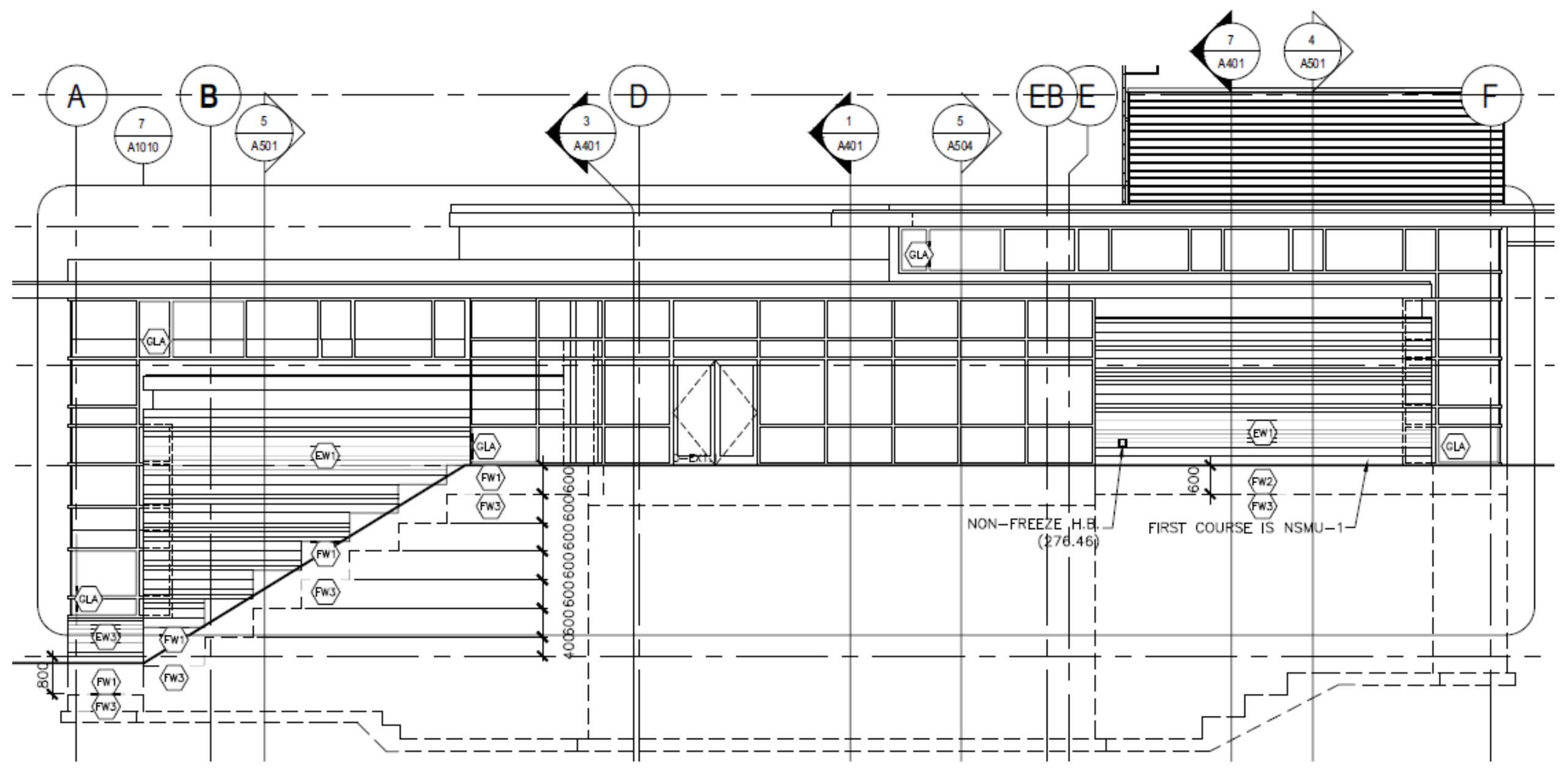

Exterior Wall Assemblies - West Wall 


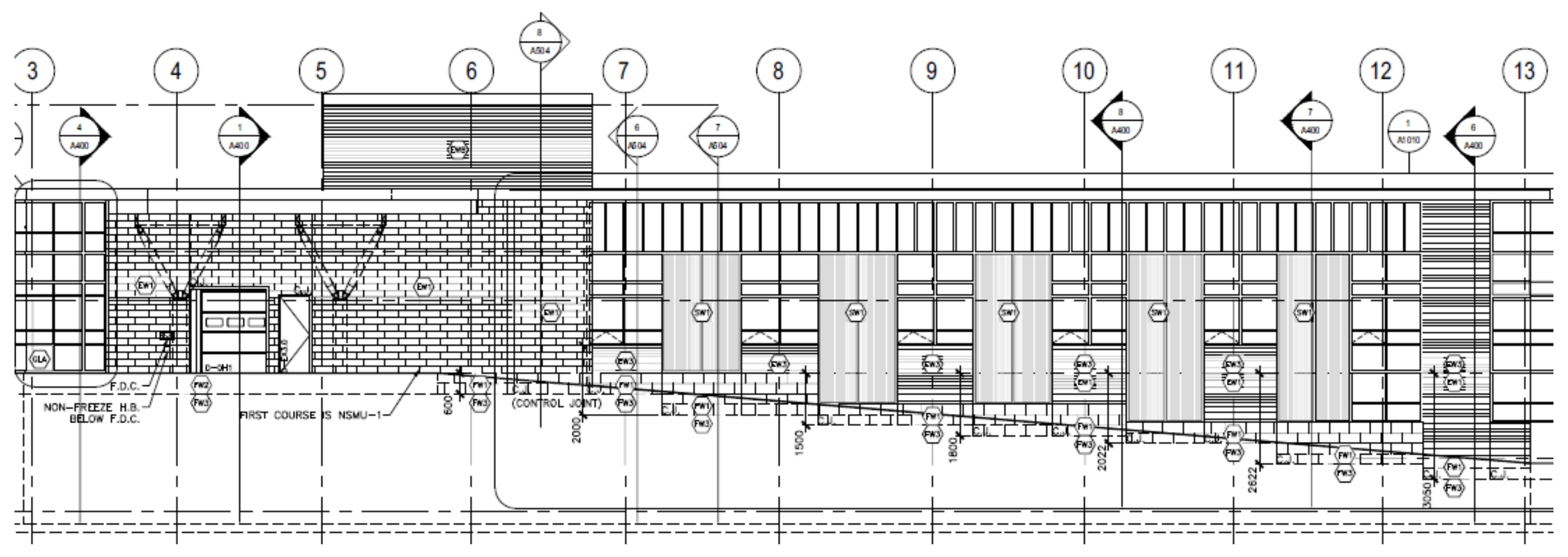

Exterior Wall Assemblies - South Wall 


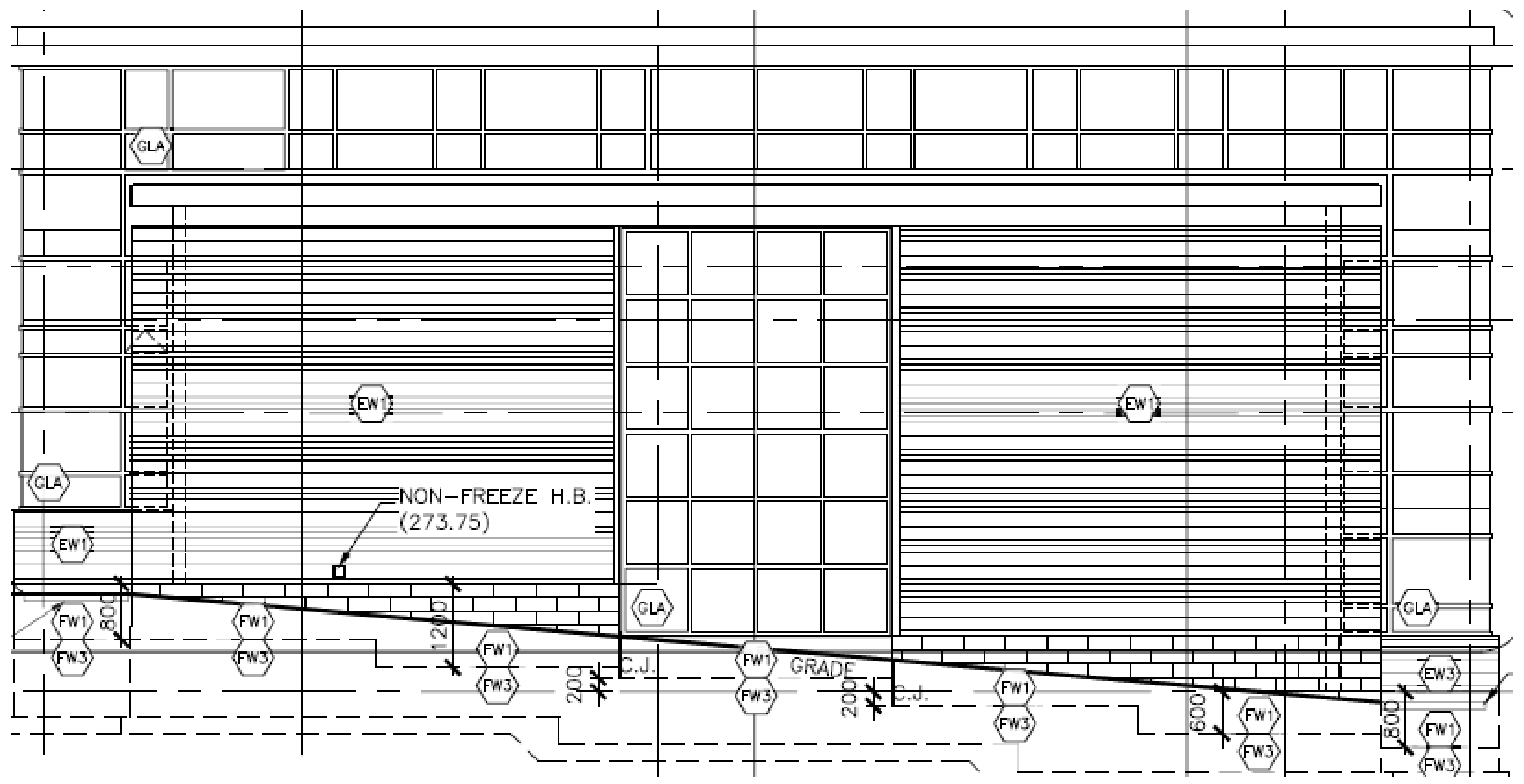

Exterior Wall Assemblies - East Wall 


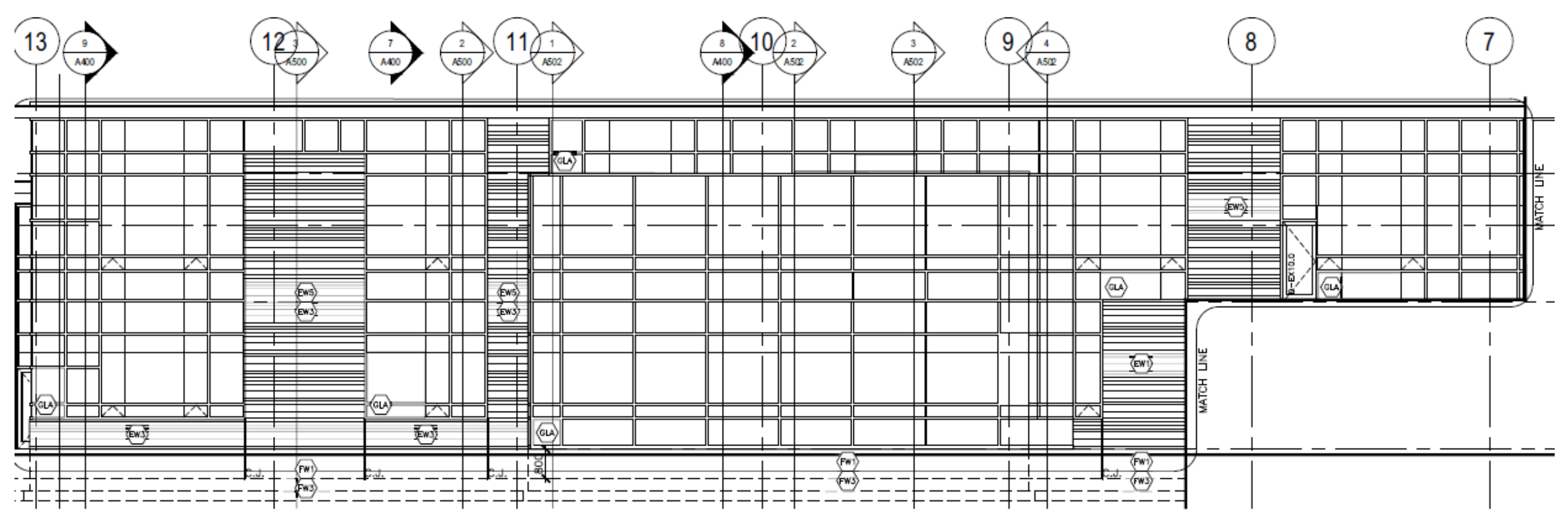

Exterior Wall Assemblies - North-East Wall 


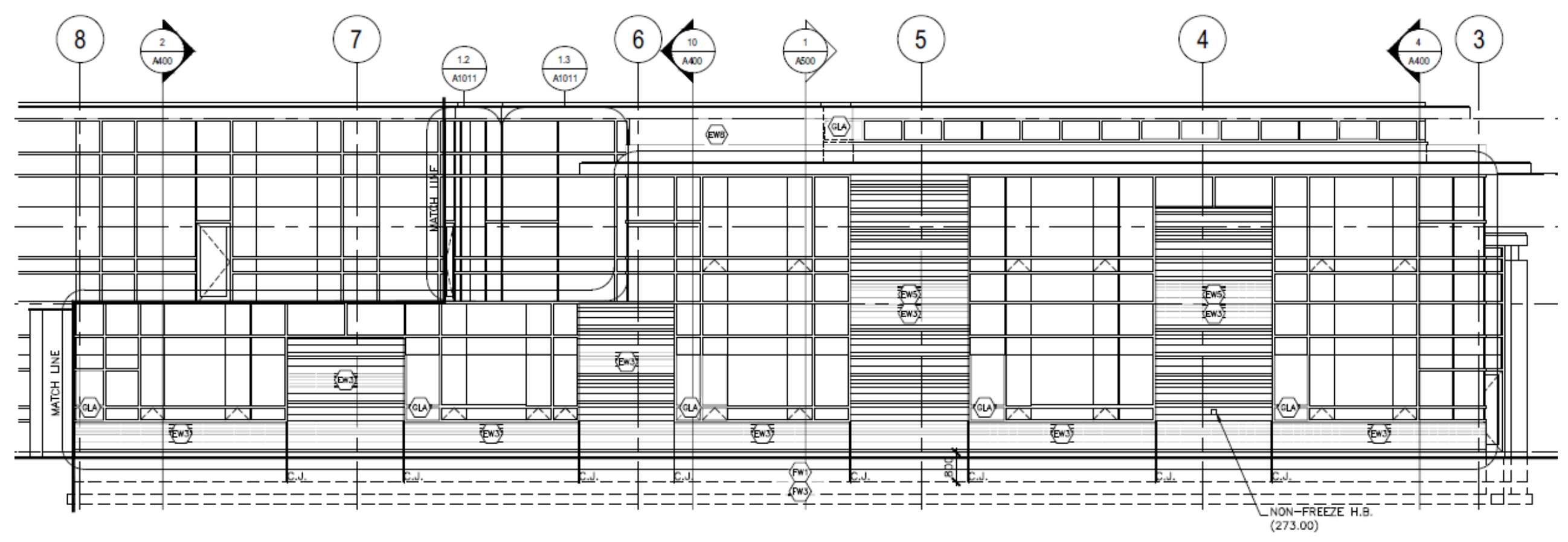

Exterior Wall Assemblies - North-West Wall 
APPENDIX D: WINDOW ELEVATIONS 
The following excerpts were taken from the Architectural Drawings A1010 and A1011.

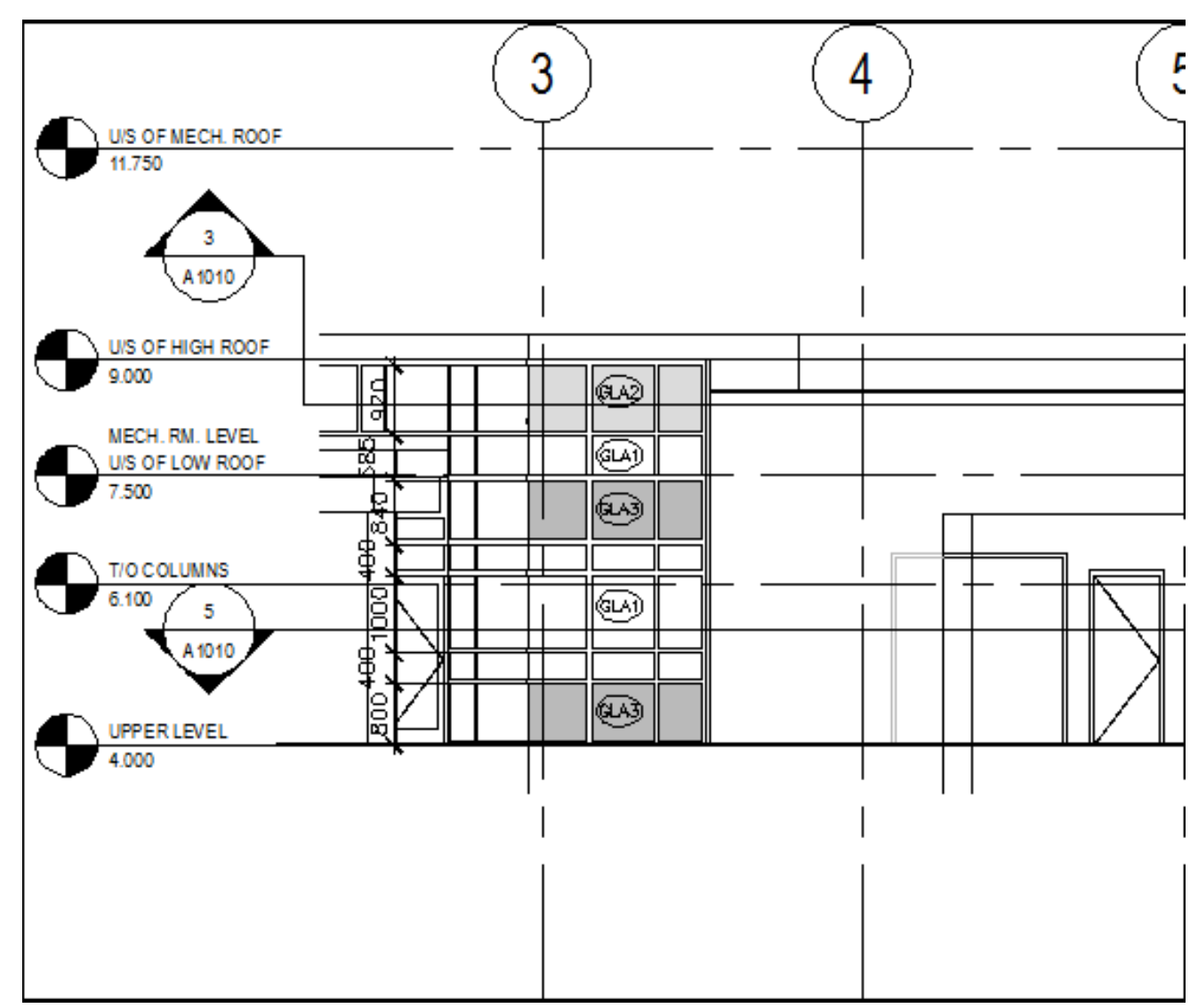

Exterior Window Assemblies - South-West Wall 


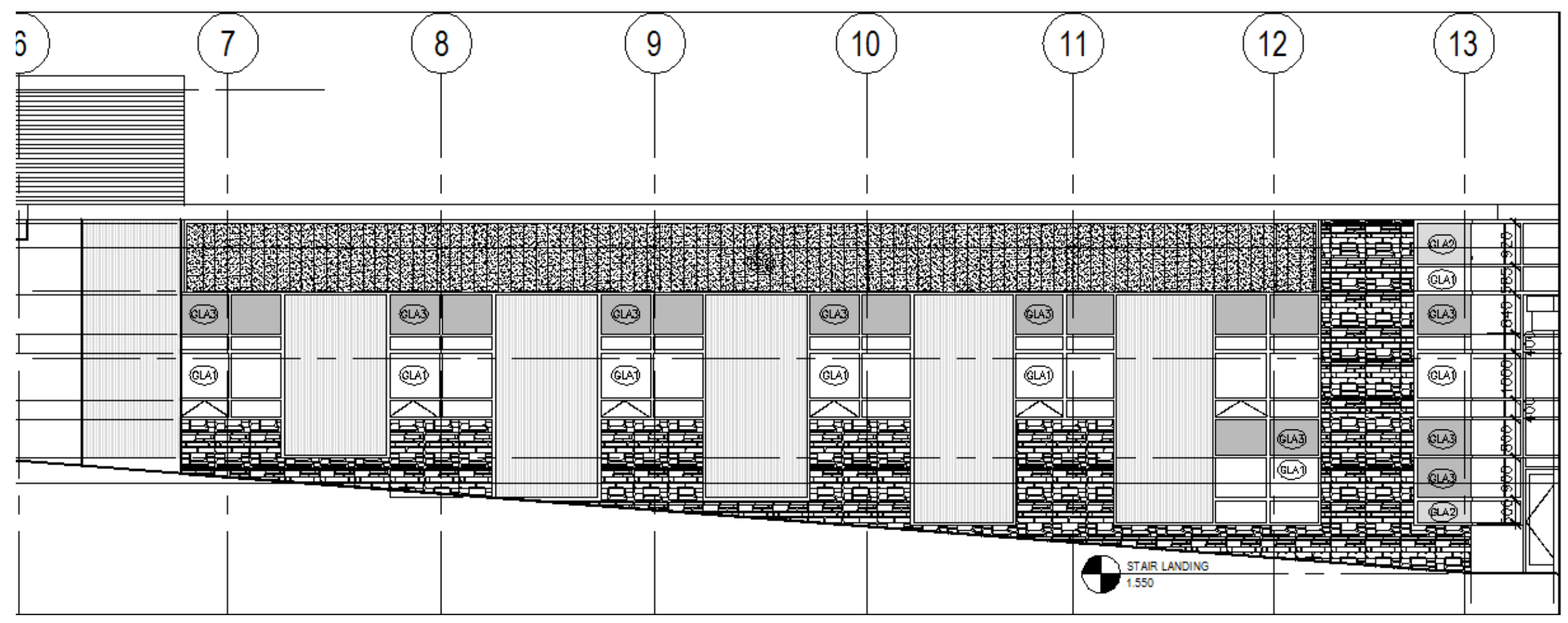

Exterior Window Assemblies - South-East Wall 


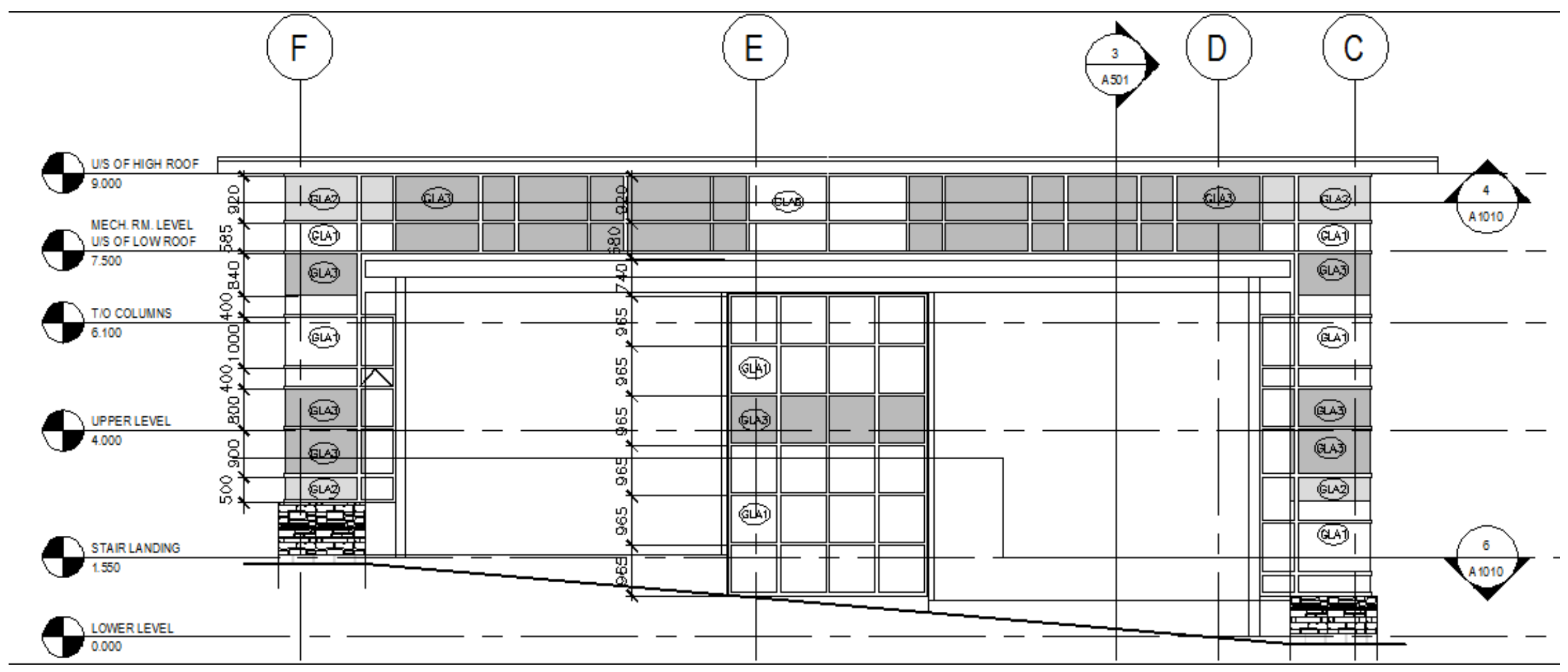

Exterior Window Assemblies - East Wall 


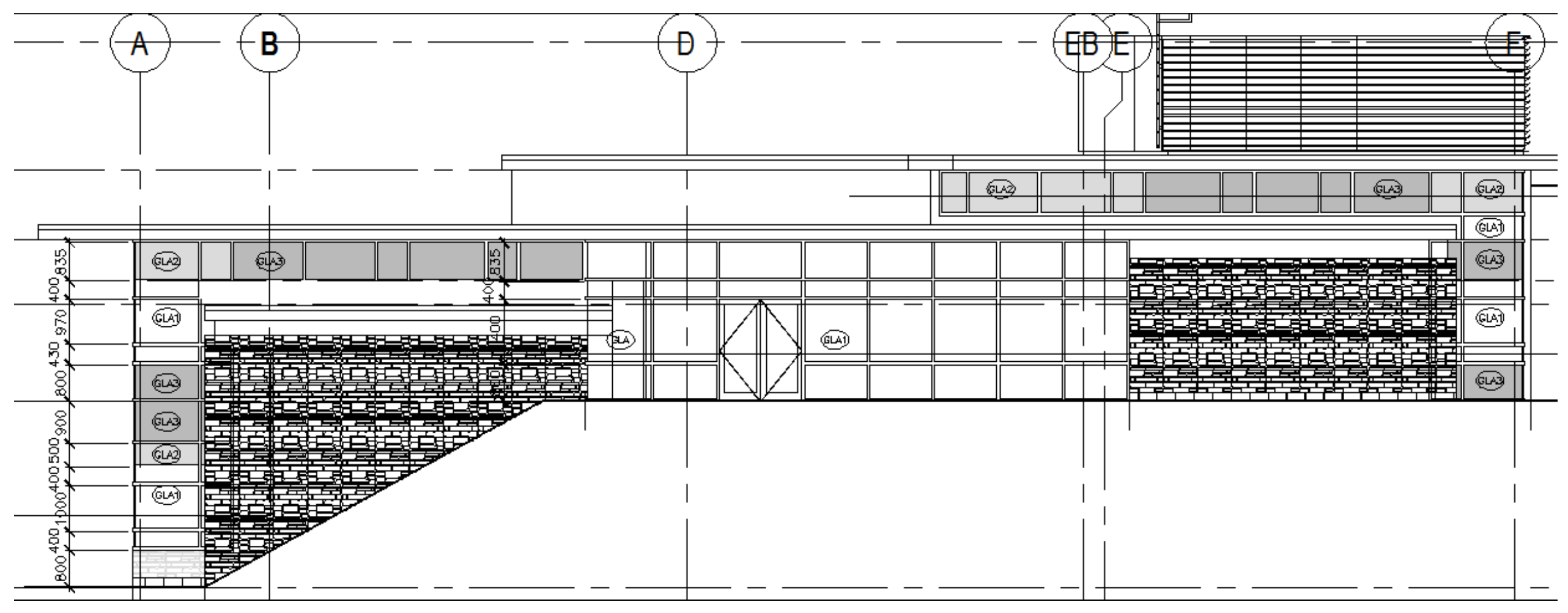

Exterior Window Assemblies - West Wall 


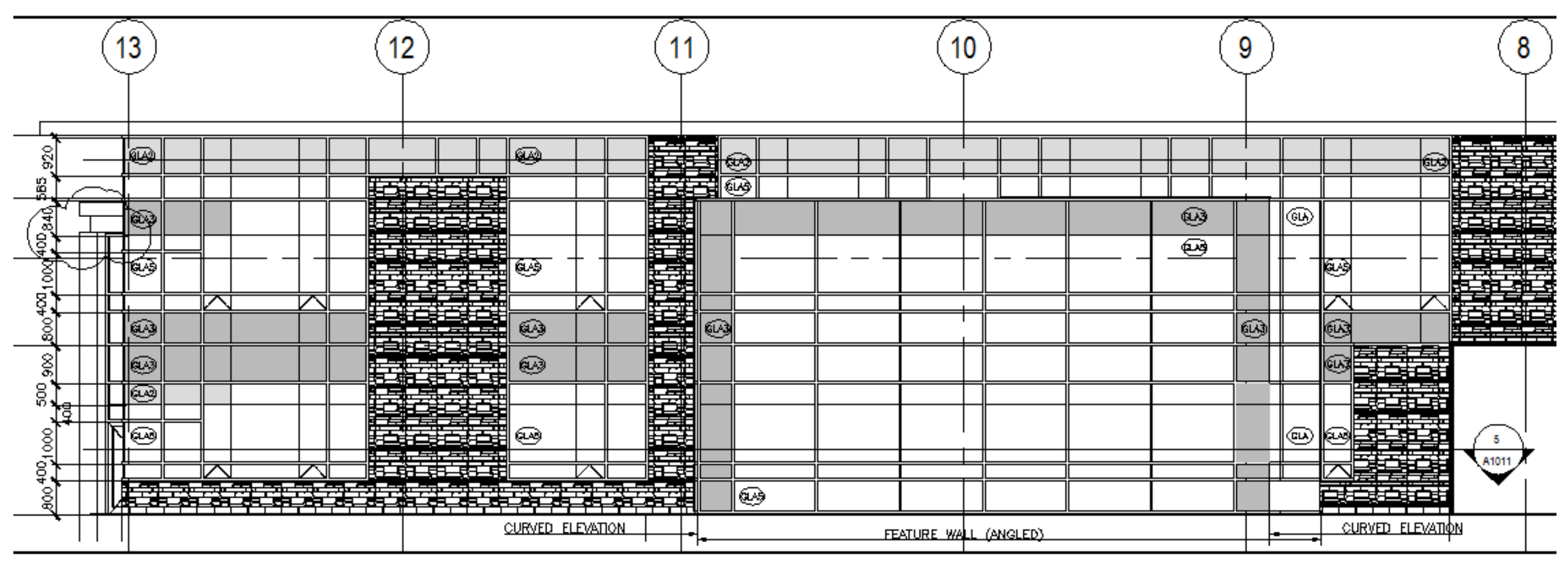

Exterior Window Assemblies - North-East Wall 


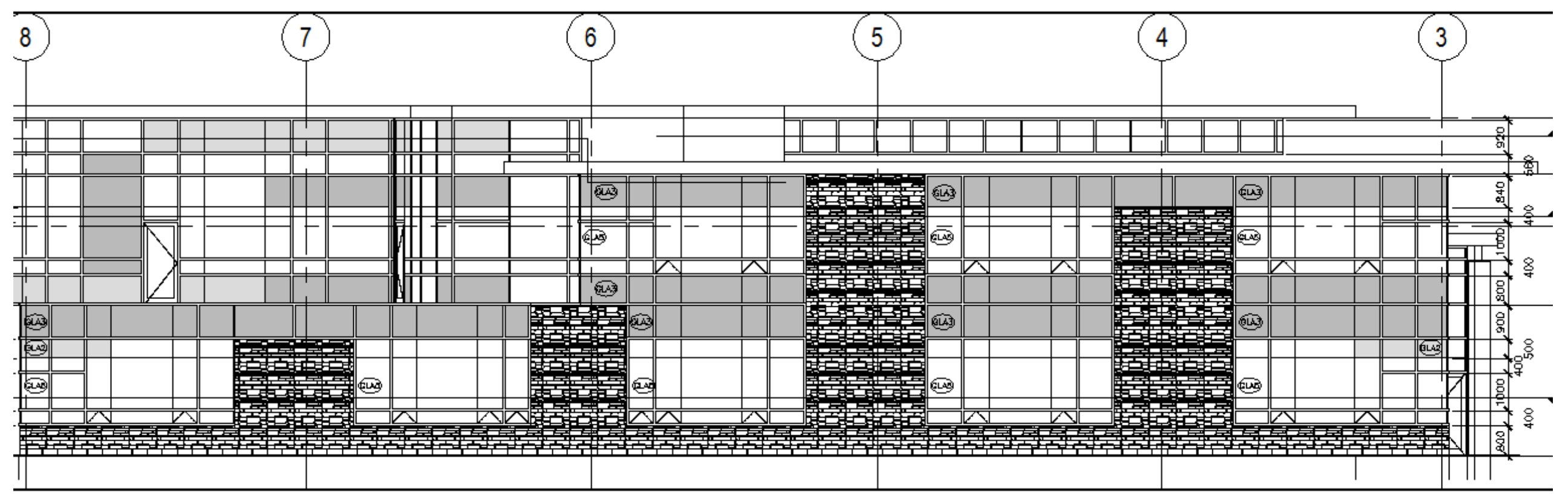

Exterior Window Assemblies - North-West Wall 
APPENDIX E: MNECB OPERATING SCHEDULE A 
Table 4.3.2.C. Operating Schedule ' $A$ '

\begin{tabular}{|c|c|c|c|c|c|c|c|c|c|c|c|c|c|c|c|c|c|c|c|c|c|c|c|c|}
\hline & $1 \mathrm{a}$ & $2 a$ & $3 a$ & $4 a$ & $5 a$ & $6 a$ & $7 \mathrm{a}$ & $8 a$ & $9 a$ & $10 a$ & 11a & 12 & $1 p$ & $2 p$ & $3 p$ & $4 p$ & $5 p$ & $6 p$ & $7 p$ & $8 p$ & $9 p$ & 10p & $11 p$ & 12 \\
\hline \multicolumn{25}{|c|}{ Occupants } \\
\hline Mon - Fri & 0 & 0 & 0 & 0 & 0 & 0 & 0.1 & 0.7 & 0.9 & 0.9 & \begin{tabular}{|l|}
0.9 \\
\end{tabular} & 0.5 & 0.5 & \begin{tabular}{|l|}
0.9 \\
\end{tabular} & \begin{tabular}{|l|}
0.9 \\
\end{tabular} & 0.9 & \begin{tabular}{|l|}
0.7 \\
\end{tabular} & 0.3 & 0.1 & \begin{tabular}{|l|}
0.1 \\
\end{tabular} & \begin{tabular}{|l|}
0.1 \\
\end{tabular} & \begin{tabular}{|l|}
0.1 \\
\end{tabular} & 0 & 0 \\
\hline Sat & 0 & 0 & 0 & 0 & 0 & 0 & 0 & 0 & 0 & 0 & 0 & 0 & 0 & 0 & 0 & 0 & 0 & 0 & 0 & 0 & 0 & 0 & 0 & 0 \\
\hline Sun & 0 & 0 & 0 & 0 & 0 & 0 & 0 & 0 & 0 & 0 & 0 & 0 & 0 & 0 & 0 & 0 & 0 & 0 & 0 & 0 & 0 & 0 & 0 & 0 \\
\hline \multicolumn{25}{|l|}{ Lighting } \\
\hline Mon - Fri & 0.05 & 0.05 & 0.05 & 0.05 & 0.05 & 0.05 & 0.3 & 0.8 & 0.9 & 0.9 & 0.9 & 0.9 & 0.9 & 0.9 & 0.9 & 0.9 & 0.8 & 0.5 & 0.3 & 0.3 & 0.1 & 0.1 & 0.05 & 0.05 \\
\hline Sat & 0.05 & 0.05 & 0.05 & 0.05 & 0.05 & 0.05 & 0.05 & 0.05 & 0.05 & 0.05 & 0.05 & 0.05 & 0.05 & 0.05 & 0.05 & 0.05 & 0.05 & 0.05 & 0.05 & 0.05 & 0.05 & 0.05 & 0.05 & 0.05 \\
\hline Sun & 0.05 & 0.05 & 0.05 & 0.05 & 0.05 & 0.05 & 0.05 & 0.05 & 0.05 & 0.05 & 0.05 & 0.05 & 0.05 & 0.05 & 0.05 & 0.05 & 0.05 & 0.05 & 0.05 & 0.05 & 0.05 & 0.05 & 0.05 & 0.05 \\
\hline \multicolumn{25}{|c|}{ ( } \\
\hline Mon - Fri & 0.2 & 0.2 & 0.2 & 0.2 & 0.2 & 0.2 & 0.3 & 0.8 & 0.9 & 0.9 & \begin{tabular}{|l|}
0.9 \\
\end{tabular} & \begin{tabular}{|l|}
0.9 \\
\end{tabular} & \begin{tabular}{|l|}
0.9 \\
\end{tabular} & \begin{tabular}{|l|}
0.9 \\
\end{tabular} & \begin{tabular}{|l|}
0.9 \\
\end{tabular} & 0.9 & \begin{tabular}{|l|}
0.9 \\
\end{tabular} & 0.5 & \begin{tabular}{|l|}
0.3 \\
\end{tabular} & \begin{tabular}{|l|}
0.3 \\
\end{tabular} & 0.2 & 0.2 & 0.2 & 0.2 \\
\hline Sat & 0.2 & 0.2 & 0.2 & 0.2 & 0.2 & 0.2 & 0.2 & 0.2 & 0.2 & 0.2 & 0.2 & 0.2 & 0.2 & 0.2 & 0.2 & 0.2 & 0.2 & 0.2 & 0.2 & 0.2 & 0.2 & 0.2 & 0.2 & 0.2 \\
\hline Sun & 0.2 & 0.2 & 0.2 & 0.2 & 0.2 & 0.2 & 0.2 & 0.2 & 0.2 & 0.2 & 0.2 & 0.2 & 0.2 & 0.2 & 0.2 & 0.2 & 0.2 & 0.2 & 0.2 & 0.2 & 0.2 & 0.2 & 0.2 & 0.2 \\
\hline \multicolumn{25}{|l|}{ Fans } \\
\hline Mon - Fri & Off & \begin{tabular}{|l|} 
Off \\
\end{tabular} & Off & \begin{tabular}{|l|} 
Off \\
\end{tabular} & Off & On & On & \begin{tabular}{|l|} 
On \\
\end{tabular} & On & \begin{tabular}{|l|} 
On \\
\end{tabular} & \begin{tabular}{|l|} 
On \\
\end{tabular} & On & On & On & On & On & On & On & On & \begin{tabular}{|l|} 
On \\
\end{tabular} & \begin{tabular}{|l|} 
Off \\
\end{tabular} & \begin{tabular}{|l|} 
Off \\
\end{tabular} & Off & Off \\
\hline Sat & Off & Off & Off & Off & Off & Off & Off & Off & Off & Off & Off & Off & Off & Off & Off & Off & Off & Off & Off & Off & Off & Off & Off & Off \\
\hline Sun & Off & Off & Off & Off & Off & Off & Off & Off & Off & Off & Off & Off & Off & Off & Off & Off & Off & Off & Off & Off & Off & Off & Off & Off \\
\hline \multicolumn{25}{|l|}{ Cooling } \\
\hline Mon - Fri & Off & Off & Off & Off & Off & 24 & 24 & 24 & 24 & 24 & 24 & 24 & 24 & 24 & 24 & 24 & 24 & 24 & 24 & 24 & Off & Off & Off & Off \\
\hline Sat & Off & Off & Off & Off & Off & Off & Off & Off & Off & Off & Off & Off & Off & Off & Off & Off & Off & Off & Off & Off & Off & Off & Off & Off \\
\hline Sun & Off & Off & Off & Off & Off & Off & Off & Off & Off & Off & Off & Off & Off & Off & Off & Off & Off & Off & Off & Off & Off & Off & Off & Off \\
\hline \multicolumn{25}{|l|}{ Heating } \\
\hline Mon - Fri & 18 & 18 & 18 & 18 & 18 & 20 & 22 & 22 & 22 & 22 & 22 & 22 & 22 & 22 & 22 & 22 & 22 & 22 & 22 & 22 & 18 & 18 & 18 & 18 \\
\hline Sat & 18 & 18 & 18 & 18 & 18 & 18 & 18 & 18 & 18 & 18 & 18 & 18 & 18 & 18 & 18 & 18 & 18 & 18 & 18 & 18 & 18 & 18 & 18 & 18 \\
\hline Sun & 18 & 18 & 18 & 18 & 18 & 18 & 18 & 18 & 18 & 18 & 18 & 18 & 18 & 18 & 18 & 18 & 18 & 18 & 18 & 18 & 18 & 18 & 18 & 18 \\
\hline \multicolumn{25}{|l|}{ Hot Water } \\
\hline Mon - Fri & 0.05 & 0.05 & 0.05 & 0.05 & 0.05 & 0.05 & \begin{tabular}{|l|}
0.1 \\
\end{tabular} & 0.5 & 0.5 & \begin{tabular}{|l|}
0.9 \\
\end{tabular} & \begin{tabular}{|l|}
0.9 \\
\end{tabular} & 0.9 & \begin{tabular}{|l|}
0.9 \\
\end{tabular} & \begin{tabular}{|l|}
0.9 \\
\end{tabular} & \begin{tabular}{|l|}
0.9 \\
\end{tabular} & 0.7 & 0.5 & 0.3 & 0.2 & \begin{tabular}{|l|}
0.2 \\
\end{tabular} & \begin{tabular}{|l|}
0.2 \\
\end{tabular} & 0.05 & 0.05 & 0.05 \\
\hline Sat & 0.05 & 0.05 & 0.05 & 0.05 & 0.05 & 0.05 & 0.05 & 0.05 & 0.05 & 0.05 & 0.05 & 0.05 & 0.05 & 0.05 & 0.05 & 0.05 & 0.05 & 0.05 & 0.05 & 0.05 & 0.05 & 0.05 & 0.05 & 0.05 \\
\hline Sun & 0.05 & 0.05 & 0.05 & 0.05 & 0.05 & 0.05 & 0.05 & 0.05 & 0.05 & 0.05 & 0.05 & 0.05 & 0.05 & 0.05 & 0.05 & 0.05 & 0.05 & 0.05 & 0.05 & 0.05 & 0.05 & 0.05 & 0.05 & 0.05 \\
\hline
\end{tabular}


APPENDIX F: MITSUBISHI EQUIPMENT SPECIFICATIONS 
VRF Outdoor Units

\begin{tabular}{|l|l|}
\hline \multicolumn{1}{|c|}{ Tag Number } & \multicolumn{1}{c|}{ Model Number } \\
\hline HPAC-1 & PURY-P168TSHMU-A \\
\hline HPAC-2 & PURY-P240TSHMU-A \\
\hline HPAC-3 & PURY-P240TSHMU-A \\
\hline HPAC-4 & PURY-P168TSHMU-A \\
\hline HPAC-5 & PUHY-HP72THMU-A \\
\hline HPAC-6 & PUHY-HP92THMU-A \\
\hline
\end{tabular}

VRF Indoor Terminal Units

\begin{tabular}{|c|c|c|c|}
\hline Tag Number & Model Number & Tag Number & Model Number \\
\hline FC-1-1 & PEFY-P12NMAUE & FC-3-3 & PEFY-12NMAUE \\
\hline FC-1-2 & PEFY-P08NMAUE & FC-3-4 & PEFY-P15NMAUE \\
\hline FC-1-3 & PEFY-P18NMAUE & FC-3-5 & PEFY-27NMAUE \\
\hline FC-1-4 & PEFY-P12NMAUE & FC-3-6 & PEFY-12NMAUE \\
\hline FC-1-5 & PEFY-P27NMAUE & FC-3-7 & PEFY-P15NMAUE \\
\hline FC-1-6A & PEFY-P08NMAUE & FC-3-8 & PLFY-P18NBMU-E \\
\hline FC-1-6B & PEFY-P08NMAUE & FC-3-9 & PEFY-27NMAUE \\
\hline FC-1-7A & PEFY-P15NMAUE & FC-3-10 & PEFY-P06NMAUE \\
\hline FC-1-7B & PEFY-P06NMAUE & FC-3-11A & PLFY-P12NBMU-E \\
\hline FC-1-8A & PEFY-P24NMAUE & FC-3-11B & PLFY-P12NBMU-E \\
\hline FC-1-8B & PEFY-P24NMAUE & FC-3-12 & PEFY-P30NMAUE \\
\hline FC-1-9 & PEFY-P18NMAUE & FC-3-13 & PKFY-P12NHMU-E \\
\hline FC-1-10 & PEFY-P18NMAUE & FC-4-1 & PEFY-12NMAUE \\
\hline FC-2-1 & PEFY-P48NMAUE & FC-4-2 & PEFY-27NMAUE \\
\hline FC-2-2A & PLFY-P08NCMU-E & FC-4-3 & PEFY-27NMAUE \\
\hline FC-2-2B & PLFY-P08NCMU-E & FC-4-4A & PLFY-P08NCMU-E \\
\hline FC-2-2C & PLFY-P08NCMU-E & FC-4-4B & PLFY-P08NCMU-E \\
\hline FC-2-3 & PEFY-P18NMAUE & FC-4-4C & PLFY-P08NCMU-E \\
\hline FC-2-4 & PEFY-12NMAUE & FC-4-4D & PLFY-P08NCMU-E \\
\hline FC-2-5 & PEFY-P15NMAUE & FC-4-4E & PLFY-P08NCMU-E \\
\hline FC-2-6 & PEFY-P08NMAUE & FC-4-5 & PEFY-P06NMAUE \\
\hline FC-2-7 & PEFY-P12NMAUE & FC-4-6 & PEFY-P15NMAUE \\
\hline FC-2-8 & PEFY-P27NMAUE & FC-4-7 & PEFY-P12NMAUE \\
\hline FC-2-9 & PEFY-P15NMAUE & FC-4-8 & PEFY-P15NMAUE \\
\hline FC-2-10 & PEFY-P08NMAUE & FC-4-9 & PEFY-12NMAUE \\
\hline FC-2-11 & PEFY-P15NMAUE & FC-4-10 & PLFY-P24NBMU-E \\
\hline FC-2-12 & PEFY-P36NMAUE & FC-5-1A & PLFY-P30NBMU-E \\
\hline FC-3-1 & PEFY-P15NMAUE & FC-5-1B & PLFY-P30NBMU-E \\
\hline FC-3-2 & PEFY-P06NMAUE & & \\
\hline
\end{tabular}


APPENDIX G: DEVELOPED MITSUBISHI PERFORMANCE CURVES 


\section{PUHY-HP72THMU-A(-BS) \& PUHY-HP96THMU-A(-BS)}

\begin{tabular}{|c|c|c|c|c|c|c|}
\hline \multicolumn{7}{|c|}{$\begin{aligned} & \text { CAPFT- Low Outdoor Dry-Bulb Temperatures } \\
= & a+b^{*} I W B+c^{*} I W^{\wedge} 2+d^{*} O D B+e^{*} O D B^{\wedge} 2+f^{*} I W B^{*} O D B\end{aligned}$} \\
\hline CCAPFT & IWB & $\mathrm{IWB}^{\wedge} 2$ & ODB & $\mathrm{ODB}^{\wedge} 2$ & IWB*ODB & Predicted \\
\hline 1.243 & 23.9 & 571.21 & -4.46 & 19.8916 & -106.594 & 1.239364 \\
\hline 1.243 & 23.9 & 571.21 & -1.1 & 1.21 & -26.29 & 1.239655 \\
\hline 1.243 & 23.9 & 571.21 & 4.4 & 19.36 & 105.16 & 1.240007 \\
\hline 1.243 & 23.9 & 571.21 & 10 & 100 & 239 & 1.240208 \\
\hline 1.243 & 23.9 & 571.21 & 15.6 & 243.36 & 372.84 & 1.24025 \\
\hline 1.243 & 23.9 & 571.21 & 21.1 & 445.21 & 504.29 & 1.240138 \\
\hline 1.243 & 23.9 & 571.21 & 23 & 529 & 549.7 & 1.240063 \\
\hline 1.178 & 22.2 & 492.84 & -4.46 & 19.8916 & -99.012 & 1.179612 \\
\hline 1.178 & 22.2 & 492.84 & -1.1 & 1.21 & -24.42 & 1.179855 \\
\hline 1.178 & 22.2 & 492.84 & 4.4 & 19.36 & 97.68 & 1.180129 \\
\hline 1.178 & 22.2 & 492.84 & 10 & 100 & 222 & 1.180251 \\
\hline 1.178 & 22.2 & 492.84 & 15.6 & 243.36 & 346.32 & 1.180214 \\
\hline 1.178 & 22.2 & 492.84 & 21.1 & 445.21 & 468.42 & 1.180023 \\
\hline 1.178 & 22.2 & 492.84 & 23.8 & 566.44 & 528.36 & 1.179873 \\
\hline 1.115 & 20.6 & 424.36 & -4.46 & 19.8916 & -91.876 & 1.120194 \\
\hline 1.115 & 20.6 & 424.36 & -1.1 & 1.21 & -22.66 & 1.120392 \\
\hline 1.115 & 20.6 & 424.36 & 4.4 & 19.36 & 90.64 & 1.120593 \\
\hline 1.115 & 20.6 & 424.36 & 10 & 100 & 206 & 1.12064 \\
\hline 1.115 & 20.6 & 424.36 & 15.6 & 243.36 & 321.36 & 1.120528 \\
\hline 1.115 & 20.6 & 424.36 & 21.1 & 445.21 & 434.66 & 1.120263 \\
\hline 1.115 & 20.6 & 424.36 & 24 & 576 & 494.4 & 1.120062 \\
\hline 1.074 & 19.4 & 376.36 & -4.46 & 19.8916 & -86.524 & 1.073607 \\
\hline 1.074 & 19.4 & 376.36 & -1.1 & 1.21 & -21.34 & 1.073771 \\
\hline 1.074 & 19.4 & 376.36 & 4.4 & 19.36 & 85.36 & 1.073916 \\
\hline 1.074 & 19.4 & 376.36 & 10 & 100 & 194 & 1.073907 \\
\hline 1.074 & 19.4 & 376.36 & 15.6 & 243.36 & 302.64 & 1.073739 \\
\hline 1.074 & 19.4 & 376.36 & 21.1 & 445.21 & 409.34 & 1.073419 \\
\hline 1.074 & 19.4 & 376.36 & 24.7 & 610.09 & 479.18 & 1.073127 \\
\hline 1.01 & 17.8 & 316.84 & -4.46 & 19.8916 & -79.388 & 1.00879 \\
\hline 1.01 & 17.8 & 316.84 & -1.1 & 1.21 & -19.58 & 1.00891 \\
\hline 1.01 & 17.8 & 316.84 & 4.4 & 19.36 & 78.32 & 1.008982 \\
\hline 1.01 & 17.8 & 316.84 & 10 & 100 & 178 & 1.008897 \\
\hline 1.01 & 17.8 & 316.84 & 15.6 & 243.36 & 277.68 & 1.008655 \\
\hline 1.01 & 17.8 & 316.84 & 21.1 & 445.21 & 375.58 & 1.008261 \\
\hline 1.01 & 17.8 & 316.84 & 25.7 & 660.49 & 457.46 & 1.007815 \\
\hline 0.947 & 16.1 & 259.21 & -4.46 & 19.8916 & -71.806 & 0.936543 \\
\hline 0.947 & 16.1 & 259.21 & -1.1 & 1.21 & -17.71 & 0.936615 \\
\hline 0.947 & 16.1 & 259.21 & 4.4 & 19.36 & 70.84 & 0.936609 \\
\hline 0.947 & 16.1 & 259.21 & 10 & 100 & 161 & 0.936445 \\
\hline
\end{tabular}




\begin{tabular}{|r|r|r|r|r|r|r|}
\hline 0.947 & 16.1 & 259.21 & 15.6 & 243.36 & 251.16 & 0.936123 \\
\hline 0.947 & 16.1 & 259.21 & 21.1 & 445.21 & 339.71 & 0.935651 \\
\hline 0.947 & 16.1 & 259.21 & 26.4 & 696.96 & 425.04 & 0.935052 \\
\hline 0.88 & 15 & 225 & -4.46 & 19.8916 & -66.9 & 0.88794 \\
0.88 & 15 & 225 & -1.1 & 1.21 & -16.5 & 0.88798 \\
\hline 0.88 & 15 & 225 & 4.4 & 19.36 & 66 & 0.887924 \\
0.88 & 15 & 225 & 10 & 100 & 150 & 0.887708 \\
\hline 0.88 & 15 & 225 & 15.6 & 243.36 & 234 & 0.887335 \\
0.88 & 15 & 225 & 21.1 & 445.21 & 316.5 & 0.886813 \\
0.88 & 15 & 225 & 26.7 & 712.89 & 400.5 & 0.886124 \\
0.88 & 15 & 225 & 27.4 & 750.76 & 411 & 0.886027 \\
\hline
\end{tabular}

\begin{tabular}{|c|c|c|c|c|c|c|}
\hline \multicolumn{7}{|c|}{ CAPFT- High Outdoor Dry-Bulb Temperatures } \\
\hline CCAPFT & IWB & $\mathrm{IWB}^{\wedge} 2$ & ODB & $\mathrm{ODB}^{\wedge} 2$ & IWB*ODB & Predicted \\
\hline 1.243 & 23.9 & 571.21 & 23 & 529 & 549.7 & 1.2452 \\
\hline 1.21 & 23.9 & 571.21 & 26.7 & 712.89 & 638.13 & 1.207877 \\
\hline 1.158 & 23.9 & 571.21 & 32.2 & 1036.84 & 769.58 & 1.153412 \\
\hline 1.104 & 23.9 & 571.21 & 37.8 & 1428.84 & 903.42 & 1.099205 \\
\hline 1.061 & 23.9 & 571.21 & 42.2 & 1780.84 & 1008.58 & 1.057497 \\
\hline 1.178 & 22.2 & 492.84 & 23.8 & 566.44 & 528.36 & 1.178774 \\
\hline 1.154 & 22.2 & 492.84 & 26.7 & 712.89 & 592.74 & 1.153344 \\
\hline 1.107 & 22.2 & 492.84 & 32.2 & 1036.84 & 714.84 & 1.106043 \\
\hline 1.058 & 22.2 & 492.84 & 37.8 & 1428.84 & 839.16 & 1.059129 \\
\hline 1.02 & 22.2 & 492.84 & 42.2 & 1780.84 & 936.84 & 1.023151 \\
\hline 1.115 & 20.6 & 424.36 & 24 & 576 & 494.4 & 1.120131 \\
\hline 1.095 & 20.6 & 424.36 & 26.7 & 712.89 & 550.02 & 1.099775 \\
\hline 1.055 & 20.6 & 424.36 & 32.2 & 1036.84 & 663.32 & 1.059216 \\
\hline 1.014 & 20.6 & 424.36 & 37.8 & 1428.84 & 778.68 & 1.019166 \\
\hline 0.979 & 20.6 & 424.36 & 42.2 & 1780.84 & 869.32 & 0.988581 \\
\hline 1.074 & 19.4 & 376.36 & 24.7 & 610.09 & 479.18 & 1.071382 \\
\hline 1.058 & 19.4 & 376.36 & 26.7 & 712.89 & 517.98 & 1.058171 \\
\hline 1.02 & 19.4 & 376.36 & 32.2 & 1036.84 & 624.68 & 1.022667 \\
\hline 0.98 & 19.4 & 376.36 & 37.8 & 1428.84 & 733.32 & 0.987766 \\
\hline 0.954 & 19.4 & 376.36 & 42.2 & 1780.84 & 818.68 & 0.961226 \\
\hline 1.01 & 17.8 & 316.84 & 25.7 & 660.49 & 457.46 & 1.006154 \\
\hline 1.005 & 17.8 & 316.84 & 26.7 & 712.89 & 475.26 & 1.000794 \\
\hline 0.973 & 17.8 & 316.84 & 32.2 & 1036.84 & 573.16 & 0.972032 \\
\hline 0.958 & 17.8 & 316.84 & 37.8 & 1428.84 & 672.84 & 0.943995 \\
\hline 0.944 & 17.8 & 316.84 & 42.2 & 1780.84 & 751.16 & 0.922849 \\
\hline 0.947 & 16.1 & 259.21 & 26.4 & 696.96 & 425.04 & 0.93866 \\
\hline 0.944 & 16.1 & 259.21 & 26.7 & 712.89 & 429.87 & 0.937447 \\
\hline 0.92 & 16.1 & 259.21 & 32.2 & 1036.84 & 518.42 & 0.915848 \\
\hline 0.895 & 16.1 & 259.21 & 37.8 & 1428.84 & 608.58 & 0.895104 \\
\hline
\end{tabular}




\begin{tabular}{|r|r|r|r|r|r|r|}
\hline 0.875 & 16.1 & 259.21 & 42.2 & 1780.84 & 679.42 & 0.879688 \\
\hline 0.88 & 15 & 225 & 27.4 & 750.76 & 411 & 0.892922 \\
\hline 0.87 & 15 & 225 & 32.2 & 1036.84 & 483 & 0.878184 \\
\hline 0.86 & 15 & 225 & 37.8 & 1428.84 & 567 & 0.86216 \\
\hline 0.85 & 15 & 225 & 42.2 & 1780.84 & 633 & 0.850452 \\
\hline
\end{tabular}

\begin{tabular}{|c|c|c|c|c|}
\hline \multicolumn{5}{|c|}{$\begin{array}{c}\text { CCAPFT - Boundary Curve } \\
O D B=a+b^{*} I W B+c^{*} I W B^{\wedge} 2+d^{*} I W B^{\wedge} 3\end{array}$} \\
\hline ODB & IWB & $\mathrm{IWB}^{\wedge} 2$ & $I W B^{\wedge} 3$ & Predicted \\
\hline 23 & 23.9 & 571.21 & 13651.92 & 23.0438 \\
\hline 23.8 & 22.2 & 492.84 & 10941.05 & 76716.56 \\
\hline 24 & 20.6 & 424.36 & 8741.816 & 61305.57 \\
\hline 24.7 & 19.4 & 376.36 & 7301.384 & 51211 \\
\hline 25.7 & 17.8 & 316.84 & 5639.752 & 39565.15 \\
\hline 26.4 & 16.1 & 259.21 & 4173.281 & 29285.74 \\
\hline 27.4 & 15 & 225 & 3375 & 23689.31 \\
\hline
\end{tabular}

\begin{tabular}{|l|r|r|r|}
\hline CCAPFT & Low & High & \multicolumn{1}{|l|}{ Boundary } \\
\hline a & 0.079147 & 0.008490 & 58.13952 \\
\hline $\mathrm{b}$ & 0.062959 & 0.072126 & -3.774880 \\
\hline $\mathrm{c}$ & -0.000602 & -0.000425 & 0.145736 \\
\hline $\mathrm{d}$ & -0.000127 & 0.007225 & -0.002060 \\
\hline $\mathrm{e}$ & -0.0000025 & 0.000020 & - \\
\hline $\mathrm{f}$ & 0.00000835 & -0.000766 & - \\
\hline $\mathrm{R}^{2}$ & 0.9978 & 0.9959 & 0.9905 \\
\hline
\end{tabular}


CEIRFT - Low Outdoor Dry-Bulb Temperatures

CEIRFT $=a+b^{*} I W B+c^{*} I W^{\wedge} 2+d^{*} O D B+e^{*} O D B^{\wedge} 2+f^{*} I W B^{*} O D B$

\begin{tabular}{|c|c|c|c|c|c|c|c|c|c|}
\hline $\begin{array}{l}\text { Power } \\
\text { Ratio }\end{array}$ & $\begin{array}{l}\text { Capacity } \\
\text { Ratio }\end{array}$ & EIRFT & IWB & $I W B^{\wedge} 2$ & ODB & $\mathrm{ODB}^{\wedge} 2$ & IWB*ODB & $\begin{array}{l}\text { Predicted } \\
\text { Power Ratio }\end{array}$ & $\begin{array}{l}\text { Predicted } \\
\text { EIRFT }\end{array}$ \\
\hline 0.79 & 1.243 & 0.635559 & 23.9 & 571.21 & -4.46 & 19.8916 & -106.594 & 0.78831234 & 0.6383175 \\
\hline 0.795 & 1.243 & 0.639582 & 23.9 & 571.21 & -1.1 & 1.21 & -26.29 & 0.79317699 & 0.64184907 \\
\hline 0.8 & 1.243 & 0.643604 & 23.9 & 571.21 & 4.4 & 19.36 & 105.16 & 0.80107952 & 0.64769734 \\
\hline 0.81 & 1.243 & 0.651649 & 23.9 & 571.21 & 10 & 100 & 239 & 0.80904865 & 0.65373796 \\
\hline 0.818 & 1.243 & 0.658085 & 23.9 & 571.21 & 15.6 & 243.36 & 372.84 & 0.81693999 & 0.65986536 \\
\hline 0.825 & 1.243 & 0.663717 & 23.9 & 571.21 & 21.1 & 445.21 & 504.29 & 0.82461469 & 0.66596783 \\
\hline 0.827 & 1.243 & 0.665326 & 23.9 & 571.21 & 23 & 529 & 549.7 & 0.82724852 & 0.66809541 \\
\hline 0.779 & 1.178 & 0.66129 & 22.2 & 492.84 & -4.46 & 19.8916 & -99.012 & 0.77993746 & 0.66017623 \\
\hline 0.783 & 1.178 & 0.664686 & 22.2 & 492.84 & -1.1 & 1.21 & -24.42 & 0.7848336 & 0.6640871 \\
\hline 0.793 & 1.178 & 0.673175 & 22.2 & 492.84 & 4.4 & 19.36 & 97.68 & 0.79278768 & 0.67055625 \\
\hline 0.8 & 1.178 & 0.679117 & 22.2 & 492.84 & 10 & 100 & 222 & 0.80080929 & 0.67722904 \\
\hline 0.807 & 1.178 & 0.685059 & 22.2 & 492.84 & 15.6 & 243.36 & 346.32 & 0.80875311 & 0.68398861 \\
\hline 0.815 & 1.178 & 0.691851 & 22.2 & 492.84 & 21.1 & 445.21 & 468.42 & 0.81647936 & 0.69071195 \\
\hline 0.82 & 1.178 & 0.696095 & 22.2 & 492.84 & 23.8 & 566.44 & 528.36 & 0.82024479 & 0.69404314 \\
\hline 0.77 & 1.115 & 0.690583 & 20.6 & 424.36 & -4.46 & 19.8916 & -91.876 & 0.77130462 & 0.68697245 \\
\hline 0.775 & 1.115 & 0.695067 & 20.6 & 424.36 & -1.1 & 1.21 & -22.66 & 0.77623039 & 0.69124031 \\
\hline 0.783 & 1.115 & 0.702242 & 20.6 & 424.36 & 4.4 & 19.36 & 90.64 & 0.78423298 & 0.69829381 \\
\hline 0.792 & 1.115 & 0.710314 & 20.6 & 424.36 & 10 & 100 & 206 & 0.79230398 & 0.70556158 \\
\hline 0.801 & 1.115 & 0.718386 & 20.6 & 424.36 & 6 & 243.36 & 321.36 & 0.8002972 & 0.71291614 \\
\hline 0.809 & 1.115 & 0.725561 & 20.6 & 424.36 & 21.1 & 445.21 & 434.66 & 0.80807197 & 0.72022384 \\
\hline 0.812 & 1.115 & 0.728251 & 20.6 & 424.36 & 24 & 576 & 494.4 & 0.81214118 & 0.7241107 \\
\hline 0.765 & 1.074 & 0.712291 & 19.4 & 376.36 & -4.46 & 19.8916 & -86.524 & 0.76435232 & 0.71102989 \\
\hline 0.77 & 1.074 & 0.716946 & 19.4 & 376.36 & -1.1 & 1.21 & -21.34 & 0.769 & 0.71556549 \\
\hline 0.778 & 1.074 & 0.724395 & 19.4 & 376.36 & 4.4 & 19.36 & 85.36 & 0.7773393 & 0.72305727 \\
\hline 0.784 & 1.074 & 0.729981 & 19.4 & 376.36 & 10 & 100 & 194 & 0.78544735 & 0.73077127 \\
\hline 0.796 & 1.074 & 0.741155 & 19.4 & 376.36 & 15.6 & 243.36 & 302.64 & 0.79347761 & 0.73857207 \\
\hline 0.802 & 1.074 & 0.746741 & 19.4 & 376.36 & 21.1 & 445.21 & 409.34 & 0.80128876 & 0.74631804 \\
\hline 0.808 & 1.074 & 0.752328 & 19.4 & 376.36 & 24.7 & 610.09 & 479.18 & 0.80636088 & 0.75143346 \\
\hline 0.755 & 1.01 & 0.747525 & 17.8 & 316.84 & -4.46 & 19.8916 & -79.388 & 0.75444571 & 0.74838686 \\
\hline 0.759 & 1.01 & 0.751485 & 17.8 & 316.84 & -1.1 & 1.21 & -19.58 & 0.75942335 & 0.75327945 \\
\hline 0.767 & 1.01 & 0.759406 & 17.8 & 316.84 & 4.4 & 19.36 & 78.32 & 0.76751084 & 0.76135558 \\
\hline 0.775 & 1.01 & 0.767327 & 17.8 & 316.84 & 10 & 100 & 178 & 0.77566828 & 0.76966457 \\
\hline 0.78 & 1.01 & 0.772277 & 17.8 & 316.84 & 15.6 & 243.36 & 277.68 & 0.78374794 & 0.77806034 \\
\hline 0.79 & 1.01 & 0.782178 & 17.8 & 316.84 & 21.1 & 445.21 & 375.58 & 0.7916076 & 0.78639067 \\
\hline 0.798 & 1.01 & 0.790099 & 17.8 & 316.84 & 25.7 & 660.49 & 457.46 & 0.79812352 & 0.79342214 \\
\hline 0.745 & 0.947 & 0.786695 & 16.1 & 259.21 & -4.46 & 19.8916 & -71.806 & 0.74312242 & 0.79469089 \\
\hline 0.751 & 0.947 & 0.793031 & 16.1 & 259.21 & -1.1 & 1.21 & -17.71 & 0.74813155 & 0.79996278 \\
\hline 0.76 & 0.947 & 0.802534 & 16.1 & 259.21 & 4.4 & 19.36 & 70.84 & 0.75627058 & 0.8086598 \\
\hline 0.766 & 0.947 & 0.80887 & 16.1 & 259.21 & 10 & 100 & 161 & 0.7644805 & 0.81760095 \\
\hline 0.775 & 0.947 & 0.818374 & 16.1 & 259.21 & 15.6 & 243.36 & 251.16 & 0.77261264 & 0.8266289 \\
\hline 0.783 & 0.947 & 0.826822 & 16.1 & 259.21 & 21.1 & 445.21 & 339.71 & 0.78052385 & 0.8355801 \\
\hline
\end{tabular}




\begin{tabular}{|c|c|c|c|c|c|c|c|c|c|}
\hline 0.789 & 0.947 & 0.833157 & 16.1 & 259.21 & 26.4 & 696.96 & 425.04 & 0.78807639 & 0.84428502 \\
\hline 0.733 & 0.88 & 0.832955 & 15 & 225 & -4.46 & 19.8916 & -66.9 & 0.73535772 & 0.82828258 \\
\hline 0.738 & 0.88 & 0.838636 & 15 & 225 & -1.1 & 1.21 & -16.5 & 0.74038723 & 0.83379991 \\
\hline 0.748 & 0.88 & 0.85 & 15 & 225 & 4.4 & 19.36 & 66 & 0.74855961 & 0.84289866 \\
\hline 0.756 & 0.88 & 0.859091 & 15 & 225 & 10 & 100 & 150 & 0.7568035 & 0.85224887 \\
\hline 0.764 & 0.88 & 0.868182 & 15 & 225 & 15.6 & 243.36 & 234 & 0.7649696 & 0.86168586 \\
\hline 0.772 & 0.88 & 0.877273 & 15 & 225 & 21.1 & 445.21 & 316.5 & 0.77291416 & 0.87103882 \\
\hline 0.78 & 0.88 & 0.886364 & 15 & 225 & 26.7 & 712.89 & 400.5 & 0.78092608 & 0.88064784 \\
\hline 0.781 & 0.88 & 0.8875 & 15 & 225 & 27.4 & 750.76 & 411 & 0.7819221 & 0.88185507 \\
\hline
\end{tabular}

CEIRFT - High Outdoor Dry-Bulb Temperatures

CEIRFT $=a+b^{*} I W B+c^{*} I W^{\wedge} 2+d^{*} O D B+e^{*} O D^{\wedge} 2+f^{*} I W B^{*} O D B$

\begin{tabular}{|c|c|c|c|c|c|c|c|c|c|}
\hline $\begin{array}{l}\text { Power } \\
\text { Ratio }\end{array}$ & $\begin{array}{l}\text { Capacity } \\
\text { Ratio }\end{array}$ & EIRFT & IWB & IWB^2 & ODB & $\mathrm{ODB}^{\wedge} 2$ & IWB*ODB & $\begin{array}{l}\text { Predicted } \\
\text { Power Ratio }\end{array}$ & $\begin{array}{l}\text { Predicted } \\
\text { EIRFT }\end{array}$ \\
\hline 0.827 & 1.243 & 0.665326 & 23.9 & 571.21 & 23 & 529 & 549.7 & 0.8248199 & 0.66058348 \\
\hline 0.893 & 1.21 & 0.738017 & 23.9 & 571.21 & 26.7 & 712.89 & 638.13 & 0.8921305 & 0.73941762 \\
\hline 0.993 & 1.158 & 0.857513 & 23.9 & 571.21 & 32.2 & 1036.84 & 769.58 & 0.9911556 & 0.86231463 \\
\hline 1.09 & 1.104 & 0.987319 & 23.9 & 571.21 & 37.8 & 1428.84 & 903.42 & 1.0907145 & 0.99446202 \\
\hline 1.17 & 1.061 & 1.102733 & 23.9 & 571.21 & 42.2 & 1780.84 & 1008.58 & 1.1680427 & 1.10325832 \\
\hline 0.82 & 1.178 & 0.696095 & 22.2 & 492.84 & 23.8 & 566.44 & 528.36 & 0.8235096 & 0.69681683 \\
\hline 0.872 & 1.154 & 0.755633 & 22.2 & 492.84 & 26.7 & 712.89 & 592.74 & 0.8769569 & 0.75990864 \\
\hline 0.975 & 1.107 & 0.880759 & 22.2 & 492.84 & 32.2 & 1036.84 & 714.84 & 0.9773811 & 0.88478006 \\
\hline 1.077 & 1.058 & 1.017958 & 22.2 & 492.84 & 37.8 & 1428.84 & 839.16 & 1.0783644 & 1.01893775 \\
\hline 1.156 & 1.02 & 1.133333 & 22.2 & 492.84 & 42.2 & 1780.84 & 936.84 & 1.1568118 & 1.12931356 \\
\hline 0.812 & 1.115 & 0.728251 & 20.6 & 424.36 & 24 & 576 & 494.4 & 0.8089904 & 0.7210613 \\
\hline 0.862 & 1.095 & 0.787215 & 20.6 & 424.36 & 26.7 & 712.89 & 550.02 & 0.8593871 & 0.78077514 \\
\hline 0.963 & 1.055 & 0.912796 & 20.6 & 424.36 & 32.2 & 1036.84 & 663.32 & 0.961128 & 0.90750481 \\
\hline 1.063 & 1.014 & 1.048323 & 20.6 & 424.36 & 37.8 & 1428.84 & 778.68 & 1.0634519 & 1.04355455 \\
\hline 1.142 & 0.979 & 1.166496 & 20.6 & 424.36 & 42.2 & 1780.84 & 869.32 & 1.1429527 & 1.15541697 \\
\hline 0.808 & 1.074 & 0.752328 & 19.4 & 376.36 & 24.7 & 610.09 & 479.18 & 0.8064553 & 0.7525337 \\
\hline 0.845 & 1.058 & 0.798677 & 19.4 & 376.36 & 26.7 & 712.89 & 517.98 & 0.8441168 & 0.79743099 \\
\hline 0.946 & 1.02 & 0.927451 & 19 & 376.36 & 32.2 & 1036.84 & 624.68 & 0.9468452 & 0.92555435 \\
\hline 1.053 & 0.98 & 1.07449 & 19.4 & 376.36 & 37.8 & 1428.84 & 733.32 & 1.0501746 & 1.06302312 \\
\hline 1.13 & 0.954 & 1.184486 & 19.4 & 376.36 & 42.2 & 1780.84 & 818.68 & 1.1304654 & 1.1760005 \\
\hline 0.798 & 1.01 & 0.790099 & 17.8 & 316.84 & 25.7 & 660.49 & 457.46 & 0.801916 & 0.79808071 \\
\hline 0.817 & 1.005 & 0.812935 & 17.8 & 316.84 & 26.7 & 712.89 & 475.26 & 0.8209658 & 0.82098009 \\
\hline 0.922 & 0.973 & 0.947585 & 17.8 & 316.84 & 32.2 & 1036.84 & 573.16 & 0.9250109 & 0.95096171 \\
\hline 1.028 & 0.958 & 1.073069 & 17.8 & 316.84 & 37.8 & 1428.84 & 672.84 & 1.029681 & 1.09032252 \\
\hline 1.11 & 0.944 & 1.175847 & 17.8 & 316.84 & 42.2 & 1780.84 & 751.16 & 1.1110252 & 1.20478651 \\
\hline 0.789 & 0.947 & 0.833157 & 16.1 & 259.21 & 26.4 & 696.96 & 425.04 & 0.7870864 & 0.84067942 \\
\hline 0.799 & 0.944 & 0.846398 & 16.1 & 259.21 & 26.7 & 712.89 & 429.87 & 0.7928734 & 0.84768063 \\
\hline 0.905 & 0.92 & 0.983696 & 16.1 & 259.21 & 32.2 & 1036.84 & 518.42 & 0.8983175 & 0.97963665 \\
\hline 1.01 & 0.895 & 1.128492 & 16.1 & 259.21 & 37.8 & 1428.84 & 608.58 & 1.0044121 & 1.12100776 \\
\hline 1.09 & 0.875 & 1.245714 & 16.1 & 259.21 & 42.2 & 1780.84 & 679.42 & 1.0868755 & 1.23705127 \\
\hline
\end{tabular}




\begin{tabular}{|c|c|c|c|c|c|c|c|c|c|}
\hline 0.781 & 0.88 & 0.8875 & 15 & 225 & 27.4 & 750.76 & 411 & 0.7863813 & 0.88245735 \\
\hline 0.878 & 0.87 & 1.009195 & 15 & 225 & 32.2 & 1036.84 & 483 & 0.8791268 & 0.99911317 \\
\hline 0.982 & 0.86 & 1.14186 & 15 & 225 & 37.8 & 1428.84 & 567 & 0.9861431 & 1.14178506 \\
\hline 1.067 & 0.85 & 1.255294 & 15 & 225 & 42.2 & 1780.84 & 633 & 1.0693307 & 1.25885061 \\
\hline
\end{tabular}

\begin{tabular}{rr|ccr|}
\multicolumn{5}{c}{ CEIRFT - Boundary Curve } \\
ODB & IWB & \multicolumn{1}{c}{ IWB^2 } & \multicolumn{1}{c}{ IWB^3 } & \multicolumn{1}{c}{ Predicted } \\
23 & 23.9 & 571.21 & 13651.92 & 23.0438 \\
23.8 & 22.2 & 492.84 & 10941.05 & 76716.56 \\
24 & 20.6 & 424.36 & 8741.816 & 61305.57 \\
24.7 & 19.4 & 376.36 & 7301.384 & 51211 \\
25.7 & 17.8 & 316.84 & 5639.752 & 39565.15 \\
26.4 & 16.1 & 259.21 & 4173.281 & 29285.74 \\
27.4 & 15 & 225 & 3375 & 23689.31
\end{tabular}

\begin{tabular}{|l|r|r|r|}
\hline CEIRFT & Low & High & Boundary \\
\hline $\mathrm{a}$ & 1.582769 & 0.552029 & 58.13952 \\
\hline $\mathrm{b}$ & -0.067490 & -0.020218 & -3.774880 \\
\hline $\mathrm{c}$ & 0.001179 & 0.000299 & 0.145736 \\
\hline $\mathrm{d}$ & 0.002646 & 0.020744 & -0.00206 \\
\hline $\mathrm{e}$ & 0.00000138 & 0.000113 & - \\
\hline $\mathrm{f}$ & -0.000066 & -0.000211 & - \\
\hline $\mathrm{R}^{2}$ & 0.9958 & 0.9977 & 0.9905 \\
\hline
\end{tabular}




\begin{tabular}{|c|c|c|c|c|c|c|}
\hline \multicolumn{7}{|c|}{$\begin{array}{l}\text { HCAPFT- Low Outdoor Dry-Bulb Temperatures } \\
=a+b^{*} I W B+c^{*} I W^{\wedge} 2+d^{*} O D B+e^{*} O D B^{\wedge} 2+f^{*} \mid\end{array}$} \\
\hline HCAPFT & IWB & $\mathrm{IWB}^{\wedge} 2$ & ODB & $\mathrm{ODB}^{\wedge} 2$ & IWB*ODB & Predicted \\
\hline 0.72 & 27.2 & 596.3364 & -24.42 & 739.84 & -664.224 & 0.76387 \\
\hline 0.72 & 27.2 & 542.89 & -23.3 & 739.84 & -633.76 & 0.759903 \\
\hline 0.72 & 27.2 & 316.84 & -17.8 & 739.84 & -484.16 & 0.742643 \\
\hline 0.76 & 25 & 596.3364 & -24.42 & 625 & -610.5 & 0.85477 \\
\hline 0.79 & 25 & 542.89 & -23.3 & 625 & -582.5 & 0.85187 \\
\hline 0.839 & 25 & 470.89 & -21.7 & 625 & -542.5 & 0.847992 \\
\hline 0.76 & 21.1 & 596.3364 & -24.42 & 445.21 & -515.262 & 0.982586 \\
\hline 0.78 & 21.1 & 542.89 & -23.3 & 445.21 & -491.63 & 0.981578 \\
\hline 0.934 & 21.1 & 470.89 & -21.7 & 445.21 & -457.87 & 0.980405 \\
\hline 1 & 21.1 & 222.01 & -14.9 & 445.21 & -314.39 & 0.978905 \\
\hline 0.76 & 15 & 596.3364 & -24.42 & 225 & -366.3 & 1.097059 \\
\hline 0.78 & 15 & 542.89 & -23.3 & 225 & -349.5 & 1.099012 \\
\hline 0.934 & 15 & 470.89 & -21.7 & 225 & -325.5 & 1.102066 \\
\hline 1.063 & 15 & 148.84 & -12.2 & 225 & -183 & 1.126644 \\
\hline 1.15 & 15 & 69.7225 & -8.35 & 225 & -125.25 & 1.139745 \\
\hline
\end{tabular}

\begin{tabular}{|c|c|c|c|c|c|c|}
\hline & CAPFT : & $\begin{array}{l}\text { HCAPFT- High } \\
a+b * I W B+c\end{array}$ & $\begin{array}{l}\text { Outdoor } \\
\text { IWB^2 }\end{array}$ & $\begin{array}{l}\text { Dry-Bulb T } \\
d^{*} O D B+\epsilon\end{array}$ & $\begin{array}{l}{ }^{2} O D B^{\wedge} 2+f^{*} I W \\
\text { natures }\end{array}$ & $3 * O D B$ \\
\hline HCAPFT & IWB & $\mathrm{IWB}^{\wedge} 2$ & ODB & $\mathrm{ODB}^{\wedge} 2$ & IWB*ODB & Predicted \\
\hline 0.72 & 27.2 & 316.84 & -17.8 & 739.84 & -484.16 & 0.742643 \\
\hline 0.72 & 27.2 & 148.84 & -12.2 & 739.84 & -331.84 & 0.728867 \\
\hline 0.72 & 27.2 & 44.89 & -6.7 & 739.84 & -182.24 & 0.719067 \\
\hline 0.72 & 27.2 & 1.21 & -1.1 & 739.84 & -29.92 & 0.712886 \\
\hline 0.72 & 27.2 & 19.36 & 4.4 & 739.84 & 119.68 & 0.710545 \\
\hline 0.72 & 27.2 & 100 & 10 & 739.84 & 272 & 0.71196 \\
\hline 0.72 & 27.2 & 209.6704 & 14.48 & 739.84 & 393.856 & 0.71585 \\
\hline 0.839 & 25 & 470.89 & -21.7 & 625 & -542.5 & 0.847992 \\
\hline 0.835 & 25 & 316.84 & -17.8 & 625 & -445 & 0.839852 \\
\hline 0.835 & 25 & 148.84 & -12.2 & 625 & -305 & 0.831414 \\
\hline 0.835 & 25 & 44.89 & -6.7 & 625 & -167.5 & 0.826856 \\
\hline 0.835 & 25 & 1.21 & -1.1 & 625 & -27.5 & 0.826012 \\
\hline 0.835 & 25 & 19.36 & 4.4 & 625 & 110 & 0.828913 \\
\hline 0.835 & 25 & 100 & 10 & 625 & 250 & 0.835665 \\
\hline 0.835 & 25 & 209.6704 & 14.48 & 625 & 362 & 0.843825 \\
\hline 1 & 21.1 & 222.01 & -14.9 & 445.21 & -314.39 & 0.978905 \\
\hline 1 & 21.1 & 148.84 & -12.2 & 445.21 & -257.42 & 0.979877 \\
\hline 1 & 21.1 & 44.89 & -6.7 & 445.21 & -141.37 & 0.984612 \\
\hline 1 & 21.1 & 1.21 & -1.1 & 445.21 & -23.21 & 0.99323 \\
\hline 1 & 21.1 & 19.36 & 4.4 & 445.21 & 92.84 & 1.005424 \\
\hline 1 & 21.1 & 100 & 10 & 445.21 & 211 & 1.021637 \\
\hline 0.999 & 21.1 & 209.6704 & 14.48 & 445.21 & 305.528 & 1.037367 \\
\hline
\end{tabular}




\begin{tabular}{|r|r|r|r|rrr|}
\hline 1.15 & 15 & 69.7225 & -8.35 & 225 & -125.25 & 1.139745 \\
1.15 & 15 & 44.89 & -6.7 & 225 & -100.5 & 1.145914 \\
1.15 & 15 & 1.21 & -1.1 & 225 & -16.5 & 1.169331 \\
1.15 & 15 & 15.7609 & 3.97 & 225 & 59.55 & 1.193837 \\
1.16 & 15 & 19.36 & 4.4 & 225 & 66 & 1.19606 \\
\hline 1.247 & 15 & 100 & 10 & 225 & 150 & 1.227072 \\
1.3 & 15 & 209.6704 & 14.48 & 225 & 217.2 & 1.254641 \\
\hline
\end{tabular}

\begin{tabular}{|c|c|c|c|c|}
\hline \multirow[b]{2}{*}{ ODB } & \multicolumn{4}{|c|}{$\begin{array}{c}\text { HCAPFT }- \text { Boundary Curve } \\
\text { ODB }=a+b^{*} I W B+c^{*} I W B^{\wedge} 2+d^{*} I W B^{\wedge} 3\end{array}$} \\
\hline & IWB & $I W B^{\wedge} 2$ & $I W B^{\wedge} 3$ & Predicted \\
\hline-17.8 & 27.2 & 739.84 & 20123.65 & -17.8 \\
\hline-21.7 & 25 & 625 & 15625 & -21.7 \\
\hline-14.9 & 21.1 & 445.21 & 9393.931 & -14.9 \\
\hline-8.35 & 15 & 225 & 3375 & -8.35 \\
\hline
\end{tabular}

\begin{tabular}{|c|c|c|c|}
\hline HCAPFT & Low & High & Boundary \\
\hline$a$ & 1.217322 & 1.171233 & -430.748 \\
\hline$b$ & 0.009506 & 0.021221 & 65.63427 \\
\hline c & -0.001910 & 0.000061 & -3.28939 \\
\hline$d$ & 0.002487 & 0.011157 & 0.05274 \\
\hline $\mathrm{e}$ & -0.001930 & -0.001400 & - \\
\hline$f$ & -0.002800 & -0.000430 & - \\
\hline$R^{2}$ & 0.9315 & 0.9861 & 1 \\
\hline
\end{tabular}




\begin{tabular}{|c|c|c|c|c|c|c|c|c|c|}
\hline \multirow[b]{2}{*}{ Power Ratio } & \multicolumn{7}{|c|}{$\begin{array}{l}\text { HEIRFT - Low Outdoor Dry-Bulb Temperatures } \\
a+b^{*} I W B+c^{*} I W B^{\wedge} 2+d^{*} O D B+e^{*} O D B^{\wedge} 2+f^{*} \mid\end{array}$} & \multirow[b]{2}{*}{$\begin{array}{l}\text { Predicted } \\
\text { Power } \\
\text { Ratio }\end{array}$} & \multirow[b]{2}{*}{$\begin{array}{l}\text { Predicted } \\
\text { EIRFT }\end{array}$} \\
\hline & $\begin{array}{l}\text { Capacity } \\
\text { Ratio }\end{array}$ & EIRFT & IWB & IWB^2 & ODB & $\mathrm{ODB}^{\wedge} 2$ & IWB*ODB & & \\
\hline 1.587 & 0.72 & 2.204167 & 27.2 & 739.84 & -24.42 & 596.3364 & -664.224 & 1.5754745 & 2.2281184 \\
\hline 1.55 & 0.72 & 2.152778 & 27.2 & 739.84 & -23.3 & 542.89 & -633.76 & 1.55758 & 2.1454985 \\
\hline 1.374 & 0.72 & 1.908333 & 27.2 & 739.84 & -17.8 & 316.84 & -484.16 & 1.4335454 & 1.9030455 \\
\hline 1.764 & 0.76 & 2.321053 & 25 & 625 & -24.42 & 596.3364 & -610.5 & 1.7529733 & 2.3210578 \\
\hline 1.775 & 0.79 & 2.246835 & 25 & 625 & -23.3 & 542.89 & -582.5 & 1.7431459 & 2.231978 \\
\hline 1.788 & 0.839 & 2.131108 & 25 & 625 & -21.7 & 470.89 & -542.5 & 1.7247846 & 2.1242365 \\
\hline 1.857 & 0.76 & 2.443421 & 21.1 & 445.21 & -24.42 & 596.3364 & -515.262 & 1.9140271 & 2.4109459 \\
\hline 1.862 & 0.78 & 2.387179 & 21.1 & 445.21 & -23.3 & 542.89 & -491.63 & 1.9185004 & 2.3104145 \\
\hline 1.914 & 0.934 & 2.049251 & 21.1 & 445.21 & -21.7 & 470.89 & -457.87 & 1.9205688 & 2.1863135 \\
\hline 1.93 & 1 & 1.93 & 21.1 & 445.21 & -14.9 & 222.01 & -314.39 & 1.872632 & 1.9150214 \\
\hline 1.796 & 0.76 & 2.363158 & 15 & 225 & -24.42 & 596.3364 & -366.3 & 1.7720779 & 2.3595705 \\
\hline 1.804 & 0.78 & 2.312821 & 15 & 225 & -23.3 & 542.89 & -349.5 & 1.798919 & 2.2411276 \\
\hline 1.845 & 0.934 & 1.975375 & 15 & 225 & -21.7 & 470.89 & -325.5 & 1.8329415 & 2.0914388 \\
\hline 1.89 & 1.063 & 1.777987 & 15 & 225 & -12.2 & 148.84 & -183 & 1.9302244 & 1.6755197 \\
\hline 1.93 & 1.15 & 1.678261 & 15 & 225 & -8.35 & 69.7225 & -125.25 & 1.9186052 & 1.7374396 \\
\hline
\end{tabular}

\begin{tabular}{|c|c|c|c|c|c|c|c|c|c|}
\hline \multirow[b]{2}{*}{ Power Ratio } & \multicolumn{7}{|c|}{$\begin{aligned} & \text { HEIRFT - Low Outdoor Dry-Bulb Temperatures } \\
= & a+b^{*} I W B+c^{*} I W^{\wedge} 2+d^{*} O D B+e^{*} O D B^{\wedge} 2+f^{*} I V\end{aligned}$} & \multirow[b]{2}{*}{$\begin{array}{l}\text { Predicted } \\
\text { Power Ratio }\end{array}$} & \multirow[b]{2}{*}{$\begin{array}{l}\text { Predicted } \\
\text { EIRFT }\end{array}$} \\
\hline & $\begin{array}{l}\text { Capacity } \\
\text { Ratio }\end{array}$ & EIRFT & IWB & $\mathrm{IWB}^{\wedge} 2$ & ODB & $\mathrm{ODB}^{\wedge} 2$ & IWB*ODB & & \\
\hline 1.374 & 0.72 & 1.908333 & 27.2 & 739.84 & -17.8 & 316.84 & -484.16 & 1.41020844 & 1.9152642 \\
\hline 1.189 & 0.72 & 1.651389 & 27.2 & 739.84 & -12.2 & 148.84 & -331.84 & 1.16717982 & 1.6238757 \\
\hline 1.03 & 0.72 & 1.430556 & 27.2 & 739.84 & -6.7 & 44.89 & -182.24 & 0.97449789 & 1.3848504 \\
\hline 0.876 & 0.72 & 1.216667 & 27.2 & 739.84 & -1.1 & 1.21 & -29.92 & 0.82515603 & 1.1894966 \\
\hline 0.765 & 0.72 & 1.0625 & 27.2 & 739.84 & 4.4 & 19.36 & 119.68 & 0.72448788 & 1.0447911 \\
\hline 0.654 & 0.72 & 0.908333 & 27.2 & 739.84 & 10 & 100 & 272 & 0.66883278 & 0.945472 \\
\hline 0.602 & 0.72 & 0.836111 & 27.2 & 739.84 & 14.48 & 209.6704 & 393.856 & 0.65833978 & 0.9009007 \\
\hline 1.788 & 0.839 & 2.131108 & 25 & 625 & -21.7 & 470.89 & -542.5 & 1.89035139 & 2.2409584 \\
\hline 1.672 & 0.835 & 2.002395 & 25 & 625 & -17.8 & 316.84 & -445 & 1.69468222 & 2.0193324 \\
\hline 1.58 & 0.835 & 1.892216 & 25 & 625 & -12.2 & 148.84 & -305 & 1.45381254 & 1.7421961 \\
\hline 1.366 & 0.835 & 1.635928 & 25 & 625 & -6.7 & 44.89 & -167.5 & 1.263251 & 1.5171686 \\
\hline 1.17 & 0.835 & 1.401198 & 25 & 625 & -1.1 & 1.21 & -27.5 & 1.11606807 & 1.336067 \\
\hline 1.022 & 0.835 & 1.223952 & 25 & 625 & 4.4 & 19.36 & 110 & 1.01752031 & 1.2053593 \\
\hline 0.878 & 0.835 & 1.051497 & 25 & 625 & 10 & 100 & 250 & 0.96402415 & 1.1202925 \\
\hline 0.762 & 0.835 & 0.912575 & 25 & 625 & 14.48 & 209.6704 & 362 & 0.9552583 & 1.087123 \\
\hline 1.93 & 1 & 1.93 & 21.1 & 445.21 & -14.9 & 222.01 & -314.39 & 1.88071644 & 1.9207852 \\
\hline 1.685 & 1 & 1.685 & 21.1 & 445.21 & -12.2 & 148.84 & -257.42 & 1.77232874 & 1.8053959 \\
\hline 1.49 & 1 & 1.49 & 21.1 & 445.21 & -6.7 & 44.89 & -141.37 & 1.58552607 & 1.6051827 \\
\hline 1.4 & 1 & 1.4 & 21.1 & 445.21 & -1.1 & 1.21 & -23.21 & 1.44217036 & 1.4493465 \\
\hline 1.212 & 1 & 1.212 & 21.1 & 445.21 & 4.4 & 19.36 & 92.84 & 1.34738146 & 1.3434531 \\
\hline
\end{tabular}




\begin{tabular}{|c|c|c|c|c|c|c|c|c|c|}
\hline 1.04 & 1 & 1.04 & 21.1 & 445.21 & 10 & 100 & 211 & 1.2977125 & 1.2836516 \\
\hline 1.93 & 0.999 & 1.931932 & 21.1 & 445.21 & 14.48 & 209.6704 & 305.528 & 1.29200842 & 1.2706944 \\
\hline 1.76 & 1.15 & 1.530435 & 15 & 225 & -8.35 & 69.7225 & -125.25 & 1.65291939 & 1.4105898 \\
\hline 1.7 & 1.15 & 1.478261 & 15 & 225 & -6.7 & 44.89 & -100.5 & 1.60342956 & 1.3670766 \\
\hline 1.45 & 1.15 & 1.26087 & 15 & 225 & -1.1 & 1.21 & -16.5 & 1.46606 & 1.2507581 \\
\hline 1.39 & 1.15 & 1.208696 & 15 & 225 & 3.97 & 15.7609 & 59.55 & 1.38245856 & 1.1872371 \\
\hline 1.264 & 1.16 & 1.089655 & 15 & 225 & 4.4 & 19.36 & 66 & 1.37715036 & 1.1836766 \\
\hline 1.238 & 1.247 & 0.992783 & 15 & 225 & 10 & 100 & 150 & 1.33346755 & 1.1633929 \\
\hline
\end{tabular}

\begin{tabular}{|l|r|r|r|}
\hline HEIRFT & Low & High & \multicolumn{1}{|l|}{ Boundary } \\
\hline $\mathrm{a}$ & 0.59891869 & -1.01623 & -430.748 \\
\hline $\mathrm{b}$ & 0.17640375 & 0.283607 & 65.63427 \\
\hline $\mathrm{c}$ & -0.00645660 & -0.007970 & -3.28939 \\
\hline $\mathrm{d}$ & 0.02568297 & -0.016020 & 0.05274 \\
\hline $\mathrm{e}$ & -0.0009931 & 0.000754 & - \\
\hline $\mathrm{f}$ & -0.0032740 & -0.000180 & - \\
\hline $\mathrm{R}^{2}$ & 0.9393 & 0.8347 & 1 \\
\hline
\end{tabular}




\begin{tabular}{|c|c|c|c|c|c|c|c|c|}
\hline & & & Cooling EIR & FPLR -PUHY-HP & 72THMU & & & \\
\hline & Cooling & & Indoor & Indoor Unit & & & & \\
\hline & $\begin{array}{l}\text { Power } \\
\text { (kW) }\end{array}$ & $\begin{array}{l}\text { Normalized } \\
\text { EIRFPLR }\end{array}$ & $\begin{array}{l}\text { Capacity } \\
\text { (kBTUh) }\end{array}$ & $\begin{array}{l}\text { Capacity } \\
\text { (kW) }\end{array}$ & PLR & $\mathrm{PLR}^{\wedge} 2$ & $\mathrm{PLR}^{\wedge} 3$ & $\begin{array}{l}\text { Predicted } \\
\text { Power }\end{array}$ \\
\hline & 3.16 & 0.53 & 36.10 & 10.58 & 0.50 & 0.25 & 0.13 & 0.53 \\
\hline & 3.42 & 0.58 & 40.00 & 11.72 & 0.56 & 0.31 & 0.17 & 0.58 \\
\hline$P \mid R<=1$ & 4.15 & 0.70 & 50.00 & 14.65 & 0.69 & 0.48 & 0.33 & 0.70 \\
\hline$r \ln -1$ & 4.90 & 0.83 & 60.00 & 17.58 & 0.83 & 0.69 & 0.58 & 0.83 \\
\hline & 5.75 & 0.97 & 70.00 & 20.51 & 0.97 & 0.94 & 0.92 & 0.97 \\
\hline & 5.91 & 1.00 & 72.04 & 21.11 & 1.00 & 1.00 & 1.00 & 1.00 \\
\hline & 5.91 & 1.00 & 72.04 & 21.11 & 1.00 & 1.00 & 1.00 & 1.00 \\
\hline$P L R>=1$ & 5.94 & 1.01 & 80.00 & 23.45 & 1.11 & 1.23 & 1.37 & 1.01 \\
\hline & 6.01 & 1.02 & 90.00 & 26.38 & 1.25 & 1.56 & 1.95 & 1.02 \\
\hline & 6.06 & 1.03 & 92.22 & 27.03 & 1.28 & 1.64 & 2.10 & 1.03 \\
\hline
\end{tabular}

\begin{tabular}{|c|c|c|c|c|c|c|c|c|}
\hline & \multirow[b]{2}{*}{$\begin{array}{l}\text { Cooling } \\
\text { Power } \\
\text { (kW) }\end{array}$} & \multirow[b]{2}{*}{$\begin{array}{l}\text { Normalized } \\
\text { EIRFPLR }\end{array}$} & \multicolumn{3}{|c|}{ Cooling EIRFPLR - PUHY-HP96THMU } & \multirow[b]{2}{*}{$\mathrm{PLR}^{\wedge} 2$} & \multirow[b]{2}{*}{$\mathrm{PLR}^{\wedge} 3$} & \multirow[b]{2}{*}{$\begin{array}{l}\text { Predicted } \\
\text { Power }\end{array}$} \\
\hline & & & $\begin{array}{l}\text { Indoor } \\
\text { Capacity } \\
\text { (kBTUh) }\end{array}$ & $\begin{array}{l}\text { Indoor Unit } \\
\text { Capacity } \\
\text { (kW) }\end{array}$ & PLR & & & \\
\hline \multirow{7}{*}{$\mathrm{PLR}<=1$} & 4.23 & 0.48 & 48.28 & 14.15 & 0.50 & 0.25 & 0.13 & 0.49 \\
\hline & 4.40 & 0.50 & 50.00 & 14.65 & 0.52 & 0.27 & 0.14 & 0.50 \\
\hline & 5.24 & 0.60 & 60.00 & 17.58 & 0.62 & 0.39 & 0.24 & 0.60 \\
\hline & 6.10 & 0.70 & 70.00 & 20.51 & 0.73 & 0.53 & 0.39 & 0.70 \\
\hline & 7.10 & 0.81 & 80.00 & 23.45 & 0.83 & 0.69 & 0.58 & 0.81 \\
\hline & 8.10 & 0.93 & 90.00 & 26.38 & 0.94 & 0.88 & 0.82 & 0.93 \\
\hline & 8.73 & 1.00 & 96.02 & 28.14 & 1.00 & 1.00 & 1.00 & 1.00 \\
\hline \multirow{5}{*}{ PLR $>=1$} & 8.73 & 1.00 & 96.02 & 28.14 & 1.00 & 1.00 & 1.00 & 1.00 \\
\hline & 8.74 & 1.00 & 100.00 & 29.31 & 1.04 & 1.08 & 1.13 & 1.00 \\
\hline & 8.82 & 1.01 & 110.00 & 32.24 & 1.15 & 1.31 & 1.50 & 1.01 \\
\hline & 8.85 & 1.01 & 120.00 & 35.17 & 1.25 & 1.56 & 1.95 & 1.01 \\
\hline & 8.90 & 1.02 & 124.82 & 36.58 & 1.30 & 1.69 & 2.20 & 1.02 \\
\hline
\end{tabular}

\begin{tabular}{|l|r|r|r|r|}
\hline \multirow{2}{*}{ CEIRPLR } & \multicolumn{2}{|c|}{ PUHY-HP72THMU } & \multicolumn{2}{c|}{ PUHY-HP96THMU } \\
\cline { 2 - 5 } & Low & Hi & \multicolumn{1}{c|}{ Low } \\
\hline $\mathrm{a}$ & 0.127161 & -3.612509 & 0.133763 & 0.142510 \\
\hline $\mathrm{b}$ & 0.830891 & 12.52042 & 0.511934 & 2.149816 \\
\hline $\mathrm{c}$ & -0.117980 & -11.32595 & 0.398784 & -1.819597 \\
\hline $\mathrm{d}$ & 0.161196 & 3.418041 & -0.044110 & 0.526518 \\
\hline $\mathrm{R}^{2}$ & 0.9999 & 1 & 0.9999 & 0.9763 \\
\hline
\end{tabular}




\begin{tabular}{|c|c|c|c|c|c|c|c|c|}
\hline & $\begin{array}{l}\text { Cooling } \\
\text { Power } \\
\text { (kW) }\end{array}$ & $\begin{array}{l}\text { Normalized } \\
\text { EIRFPLR }\end{array}$ & $\begin{array}{l}\text { Heating EIR } \\
\text { Indoor } \\
\text { Capacity } \\
\text { (kBTUh) }\end{array}$ & $\begin{array}{l}\text { PLR - PUHY-1 } \\
\text { Indoor Unit } \\
\text { Capacity } \\
\text { (kW) }\end{array}$ & P72THMU & $\mathrm{PLR}^{\wedge} 2$ & $\mathrm{PLR}^{\wedge} 3$ & $\begin{array}{l}\text { Predicted } \\
\text { Power }\end{array}$ \\
\hline \multirow{6}{*}{$P L R<=1$} & 3.46 & 0.55 & 36.09 & 10.57693 & 0.50125 & 0.251252 & 0.12594 & 0.55 \\
\hline & 3.74 & 0.59 & 40 & 11.72284 & 0.555556 & 0.308642 & 0.171468 & 0.59 \\
\hline & 4.48 & 0.71 & 50 & 14.65355 & 0.694444 & 0.482253 & 0.334898 & 0.71 \\
\hline & 5.29 & 0.84 & 60 & 17.58426 & 0.833333 & 0.694444 & 0.578704 & 0.84 \\
\hline & 6.15 & 0.98 & 70 & 20.51497 & 0.972222 & 0.945216 & 0.91896 & 0.97 \\
\hline & 6.3 & 1.00 & 72 & 21.10112 & 1 & 1 & 1 & 1.00 \\
\hline \multirow{4}{*}{ PLR>=1 } & 6.3 & 1 & 72 & 21.10112 & 1 & 1 & 1 & 1.00 \\
\hline & 6.08 & 0.97 & 80 & 23.44569 & 1.111111 & 1.234568 & 1.371742 & 0.97 \\
\hline & 5.78 & 0.92 & 90 & 26.3764 & 1.25 & 1.5625 & 1.953125 & 0.92 \\
\hline & 5.71 & 0.91 & 93.38 & 27.36698 & 1.296944 & 1.682065 & 2.181545 & 0.91 \\
\hline
\end{tabular}

\begin{tabular}{|c|c|c|c|c|c|c|c|c|}
\hline & & & Heating EIR & $=P L R-P U H Y-H$ & P96THMU & & & \\
\hline & Cooling & & Indoor & Indoor Unit & & & & \\
\hline & $\begin{array}{l}\text { Power } \\
\text { (kW) }\end{array}$ & $\begin{array}{l}\text { Normalized } \\
\text { EIRFPLR }\end{array}$ & $\begin{array}{l}\text { Capacity } \\
\text { (kBTUh) }\end{array}$ & $\begin{array}{l}\text { Capacity } \\
\text { (kW) }\end{array}$ & PLR & $\mathrm{PLR}^{\wedge} 2$ & $P^{P L} R^{\wedge} 3$ & $\begin{array}{l}\text { Predicted } \\
\text { Power }\end{array}$ \\
\hline & 4.47 & 0.49 & 48.12 & 14.10258 & 0.501146 & 0.251147 & 0.125861 & 0.49 \\
\hline & 4.63 & 0.51 & 50 & 14.65355 & 0.520725 & 0.271154 & 0.141197 & 0.51 \\
\hline$P \mid R<=1$ & 5.49 & 0.60 & 60 & 17.58426 & 0.62487 & 0.390462 & 0.243988 & 0.60 \\
\hline & 6.41 & 0.70 & 70 & 20.51497 & 0.729015 & 0.531463 & 0.387444 & 0.70 \\
\hline & 7.41 & 0.81 & 80 & 23.44569 & 0.83316 & 0.694155 & 0.578342 & 0.81 \\
\hline & 8.45 & 0.92 & 90 & 26.3764 & 0.937305 & 0.87854 & 0.82346 & 0.92 \\
\hline & 9.16 & 1.00 & 96.02 & 28.14068 & 1 & 1 & 1 & 1.00 \\
\hline & 9.16 & 1 & 96.02 & 28.14068 & 1 & 1 & 1 & 1.00 \\
\hline & 9.01 & 0.98 & 100 & 29.30711 & 1.04145 & 1.084617 & 1.129575 & 0.98 \\
\hline PLR $>=1$ & 8.71 & 0.95 & 110 & 32.23782 & 1.145595 & 1.312387 & 1.503464 & 0.95 \\
\hline & 8.44 & 0.92 & 120 & 35.16853 & 1.24974 & 1.561849 & 1.951905 & 0.92 \\
\hline & 8.3 & 0.91 & 124.52 & 36.49321 & 1.296813 & 1.681724 & 2.180882 & 0.91 \\
\hline
\end{tabular}

\begin{tabular}{|l|r|r|r|r|}
\hline \multirow{2}{*}{ HEIRPLR } & \multicolumn{2}{|c|}{ PUHY-HP72THMU } & \multicolumn{2}{c|}{ PUHY-HP96THMU } \\
\cline { 2 - 5 } & Low & Hi & \multicolumn{1}{c|}{ Low } \\
\hline a & 0.301116 & -2.019472 & 0.635250 & 3.938307 \\
\hline $\mathrm{b}$ & 0.157290 & 8.585272 & 0.875555 & -7.091277 \\
\hline $\mathrm{c}$ & 0.809592 & -7.874677 & -0.174580 & 5.796324 \\
\hline $\mathrm{d}$ & -0.266570 & 2.308877 & 0.234770 & -1.643346 \\
\hline $\mathrm{R}^{2}$ & 0.9999 & 1 & 0.9999 & 1 \\
\hline
\end{tabular}




\begin{tabular}{|c|c|c|c|c|c|}
\hline \multicolumn{6}{|c|}{$\begin{array}{l}\text { CRcooling - Cooling Combination Ratio Correction Factor - PUHY-HP72THMU } \\
\qquad \text { CRcooling }=a+b^{*}(\text { Crrated })+c(\text { Crrated })^{\wedge} 2+c(\text { Crrated })^{\wedge} 3\end{array}$} \\
\hline & $\begin{array}{l}\text { Outdoor Unit } \\
\text { Capacity (kW) }\end{array}$ & $\begin{array}{l}\text { Capacity } \\
\text { Ratio }\end{array}$ & $\begin{array}{l}\text { Indoor Unit } \\
\text { Capacity (kBTUh) }\end{array}$ & $\begin{array}{l}\text { Indoor Unit } \\
\text { Capacity (kW) }\end{array}$ & $\begin{array}{l}\text { Condenser } \\
\text { PLR }\end{array}$ \\
\hline \multirow{4}{*}{ PLR $>=1$} & 21.10 & 1.000609 & 72.04 & 21.11 & 1.00 \\
\hline & 21.67 & 1.081942 & 80.00 & 23.45 & 1.11 \\
\hline & 22.4 & 1.177518 & 90.00 & 26.38 & 1.25 \\
\hline & 22.56 & 1.198006 & 92.22 & 27.03 & 1.28 \\
\hline
\end{tabular}

\begin{tabular}{|c|c|c|c|c|c|}
\hline \multicolumn{6}{|c|}{$\begin{array}{l}\text { CRcooling - Cooling Combination Ratio Correction Factor - PUHY-HP96THMU } \\
\qquad \text { CRcooling }=a+b^{*}(\text { Crrated })+c(\text { Crrated })^{\wedge} 2+c(\text { Crrated })^{\wedge} 3\end{array}$} \\
\hline & $\begin{array}{l}\text { Outdoor Unit } \\
\text { Capacity (kW) }\end{array}$ & $\begin{array}{l}\text { Capacity } \\
\text { Ratio }\end{array}$ & $\begin{array}{l}\text { Indoor Unit } \\
\text { Capacity (kBTUh) }\end{array}$ & $\begin{array}{l}\text { Indoor Unit } \\
\text { Capacity (kW) }\end{array}$ & $\begin{array}{l}\text { Condenser } \\
\text { PLR }\end{array}$ \\
\hline \multirow{5}{*}{ PLR $>=1$} & 28.14 & 1 & 96.02 & 28.14 & 1.00 \\
\hline & 28.41 & 1.031577 & 100.00 & 29.31 & 1.04 \\
\hline & 29.05 & 1.109736 & 110.00 & 32.24 & 1.15 \\
\hline & 30.03 & 1.171113 & 120.00 & 35.17 & 1.25 \\
\hline & 30.19 & 1.211697 & 124.82 & 36.58 & 1.30 \\
\hline
\end{tabular}

\begin{tabular}{|l|r|r|}
\hline CRcooling & PUHY-HP72THMU & PUHY-HP96THMU \\
\hline $\mathrm{a}$ & 0.298527 & 0.308543 \\
\hline $\mathrm{b}$ & 0.703453 & 0.694022 \\
\hline $\mathrm{R}^{2}$ & 0.9997 & 0.9979 \\
\hline
\end{tabular}




\begin{tabular}{|c|c|c|c|c|c|}
\hline \multicolumn{6}{|c|}{$\begin{array}{l}\text { CRheating - Heating Combination Ratio Correction Factor - PUHY-HP72 } \\
\text { Crheating }=a+b^{*}(\text { Crrated })+c(\text { Crrated })^{\wedge} 2+d(\text { Crrated })^{\wedge} 3\end{array}$} \\
\hline & $\begin{array}{l}\text { Outdoor Unit } \\
\text { Capacity (kW) }\end{array}$ & $\begin{array}{l}\text { Capacity } \\
\text { Ratio }\end{array}$ & $\begin{array}{l}\text { Indoor Unit } \\
\text { Capacity (kBTUh) }\end{array}$ & $\begin{array}{l}\text { Indoor Unit } \\
\text { Capacity (kW) }\end{array}$ & $\begin{array}{l}\text { Condenser } \\
\text { PLR }\end{array}$ \\
\hline \multirow{4}{*}{ PLR $>=1$} & 23.48 & 0.90 & 72 & 21.10 & 1.00 \\
\hline & 23.56 & 1.00 & 80 & 23.45 & 1.11 \\
\hline & 23.73 & 1.11 & 90 & 26.38 & 1.25 \\
\hline & 23.89 & 1.15 & 93.38 & 27.37 & 1.30 \\
\hline
\end{tabular}

\begin{tabular}{|c|c|c|c|c|c|}
\hline \multicolumn{6}{|c|}{$\begin{array}{l}\text { CRheating - Heating Combination Ratio Correction Factor- PUHY-HP96THMU } \\
\text { CRheating }=a+b^{*}(\text { CRrated })+c(\text { CRrated })^{\wedge} 2+d(\text { CRrated })^{\wedge} 3\end{array}$} \\
\hline & $\begin{array}{l}\text { Outdoor Unit } \\
\text { Capacity (kW) }\end{array}$ & $\begin{array}{l}\text { Capacity } \\
\text { Ratio }\end{array}$ & $\begin{array}{l}\text { Indoor Unit } \\
\text { Capacity (kBTUh) }\end{array}$ & $\begin{array}{l}\text { Indoor Unit } \\
\text { Capacity (kW) }\end{array}$ & $\begin{array}{l}\text { Condenser } \\
\text { PLR }\end{array}$ \\
\hline \multirow{5}{*}{ PLR $>=1$} & 31.68 & 0.89 & 96.02 & 28.14 & 1.00 \\
\hline & 31.76 & 0.92 & 100 & 29.31 & 1.04 \\
\hline & 31.84 & 1.01 & 110 & 32.24 & 1.15 \\
\hline & 31.87 & 1.10 & 120 & 35.17 & 1.25 \\
\hline & 31.93 & 1.14 & 124.52 & 36.49 & 1.30 \\
\hline
\end{tabular}

\begin{tabular}{|l|r|r|}
\hline CRheating & PUHY-HP72THMU & PUHY-HP96THMU \\
\hline $\mathrm{a}$ & 0.065187 & 0.026506 \\
\hline $\mathrm{b}$ & 0.835144 & 0.861139 \\
\hline $\mathrm{R}^{2}$ & 0.9995 & 0.9999 \\
\hline
\end{tabular}




\begin{tabular}{|c|c|c|c|c|c|c|c|}
\hline \multicolumn{8}{|c|}{$\begin{array}{l}\text { Pcorrection - Piping Correction Factor for Length in Cooling Mode } \\
\text { Pcorrection }=a+b^{*}\left(P_{-} E Q, \text { cooling }\right)+c^{*}\left(P_{-} E Q, \text { cooling }\right)^{\wedge} 2+d^{*}(\text { CRcooling })+e(\text { CRcooling })^{\wedge} 2\end{array}$} \\
\hline Piping Correction & Length (ft.) & Length (m) & Length^2 & $\mathrm{CR}$ & $\mathrm{CR}^{\wedge} 2$ & Length*CR & Predicted \\
\hline 1 & 25 & 7.62 & 58.0644 & 1.3 & 1.69 & 9.906 & 1.007 \\
\hline 0.985 & 50 & 15.24 & 232.2576 & 1.3 & 1.69 & 19.812 & 0.994 \\
\hline 0.957 & 100 & 30.48 & 929.0304 & 1.3 & 1.69 & 39.624 & 0.967 \\
\hline 0.903 & 200 & 60.96 & 3716.1216 & 1.3 & 1.69 & 79.248 & 0.914 \\
\hline 0.854 & 300 & 91.44 & 8361.2736 & 1.3 & 1.69 & 118.872 & 0.860 \\
\hline 0.81 & 400 & 121.92 & 14864.4864 & 1.3 & 1.69 & 158.496 & 0.805 \\
\hline 0.77 & 500 & 152.4 & 23225.76 & 1.3 & 1.69 & 198.12 & 0.749 \\
\hline 0.74 & 575 & 175.26 & 30716.0676 & 1.3 & 1.69 & 227.838 & 0.706 \\
\hline 1 & 25 & 7.62 & 58.0644 & 1 & 1 & 7.62 & 0.983 \\
\hline 0.986 & 50 & 15.24 & 232.2576 & 1 & 1 & 15.24 & 0.974 \\
\hline 0.961 & 100 & 30.48 & 929.0304 & 1 & 1 & 30.48 & 0.956 \\
\hline 0.91 & 200 & 60.96 & 3716.1216 & 1 & 1 & 60.96 & 0.920 \\
\hline 0.863 & 300 & 91.44 & 8361.2736 & 1 & 1 & 91.44 & 0.883 \\
\hline 0.821 & 400 & 121.92 & 14864.4864 & 1 & 1 & 121.92 & 0.845 \\
\hline 0.784 & 500 & 152.4 & 23225.76 & 1 & 1 & 152.4 & 0.806 \\
\hline 0.757 & 575 & 175.26 & 30716.0676 & 1 & 1 & 175.26 & 0.777 \\
\hline 1 & 25 & 7.62 & 58.0644 & 0.75 & 0.5625 & 5.715 & 0.990 \\
\hline 1 & 50 & 15.24 & 232.2576 & 0.75 & 0.5625 & 11.43 & 0.985 \\
\hline 1 & 100 & 30.48 & 929.0304 & 0.75 & 0.5625 & 22.86 & 0.975 \\
\hline 1 & 205 & 62.484 & 3904.25026 & 0.75 & 0.5625 & 46.863 & 0.952 \\
\hline 0.953 & 300 & 91.44 & 8361.2736 & 0.75 & 0.5625 & 68.58 & 0.930 \\
\hline 0.907 & 400 & 121.92 & 14864.4864 & 0.75 & 0.5625 & 91.44 & 0.906 \\
\hline 0.862 & 500 & 152.4 & 23225.76 & 0.75 & 0.5625 & 114.3 & 0.882 \\
\hline 0.83 & 575 & 175.26 & 30716.0676 & 0.75 & 0.5625 & 131.445 & 0.863 \\
\hline 1 & 25 & 7.62 & 58.0644 & 0.5 & 0.25 & 3.81 & 1.023 \\
\hline 1 & 50 & 15.24 & 232.2576 & 0.5 & 0.25 & 7.62 & 1.021 \\
\hline 1 & 100 & 30.48 & 929.0304 & 0.5 & 0.25 & 15.24 & 1.018 \\
\hline 1 & 200 & 60.96 & 3716.1216 & 0.5 & 0.25 & 30.48 & 1.010 \\
\hline 1 & 300 & 91.44 & 8361.2736 & 0.5 & 0.25 & 45.72 & 1.002 \\
\hline 1 & 400 & 121.92 & 14864.4864 & 0.5 & 0.25 & 60.96 & 0.993 \\
\hline 1 & 500 & 152.4 & 23225.76 & 0.5 & 0.25 & 76.2 & 0.983 \\
\hline 1 & 575 & 175.26 & 30716.0676 & 0.5 & 0.25 & 87.63 & 0.974 \\
\hline
\end{tabular}

\begin{tabular}{|l|r|}
\hline PCFLcooling & PUHY-HP72\&96THMU \\
\hline a & 1.2937951 \\
\hline $\mathrm{b}$ & -0.000934 \\
\hline $\mathrm{c}$ & -0.000000462 \\
\hline $\mathrm{d}$ & -0.518906 \\
\hline $\mathrm{e}$ & 0.1995131 \\
\hline $\mathrm{R}^{2}$ & 0.8034 \\
\hline
\end{tabular}


Pcorrection - Piping CorrectionFactor for Length in Heating Mode

Pcorrection $=a+b^{*}\left(P_{-} E Q\right.$, heating $)+c^{*}\left(P_{-} E Q \text {, heating }\right)^{\wedge} 2+d^{*}(C R h e a t i n g)+E(C R h e a t i n g) \wedge 2$

Length

Piping Correction

(ft.)

Length $(m) \quad$ Length^2

CR

$\mathrm{CR}^{\wedge} 2$ Length* $\mathrm{CR}$

Predicted

1
0.996

25

$7.62 \quad 58.0644$

$1.5 \quad 2.25$

11.43

1.000

0.987

$15.24 \quad 232.2576$

2.5

6.25

38.1

0.996

100

$30.48 \quad 929.0304$

$3.5 \quad 12.25$

106.68

0.987

0.97

$60.96 \quad 3716.1216$

4.5

274.32

0.970

0.954

300

$91.44 \quad 8361.2736$

5.5

20.25

502.92

0.954

0.941

400

$121.92 \quad 14864.4864$

6.5

30.25

792.48

0.941

0.928

$152.4 \quad 23225.76$

42.25

1143

0.928

0.921

575

$175.26 \quad 30716.0676$

$\begin{array}{ll}7.5 & 56.25\end{array}$

1489.71

0.921

\begin{tabular}{|l|r|}
\hline PCFLheating & PUHY-HP72\&96THMU \\
\hline a & 1.0046924 \\
\hline $\mathrm{b}$ & -0.000679 \\
\hline $\mathrm{c}$ & -0.0000006945 \\
\hline $\mathrm{d}$ & 0.00005871 \\
\hline $\mathrm{e}$ & 0.0001848 \\
\hline $\mathrm{R}^{2}$ & 0.9999 \\
\hline
\end{tabular}




\begin{tabular}{|c|c|c|c|c|c|c|}
\hline \multicolumn{7}{|c|}{ CCAPFT- Low Outdoor Dry-Bulb Temperatures } \\
\hline CAPFT & IWB & $I^{\prime W} B^{\wedge} 2$ & ODB & $\mathrm{ODB}^{\wedge} 2$ & IWB*ODB & Predicted \\
\hline 1.278 & 23.9 & 571.21 & -4.46 & 19.8916 & -106.594 & 1.274207 \\
\hline 1.278 & 23.9 & 571.21 & -1.1 & 1.21 & -26.29 & 1.27372 \\
\hline 1.278 & 23.9 & 571.21 & 4.4 & 19.36 & 105.16 & 1.272873 \\
\hline 1.278 & 23.9 & 571.21 & 10 & 100 & 239 & 1.27195 \\
\hline 1.278 & 23.9 & 571.21 & 15.32 & 234.7024 & 366.148 & 1.271014 \\
\hline 1.205 & 22.2 & 492.84 & -4.46 & 19.8916 & -99.012 & 1.203631 \\
\hline 1.203 & 22.2 & 492.84 & -1.1 & 1.21 & -24.42 & 1.203277 \\
\hline 1.201 & 22.2 & 492.84 & 4.4 & 19.36 & 97.68 & 1.202648 \\
\hline 1.2005 & 22.2 & 492.84 & 10 & 100 & 222 & 1.201946 \\
\hline 1.199 & 22.2 & 492.84 & 16 & 256 & 355.2 & 1.201125 \\
\hline 1.125 & 20.6 & 424.36 & -4.46 & 19.8916 & -91.876 & 1.140784 \\
\hline 1.125 & 20.6 & 424.36 & -1.1 & 1.21 & -22.66 & 1.140554 \\
\hline 1.125 & 20.6 & 424.36 & 4.4 & 19.36 & 90.64 & 1.14013 \\
\hline 1.125 & 20.6 & 424.36 & 10 & 100 & 206 & 1.139637 \\
\hline 1.125 & 20.6 & 424.36 & 15.6 & 243.36 & 321.36 & 1.139081 \\
\hline 1.125 & 20.6 & 424.36 & 16.9 & 285.61 & 348.14 & 1.138944 \\
\hline 1.097 & 19.4 & 376.36 & -4.46 & 19.8916 & -86.524 & 1.095924 \\
\hline 1.097 & 19.4 & 376.36 & -1.1 & 1.21 & -21.34 & 1.095789 \\
\hline 1.097 & 19.4 & 376.36 & 4.4 & 19.36 & 85.36 & 1.095519 \\
\hline 1.097 & 19.4 & 376.36 & 10 & 100 & 194 & 1.095182 \\
\hline 1.097 & 19.4 & 376.36 & 15.6 & 243.36 & 302.64 & 1.094783 \\
\hline 1.097 & 19.4 & 376.36 & 17.5 & 306.25 & 339.5 & 1.094633 \\
\hline 1.055 & 17.8 & 316.84 & -4.46 & 19.8916 & -79.388 & 1.039147 \\
\hline 1.055 & 17.8 & 316.84 & -1.1 & 1.21 & -19.58 & 1.039137 \\
\hline 1.055 & 17.8 & 316.84 & 4.4 & 19.36 & 78.32 & 1.039071 \\
\hline 1.055 & 17.8 & 316.84 & 10 & 100 & 178 & 1.038943 \\
\hline 1.055 & 17.8 & 316.84 & 15.6 & 243.36 & 277.68 & 1.038753 \\
\hline 1.055 & 17.8 & 316.84 & 17.8 & 316.84 & 316.84 & 1.038661 \\
\hline 0.98 & 16.1 & 259.21 & -4.46 & 19.8916 & -71.806 & 0.982622 \\
\hline 0.98 & 16.1 & 259.21 & -1.1 & 1.21 & -17.71 & 0.982745 \\
\hline 0.98 & 16.1 & 259.21 & 4.4 & 19.36 & 70.84 & 0.982897 \\
\hline 0.98 & 16.1 & 259.21 & 10 & 100 & 161 & 0.98299 \\
\hline 0.98 & 16.1 & 259.21 & 15.6 & 243.36 & 251.16 & 0.983022 \\
\hline 0.98 & 16.1 & 259.21 & 18.35 & 336.7225 & 295.435 & 0.983014 \\
\hline 0.945 & 15 & 225 & -4.46 & 19.8916 & -66.9 & 0.948134 \\
\hline 0.945 & 15 & 225 & -1.1 & 1.21 & -16.5 & 0.948342 \\
\hline 0.945 & 15 & 225 & 4.4 & 19.36 & 66 & 0.948636 \\
\hline 0.945 & 15 & 225 & 10 & 100 & 150 & 0.948872 \\
\hline 0.945 & 15 & 225 & 15.6 & 243.36 & 234 & 0.949047 \\
\hline 0.945 & 15 & 225 & 18.7 & 349.69 & 280.5 & 0.949117 \\
\hline
\end{tabular}




\begin{tabular}{|c|c|c|c|c|c|c|}
\hline \multicolumn{7}{|c|}{ CCAPFT- High Outdoor Dry-Bulb Temperatures } \\
\hline CCAPFT & IWB & $\mathrm{IWB}^{\wedge} 2$ & ODB & $\mathrm{ODB}^{\wedge} 2$ & IWB*ODB & Predicted \\
\hline 1.278 & 23.9 & 571.21 & 15.32 & 234.7024 & 366.148 & 1.27437 \\
\hline 1.25 & 23.9 & 571.21 & 21.1 & 445.21 & 504.29 & 1.251025 \\
\hline 1.227 & 23.9 & 571.21 & 26.7 & 712.89 & 638.13 & 1.226888 \\
\hline 1.205 & 23.9 & 571.21 & 32.2 & 1036.84 & 769.58 & 1.201728 \\
\hline 1.18 & 23.9 & 571.21 & 37.8 & 1428.84 & 903.42 & 1.174628 \\
\hline 1.1605 & 23.9 & 571.21 & 42.2 & 1780.84 & 1008.58 & 1.152287 \\
\hline 1.199 & 22.2 & 492.84 & 6 & 256 & 555.2 & 1.20175 \\
\hline 1.177 & 22.2 & 492.84 & 21.1 & 445.21 & 468.42 & 1.181523 \\
\hline 1.155 & 22.2 & 492.84 & 26.7 & 712.89 & 592.74 & 1.157884 \\
\hline 1.13 & 22.2 & 492.84 & 32.2 & 1036.84 & 714.84 & 1.133213 \\
\hline 1.104 & 22.2 & 492.84 & 37.8 & 1428.84 & 839.16 & 1.106612 \\
\hline 1.082 & 22.2 & 492.84 & .2 & 1780.84 & 36.84 & .084663 \\
\hline 1.125 & 20.6 & 424.36 & 16.9 & 285.61 & 48.14 & 137065 \\
\hline 1.09 & 20.6 & 424.36 & 26.7 & 712.89 & 550.02 & 1.0975 \\
\hline 1.073 & 20.6 & 424.36 & 32.2 & 1036.84 & 663.32 & 1.07329 \\
\hline 1.035 & 20.6 & 424.36 & 37.8 & 428.84 & 78.68 & 1.047158 \\
\hline 1.015 & 20.6 & 424.36 & 42.2 & 1780.84 & 869.32 & 1.025577 \\
\hline 1.097 & 19.4 & 376.36 & 17.5 & 306.25 & 339.5 & 1.09181 \\
\hline 1.071 & 19.4 & 376.36 & 26.7 & 712.89 & 517.98 & 1.055114 \\
\hline 1.032 & 19.4 & 376.36 & 32.2 & 1036.84 & 624.68 & 1.031249 \\
\hline 1.003 & 19.4 & 376.36 & 37.8 & 1428.84 & 733.32 & 1.005469 \\
\hline 0.982 & 19.4 & 376.36 & 42.2 & 1780.84 & 818.68 & 0.984165 \\
\hline 1.055 & 17.8 & 316.84 & 17.8 & 316.84 & 316.84 & 1.037285 \\
\hline 1.015 & 17.8 & 316.84 & 26.7 & 712.89 & 475.26 & 1.002468 \\
\hline 0.985 & 17.8 & 316.84 & 32.2 & 1036.84 & 573.16 & 0.979064 \\
\hline 0.97 & 17.8 & 316.84 & 37.8 & 1428.84 & 672.84 & 0.953754 \\
\hline 0.94 & 17.8 & 316.84 & 42.2 & 1780.84 & 751.16 & 0.932818 \\
\hline 0.98 & 16.1 & 259.21 & 18.35 & 336.7225 & 295.435 & 0.983409 \\
\hline 0.94 & 16.1 & 259.21 & 26.7 & 712.89 & 429.87 & 0.951378 \\
\hline 0.92 & 16.1 & 259.21 & 32.2 & 1036.84 & 518.42 & 0.928464 \\
\hline 0.893 & 16.1 & 259.21 & 37.8 & 1428.84 & 608.58 & 0.903652 \\
\hline 0.877 & 16.1 & 259.21 & 42.2 & 1780.84 & 679.42 & 0.883108 \\
\hline 0.945 & 15 & 225 & 18.7 & 349.69 & 280.5 & 0.951274 \\
\hline 0.92 & 15 & 225 & 26.7 & 712.89 & 400.5 & 0.920979 \\
\hline 0.898 & 15 & 225 & 32.2 & 1036.84 & 483 & 0.898382 \\
\hline 0.88 & 15 & 225 & 37.8 & 1428.84 & 567 & 0.873893 \\
\hline 0.86 & 15 & 225 & 42.2 & 1780.84 & 633 & 0.853603 \\
\hline
\end{tabular}




\begin{tabular}{|c|c|c|c|c|}
\hline \multicolumn{5}{|c|}{$\begin{array}{c}\text { CCAPFT }- \text { Boundary Curve } \\
O D B=a+b^{*} I W B+c^{*} I W B^{\wedge} 2+d^{*} I W B^{\wedge} 3\end{array}$} \\
\hline ODB & IWB & $I W B^{\wedge} 2$ & $I^{\prime} B^{\wedge} 3$ & Predicted \\
\hline 15.32 & 23.9 & 571.21 & 13651.92 & 15.27059 \\
\hline 16 & 22.2 & 492.84 & 10941.05 & 16.141 \\
\hline 16.9 & 20.6 & 424.36 & 8741.816 & 16.86241 \\
\hline 17.5 & 19.4 & 376.36 & 7301.384 & 17.34202 \\
\hline 17.8 & 17.8 & 316.84 & 5639.752 & 17.90061 \\
\hline 18.35 & 16.1 & 259.21 & 4173.281 & 18.39412 \\
\hline 18.7 & 15 & 225 & 3375 & 18.65926 \\
\hline
\end{tabular}

\begin{tabular}{|l|r|r|r|}
\hline CCAPFT & Low & High & Boundary \\
\hline $\mathrm{a}$ & 0.64328 & 0.78328 & 18.25046 \\
\hline $\mathrm{b}$ & 0.010179 & 0.002171 & 0.264613 \\
\hline $\mathrm{c}$ & 0.000677 & 0.000864 & -0.01504 \\
\hline $\mathrm{d}$ & 0.000406 & -0.001920 & -0.000052 \\
\hline $\mathrm{e}$ & -0.00000099 & -0.000024 & - \\
\hline $\mathrm{f}$ & -0.000023 & -0.000052 & - \\
\hline $\mathrm{R}^{2}$ & 0.9930 & 0.9954 & 0.9931 \\
\hline
\end{tabular}


CEIRFT - Low Outdoor Dry-Bulb Temperatures

CEIRFT $=a+b^{*} I W B+c^{*} I W B^{\wedge} 2+d^{*} O D B+e^{*} O D^{\wedge} 2+f^{*} I W B^{*} O D B$

\begin{tabular}{|c|c|c|c|c|c|c|c|c|c|}
\hline $\begin{array}{l}\text { Power } \\
\text { Ratio }\end{array}$ & $\begin{array}{l}\text { Capacity } \\
\text { Ratio }\end{array}$ & EIRFT & IWB & $I W B^{\wedge} 2$ & ODB & $\mathrm{ODB}^{\wedge} 2$ & IWB*ODB & $\begin{array}{l}\text { Predicted } \\
\text { Power Ratio }\end{array}$ & $\begin{array}{l}\text { Predicted } \\
\text { EIRFT }\end{array}$ \\
\hline 0.685 & 1.278 & 0.535994 & 23.9 & 571.21 & -4.46 & 19.8916 & -106.594 & 0.6666013 & 0.5195587 \\
\hline 0.7 & 1.278 & 0.547731 & 23.9 & 571.21 & -1.1 & 1.21 & -26.29 & 0.6846103 & 0.5341709 \\
\hline 0.73 & 1.278 & 0.571205 & 23.9 & 571.21 & 4.4 & 19.36 & 105.16 & 0.7144784 & 0.5584899 \\
\hline 0.757 & 1.278 & 0.592332 & 23.9 & 571.21 & 10 & 100 & 239 & 0.745386 & 0.5837615 \\
\hline 0.778 & 1.278 & 0.608764 & 23.9 & 571.21 & 15.32 & 234.7024 & 366.148 & 0.7752121 & 0.6082466 \\
\hline 0.665 & 1.205 & 0.551867 & 22.2 & 492.84 & -4.46 & 19.8916 & -99.012 & 0.6735744 & 0.5613928 \\
\hline 0.68 & 1.203 & 0.565254 & 22.2 & 492.84 & -1.1 & 1.21 & -24.42 & 0.6907919 & 0.5759702 \\
\hline 0.71 & 1.201 & 0.591174 & 22.2 & 492.84 & 4.4 & 19.36 & 97.68 & 0.7193644 & 0.6002323 \\
\hline 0.74 & 1.2005 & 0.61641 & 22.2 & 492.84 & 10 & 100 & 222 & 0.7489529 & 0.6254459 \\
\hline 0.77 & 1.199 & 0.642202 & 22.2 & 492.84 & 16 & 256 & 355.2 & 0.7812107 & 0.6530321 \\
\hline 0.645 & 1.125 & 0.573333 & 20.6 & 424.36 & -4.46 & 19.8916 & -91.876 & 0.6648717 & 0.5850117 \\
\hline 0.665 & 1.125 & 0.591111 & 20.6 & 424.36 & -1.1 & 1.21 & -22.66 & 0.6813443 & 0.5995563 \\
\hline 0.687 & 1.125 & 0.610667 & 20.6 & 424.36 & 4.4 & 19.36 & 90.64 & 0.7086975 & 0.6237648 \\
\hline 0.725 & 1.125 & 0.644444 & 20.6 & 424.36 & 10 & 100 & 206 & 0.7370445 & 0.6489239 \\
\hline 0.75 & 1.125 & 0.666667 & 20.6 & 424.36 & 15.6 & 243.36 & 321.36 & 0.7658924 & 0.674598 \\
\hline 0.76 & 1.125 & 0.675556 & 20.6 & 424.36 & 16.9 & 285.61 & 348.14 & 0.7726609 & 0.6806318 \\
\hline 0.64 & 1.097 & 0.583409 & 19.4 & 376.36 & -4.46 & 19.8916 & -86.524 & 0.6486303 & 0.5927002 \\
\hline 0.66 & 1.097 & 0.601641 & 19.4 & 376.36 & -1.1 & 1.21 & -21.34 & 0.6645442 & 0.6072203 \\
\hline 0.685 & 1.097 & 0.62443 & 19.4 & 376.36 & 4.4 & 19.36 & 85.36 & 0.6909829 & 0.6313886 \\
\hline 0.72 & 1.097 & 0.656335 & 19.4 & 376.36 & 10 & 100 & 194 & 0.7183988 & 0.6565067 \\
\hline 0.745 & 1.097 & 0.679125 & 19.4 & 376.36 & 15.6 & 243.36 & 302.64 & 0.7463155 & 0.68214 \\
\hline 0.755 & 1.097 & 0.688241 & 19.4 & 376.36 & 17.5 & 306.25 & 339.5 & 0.7559011 & 0.690954 \\
\hline 0.63 & 1.055 & 0.597156 & 17.8 & 316.84 & -4.46 & 19.8916 & -79.388 & 0.6140226 & 0.5895841 \\
\hline 0.65 & 1.055 & 0.616114 & 17.8 & 316.84 & -1.1 & 1.21 & -19.58 & 0.6291916 & 0.6040715 \\
\hline 0.68 & 1.055 & 0.64455 & 17.8 & 316.84 & 4.4 & 19.36 & 78.32 & 0.6544109 & 0.6281862 \\
\hline 0.71 & 1.055 & 0.672986 & 17.8 & 316.84 & 10 & 100 & 178 & 0.6805853 & 0.6532498 \\
\hline 0.738 & 1.055 & 0.699526 & 17.8 & 316.84 & 15.6 & 243.36 & 277.68 & 0.7072605 & 0.6788284 \\
\hline 0.744 & 1.055 & 0.705213 & 17.8 & 316.84 & 17.8 & 316.84 & 316.84 & 0.7178771 & 0.6890181 \\
\hline 0.572 & 0.98 & 0.583673 & 16.1 & 259.21 & -4.46 & 19.8916 & -71.806 & 0.5610323 & 0.5695342 \\
\hline 0.588 & 0.98 & 0.6 & 16.1 & 259.21 & -1.1 & 1.21 & -17.71 & 0.5754098 & 0.5839868 \\
\hline 0.618 & 0.98 & 0.630612 & 16.1 & 259.21 & 4.4 & 19.36 & 70.84 & 0.5993336 & 0.6080445 \\
\hline 0.64 & 0.98 & 0.653061 & 16.1 & 259.21 & 10 & 100 & 161 & 0.6241888 & 0.6330501 \\
\hline 0.665 & 0.98 & 0.678571 & 16.1 & 259.21 & 15.6 & 243.36 & 251.16 & 0.649545 & 0.6585708 \\
\hline 0.678 & 0.98 & 0.691837 & 16.1 & 259.21 & 18.35 & 336.7225 & 295.435 & 0.66218 & 0.6712918 \\
\hline 0.512 & 0.945 & 0.541799 & 15 & 225 & -4.46 & 19.8916 & -66.9 & 0.5178395 & 0.5473705 \\
\hline 0.523 & 0.945 & 0.553439 & 15 & 225 & -1.1 & 1.21 & -16.5 & 0.5317049 & 0.5618006 \\
\hline 0.54 & 0.945 & 0.571429 & 15 & 225 & 4.4 & 19.36 & 66 & 0.5547904 & 0.5858215 \\
\hline 0.56 & 0.945 & 0.592593 & 15 & 225 & 10 & 100 & 150 & 0.5787921 & 0.6107896 \\
\hline 0.578 & 0.945 & 0.61164 & 15 & 225 & 15.6 & 243.36 & 234 & 0.6032947 & 0.6362727 \\
\hline 0.588 & 0.945 & 0.622222 & 15 & 225 & 18.7 & 349.69 & 280.5 & 0.6170741 & 0.650601 \\
\hline
\end{tabular}


CEIRFT - High Outdoor Dry-Bulb Temperatures

CEIRFT $=a+b^{*} I W B+c^{*} I W B^{\wedge} 2+d^{*} O D B+e^{*} O D B^{\wedge} 2+f^{*} I W B^{*} O D B$

\begin{tabular}{|c|c|c|c|c|c|c|c|c|c|}
\hline $\begin{array}{l}\text { Power } \\
\text { Ratio }\end{array}$ & $\begin{array}{l}\text { Capacity } \\
\text { Ratio }\end{array}$ & EIRFT & IWB & IWB^2 & ODB & $\mathrm{ODB}^{\wedge} 2$ & IWB*ODB & $\begin{array}{l}\text { Predicted } \\
\text { Power Ratio }\end{array}$ & $\begin{array}{l}\text { Predicted } \\
\text { EIRFT }\end{array}$ \\
\hline 0.778 & 1.278 & 0.608764 & 23.9 & 571.21 & 15.32 & 234.7024 & 366.148 & 0.77260257 & 0.6033167 \\
\hline 0.86 & 1.25 & 0.688 & 23.9 & 571.21 & 21.1 & 445.21 & 504.29 & 0.8541684 & 0.6770684 \\
\hline 0.937 & 1.227 & 0.763651 & 23.9 & 571.21 & 26.7 & 712.89 & 638.13 & 0.93310056 & 0.7543931 \\
\hline 1.085 & 1.205 & 0.900415 & 23.9 & 571.21 & 32.2 & 1036.84 & 769.58 & 1.01053359 & 0.8359601 \\
\hline 1.082 & 1.18 & 0.916949 & 23.9 & 571.21 & 37.8 & 1428.84 & 903.42 & 1.08928324 & 0.9247355 \\
\hline 1.142 & 1.1605 & 0.984059 & 23.9 & 571.21 & 42.2 & 1780.84 & 1008.58 & 1.15109337 & 0.9985402 \\
\hline 0.77 & 1.199 & 0.642202 & 22.2 & 492.84 & 16 & 256 & 355.2 & 0.77686457 & 0.6504399 \\
\hline 0.84 & 1.177 & 0.713679 & 22.2 & 492.84 & 21.1 & 445.21 & 468.42 & 0.84859767 & 0.7201307 \\
\hline 0.917 & 1.155 & 0.793939 & 22.2 & 492.84 & 26.7 & 712.89 & 592.74 & 0.92727548 & 0.8021729 \\
\hline 1.03 & 1.13 & 0.911504 & 22.2 & 492.84 & 32.2 & 1036.84 & 714.84 & 1.00445869 & 0.8883732 \\
\hline 1.072 & 1.104 & 0.971014 & 22.2 & 492.84 & 37.8 & 1428.84 & 839.16 & 1.08295398 & 0.981866 \\
\hline 1.13 & 1.082 & 1.044362 & 22.2 & 492.84 & 42.2 & 1780.84 & 936.84 & 1.14456426 & 1.0593774 \\
\hline 0.76 & 1.125 & 0.675556 & 20.6 & 424.36 & 16.9 & 285.61 & 348.14 & 0.7696181 & 0.6814594 \\
\hline 0.795 & 1.09 & 0.729358 & 20.6 & 424.36 & 26.7 & 712.89 & 550.02 & 0.90694573 & 0.8290122 \\
\hline 0.948 & 1.073 & 0.883504 & 20.6 & 424.36 & 32.2 & 1036.84 & 663.32 & 0.98389383 & 0.9195732 \\
\hline 1.045 & 1.035 & 1.009662 & 20.6 & 424.36 & 37.8 & 1428.84 & 778.68 & 1.06214972 & 1.017506 \\
\hline 1.106 & 1.015 & 1.089655 & 20.6 & 424.36 & 42.2 & 1780.84 & 869.32 & 1.12357191 & 1.098506 \\
\hline 0.755 & 1.097 & 0.688241 & 19.4 & 376.36 & 17.5 & 306.25 & 339.5 & 0.75363339 & 0.6931063 \\
\hline 0.89 & 1.071 & 0.830999 & 19.4 & 376.36 & 26.7 & 712.89 & 517.98 & 0.88225014 & 0.8376044 \\
\hline 0.943 & 1.032 & 0.91376 & 19.4 & 376.36 & 32.2 & 1036.84 & 624.68 & 0.95902189 & 0.9314359 \\
\hline 1.04 & 1.003 & 1.036889 & 19.4 & 376.36 & 37.8 & 1428.84 & 733.32 & 1.03709824 & 1.0326988 \\
\hline 1.102 & 0.982 & 1.1222 & 19.4 & 376.36 & 42.2 & 1780.84 & 818.68 & 1.09837935 & 1.1163152 \\
\hline 0.744 & 1.055 & 0.705213 & 17.8 & 316.84 & 17.8 & 316.84 & 316.84 & 0.71268663 & 0.6865891 \\
\hline 0.875 & 1.015 & 0.862069 & 17.8 & 316.84 & 26.7 & 712.89 & 475.26 & 0.83672497 & 0.8336776 \\
\hline 0.953 & 0.985 & 0.967513 & 17.8 & 316.84 & 32.2 & 1036.84 & 573.16 & 0.9132616 & 0.9318699 \\
\hline 1.03 & 0.97 & 1.061856 & 17.8 & 316.84 & 37.8 & 1428.84 & 672.84 & 0.99109855 & 1.0375728 \\
\hline 1.092 & 0.94 & 1.161702 & 17.8 & 316.84 & 42.2 & 1780.84 & 751.16 & 1.05219156 & 1.1246777 \\
\hline 0.678 & 0.98 & 0.691837 & 16.1 & 259.21 & 18.35 & 336.7225 & 295.435 & 0.65659216 & 0.6647865 \\
\hline 0.792 & 0.94 & 0.842553 & 16.1 & 259.21 & 26.7 & 712.89 & 429.87 & 0.7725792 & 0.8102424 \\
\hline 0.86 & 0.92 & 0.934783 & 16.1 & 259.21 & 32.2 & 1036.84 & 518.42 & 0.84886602 & 0.913068 \\
\hline 0.94 & 0.893 & 1.052632 & 16.1 & 259.21 & 37.8 & 1428.84 & 608.58 & 0.92644861 & 1.0234884 \\
\hline 0.999 & 0.877 & 1.139111 & 16.1 & 259.21 & 42.2 & 1780.84 & 679.42 & 0.98734177 & 1.1142999 \\
\hline 0.588 & 0.945 & 0.622222 & 15 & 225 & 18.7 & 349.69 & 280.5 & 0.61152611 & 0.640525 \\
\hline 0.7 & 0.92 & 0.76087 & 15 & 225 & 26.7 & 712.89 & 400.5 & 0.72241219 & 0.7845027 \\
\hline 0.777 & 0.898 & 0.865256 & 15 & 225 & 32.2 & 1036.84 & 483 & 0.79853736 & 0.8903262 \\
\hline 0.85 & 0.88 & 0.965909 & 15 & 225 & 37.8 & 1428.84 & 567 & 0.87595537 & 1.0037991 \\
\hline 0.91 & 0.86 & 1.05814 & 15 & 225 & 42.2 & 1780.84 & 633 & 0.93671921 & 1.0970091 \\
\hline
\end{tabular}




\begin{tabular}{|c|c|c|c|c|}
\hline \multicolumn{5}{|c|}{$\begin{array}{c}\text { CEIRFT - Boundary Curve } \\
\text { CEIRFT }=a+b^{*} I W B+c^{*} I W^{\wedge} 2+d^{*} I W B^{\wedge} 3\end{array}$} \\
\hline ODB & IWB & IWB^2 & $\mathrm{IWB}^{\wedge} 3$ & Predicted \\
\hline 15.32 & 23.9 & 571.21 & 13651.92 & 15.27059 \\
\hline 16 & 22.2 & 492.84 & 10941.05 & 16.141 \\
\hline 16.9 & 20.6 & 424.36 & 8741.816 & 16.86241 \\
\hline 17.5 & 19.4 & 376.36 & 7301.384 & 17.34202 \\
\hline 17.8 & 17.8 & 316.84 & 5639.752 & 17.90061 \\
\hline 18.35 & 16.1 & 259.21 & 4173.281 & 18.39412 \\
\hline 18.7 & 15 & 225 & 3375 & 18.65926 \\
\hline
\end{tabular}

\begin{tabular}{|l|r|r|r|}
\hline CEIRFT & Low & High & Boundary \\
\hline $\mathrm{a}$ & -0.760202 & -1.02873355 & 18.25046 \\
\hline $\mathrm{b}$ & 0.129003 & 0.14341878 & 0.264613 \\
\hline $\mathrm{c}$ & -0.002891 & -0.0034337 & -0.01504 \\
\hline $\mathrm{d}$ & 0.0020926 & 0.02124863 & -0.000052 \\
\hline $\mathrm{e}$ & 0.000007986 & 0.000092106 & - \\
\hline $\mathrm{f}$ & 0.0001386 & -0.00049554 & - \\
\hline $\mathrm{R}^{2}$ & 0.9496 & 0.9673 & 0.9931 \\
\hline
\end{tabular}




\begin{tabular}{|c|c|c|c|c|c|c|}
\hline \multicolumn{7}{|c|}{ HCAPFT- Low Outdoor Dry-Bulb Temperatures } \\
\hline HCAPFT & IWB & $I W B^{\wedge} 2$ & ODB & $\mathrm{ODB}^{\wedge} 2$ & IWB*ODB & Predicted \\
\hline 0.514 & 27.2 & 739.84 & -18.9 & 357.21 & -514.08 & 0.510619 \\
\hline 0.532 & 27.2 & 739.84 & -17.8 & 316.84 & -484.16 & 0.529802 \\
\hline 0.625 & 27.2 & 739.84 & -12.2 & 148.84 & -331.84 & 0.62802 \\
\hline 0.709 & 27.2 & 739.84 & -7.28 & 52.9984 & -198.016 & 0.715086 \\
\hline 0.531 & 25 & 625 & -18.9 & 357.21 & -472.5 & 0.522687 \\
\hline 0.55 & 25 & 625 & -17.8 & 316.84 & -445 & 0.542149 \\
\hline 0.643 & 25 & 625 & -12.2 & 148.84 & -305 & 0.64179 \\
\hline 0.738 & 25 & 625 & -6.7 & 44.89 & -167.5 & 0.740565 \\
\hline 0.794 & 25 & 625 & -3.3 & 10.89 & -82.5 & 0.80208 \\
\hline 0.527 & 21.1 & 445.21 & -18.9 & 357.21 & -398.79 & 0.538492 \\
\hline 0.55 & 21.1 & 445.21 & -17.8 & 316.84 & -375.58 & 0.558449 \\
\hline 0.656 & 21.1 & 445.21 & -12.2 & 148.84 & -257.42 & 0.660613 \\
\hline 0.764 & 21.1 & 445.21 & -6.7 & 44.89 & -141.37 & 0.761866 \\
\hline 0.869 & 21.1 & 445.21 & -1.1 & 1.21 & -23.21 & 0.865891 \\
\hline 0.976 & 21.1 & 445.21 & 4.4 & 19.36 & 92.84 & 0.968971 \\
\hline 0.998 & 21.1 & 445.21 & 5.5 & 30.25 & 116.05 & 0.989696 \\
\hline 0.55 & 15 & 225 & -18.9 & 357.21 & -283.5 & 0.548888 \\
\hline 0.572 & 15 & 225 & -17.8 & 316.84 & -267 & 0.56962 \\
\hline 0.677 & 15 & 225 & -12.2 & 148.84 & -183 & 0.67573 \\
\hline 0.784 & 15 & 225 & -6.7 & 44.89 & -100.5 & 0.780858 \\
\hline 0.89 & 15 & 225 & -1.1 & 1.21 & -16.5 & 0.888828 \\
\hline 0.995 & 15 & 225 & 4.4 & 19.36 & 66 & 0.995784 \\
\hline 1.103 & 15 & 225 & 10 & 100 & 150 & 1.105614 \\
\hline 1.154 & 15 & 225 & 12.7 & 161.29 & 190.5 & 1.158903 \\
\hline
\end{tabular}

\begin{tabular}{|c|c|c|c|c|c|c|}
\hline \multicolumn{7}{|c|}{$\begin{array}{c}\text { HCAPFT- High Outdoor Dry-Bulb Temperatures } \\
\text { HCAPFT }=a+b^{*} I W B+c^{*} I W^{\wedge} 2+d^{*} O D B+e^{*} O D B^{\wedge} 2+f^{*} I W B^{*} O D B\end{array}$} \\
\hline HCAPFT & IWB & $\mathrm{IWB}^{\wedge} 2$ & ODB & $\mathrm{ODB}^{\wedge} 2$ & IWB*ODB & Predicted \\
\hline 0.709 & 27.2 & 739.84 & -7.28 & 52.9984 & -198.016 & 0.702632 \\
\hline 0.709 & 27.2 & 739.84 & -6.7 & 44.89 & -182.24 & 0.702668 \\
\hline 0.709 & 27.2 & 739.84 & -1.1 & 1.21 & -29.92 & 0.702507 \\
\hline 0.709 & 27.2 & 739.84 & 4.4 & 19.36 & 119.68 & 0.701454 \\
\hline 0.709 & 27.2 & 739.84 & 10 & 100 & 272 & 0.699468 \\
\hline 0.709 & 27.2 & 739.84 & 14.5 & 210.25 & 394.4 & 0.697206 \\
\hline 0.794 & 25 & 625 & -3.3 & 10.89 & -82.5 & 0.808518 \\
\hline 0.794 & 25 & 625 & -1.1 & 1.21 & -27.5 & 0.809698 \\
\hline 0.794 & 25 & 625 & 4.4 & 19.36 & 110 & 0.812026 \\
\hline 0.792 & 25 & 625 & 10 & 100 & 250 & 0.813485 \\
\hline 0.792 & 25 & 625 & 14.5 & 210.25 & 362.5 & 0.81399 \\
\hline 0.998 & 21.1 & 445.21 & 5.5 & 30.25 & 116.05 & 0.974118 \\
\hline 0.998 & 21.1 & 445.21 & 10 & 100 & 211 & 0.980123 \\
\hline
\end{tabular}




\begin{tabular}{|c|c|c|c|c|c|c|}
\hline 0.998 & 21.1 & 445.21 & 14.5 & 210.25 & 305.95 & 0.98553 \\
\hline 115 & 15 & 225 & 12.7 & 161.29 & 190.5 & 1.1 \\
\hline & 1 & 225 & 14.5 & 210.25 & 217.5 & 1.1 \\
\hline
\end{tabular}

\begin{tabular}{rrrrr}
\multicolumn{8}{c}{ HCAPFT - Boundary Curve } \\
\multicolumn{5}{c}{ ODB = $a+b^{*} I W B+c^{*} I W B^{\wedge} 2+d^{*} I W B^{\wedge} 3$} \\
\hline ODB & IWB & IWB^2 & IWB^3 & Predicted \\
-7.28 & 27.2 & 739.84 & 20123.65 & -7.28 \\
-3.3 & 25 & 625 & 15625 & -3.3 \\
5.5 & 21.1 & 445.21 & 9393.931 & 5.5 \\
12.7 & 15 & 225 & 3375 & 12.7
\end{tabular}

\begin{tabular}{|l|r|r|r|}
\hline HCAPFT & Low & High & Boundary \\
\hline $\mathrm{a}$ & 0.894127 & 1.021813 & -121.004 \\
\hline $\mathrm{b}$ & 0.004591 & 0.028823 & 20.78343 \\
\hline $\mathrm{c}$ & -0.000230 & -0.001491 & -1.01379 \\
\hline $\mathrm{d}$ & 0.021130 & 0.007460 & 0.014831 \\
\hline $\mathrm{e}$ & 0.000015 & -0.000015 & - \\
\hline $\mathrm{f}$ & -0.000116 & -0.000280 & - \\
\hline $\mathrm{R}^{2}$ & 0.9992 & 0.9916 & 1 \\
\hline
\end{tabular}


HEIRFT - Low Outdoor Dry-Bulb Temperatures

HEIRFT $=a+b^{*} I W B+c^{*} I W^{\wedge} 2+d^{*} O D B+e^{*} O D^{\wedge} 2+f^{*} I W B^{*} O D B$

\begin{tabular}{|c|c|c|c|c|c|c|c|c|c|}
\hline $\begin{array}{l}\text { Power } \\
\text { Ratio }\end{array}$ & $\begin{array}{l}\text { Capacity } \\
\text { Ratio }\end{array}$ & EIRFT & IWB & IWB^2 & ODB & $\mathrm{ODB}^{\wedge} 2$ & IWB*ODB & $\begin{array}{l}\text { Predicted } \\
\text { Power Ratio }\end{array}$ & $\begin{array}{l}\text { Predicted } \\
\text { EIRFT }\end{array}$ \\
\hline 0.883 & 0.514 & 1.717899 & 27.2 & 739.84 & -18.9 & 357.21 & -514.08 & 0.887028796 & 1.70332144 \\
\hline 0.889 & 0.532 & 1.671053 & 27.2 & 739.84 & -17.8 & 316.84 & -484.16 & 0.891645653 & 1.66309171 \\
\hline 0.915 & 0.625 & 1.464 & 27.2 & 739.84 & -12.2 & 148.84 & -331.84 & 0.922949035 & 1.481845312 \\
\hline 0.958 & 0.709 & 1.351199 & 27.2 & 739.84 & -7.28 & 52.9984 & -198.016 & 0.961210455 & 1.355107459 \\
\hline 0.858 & 0.531 & 1.615819 & 25 & 625 & -18.9 & 357.21 & -472.5 & 0.848769762 & 1.612437739 \\
\hline 0.861 & 0.55 & 1.565455 & 25 & 625 & -17.8 & 316.84 & -445 & 0.853162038 & 1.573111883 \\
\hline 0.886 & 0.643 & 1.377916 & 25 & 625 & -12.2 & 148.84 & -305 & 0.883322104 & 1.396467023 \\
\hline 0.931 & 0.738 & 1.261518 & 25 & 625 & -6.7 & 44.89 & -167.5 & 0.925634232 & 1.261310957 \\
\hline 0.967 & 0.794 & 1.217884 & 25 & 625 & -3.3 & 10.89 & -82.5 & 0.95808105 & 1.196760746 \\
\hline 0.786 & 0.527 & 1.491461 & 21.1 & 445.21 & -18.9 & 357.21 & -398.79 & 0.789888498 & 1.472565234 \\
\hline 0.792 & 0.55 & 1.44 & 21.1 & 445.21 & -17.8 & 316.84 & -375.58 & 0.793882655 & 1.434841699 \\
\hline 0.816 & 0.656 & 1.243902 & 21.1 & 445.21 & -12.2 & 148.84 & -257.42 & 0.822015934 & 1.266354112 \\
\hline 0.86 & 0.764 & 1.125654 & 21.1 & 445.21 & -6.7 & 44.89 & -141.37 & 0.862337466 & 1.139209653 \\
\hline 0.913 & 0.869 & 1.050633 & 21.1 & 445.21 & -1.1 & 1.21 & -23.21 & 0.91631349 & 1.048784886 \\
\hline 0.979 & 0.976 & 1.003074 & 21.1 & 445.21 & 4.4 & 19.36 & 92.84 & 0.982016291 & 0.998309269 \\
\hline 0.997 & 0.998 & 0.998998 & 21.1 & 445.21 & 5.5 & 30.25 & 116.05 & 0.996666007 & 0.992772833 \\
\hline 0.721 & 0.55 & 1.310909 & 15 & 225 & -18.9 & 357.21 & -283.5 & 0.720719266 & 1.308250573 \\
\hline 0.724 & 0.572 & 1.265734 & 15 & 225 & -17.8 & 316.84 & -267 & 0.724090724 & 1.273033233 \\
\hline 0.75 & 0.677 & 1.107829 & 15 & 225 & -12.2 & 148.84 & -183 & 0.749053898 & 1.117304457 \\
\hline 0.787 & 0.784 & 1.003827 & 15 & 225 & -6.7 & 44.89 & -100.5 & 0.786261936 & 1.002690972 \\
\hline 0.838 & 0.89 & 0.941573 & 15 & 225 & -1.1 & 1.21 & -16.5 & 0.837067856 & 0.925025017 \\
\hline 0.9 & 0.995 & 0.904523 & 15 & 225 & 4.4 & 19.36 & 66 & 0.899657162 & 0.887080374 \\
\hline 0.98 & 1.103 & 0.888486 & 15 & 225 & 10 & 100 & 150 & 0.976305828 & 0.88747724 \\
\hline 1.015 & 1.154 & 0.879549 & 15 & 225 & 12.7 & 161.29 & 190.5 & 1.017919864 & 0.901740238 \\
\hline
\end{tabular}

HEIRFT - High Outdoor Dry-Bulb Temperatures

HEIRFT $=a+b^{*} I W B+c^{*} I W^{\wedge} 2+d^{*} O D B+e^{*} O D^{\wedge} 2+f^{*} I W B^{*} O D B$

\begin{tabular}{|c|c|c|c|c|c|c|c|c|c|}
\hline $\begin{array}{l}\text { Power } \\
\text { Ratio }\end{array}$ & $\begin{array}{l}\text { Capacity } \\
\text { Ratio }\end{array}$ & EIRFT & IWB & IWB^2 & ODB & $\mathrm{ODB}^{\wedge} 2$ & IWB*ODB & $\begin{array}{l}\text { Predicted } \\
\text { Power Ratio }\end{array}$ & $\begin{array}{l}\text { Predicted } \\
\text { EIRFT }\end{array}$ \\
\hline 0.958 & 0.709 & 1.351199 & 27.2 & 739.84 & -7.28 & 52.9984 & -198.016 & 0.952935149 & 1.3513351 \\
\hline 0.947 & 0.709 & 1.335684 & 27.2 & 739.84 & -6.7 & 44.89 & -182.24 & 0.936030893 & 1.3277003 \\
\hline 0.802 & 0.709 & 1.131171 & 27.2 & 739.84 & -1.1 & 1.21 & -29.92 & 0.792929764 & 1.1275825 \\
\hline 0.682 & 0.709 & 0.961918 & 27.2 & 739.84 & 4.4 & 19.36 & 119.68 & 0.687863106 & 0.9805728 \\
\hline 0.634 & 0.709 & 0.894217 & 27.2 & 739.84 & 10 & 100 & 272 & 0.617010314 & 0.8813254 \\
\hline 0.589 & 0.709 & 0.830748 & 27.2 & 739.84 & 14.5 & 210.25 & 394.4 & 0.586488217 & 0.83845 \\
\hline 0.967 & 0.794 & 1.217884 & 25 & 625 & -3.3 & 10.89 & -82.5 & 0.988676759 & 1.2307332 \\
\hline 0.918 & 0.794 & 1.156171 & 25 & 625 & -1.1 & 1.21 & -27.5 & 0.928888551 & 1.1523443 \\
\hline 0.785 & 0.794 & 0.988665 & 25 & 625 & 4.4 & 19.36 & 110 & 0.804029654 & 0.990734 \\
\hline 0.704 & 0.792 & 0.888889 & 25 & 625 & 10 & 100 & 250 & 0.713024764 & 0.8766204 \\
\hline
\end{tabular}




\begin{tabular}{|c|c|c|c|c|c|c|c|c|c|}
\hline 0.653 & 0.792 & 0.824495 & 25 & 625 & 14.5 & 210.25 & 362.5 & 0.666309017 & 0.8217991 \\
\hline 0.997 & 0.998 & 0.998998 & 21.1 & 445.21 & 5.5 & 30.25 & 116.05 & 0.970877155 & 0.9947943 \\
\hline 0.884 & 0.998 & 0.885772 & 21.1 & 445.21 & 10 & 100 & 211 & 0.871917983 & 0.8859353 \\
\hline 0.802 & 0.998 & 0.803607 & 21.1 & 445.21 & 14.5 & 210.25 & 305.95 & 0.796495311 & 0.809937 \\
\hline 1.015 & 1.154 & 0.879549 & 15 & 225 & 12.7 & 161.29 & 190.5 & 1.016414141 & 0.876359 \\
\hline 0.964 & 1.156 & 0.83391 & 15 & 225 & 14.5 & 210.25 & 217.5 & 0.971109222 & 0.8366538 \\
\hline
\end{tabular}

\begin{tabular}{|c|c|c|c|c|}
\hline \multirow[b]{2}{*}{ ODB } & \multicolumn{4}{|c|}{$\begin{array}{r}\text { HEIRFT - Boundary Curve } \\
\text { HEIRFT }=a+b^{*} I W B+c^{*} I W^{\wedge} 2+d^{*}\end{array}$} \\
\hline & IWB & $\mathrm{IWB}^{\wedge} 2$ & $I W B^{\wedge} 3$ & Predicted \\
\hline-7.28 & 27.2 & 739.84 & 20123.65 & -7.28 \\
\hline-3.3 & 25 & 625 & 15625 & -3.3 \\
\hline 5.5 & 21.1 & 445.21 & 9393.931 & 5.5 \\
\hline 12.7 & 15 & 225 & 3375 & 12.7 \\
\hline
\end{tabular}

\begin{tabular}{|c|c|c|c|}
\hline HEIRFT & Low & High & Boundary \\
\hline$a$ & 0.898801 & 0.186895 & -121.004 \\
\hline$b$ & -0.012352 & -0.048667 & 20.78343 \\
\hline c & 0.000893 & 0.000742 & -1.01379 \\
\hline$d$ & -0.003369 & -0.062228 & 0.014831 \\
\hline $\mathrm{e}$ & 0.000628 & 0.000811 & - \\
\hline$f$ & -0.000374 & 0.001207 & - \\
\hline$R^{2}$ & 0.9975 & 0.9979 & 1 \\
\hline
\end{tabular}




\begin{tabular}{|c|c|c|c|c|c|c|c|c|}
\hline & $\begin{array}{l}\text { Cooling } \\
\text { Power } \\
\text { (kW) }\end{array}$ & $\begin{array}{l}\text { Normalized } \\
\text { EIRFPLR }\end{array}$ & $\begin{array}{l}\text { ling EIRFP } \\
\text { Indoor } \\
\text { Capacity } \\
\text { (kBTUh) }\end{array}$ & $\begin{array}{l}\text { R - PURY-P } \\
\text { Indoor } \\
\text { Unit } \\
\text { Capacity } \\
\text { (kW) }\end{array}$ & 68TSHMU-A & $\mathrm{PLR}^{\wedge} 2$ & $\mathrm{PLR}^{\wedge} 3$ & $\begin{array}{l}\text { Predicted } \\
\text { Power }\end{array}$ \\
\hline \multirow{6}{*}{ PLR $<=1$} & 7.56 & 0.53 & 84.59 & 24.79 & 0.51 & 0.26 & 0.13 & 0.53 \\
\hline & 8.65 & 0.61 & 100.00 & 29.31 & 0.60 & 0.36 & 0.21 & 0.61 \\
\hline & 10.14 & 0.71 & 120.00 & 35.17 & 0.72 & 0.52 & 0.37 & 0.71 \\
\hline & 11.76 & 0.83 & 140.00 & 41.03 & 0.84 & 0.70 & 0.59 & 0.83 \\
\hline & 13.54 & 0.95 & 160.00 & 46.89 & 0.96 & 0.92 & 0.88 & 0.95 \\
\hline & 14.19 & 1.00 & 167.00 & 48.94 & 1.00 & 1.00 & 1.00 & 1.00 \\
\hline \multirow{6}{*}{ PLR $>=1$} & 14.19 & 1.00 & 167.00 & 48.94 & 1.00 & 1.00 & 1.00 & 1.00 \\
\hline & 14.19 & 1.00 & 180.00 & 52.75 & 1.08 & 1.16 & 1.25 & 1.00 \\
\hline & 14.19 & 1.00 & 200.00 & 58.61 & 1.20 & 1.43 & 1.72 & 1.00 \\
\hline & 14.19 & 1.00 & 220.00 & 64.48 & 1.32 & 1.74 & 2.29 & 1.00 \\
\hline & 14.19 & 1.00 & 240.00 & 70.34 & 1.44 & 2.07 & 2.97 & 1.00 \\
\hline & 14.19 & 1.00 & 251.00 & 73.56 & 1.50 & 2.26 & 3.40 & 1.00 \\
\hline
\end{tabular}

\begin{tabular}{|c|c|c|c|c|c|c|c|c|}
\hline & & & Cooling EIRF & PLR - PURY-P2 & OTSHMU-A & & & \\
\hline & Cooling & & Indoor & Indoor Unit & & & & \\
\hline & $\begin{array}{l}\text { Power } \\
\text { (kW) }\end{array}$ & $\begin{array}{l}\text { Normalized } \\
\text { EIRFPLR }\end{array}$ & $\begin{array}{l}\text { Capacity } \\
\text { (kBTUh) }\end{array}$ & $\begin{array}{l}\text { Capacity } \\
(\mathrm{kW})\end{array}$ & PLR & $\mathrm{PLR}^{\wedge} 2$ & $\mathrm{PLR}^{\wedge} 3$ & $\begin{array}{l}\text { Predicted } \\
\text { Power }\end{array}$ \\
\hline & 10.26 & 0.48 & 120.00 & 35.17 & 0.50 & 0.25 & 0.13 & 0.47 \\
\hline & 11.64 & 0.54 & 140.00 & 41.03 & 0.59 & 0.34 & 0.20 & 0.54 \\
\hline & 13.28 & 0.62 & 160.00 & 46.89 & 0.67 & 0.45 & 0.30 & 0.61 \\
\hline$P L R<=1$ & 15.02 & 0.70 & 180.00 & 52.75 & 0.75 & 0.57 & 0.43 & 0.70 \\
\hline & 17.04 & 0.79 & 200.00 & 58.61 & 0.84 & 0.70 & 0.59 & 0.79 \\
\hline & 19.20 & 0.89 & 220.00 & 64.48 & 0.92 & 0.85 & 0.78 & 0.89 \\
\hline & 21.58 & 1.00 & 239.00 & 70.04 & 1.00 & 1.00 & 1.00 & 1.00 \\
\hline & 21.58 & 1.00 & 239.00 & 70.04 & 1.00 & 1.00 & 1.00 & 1.00 \\
\hline & 21.58 & 1.00 & 260.00 & 76.20 & 1.09 & 1.18 & 1.29 & 1.00 \\
\hline & 21.58 & 1.00 & 280.00 & 82.06 & 1.17 & 1.37 & 1.61 & 1.00 \\
\hline PLR $>=1$ & 21.58 & 1.00 & 300.00 & 87.92 & 1.26 & 1.58 & 1.98 & 1.00 \\
\hline & 21.58 & 1.00 & 320.00 & 93.78 & 1.34 & 1.79 & 2.40 & 1.00 \\
\hline & 21.58 & 1.00 & 340.00 & 99.64 & 1.42 & 2.02 & 2.88 & 1.00 \\
\hline & 21.58 & 1.00 & 360.00 & 105.51 & 1.51 & 2.27 & 3.42 & 1.00 \\
\hline
\end{tabular}

\begin{tabular}{|l|r|r|r|r|}
\hline \multirow{2}{*}{ CEIRPLR } & \multicolumn{2}{|c|}{ PURY-P168TSHMU-A } & \multicolumn{2}{c|}{ PURY-P240TSHMU-A } \\
\cline { 2 - 5 } & Low & Hi & Low & Hi \\
\hline a & 0.14614 & 1 & 0.187513 & 1 \\
\hline $\mathrm{b}$ & 0.764916 & 0 & -0.472063 & 0 \\
\hline $\mathrm{c}$ & -0.09731 & 0 & 0.059014 & 0 \\
\hline $\mathrm{d}$ & 0.186546 & 0 & 0.280888 & 0 \\
\hline $\mathrm{R}^{2}$ & 0.9999 & 1 & 0.9999 & 1 \\
\hline
\end{tabular}




\begin{tabular}{|c|c|c|c|c|c|c|c|c|}
\hline \multicolumn{9}{|c|}{ Heating EIRFPLR - PURY-P168TSHMU-A } \\
\hline & $\begin{array}{l}\text { Cooling } \\
\text { Power (kW) }\end{array}$ & $\begin{array}{l}\text { Normalized } \\
\text { EIRFPLR }\end{array}$ & $\begin{array}{l}\text { Indoor Capacity } \\
\text { (kBTUh) }\end{array}$ & $\begin{array}{l}\text { Indoor Unit } \\
\text { Capacity (kW) }\end{array}$ & PLR & $\mathrm{PLR}^{\wedge} 2$ & $\mathrm{PLR}^{\wedge} 3$ & $\begin{array}{l}\text { Predicted } \\
\text { Power }\end{array}$ \\
\hline \multirow{6}{*}{ PLR $<=1$} & 26.04 & 0.66 & 84.00 & 24.62 & 0.50 & 0.25 & 0.13 & 0.66 \\
\hline & 28.62 & 0.72 & 100.00 & 29.31 & 0.60 & 0.35 & 0.21 & 0.72 \\
\hline & 31.80 & 0.80 & 120.00 & 35.17 & 0.71 & 0.51 & 0.36 & 0.80 \\
\hline & 35.06 & 0.88 & 140.00 & 41.03 & 0.83 & 0.69 & 0.58 & 0.88 \\
\hline & 38.35 & 0.97 & 160.00 & 46.89 & 0.95 & 0.91 & 0.86 & 0.97 \\
\hline & 39.70 & 1.00 & 168.00 & 49.24 & 1.00 & 1.00 & 1.00 & 1.00 \\
\hline \multirow{6}{*}{ PLR $>=1$} & 39.70 & 1.00 & 168.00 & 49.24 & 1.00 & 1.00 & 1.00 & 1.00 \\
\hline & 39.81 & 1.00 & 180.00 & 52.75 & 1.07 & 1.15 & 1.23 & 1.00 \\
\hline & 40.10 & 1.01 & 200.00 & 58.61 & 1.19 & 1.42 & 1.69 & 1.01 \\
\hline & 40.40 & 1.02 & 220.00 & 64.48 & 1.31 & 1.71 & 2.25 & 1.02 \\
\hline & 40.70 & 1.03 & 240.00 & 70.34 & 1.43 & 2.04 & 2.92 & 1.03 \\
\hline & 40.83 & 1.03 & 251.00 & 73.56 & 1.49 & 2.23 & 3.33 & 1.03 \\
\hline
\end{tabular}

\begin{tabular}{|c|c|c|c|c|c|c|c|c|}
\hline \multicolumn{9}{|c|}{ Heating EIRFPLR - PURY-P240TSHMU-A } \\
\hline & $\begin{array}{l}\text { Cooling } \\
\text { Power (kW) }\end{array}$ & $\begin{array}{l}\text { Normalized } \\
\text { EIRFPLR }\end{array}$ & $\begin{array}{l}\text { Indoor Capacity } \\
\text { (kBTUh) }\end{array}$ & $\begin{array}{l}\text { Indoor Unit } \\
\text { Capacity (kW) }\end{array}$ & PLR & $\mathrm{PLR}^{\wedge} 2$ & $\mathrm{PLR}^{\wedge} 3$ & $\begin{array}{l}\text { Predicted } \\
\text { Power }\end{array}$ \\
\hline \multirow{7}{*}{ PLR $<=1$} & 11.08 & 0.53 & 120.00 & 35.17 & 0.50 & 0.25 & 0.13 & 0.53 \\
\hline & 12.20 & 0.58 & 140.00 & 41.03 & 0.59 & 0.34 & 0.20 & 0.59 \\
\hline & 13.64 & 0.65 & 160.00 & 46.89 & 0.67 & 0.45 & 0.30 & 0.65 \\
\hline & 15.14 & 0.72 & 180.00 & 52.75 & 0.75 & 0.57 & 0.43 & 0.72 \\
\hline & 16.88 & 0.81 & 200.00 & 58.61 & 0.84 & 0.70 & 0.59 & 0.81 \\
\hline & 18.86 & 0.90 & 220.00 & 64.48 & 0.92 & 0.85 & 0.78 & 0.90 \\
\hline & 20.91 & 1.00 & 239.00 & 70.04 & 1.00 & 1.00 & 1.00 & 1.00 \\
\hline \multirow{7}{*}{ PLR $>=1$} & 20.91 & 1.00 & 239.00 & 70.04 & 1.00 & 1.00 & 1.00 & 1.00 \\
\hline & 20.69 & 0.99 & 260.00 & 76.20 & 1.09 & 1.18 & 1.29 & 0.99 \\
\hline & 20.45 & 0.98 & 280.00 & 82.06 & 1.17 & 1.37 & 1.61 & 0.98 \\
\hline & 20.23 & 0.97 & 300.00 & 87.92 & 1.26 & 1.58 & 1.98 & 0.97 \\
\hline & 19.95 & 0.95 & 320.00 & 93.78 & 1.34 & 1.79 & 2.40 & 0.95 \\
\hline & 19.69 & 0.94 & 340.00 & 99.64 & 1.42 & 2.02 & 2.88 & 0.94 \\
\hline & 19.47 & 0.93 & 360.00 & 105.51 & 1.51 & 2.27 & 3.42 & 0.93 \\
\hline
\end{tabular}

\begin{tabular}{|l|r|r|r|r|}
\hline \multirow{2}{*}{ HEIRPLR } & \multicolumn{2}{|c|}{ PURY-P168TSHMU-A } & \multicolumn{2}{c|}{ PURY-P240TSHMU-A } \\
\cline { 2 - 5 } & \multicolumn{1}{|c|}{ Low } & \multicolumn{1}{c|}{$\mathrm{Hi}$} & \multicolumn{1}{c|}{ Low } \\
\hline $\mathrm{a}$ & 0.297408 & 1.234054 & 0.359792 & 0.808082 \\
\hline $\mathrm{b}$ & 0.775757 & -0.651587 & 0.082454 & 0.644143 \\
\hline $\mathrm{c}$ & -0.161088 & 0.566104 & 0.458441 & -0.608138 \\
\hline $\mathrm{d}$ & 0.087919 & -0.148646 & 0.099323 & 0.155768 \\
\hline $\mathrm{R}^{2}$ & 0.9999 & 0.9998 & 0.9999 & 0.9991 \\
\hline
\end{tabular}




\begin{tabular}{|c|c|c|c|c|c|}
\hline \multicolumn{6}{|c|}{$\begin{array}{l}\text { CRcooling - Cooling Combination Ratio Correction Factor - PURY-P168TSHMU-A } \\
\text { Crcooling }=a+b^{*}(\text { Crrated })+c(\text { Crrated })^{\wedge} 2+c(\text { Crrated })^{\wedge} 3\end{array}$} \\
\hline & $\begin{array}{l}\text { Outdoor Unit } \\
\text { Capacity (kW) }\end{array}$ & $\begin{array}{l}\text { Capacity } \\
\text { Ratio }\end{array}$ & $\begin{array}{l}\text { Indoor Unit } \\
\text { Capacity (kBTUh) }\end{array}$ & $\begin{array}{l}\text { Indoor Unit } \\
\text { Capacity (kW) }\end{array}$ & $\begin{array}{l}\text { Condenser } \\
\text { PLR }\end{array}$ \\
\hline \multirow{6}{*}{ PLR $>=1$} & 48.94 & 1.00 & 167.00 & 48.94 & 1.00 \\
\hline & 50.29 & 1.05 & 180.00 & 52.75 & 1.08 \\
\hline & 51.92 & 1.13 & 200.00 & 58.61 & 1.20 \\
\hline & 53.54 & 1.20 & 220.00 & 64.48 & 1.32 \\
\hline & 55.17 & 1.27 & 240.00 & 70.34 & 1.44 \\
\hline & 56.14 & 1.31 & 251.00 & 73.56 & 1.50 \\
\hline
\end{tabular}

\begin{tabular}{|c|c|c|c|c|c|}
\hline \multicolumn{6}{|c|}{$\begin{array}{l}\text { CRcooling - Cooling Combination Ratio Correction Factor - PURY-P240TSHMU-A } \\
\qquad \text { Crcooling }=a+b^{*}(\text { Crrated })+c(\text { Crrated })^{\wedge} 2+c(\text { Crrated })^{\wedge} 3\end{array}$} \\
\hline & $\begin{array}{l}\text { Outdoor Unit } \\
\text { Capacity (kW) }\end{array}$ & $\begin{array}{l}\text { Capacity } \\
\text { Ratio }\end{array}$ & $\begin{array}{l}\text { Indoor Unit } \\
\text { Capacity (kBTUh) }\end{array}$ & $\begin{array}{l}\text { Indoor Unit } \\
\text { Capacity (kW) }\end{array}$ & $\begin{array}{l}\text { Condenser } \\
\text { PLR }\end{array}$ \\
\hline \multirow{7}{*}{ PLR $>=1$} & 70.04 & 1.00 & 239.00 & 70.04 & 1.00 \\
\hline & 70.85 & 1.08 & 260.00 & 76.20 & 1.09 \\
\hline & 71.44 & 1.15 & 280.00 & 82.06 & 1.17 \\
\hline & 72.04 & 1.22 & 300.00 & 87.92 & 1.26 \\
\hline & 75.58 & 1.24 & 320.00 & 93.78 & 1.34 \\
\hline & 73.07 & 1.36 & 340.00 & 99.64 & 1.42 \\
\hline & 73.67 & 1.43 & 360.00 & 105.51 & 1.51 \\
\hline
\end{tabular}

\begin{tabular}{|l|r|r|}
\hline CRcooling & PURY-P168TSHMU-A & PURY-P240TSHMU-A \\
\hline $\mathrm{a}$ & 0.380984 & 0.165069 \\
\hline $\mathrm{b}$ & 0.621468 & 0.83414 \\
\hline $\mathrm{R}^{2}$ & 0.9991 & 0.9853 \\
\hline
\end{tabular}




\begin{tabular}{|c|c|c|c|c|c|}
\hline \multicolumn{6}{|c|}{$\begin{array}{l}\text { CRheating - Heating Combination Ratio Correction Factor - PURY-P168TSHMU-A } \\
\text { Crheating }=a+b^{*}(\text { Crrated })+c(\text { Crrated })^{\wedge} 2+c(\text { Crrated })^{\wedge} 3\end{array}$} \\
\hline & $\begin{array}{l}\text { Outdoor Unit } \\
\text { Capacity (kW) }\end{array}$ & $\begin{array}{l}\text { Capacity } \\
\text { Ratio }\end{array}$ & $\begin{array}{l}\text { Indoor Unit } \\
\text { Capacity (kBTUh) }\end{array}$ & $\begin{array}{l}\text { Indoor Unit } \\
\text { Capacity (kW) }\end{array}$ & $\begin{array}{l}\text { Condenser } \\
\text { PLR }\end{array}$ \\
\hline \multirow{6}{*}{ PLR >=1 } & 55.10 & 0.89 & 168.00 & 49.24 & 1.00 \\
\hline & 55.43 & 0.95 & 180.00 & 52.75 & 1.07 \\
\hline & 56.03 & 1.05 & 200.00 & 58.61 & 1.19 \\
\hline & 56.62 & 1.14 & 220.00 & 64.48 & 1.31 \\
\hline & 57.22 & 1.23 & 240.00 & 70.34 & 1.43 \\
\hline & 57.49 & 1.28 & 251.00 & 73.56 & 1.49 \\
\hline
\end{tabular}

\begin{tabular}{|c|c|c|c|c|c|}
\hline \multicolumn{6}{|c|}{$\begin{array}{l}\text { CRheating - Heating Combination Ratio Correction Factor - PURY-P240TSHMU-A } \\
\text { Crheating }=a+b^{*}(\text { Crrated })+c(\text { Crrated })^{\wedge} 2+c(\text { Crrated })^{\wedge} 3\end{array}$} \\
\hline & $\begin{array}{l}\text { Outdoor Unit } \\
\text { Capacity (kW) }\end{array}$ & $\begin{array}{l}\text { Capacity } \\
\text { Ratio }\end{array}$ & $\begin{array}{l}\text { Indoor Unit } \\
\text { Capacity (kBTUh) }\end{array}$ & $\begin{array}{l}\text { Indoor Unit } \\
\text { Capacity (kW) }\end{array}$ & $\begin{array}{l}\text { Condenser } \\
\text { PLR }\end{array}$ \\
\hline \multirow{7}{*}{ PLR $>=1$} & 70.04 & 1.00 & 239.00 & 70.04 & 1.00 \\
\hline & 70.65 & 1.08 & 260.00 & 76.20 & 1.09 \\
\hline & 70.98 & 1.16 & 280.00 & 82.06 & 1.17 \\
\hline & 71.31 & 1.23 & 300.00 & 87.92 & 1.26 \\
\hline & 71.64 & 1.31 & 320.00 & 93.78 & 1.34 \\
\hline & 71.96 & 1.38 & 340.00 & 99.64 & 1.42 \\
\hline & 72.21 & 1.46 & 360.00 & 105.51 & 1.51 \\
\hline
\end{tabular}

\begin{tabular}{|l|r|r|}
\hline CRheating & PURY-P168TSHMU-A & PURY-P240TSHMU-A \\
\hline $\mathrm{a}$ & 0.115838 & 0.087522 \\
\hline $\mathrm{b}$ & 0.779805 & 0.912035 \\
\hline $\mathrm{R}^{2}$ & 0.9999 & 0.9999 \\
\hline
\end{tabular}




\begin{tabular}{|c|c|c|c|c|c|c|c|}
\hline \multicolumn{8}{|c|}{$\begin{array}{l}\text { Pcorrection - Piping Correction Factor for Length in Cooling Mode - PURY-P168TSHMU-A } \\
\text { Pcorrection }=a+b^{*}\left(P_{-} E Q, \text { cooling }\right)+c^{*}\left(P_{-} E Q, \text { cooling }\right)^{\wedge} 2+d^{*}(C R \text { cooling })+e(C R c o o l i n g)^{\wedge} 2\end{array}$} \\
\hline $\begin{array}{l}\text { Piping } \\
\text { Correction }\end{array}$ & Length (ft.) & $\begin{array}{l}\text { Length } \\
(\mathrm{m})\end{array}$ & Length^2 & $C R$ & $\mathrm{CR}^{\wedge} 2$ & Length*CR & Predicted \\
\hline 1 & 25 & 7.62 & 58.0644 & 1.5 & 2.25 & 11.43 & 1.008 \\
\hline 0.985 & 50 & 15.24 & 232.2576 & 1.5 & 2.25 & 22.86 & 0.995 \\
\hline 0.956 & 100 & 30.48 & 929.0304 & 1.5 & 2.25 & 45.72 & 0.968 \\
\hline 0.902 & 200 & 60.96 & 3716.1216 & 1.5 & 2.25 & 91.44 & 0.914 \\
\hline 0.853 & 300 & 91.44 & 8361.2736 & 1.5 & 2.25 & 137.16 & 0.859 \\
\hline 0.809 & 400 & 121.92 & 14864.4864 & 1.5 & 2.25 & 182.88 & 0.805 \\
\hline 0.771 & 500 & 152.4 & 23225.76 & 1.5 & 2.25 & 228.6 & 0.751 \\
\hline 0.732 & 600 & 182.88 & 33445.0944 & 1.5 & 2.25 & 274.32 & 0.697 \\
\hline 1 & 25 & 7.62 & 58.0644 & 1 & 1 & 7.62 & 0.973 \\
\hline 0.985 & 50 & 15.24 & 232.2576 & 1 & 1 & 15.24 & 0.965 \\
\hline 0.958 & 100 & 30.48 & 929.0304 & 1 & 1 & 30.48 & 0.948 \\
\hline 0.908 & 200 & 60.96 & 3716.1216 & 1 & 1 & 60.96 & 0.916 \\
\hline 0.861 & 300 & 91.44 & 8361.2736 & 1 & 1 & 91.44 & 0.883 \\
\hline 0.822 & 400 & 121.92 & 14864.4864 & 1 & 1 & 121.92 & 0.851 \\
\hline 0.786 & 500 & 152.4 & 23225.76 & 1 & 1 & 152.4 & 0.818 \\
\hline 0.751 & 600 & 182.88 & 33445.0944 & 1 & 1 & 182.88 & 0.785 \\
\hline 1 & 25 & 7.62 & 58.0644 & 0.75 & 0.5625 & 5.715 & 0.990 \\
\hline 1 & 50 & 15.24 & 232.2576 & 0.75 & 0.5625 & 11.43 & 0.985 \\
\hline 1 & 100 & 30.48 & 929.0304 & 0.75 & 0.5625 & 22.86 & 0.974 \\
\hline 1 & 208 & 63.3984 & 4019.35712 & 0.75 & 0.5625 & 47.5488 & 0.951 \\
\hline 0.956 & 300 & 91.44 & 8361.2736 & 0.75 & 0.5625 & 68.58 & 0.931 \\
\hline 0.914 & 400 & 121.92 & 14864.4864 & 0.75 & 0.5625 & 91.44 & 0.909 \\
\hline 0.876 & 500 & 152.4 & 23225.76 & 0.75 & 0.5625 & 114.3 & 0.887 \\
\hline 0.837 & 600 & 182.88 & 33445.0944 & 0.75 & 0.5625 & 137.16 & 0.865 \\
\hline 1 & 25 & 7.62 & 58.0644 & 0.5 & 0.25 & 3.81 & 1.031 \\
\hline 1 & 50 & 15.24 & 232.2576 & 0.5 & 0.25 & 7.62 & 1.029 \\
\hline 1 & 100 & 30.48 & 929.0304 & 0.5 & 0.25 & 15.24 & 1.023 \\
\hline 1 & 200 & 60.96 & 3716.1216 & 0.5 & 0.25 & 30.48 & 1.012 \\
\hline 1 & 300 & 91.44 & 8361.2736 & 0.5 & 0.25 & 45.72 & 1.001 \\
\hline 1 & 400 & 121.92 & 14864.4864 & 0.5 & 0.25 & 60.96 & 0.990 \\
\hline 1 & 500 & 152.4 & 23225.76 & 0.5 & 0.25 & 76.2 & 0.979 \\
\hline 1 & 600 & 182.88 & 33445.0944 & 0.5 & 0.25 & 91.44 & 0.968 \\
\hline
\end{tabular}

\begin{tabular}{|c|c|c|c|c|c|c|c|}
\hline \multicolumn{8}{|c|}{$\begin{array}{l}\text { Pcorrection - Piping CorrectionFactor for Length in Cooling Mode - PURY-P240TSHMU-A } \\
\text { Pcorrection }=a+b^{*}\left(P_{-} E Q, \text { cooling }\right)+c^{*}\left(P_{-} E Q, \text { cooling }\right)^{\wedge} 2+d^{*}(\text { CRcooling })+e(C R c o o l i n g)^{\wedge} 2\end{array}$} \\
\hline $\begin{array}{c}\text { Piping } \\
\text { Correction }\end{array}$ & Length (ft.) & Length (m) & Length^2 & $\mathrm{CR}$ & $\mathrm{CR}^{\wedge} 2$ & Length*CR & Predicted \\
\hline 1 & 25 & 7.62 & 58.0644 & 1.5 & 2.25 & 11.43 & 1.013 \\
\hline 0.982 & 50 & 15.24 & 232.2576 & 1.5 & 2.25 & 22.86 & 0.995 \\
\hline 0.945 & 100 & 30.48 & 929.0304 & 1.5 & 2.25 & 45.72 & 0.960 \\
\hline
\end{tabular}




\begin{tabular}{|c|c|c|c|c|c|c|c|}
\hline 0.875 & 200 & 60.96 & 3716.1216 & 1.5 & 2.25 & 91.44 & 0.891 \\
\hline 0.815 & 300 & 91.44 & 8361.2736 & 1.5 & 2.25 & 137.16 & 0.824 \\
\hline 0.762 & 400 & 121.92 & 14864.486 & 1.5 & 2.25 & 182.88 & 0.758 \\
\hline 0.716 & 500 & 152.4 & 23225.76 & 1.5 & 2.25 & 228.6 & 0.694 \\
\hline 0.679 & 600 & 182.88 & 33445.094 & 1.5 & 2.25 & 274.32 & 0.631 \\
\hline 1 & 25 & 7.62 & 58.0644 & 1 & 1 & 7.62 & 0.966 \\
\hline 0.984 & 50 & 15.24 & 232.2576 & 1 & 1 & 15.24 & 0.955 \\
\hline 0.949 & 100 & 30.48 & 929.0304 & 1 & 1 & 30.48 & 0.932 \\
\hline 0.884 & 200 & 60.96 & 3716.1216 & 1 & 1 & 60.96 & 0.889 \\
\hline 0.827 & 300 & 91.44 & 8361.2736 & 1 & 1 & 91.44 & 0.847 \\
\hline 0.776 & 400 & 121.92 & 14864.486 & 1 & 1 & 121.92 & 0.807 \\
\hline 0.732 & 500 & 152.4 & 23225.76 & 1 & 1 & 152.4 & 0.768 \\
\hline 0.694 & 600 & 182.88 & 33445.094 & 1 & 1 & 182.88 & 0.731 \\
\hline 1 & 25 & 7.62 & 58.0644 & 0.75 & 0.5625 & 5.715 & 0.990 \\
\hline 1 & 50 & 15.24 & 232.2576 & 0.75 & 0.5625 & 11.43 & 0.982 \\
\hline 1 & 100 & 30.48 & 929.0304 & 0.75 & 0.5625 & 22.86 & 0.966 \\
\hline 1 & 175 & 53.34 & 2845.1556 & 0.75 & 0.5625 & 40.005 & 0.942 \\
\hline 0.985 & 200 & 60.96 & 3716.1216 & 0.75 & 0.5625 & 45.72 & 0.935 \\
\hline 0.927 & 300 & 91.44 & 8361.2736 & 0.75 & 0.5625 & 68.58 & 0.906 \\
\hline 0.873 & 400 & 121.92 & 14864.486 & 0.75 & 0.5625 & 91.44 & 0.878 \\
\hline 0.826 & 500 & 152.4 & 23225.76 & 0.75 & 0.5625 & 114.3 & 0.852 \\
\hline 0.784 & 600 & 182.88 & 33445.094 & 0.75 & 0.5625 & 137.16 & 0.828 \\
\hline 1 & 25 & 7.62 & 58.0644 & 0.5 & 0.25 & 3.81 & 1.044 \\
\hline 1 & 50 & 15.24 & 232.2576 & 0.5 & 0.25 & 7.62 & 1.040 \\
\hline 1 & 100 & 30.48 & 929.0304 & 0.5 & 0.25 & 15.24 & 1.030 \\
\hline 1 & 200 & 60.96 & 3716.1216 & 0.5 & 0.25 & 30.48 & 1.012 \\
\hline 1 & 300 & 91.44 & 8361.2736 & 0.5 & 0.25 & 45.72 & 0.995 \\
\hline 1 & 400 & 121.92 & 14864.486 & 0.5 & 0.25 & 60.96 & 0.981 \\
\hline 1 & 500 & 152.4 & 23225.76 & 0.5 & 0.25 & 76.2 & 0.967 \\
\hline 1 & 600 & 182.88 & 33445.094 & 0.5 & 0.25 & 91.44 & 0.956 \\
\hline
\end{tabular}

\begin{tabular}{|l|r|r|}
\hline PCFLcooling & PURY-P168TSHMU-A & PURY-P240TSHMU-A \\
\hline $\mathrm{a}$ & 1.181018 & 1.246488 \\
\hline $\mathrm{b}$ & 0.000355 & 0.000164 \\
\hline $\mathrm{c}$ & -0.0000000391 & 0.0000008629 \\
\hline $\mathrm{d}$ & -0.388003 & -0.518919 \\
\hline $\mathrm{e}$ & 0.187866 & 0.250008 \\
\hline $\mathrm{f}$ & -0.001417 & -0.001671 \\
\hline $\mathrm{R}^{2}$ & 0.9343 & 0.9309 \\
\hline
\end{tabular}


Pcorrection - Piping Correction Factor for Length in Heating Mode

Pcorrection $=a+b^{*}\left(P_{-} E Q\right.$, heating $)+c^{*}\left(P_{-} E Q \text {, heating }\right)^{\wedge} 2+d^{*}(C R h e a t i n g)+E(C R h e a t i n g)^{\wedge} 2$

\begin{tabular}{|c|c|c|c|c|c|c|c|}
\hline $\begin{array}{c}\text { Piping } \\
\text { Correction }\end{array}$ & $\begin{array}{l}\text { Length } \\
\text { (ft.) }\end{array}$ & Length (m) & Length^2 & CR & $\mathrm{CR}^{\wedge} 2$ & Length*CR & Predicted \\
\hline 1 & 25 & 7.62 & 58.0644 & 1.5 & 2.25 & 11.43 & 1.000 \\
\hline 0.994 & 50 & 15.24 & 232.2576 & 2.5 & 6.25 & 38.1 & 0.994 \\
\hline 0.983 & 100 & 30.48 & 929.0304 & 3.5 & 12.25 & 106.68 & 0.983 \\
\hline 0.962 & 200 & 60.96 & 3716.1216 & 4.5 & 20.25 & 274.32 & 0.962 \\
\hline 0.943 & 300 & 91.44 & 8361.2736 & 5.5 & 30.25 & 502.92 & 0.943 \\
\hline 0.925 & 400 & 121.92 & 14864.4864 & 6.5 & 42.25 & 792.48 & 0.925 \\
\hline 0.908 & 500 & 152.4 & 23225.76 & 7.5 & 56.25 & 1143 & 0.909 \\
\hline 0.894 & 600 & 182.88 & 33445.0944 & 8.5 & 72.25 & 1554.48 & 0.894 \\
\hline
\end{tabular}

\section{Pcorrection - Piping Correction Factor for Length in Cooling Mode}

Pcorrection $=a+b^{*}\left(P_{-} E Q\right.$, heating $)+c^{*}\left(P_{-} E Q \text {, heating }\right)^{\wedge} 2+d^{*}(C R h e a t i n g)+E(C R h e a t i n g)^{\wedge} 2$

\begin{tabular}{|c|c|c|c|c|c|c|c|}
\hline $\begin{array}{c}\text { Piping } \\
\text { Correction }\end{array}$ & $\begin{array}{l}\text { Length } \\
\text { (ft.) }\end{array}$ & Length (m) & Length^2 & CR & $C R^{\wedge} 2$ & Length*CR & Predicted \\
\hline 1 & 25 & 7.62 & 58.0644 & 1.5 & 2.25 & 11.43 & 1.000 \\
\hline 0.994 & 50 & 15.24 & 232.2576 & 2.5 & 6.25 & 38.1 & 0.994 \\
\hline 0.984 & 100 & 30.48 & 929.0304 & 3.5 & 12.25 & 106.68 & 0.984 \\
\hline 0.965 & 200 & 60.96 & 3716.1216 & 4.5 & 20.25 & 274.32 & 0.965 \\
\hline 0.948 & 300 & 91.44 & 8361.2736 & 5.5 & 30.25 & 502.92 & 0.948 \\
\hline 0.932 & 400 & 121.92 & 14864.486 & 6.5 & 42.25 & 792.48 & 0.932 \\
\hline 0.916 & 500 & 152.4 & 23225.76 & 7.5 & 56.25 & 1143 & 0.916 \\
\hline 0.902 & 600 & 182.88 & 33445.094 & 8.5 & 72.25 & 1554.48 & 0.902 \\
\hline
\end{tabular}

\begin{tabular}{|l|r|r|}
\hline PCFLheating & PURY-P168TSHMU-A & PURY-P240TSHMU-A \\
\hline $\mathrm{a}$ & 1.006683 & 1.006486 \\
\hline $\mathrm{b}$ & -0.000927 & -0.0008458 \\
\hline $\mathrm{c}$ & 0.000000154 & 0.000002481 \\
\hline $\mathrm{d}$ & 0 & 0 \\
\hline $\mathrm{e}$ & -0.000189 & -0.000509 \\
\hline $\mathrm{f}$ & 0.00007827 & 0.0001093 \\
\hline $\mathrm{R}^{2}$ & 0.9999 & 0.9999 \\
\hline
\end{tabular}


APPENDix G-2: TERMinAl Units

\begin{tabular}{|c|c|c|c|c|c|c|c|c|}
\hline \multicolumn{9}{|c|}{ Cooling Capacity Ratio Modifier Function of Temperature Curve - PEFY-P06-NMAU-E } \\
\hline TOTAL & SENSIBLE & CR & IWB & $\mathrm{IWB}^{\wedge} 2$ & ODB & $\mathrm{ODB}^{\wedge} 2$ & IWB*ODB & Predicted \\
\hline 1.7 & 1.7 & 1.00 & 15 & 225 & 20 & 400 & 300 & 0.986 \\
\hline 1.7 & 1.7 & 1.00 & 15 & 225 & 22.8 & 519.84 & 342 & 0.992 \\
\hline 1.7 & 1.7 & 1.00 & 15 & 225 & 25 & 625 & 375 & 0.996 \\
\hline 1.6 & 1.6 & 1.00 & 15 & 225 & 27.8 & 772.84 & 417 & 0.999 \\
\hline 1.6 & 1.6 & 1.00 & 15 & 225 & 30 & 900 & 450 & 1.000 \\
\hline 1.6 & 1.6 & 1.00 & 15 & 225 & 32.8 & 1075.84 & 492 & 0.999 \\
\hline 1.6 & 1.6 & 1.00 & 15 & 225 & 35 & 1225 & 525 & 0.998 \\
\hline 1.6 & 1.6 & 1.00 & 15 & 225 & 37.8 & 1428.84 & 567 & 0.994 \\
\hline 1.6 & 1.6 & 1.00 & 15 & 225 & 40 & 1600 & 600 & 0.990 \\
\hline 1.5 & 1.5 & 1.00 & 15 & 225 & 43.3 & 1874.89 & 649.5 & 0.981 \\
\hline 1.2 & 1.2 & 1.00 & 15 & 225 & 46.1 & 2125.21 & 691.5 & 0.972 \\
\hline 1.8 & 1.7 & 1.06 & 16.1 & 259.21 & 20 & 400 & 322 & 1.012 \\
\hline 1.7 & 1.7 & 1.00 & 16.1 & 259.21 & 22.8 & 519.84 & 367.08 & 1.017 \\
\hline 1.7 & 1.7 & 1.00 & 16.1 & 259.21 & 25 & 625 & 402.5 & 1.019 \\
\hline 1.7 & 1.7 & 1.00 & 16.1 & 259.21 & 27.8 & 772.84 & 447.58 & 1.020 \\
\hline 1.7 & 1.7 & 1.00 & 16.1 & 259.21 & 30 & 900 & 483 & 1.020 \\
\hline 1.6 & 1.6 & 1.00 & 16.1 & 259.21 & 32.8 & 1075.84 & 528.08 & 1.018 \\
\hline 1.6 & 1.6 & 1.00 & 16.1 & 259.21 & 35 & 1225 & 563.5 & 1.015 \\
\hline 1.6 & 1.6 & 1.00 & 16.1 & 259.21 & 37.8 & 1428.84 & 608.58 & 1.009 \\
\hline 1.6 & 1.6 & 1.00 & 16.1 & 259.21 & 40 & 1600 & 644 & 1.003 \\
\hline 1.5 & 1.5 & 1.00 & 16.1 & 259.21 & 43.3 & 1874.89 & 697.13 & 0.993 \\
\hline 1.2 & 1.2 & 1.00 & 16.1 & 259.21 & 46.1 & 2125.21 & 742.21 & 0.982 \\
\hline 1.9 & 1.8 & 1.06 & 17.8 & 316.84 & 20 & 400 & 356 & 1.054 \\
\hline 1.9 & 1.8 & 1.06 & 17.8 & 316.84 & 22.8 & 519.84 & 405.84 & 1.056 \\
\hline 1.8 & 1.8 & 1.00 & 17.8 & 316.84 & 25 & 625 & 445 & 1.056 \\
\hline 1.8 & 1.8 & 1.00 & 17.8 & 316.84 & 27.8 & 772.84 & 494.84 & 1.054 \\
\hline 1.8 & 1.7 & 1.06 & 17.8 & 316.84 & 30 & 900 & 534 & 1.052 \\
\hline 1.8 & 1.7 & 1.06 & 17.8 & 316.84 & 32.8 & 1075.84 & 583.84 & 1.047 \\
\hline 1.8 & 1.7 & 1.06 & 17.8 & 316.84 & 35 & 1225 & 623 & 1.042 \\
\hline 1.7 & 1.7 & 1.00 & 17.8 & 316.84 & 37.8 & 1428.84 & 672.84 & 1.033 \\
\hline 1.7 & 1.7 & 1.00 & 17.8 & 316.84 & 40 & 1600 & 712 & 1.025 \\
\hline 1.7 & 1.7 & 1.00 & 17.8 & 316.84 & 43.3 & 1874.89 & 770.74 & 1.012 \\
\hline 1.4 & 1.4 & 1.00 & 17.8 & 316.84 & 46.1 & 2125.21 & 820.58 & 0.998 \\
\hline 1.9 & 1.8 & 1.06 & 19.4 & 376.36 & 20 & 400 & 388 & 1.095 \\
\hline 1.9 & 1.8 & 1.06 & 19.4 & 376.36 & 22.8 & 519.84 & 442.32 & 1.094 \\
\hline 1.9 & 1.7 & 1.12 & 19.4 & 376.36 & 25 & 625 & 485 & 1.092 \\
\hline 1.9 & 1.7 & 1.12 & 19.4 & 376.36 & 27.8 & 772.84 & 539.32 & 1.088 \\
\hline 1.8 & 1.7 & 1.06 & 19.4 & 376.36 & 30 & 900 & 582 & 1.083 \\
\hline 1.8 & 1.7 & 1.06 & 19.4 & 376.36 & 32.8 & 1075.84 & 636.32 & 1.075 \\
\hline 1.8 & 1.7 & 1.06 & 19.4 & 376.36 & 35 & 1225 & 679 & 1.068 \\
\hline
\end{tabular}




\begin{tabular}{|c|c|c|c|c|c|c|c|c|}
\hline & & & & & & & & \\
\hline 1.8 & 1.7 & 1.06 & 19.4 & 376.36 & 37.8 & 1428.84 & 733.32 & 1.057 \\
\hline 1.8 & 1.7 & 1.06 & 19.4 & 376.36 & 40 & 1600 & 776 & 1.047 \\
\hline 1.7 & 1.7 & 1.00 & 19.4 & 376.36 & 43.3 & 1874.89 & 840.02 & 1.030 \\
\hline 1.4 & 1.4 & 1.00 & 19.4 & 376.36 & 46.1 & 2125.21 & 894.34 & 1.014 \\
\hline 2 & 1.7 & 1.18 & 20.6 & 424.36 & 20 & 400 & 412 & 1.126 \\
\hline 2 & 1.7 & 1.18 & 20.6 & 424.36 & 22.8 & 519.84 & 469.68 & 1.123 \\
\hline 2 & 1.7 & 1.18 & 20.6 & 424.36 & 25 & 625 & 515 & 1.119 \\
\hline 1.9 & 1.7 & 1.12 & 20.6 & 424.36 & 27.8 & 772.84 & 572.68 & 1.113 \\
\hline 1.9 & 1.7 & 1.12 & 20.6 & 424.36 & 30 & 900 & 618 & 1.107 \\
\hline 1.9 & 1.7 & 1.12 & 20.6 & 424.36 & 32.8 & 1075.84 & 675.68 & 1.097 \\
\hline 1.9 & 1.7 & 1.12 & 20.6 & 424.36 & 35 & 1225 & 721 & 1.088 \\
\hline 1.9 & 1.7 & 1.12 & 20.6 & 424.36 & 37.8 & 1428.84 & 778.68 & 1.076 \\
\hline 1.8 & 1.7 & 1.06 & 20.6 & 424.36 & 40 & 1600 & 824 & 1.064 \\
\hline 1.8 & 1.7 & 1.06 & 20.6 & 424.36 & 43.3 & 1874.89 & 891.98 & 1.045 \\
\hline 1.5 & 1.5 & 1.00 & 20.6 & 424.36 & 46.1 & 2125.21 & 949.66 & 1.026 \\
\hline 2.1 & 1.8 & 1.17 & 22.2 & 492.84 & 20 & 400 & 444 & 1.168 \\
\hline 2.1 & 1.8 & 1.17 & 22.2 & 492.84 & 22.8 & 519.84 & 506.16 & 1.162 \\
\hline 2.1 & 1.8 & 1.17 & 22.2 & 492.84 & 25 & 625 & 555 & 1.157 \\
\hline 2.1 & 1.8 & 1.17 & 22.2 & 492.84 & 27.8 & 772.84 & 617.16 & 1.148 \\
\hline 2.1 & 1.8 & 1.17 & 22.2 & 492.84 & 30 & 900 & 666 & 1.139 \\
\hline 2 & 1.8 & 1.11 & 22.2 & 492.84 & 32.8 & 1075.84 & 728.16 & 1.127 \\
\hline 2 & 1.8 & 1.11 & 22.2 & 492.84 & 35 & 1225 & 777 & 1.116 \\
\hline 2 & 1.8 & 1.11 & 22.2 & 492.84 & 37.8 & 1428.84 & 839.16 & 1.101 \\
\hline 2 & 1.8 & 1.11 & 22.2 & 492.84 & 40 & 1600 & 888 & 1.087 \\
\hline 1.9 & 1.8 & 1.06 & 22.2 & 492.84 & 43.3 & 1874.89 & 961.26 & 1.065 \\
\hline 1.6 & 1.6 & 1.00 & 22.2 & 492.84 & 46.1 & 2125.21 & 1023.42 & 1.044 \\
\hline 2.3 & 1.9 & 1.21 & 23.9 & 571.21 & 20 & 400 & 478 & 1.213 \\
\hline 2.2 & 1.9 & 1.16 & 23.9 & 571.21 & 22.8 & 519.84 & 544.92 & 1.205 \\
\hline 2.2 & 1.9 & 1.16 & 23.9 & 571.21 & 25 & 625 & 597.5 & 1.197 \\
\hline 2.2 & 1.9 & 1.16 & 23.9 & 571.21 & 27.8 & 772.84 & 664.42 & 1.186 \\
\hline 2.2 & 1.9 & 1.16 & 23.9 & 571.21 & 30 & 900 & 717 & 1.175 \\
\hline 2.2 & 1.9 & 1.16 & 23.9 & 571.21 & 32.8 & 1075.84 & 783.92 & 1.160 \\
\hline 2.1 & 1.9 & 1.11 & 23.9 & 571.21 & 35 & 1225 & 836.5 & 1.147 \\
\hline 2.1 & 1.8 & 1.17 & 23.9 & 571.21 & 37.8 & 1428.84 & 903.42 & 1.129 \\
\hline 2.1 & 1.8 & 1.17 & 23.9 & 571.21 & 40 & 1600 & 956 & 1.113 \\
\hline 2.1 & 1.8 & 1.17 & 23.9 & 571.21 & 43.3 & 1874.89 & 1034.87 & 1.088 \\
\hline 1.7 & 1.7 & 1.00 & 23.9 & 571.21 & 46.1 & 2125.21 & 1101.79 & 1.064 \\
\hline
\end{tabular}

\begin{tabular}{|c|c|c|c|c|c|c|c|c|}
\hline \multicolumn{9}{|c|}{$\begin{array}{l}\text { Cooling Capacity Ratio Modifier Function of Temperature Curve } \\
C A P=a+b^{*} I W B+c^{*} I W^{\wedge} 2+d^{*} O D B+e^{*} O D B^{\wedge} 2+f^{*} I W B^{*} O D B\end{array}$} \\
\hline TOTAL & SENSIBLE & CAP & IWB & $\mathrm{IWB}^{\wedge} 2$ & ODB & $\mathrm{ODB}^{\wedge} 2$ & IWB*ODB & Predicted \\
\hline 2.2 & 1.9 & 1.16 & 15 & 225 & 20 & 400 & 300 & 1.117 \\
\hline 2.1 & 1.9 & 1.11 & 15 & 225 & 22.8 & 519.84 & 342 & 1.129 \\
\hline 2.1 & 1.9 & 1.11 & 15 & 225 & 25 & 625 & 375 & 1.135 \\
\hline
\end{tabular}




\begin{tabular}{|c|c|c|c|c|c|c|c|c|}
\hline 2.1 & 1.9 & 1.11 & 15 & 225 & 27.8 & 772.84 & 417 & 1.137 \\
\hline 2.1 & 1.9 & 1.11 & 15 & 225 & 30 & 900 & 450 & 1.135 \\
\hline 2.1 & 1.8 & 1.17 & 15 & 225 & 32.8 & 1075.84 & 492 & 1.126 \\
\hline 2 & 1.8 & 1.11 & 15 & 225 & 35 & 1225 & 525 & 1.115 \\
\hline 2 & 1.8 & 1.11 & 15 & 225 & 37.8 & 1428.84 & 567 & 1.096 \\
\hline 2 & 1.8 & 1.11 & 15 & 225 & 40 & 1600 & 600 & 1.077 \\
\hline 1.9 & 1.8 & 1.06 & 15 & 225 & 43.3 & 1874.89 & 649.5 & 1.042 \\
\hline 1.5 & 1.5 & 1.00 & 15 & 225 & 46.1 & 2125.21 & 691.5 & 1.006 \\
\hline 2.2 & 1.9 & 1.16 & 16.1 & 259.21 & 20 & 400 & 322 & 1.151 \\
\hline 2.2 & 1.9 & 1.16 & 16.1 & 259.21 & 22.8 & 519.84 & 367.08 & 1.163 \\
\hline 2.2 & 1.9 & 1.16 & 16.1 & 259.21 & 25 & 625 & 402.5 & 1.168 \\
\hline 2.2 & 1.9 & 1.16 & 16.1 & 259.21 & 27.8 & 772.84 & 447.58 & 1.169 \\
\hline 2.1 & 1.8 & 1.17 & 16.1 & 259.21 & 30 & 900 & 483 & 1.166 \\
\hline 2.1 & 1.8 & 1.17 & 16.1 & 259.21 & 32.8 & 1075.84 & 528.08 & 1.157 \\
\hline 2.1 & 1.8 & 1.17 & 16.1 & 259.21 & 35 & 1225 & 563.5 & 1.146 \\
\hline 2.1 & 1.8 & 1.17 & 16.1 & 259.21 & 37.8 & 1428.84 & 608.58 & 1.126 \\
\hline 2 & 1.8 & 1.11 & 16.1 & 259.21 & 40 & 1600 & 644 & 1.106 \\
\hline 2 & 1.8 & 1.11 & 16.1 & 259.21 & 43.3 & 1874.89 & 697.13 & 1.070 \\
\hline 1.6 & 1.6 & 1.00 & 16.1 & 259.21 & 46.1 & 2125.21 & 742.21 & 1.033 \\
\hline 2.4 & 2 & 1.20 & 17.8 & 316.84 & 20 & 400 & 356 & 1.205 \\
\hline 2.4 & 2 & 1.20 & 17.8 & 316.84 & 22.8 & 519.84 & 405.84 & 1.215 \\
\hline 2.3 & 1.9 & 1.21 & 17.8 & 316.84 & 25 & 625 & 445 & 1.220 \\
\hline 2.3 & 1.9 & 1.21 & 17.8 & 316.84 & 27.8 & 772.84 & 494.84 & 1.220 \\
\hline 2.3 & 1.9 & 1.21 & 17.8 & 316.84 & 30 & 900 & 534 & 1.216 \\
\hline 2.3 & 1.9 & 1.21 & 17.8 & 316.84 & 32.8 & 1075.84 & 583.84 & 1.205 \\
\hline 2.2 & 1.9 & 1.16 & 17.8 & 316.84 & 35 & 1225 & 623 & 1.193 \\
\hline 2.2 & 1.9 & 1.16 & 17.8 & 316.84 & 37.8 & 1428.84 & 672.84 & 1.172 \\
\hline 2.2 & 1.9 & 1.16 & 17.8 & 316.84 & 40 & 1600 & 712 & 1.152 \\
\hline 2.1 & 1.9 & 1.11 & 17.8 & 316.84 & 43.3 & 1874.89 & 770.74 & 1.114 \\
\hline 1.7 & 1.7 & 1.00 & 17.8 & 316.84 & 46.1 & 2125.21 & 820.58 & 1.076 \\
\hline 2.5 & 1.9 & 1.32 & 19.4 & 376.36 & 20 & 400 & 388 & 1.257 \\
\hline 2.4 & 1.9 & 1.26 & 19.4 & 376.36 & 22.8 & 519.84 & 442.32 & 1.266 \\
\hline 2.4 & 1.9 & 1.26 & 19.4 & 376.36 & 25 & 625 & 485 & 1.269 \\
\hline 2.4 & 1.9 & 1.26 & 19.4 & 376.36 & 27.8 & 772.84 & 539.32 & 1.268 \\
\hline 2.3 & 1.9 & 1.21 & 19.4 & 376.36 & 30 & 900 & 582 & 1.264 \\
\hline 2.3 & 1.9 & 1.21 & 19.4 & 376.36 & 32.8 & 1075.84 & 636.32 & 1.252 \\
\hline 2.3 & 1.9 & 1.21 & 19.4 & 376.36 & 35 & 1225 & 679 & 1.239 \\
\hline 2.3 & 1.9 & 1.21 & 19.4 & 376.36 & 37.8 & 1428.84 & 733.32 & 1.217 \\
\hline 2.2 & 1.9 & 1.16 & 19.4 & 376.36 & 40 & 1600 & 776 & 1.196 \\
\hline 2.2 & 1.8 & 1.22 & 19.4 & 376.36 & 43.3 & 1874.89 & 840.02 & 1.157 \\
\hline 1.8 & 1.7 & 1.06 & 19.4 & 376.36 & 46.1 & 2125.21 & 894.34 & 1.118 \\
\hline 2.6 & 1.9 & 1.37 & 20.6 & 424.36 & 20 & 400 & 412 & 1.296 \\
\hline 2.5 & 1.9 & 1.32 & 20.6 & 424.36 & 22.8 & 519.84 & 469.68 & 1.305 \\
\hline 2.5 & 1.9 & 1.32 & 20.6 & 424.36 & 25 & 625 & 515 & 1.308 \\
\hline 2.5 & 1.9 & 1.32 & 20.6 & 424.36 & 27.8 & 772.84 & 572.68 & 1.306 \\
\hline
\end{tabular}




\begin{tabular}{|c|c|c|c|c|c|c|c|c|}
\hline 2.5 & 1.9 & 1.32 & 20.6 & 424.36 & 30 & 900 & 618 & 1.300 \\
\hline 2.4 & 1.9 & 1.26 & 20.6 & 424.36 & 32.8 & 1075.84 & 675.68 & 1.288 \\
\hline 2.4 & 1.9 & 1.26 & 20.6 & 424.36 & 35 & 1225 & 721 & 1.274 \\
\hline 2.4 & 1.8 & 1.33 & 20.6 & 424.36 & 37.8 & 1428.84 & 778.68 & 1.252 \\
\hline 2.4 & 1.8 & 1.33 & 20.6 & 424.36 & 40 & 1600 & 824 & 1.230 \\
\hline 2.3 & 1.8 & 1.28 & 20.6 & 424.36 & 43.3 & 1874.89 & 891.98 & 1.190 \\
\hline 1.9 & 1.7 & 1.12 & 20.6 & 424.36 & 46.1 & 2125.21 & 949.66 & 1.150 \\
\hline 2.7 & 2 & 1.35 & 22.2 & 492.84 & 20 & 400 & 444 & 1.350 \\
\hline 2.7 & 2 & 1.35 & 22.2 & 492.84 & 22.8 & 519.84 & 506.16 & 1.357 \\
\hline 2.7 & 2 & 1.35 & 22.2 & 492.84 & 25 & 625 & 555 & 1.359 \\
\hline 2.6 & 2 & 1.30 & 22.2 & 492.84 & 27.8 & 772.84 & 617.16 & 1.356 \\
\hline 2.6 & 2 & 1.30 & 22.2 & 492.84 & 30 & 900 & 666 & 1.350 \\
\hline 2.6 & 2 & 1.30 & 22.2 & 492.84 & 32.8 & 1075.84 & 728.16 & 1.337 \\
\hline 2.6 & 1.9 & 1.37 & 22.2 & 492.84 & 35 & 1225 & 777 & 1.322 \\
\hline 2.5 & 1.9 & 1.32 & 22.2 & 492.84 & 37.8 & 1428.84 & 839.16 & 1.298 \\
\hline 2.5 & 1.9 & 1.32 & 22.2 & 492.84 & 40 & 1600 & 888 & 1.276 \\
\hline 2.4 & 1.9 & 1.26 & 22.2 & 492.84 & 43.3 & 1874.89 & 961.26 & 1.235 \\
\hline 2 & 1.8 & 1.11 & 22.2 & 492.84 & 46.1 & 2125.21 & 1023.42 & 1.193 \\
\hline 2.9 & 2.1 & 1.38 & 23.9 & 571.21 & 20 & 400 & 478 & 1.408 \\
\hline 2.9 & 2 & 1.45 & 23.9 & 571.21 & 22.8 & 519.84 & 544.92 & 1.414 \\
\hline 2.8 & 2 & 1.40 & 23.9 & 571.21 & 25 & 625 & 597.5 & 1.415 \\
\hline 2.8 & 2 & 1.40 & 23.9 & 571.21 & 27.8 & 772.84 & 664.42 & 1.411 \\
\hline 2.8 & 2 & 1.40 & 23.9 & 571.21 & 30 & 900 & 717 & 1.404 \\
\hline 2.8 & 2 & 1.40 & 23.9 & 571.21 & 32.8 & 1075.84 & 783.92 & 1.390 \\
\hline 2.7 & 2 & 1.35 & 23.9 & 571.21 & 35 & 1225 & 836.5 & 1.374 \\
\hline 2.7 & 2 & 1.35 & 23.9 & 571.21 & 37.8 & 1428.84 & 903.42 & 1.349 \\
\hline 2.7 & 2 & 1.35 & 23.9 & 571.21 & 40 & 1600 & 956 & 1.325 \\
\hline 2.6 & 2 & 1.30 & 23.9 & 571.21 & 43.3 & 1874.89 & 1034.87 & 1.283 \\
\hline 2.2 & 1.8 & 1.22 & 23.9 & 571.21 & 46.1 & 2125.21 & 1101.79 & 1.241 \\
\hline
\end{tabular}

\begin{tabular}{|c|c|c|c|c|c|c|c|c|}
\hline \multicolumn{9}{|c|}{$\begin{array}{l}\text { Cooling Capacity Ratio Modifier Function of Temperature Curve } \\
C A P=a+b^{*} I W B+c^{*} I W^{\wedge} 2+d^{*} O D B+e^{*} O D B^{\wedge} 2+f^{*} I W B^{*} O D B\end{array}$} \\
\hline TOTAL & SENSIBLE & CAP & IWB & $\mathrm{IWB}^{\wedge} 2$ & ODB & $\mathrm{ODB}^{\wedge} 2$ & IWB*ODB & Predicted \\
\hline 3.3 & 2.5 & 1.32 & 15 & 225 & 20 & 400 & 300 & 1.298 \\
\hline 3.3 & 2.5 & 1.32 & 15 & 225 & 22.8 & 519.84 & 342 & 1.305 \\
\hline 3.2 & 2.5 & 1.28 & 15 & 225 & 25 & 625 & 375 & 1.308 \\
\hline 3.2 & 2.5 & 1.28 & 15 & 225 & 27.8 & 772.84 & 417 & 1.306 \\
\hline 3.2 & 2.5 & 1.28 & 15 & 225 & 30 & 900 & 450 & 1.300 \\
\hline 3.1 & 2.4 & 1.29 & 15 & 225 & 32.8 & 1075.84 & 492 & 1.288 \\
\hline 3.1 & 2.4 & 1.29 & 15 & 225 & 35 & 1225 & 525 & 1.275 \\
\hline 3.1 & 2.4 & 1.29 & 15 & 225 & 37.8 & 1428.84 & 567 & 1.253 \\
\hline 3 & 2.4 & 1.25 & 15 & 225 & 40 & 1600 & 600 & 1.233 \\
\hline 2.9 & 2.4 & 1.21 & 15 & 225 & 43.3 & 1874.89 & 649.5 & 1.195 \\
\hline 2.3 & 2.1 & 1.10 & 15 & 225 & 46.1 & 2125.21 & 691.5 & 1.157 \\
\hline
\end{tabular}




\begin{tabular}{|c|c|c|c|c|c|c|c|c|}
\hline 3.4 & 2.5 & 1.36 & 16.1 & 259.21 & 20 & 400 & 322 & 1.337 \\
\hline 3.4 & 2.5 & 1.36 & 16.1 & 259.21 & 22.8 & 519.84 & 367.08 & 1.344 \\
\hline 3.3 & 2.5 & 1.32 & 16.1 & 259.21 & 25 & 625 & 402.5 & 1.347 \\
\hline 3.3 & 2.5 & 1.32 & 16.1 & 259.21 & 27.8 & 772.84 & 447.58 & 1.345 \\
\hline 3.3 & 2.4 & 1.38 & 16.1 & 259.21 & 30 & 900 & 483 & 1.340 \\
\hline 3.2 & 2.4 & 1.33 & 16.1 & 259.21 & 32.8 & 1075.84 & 528.08 & 1.328 \\
\hline 3.2 & 2.4 & 1.33 & 16.1 & 259.21 & 35 & 1225 & 563.5 & 1.315 \\
\hline 3.1 & 2.4 & 1.29 & 16.1 & 259.21 & 37.8 & 1428.84 & 608.58 & 1.294 \\
\hline 3.1 & 2.4 & 1.29 & 16.1 & 259.21 & 40 & 1600 & 644 & 1.274 \\
\hline 3 & 2.3 & 1.30 & 16.1 & 259.21 & 43.3 & 1874.89 & 697.13 & 1.236 \\
\hline 2.4 & 2 & 1.20 & 16.1 & 259.21 & 46.1 & 2125.21 & 742.21 & 1.199 \\
\hline 3.6 & 2.6 & 1.38 & 17.8 & 316.84 & 20 & 400 & 356 & 1.397 \\
\hline 3.6 & 2.6 & 1.38 & 17.8 & 316.84 & 22.8 & 519.84 & 405.84 & 1.406 \\
\hline 3.6 & 2.6 & 1.38 & 17.8 & 316.84 & 25 & 625 & 445 & 1.409 \\
\hline 3.5 & 2.5 & 1.40 & 17.8 & 316.84 & 27.8 & 772.84 & 494.84 & 1.407 \\
\hline 3.5 & 2.5 & 1.40 & 17.8 & 316.84 & 30 & 900 & 534 & 1.403 \\
\hline 3.4 & 2.5 & 1.36 & 17.8 & 316.84 & 32.8 & 1075.84 & 583.84 & 1.392 \\
\hline 3.4 & 2.5 & 1.36 & 17.8 & 316.84 & 35 & 1225 & 623 & 1.379 \\
\hline 3.4 & 2.5 & 1.36 & 17.8 & 316.84 & 37.8 & 1428.84 & 672.84 & 1.358 \\
\hline 3.3 & 2.5 & 1.32 & 17.8 & 316.84 & 40 & 1600 & 712 & 1.338 \\
\hline 3.2 & 2.4 & 1.33 & 17.8 & 316.84 & 43.3 & 1874.89 & 770.74 & 1.301 \\
\hline 2.6 & 2.2 & 1.18 & 17.8 & 316.84 & 46.1 & 2125.21 & 820.58 & 1.265 \\
\hline 3.7 & 2.6 & 1.42 & 19.4 & 376.36 & 20 & 400 & 388 & 1.456 \\
\hline 3.7 & 2.5 & 1.48 & 19.4 & 376.36 & 22.8 & 519.84 & 442.32 & 1.465 \\
\hline 3.7 & 2.5 & 1.48 & 19.4 & 376.36 & 25 & 625 & 485 & 1.468 \\
\hline 3.6 & 2.5 & 1.44 & 19.4 & 376.36 & 27.8 & 772.84 & 539.32 & 1.467 \\
\hline 3.6 & 2.5 & 1.44 & 19.4 & 376.36 & 30 & 900 & 582 & 1.463 \\
\hline 3.5 & 2.5 & 1.40 & 19.4 & 376.36 & 32.8 & 1075.84 & 636.32 & 1.452 \\
\hline 3.5 & 2.5 & 1.40 & 19.4 & 376.36 & 35 & 1225 & 679 & 1.440 \\
\hline 3.4 & 2.4 & 1.42 & 19.4 & 376.36 & 37.8 & 1428.84 & 733.32 & 1.420 \\
\hline 3.4 & 2.4 & 1.42 & 19.4 & 376.36 & 40 & 1600 & 776 & 1.400 \\
\hline 3.3 & 2.4 & 1.38 & 19.4 & 376.36 & 43.3 & 1874.89 & 840.02 & 1.364 \\
\hline 2.7 & 2.1 & 1.29 & 19.4 & 376.36 & 46.1 & 2125.21 & 894.34 & 1.328 \\
\hline 3.9 & 2.5 & 1.56 & 20.6 & 424.36 & 20 & 400 & 412 & 1.501 \\
\hline 3.8 & 2.5 & 1.52 & 20.6 & 424.36 & 22.8 & 519.84 & 469.68 & 1.510 \\
\hline 3.8 & 2.5 & 1.52 & 20.6 & 424.36 & 25 & 625 & 515 & 1.514 \\
\hline 3.8 & 2.5 & 1.52 & 20.6 & 424.36 & 27.8 & 772.84 & 572.68 & 1.513 \\
\hline 3.7 & 2.5 & 1.48 & 20.6 & 424.36 & 30 & 900 & 618 & 1.509 \\
\hline 3.7 & 2.4 & 1.54 & 20.6 & 424.36 & 32.8 & 1075.84 & 675.68 & 1.499 \\
\hline 3.7 & 2.4 & 1.54 & 20.6 & 424.36 & 35 & 1225 & 721 & 1.487 \\
\hline 3.6 & 2.4 & 1.50 & 20.6 & 424.36 & 37.8 & 1428.84 & 778.68 & 1.467 \\
\hline 3.6 & 2.4 & 1.50 & 20.6 & 424.36 & 40 & 1600 & 824 & 1.447 \\
\hline 3.5 & 2.4 & 1.46 & 20.6 & 424.36 & 43.3 & 1874.89 & 891.98 & 1.412 \\
\hline 2.9 & 2.1 & 1.38 & 20.6 & 424.36 & 46.1 & 2125.21 & 949.66 & 1.376 \\
\hline 4.2 & 2.6 & 1.62 & 22.2 & 492.84 & 20 & 400 & 444 & 1.562 \\
\hline
\end{tabular}




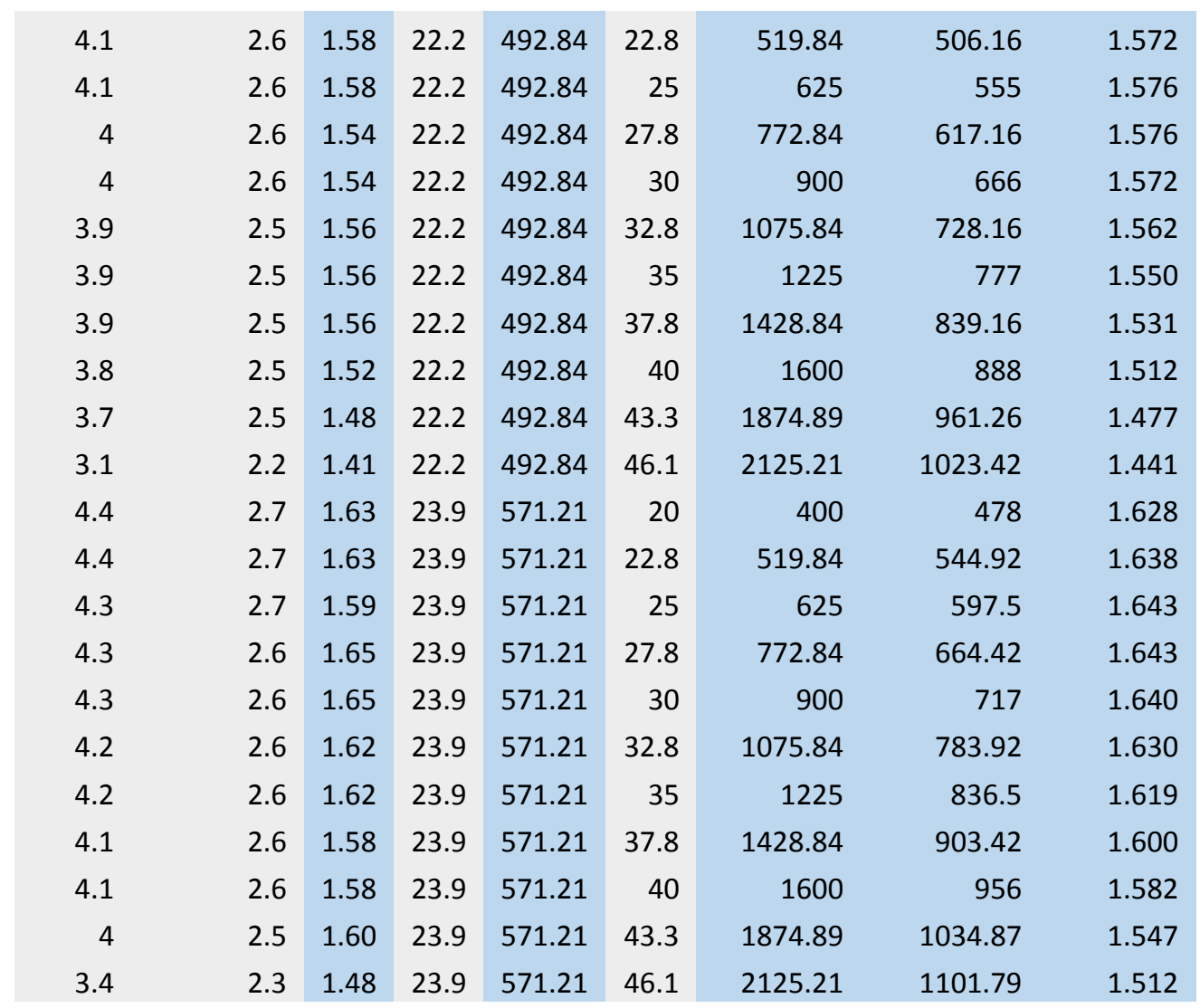

\begin{tabular}{|c|c|c|c|c|c|c|c|c|}
\hline \multicolumn{9}{|c|}{$\begin{array}{l}\text { Cooling Capacity Ratio Modifier Function of Temperature Curve } \\
C A P=a+b^{*} I W B+c^{*} I W^{\wedge} 2+d^{*} O D B+e^{*} O D B^{\wedge} 2+f^{*} I W B^{*} O D B\end{array}$} \\
\hline TOTAL & SENSIBLE & CAP & IWB & $\mathrm{IWB}^{\wedge} 2$ & ODB & $\mathrm{ODB}^{\wedge} 2$ & IWB*ODB & Predicted \\
\hline 4.2 & 3.4 & 1.24 & 15 & 225 & 20 & 400 & 300 & 1.202 \\
\hline 4.1 & 3.4 & 1.21 & 15 & 225 & 22.8 & 519.84 & 342 & 1.211 \\
\hline 4.1 & 3.4 & 1.21 & 15 & 225 & 25 & 625 & 375 & 1.213 \\
\hline 4 & 3.4 & 1.18 & 15 & 225 & 27.8 & 772.84 & 417 & 1.212 \\
\hline 4 & 3.3 & 1.21 & 15 & 225 & 30 & 900 & 450 & 1.207 \\
\hline 3.9 & 3.3 & 1.18 & 15 & 225 & 32.8 & 1075.84 & 492 & 1.195 \\
\hline 3.9 & 3.3 & 1.18 & 15 & 225 & 35 & 1225 & 525 & 1.182 \\
\hline 3.9 & 3.3 & 1.18 & 15 & 225 & 37.8 & 1428.84 & 567 & 1.160 \\
\hline 3.8 & 3.3 & 1.15 & 15 & 225 & 40 & 1600 & 600 & 1.139 \\
\hline 3.7 & 3.2 & 1.16 & 15 & 225 & 43.3 & 1874.89 & 649.5 & 1.101 \\
\hline 2.9 & 2.9 & 1.00 & 15 & 225 & 46.1 & 2125.21 & 691.5 & 1.063 \\
\hline 4.3 & 3.4 & 1.26 & 16.1 & 259.21 & 20 & 400 & 322 & 1.236 \\
\hline 4.2 & 3.4 & 1.24 & 16.1 & 259.21 & 22.8 & 519.84 & 367.08 & 1.245 \\
\hline 4.2 & 3.4 & 1.24 & 16.1 & 259.21 & 25 & 625 & 402.5 & 1.248 \\
\hline 4.1 & 3.3 & 1.24 & 16.1 & 259.21 & 27.8 & 772.84 & 447.58 & 1.247 \\
\hline 4.1 & 3.3 & 1.24 & 16.1 & 259.21 & 30 & 900 & 483 & 1.242 \\
\hline 4 & 3.3 & 1.21 & 16.1 & 259.21 & 32.8 & 1075.84 & 528.08 & 1.230 \\
\hline 4 & 3.3 & 1.21 & 16.1 & 259.21 & 35 & 1225 & 563.5 & 1.217 \\
\hline 3.9 & 3.2 & 1.22 & 16.1 & 259.21 & 37.8 & 1428.84 & 608.58 & 1.195 \\
\hline
\end{tabular}




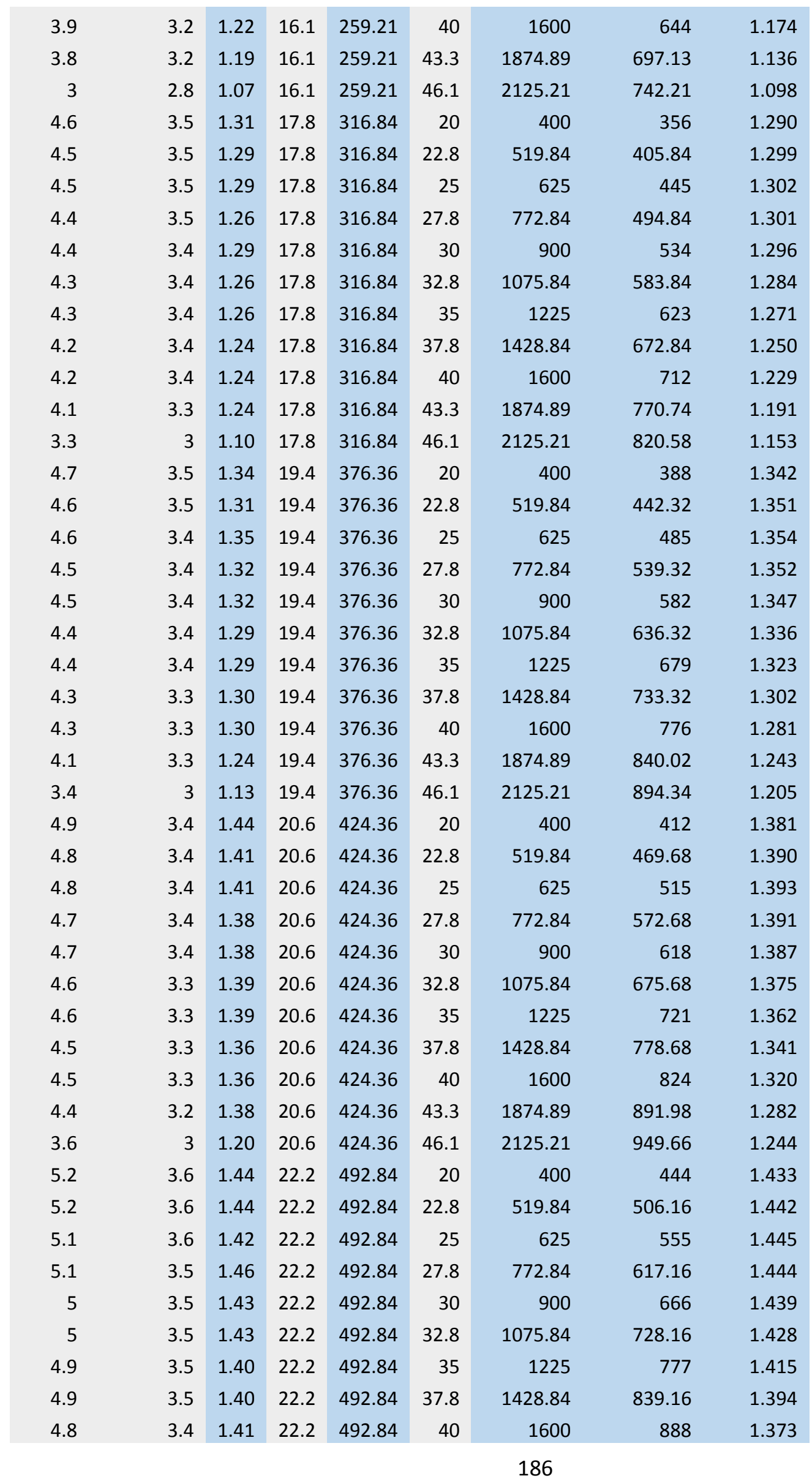




\begin{tabular}{|c|c|c|c|c|c|c|c|c|}
\hline 4.7 & 3.4 & 1.38 & 22.2 & 492.84 & 43.3 & 1874.89 & 961.26 & 1.335 \\
\hline 3.9 & 3.1 & 1.26 & 22.2 & 492.84 & 46.1 & 2125.21 & 1023.42 & 1.297 \\
\hline 5.5 & 3.7 & 1.49 & 23.9 & 571.21 & 20 & 400 & 478 & 1.489 \\
\hline 5.5 & 3.7 & 1.49 & 23.9 & 571.21 & 22.8 & 519.84 & 544.92 & 1.498 \\
\hline 5.4 & 3.6 & 1.50 & 23.9 & 571.21 & 25 & 625 & 597.5 & 1.502 \\
\hline 5.4 & 3.6 & 1.50 & 23.9 & 571.21 & 27.8 & 772.84 & 664.42 & 1.500 \\
\hline 5.3 & 3.6 & 1.47 & 23.9 & 571.21 & 30 & 900 & 717 & 1.496 \\
\hline 5.3 & 3.6 & 1.47 & 23.9 & 571.21 & 32.8 & 1075.84 & 783.92 & 1.485 \\
\hline 5.3 & 3.6 & 1.47 & 23.9 & 571.21 & 35 & 1225 & 836.5 & 1.472 \\
\hline 5.2 & 3.6 & 1.44 & 23.9 & 571.21 & 37.8 & 1428.84 & 903.42 & 1.451 \\
\hline 5.2 & 3.6 & 1.44 & 23.9 & 571.21 & 40 & 1600 & 956 & 1.430 \\
\hline 5 & 3.5 & 1.43 & 23.9 & 571.21 & 43.3 & 1874.89 & 1034.87 & 1.392 \\
\hline 4.3 & 3.3 & 1.30 & 23.9 & 571.21 & 46.1 & 2125.21 & 1101.79 & 1.354 \\
\hline
\end{tabular}

\begin{tabular}{|c|c|c|c|c|c|c|c|c|}
\hline \multicolumn{9}{|c|}{$\begin{array}{l}\text { Cooling Capacity Ratio Modifier Function of Temperature Curve } \\
C A P=a+b^{*} I W B+c^{*} I W^{\wedge} 2+d^{*} O D B+e^{*} O D B^{\wedge} 2+f^{*} I W B^{*} O D B\end{array}$} \\
\hline TOTAL & SENSIBLE & CAP & IWB & $I^{\prime W} B^{\wedge} 2$ & ODB & $\mathrm{ODB}^{\wedge} 2$ & IWB*ODB & Predicted \\
\hline 5 & 4.1 & 1.22 & 15 & 225 & 20 & 400 & 300 & 1.200 \\
\hline 5 & 4.1 & 1.22 & 15 & 225 & 22.8 & 519.84 & 342 & 1.208 \\
\hline 4.9 & 4.1 & 1.20 & 15 & 225 & 25 & 625 & 375 & 1.211 \\
\hline 4.9 & 4.1 & 1.20 & 15 & 225 & 27.8 & 772.84 & 417 & 1.210 \\
\hline 4.8 & 4 & 1.20 & 15 & 225 & 30 & 900 & 450 & 1.205 \\
\hline 4.8 & 4 & 1.20 & 15 & 225 & 32.8 & 1075.84 & 492 & 1.194 \\
\hline 4.7 & 4 & 1.18 & 15 & 225 & 35 & 1225 & 525 & 1.182 \\
\hline 4.7 & 4 & 1.18 & 15 & 225 & 37.8 & 1428.84 & 567 & 1.162 \\
\hline 4.6 & 4 & 1.15 & 15 & 225 & 40 & 1600 & 600 & 1.142 \\
\hline 4.5 & 3.9 & 1.15 & 15 & 225 & 43.3 & 1874.89 & 649.5 & 1.107 \\
\hline 3.6 & 3.5 & 1.03 & 15 & 225 & 46.1 & 2125.21 & 691.5 & 1.071 \\
\hline 5.2 & 4.1 & 1.27 & 16.1 & 259.21 & 20 & 400 & 322 & 1.236 \\
\hline 5.1 & 4.1 & 1.24 & 16.1 & 259.21 & 22.8 & 519.84 & 367.08 & 1.244 \\
\hline 5 & 4.1 & 1.22 & 16.1 & 259.21 & 25 & 625 & 402.5 & 1.246 \\
\hline 5 & 4 & 1.25 & 16.1 & 259.21 & 27.8 & 772.84 & 447.58 & 1.245 \\
\hline 4.9 & 4 & 1.23 & 16.1 & 259.21 & 30 & 900 & 483 & 1.240 \\
\hline 4.9 & 4 & 1.23 & 16.1 & 259.21 & 32.8 & 1075.84 & 528.08 & 1.229 \\
\hline 4.8 & 3.9 & 1.23 & 16.1 & 259.21 & 35 & 1225 & 563.5 & 1.217 \\
\hline 4.7 & 3.9 & 1.21 & 16.1 & 259.21 & 37.8 & 1428.84 & 608.58 & 1.196 \\
\hline 4.7 & 3.9 & 1.21 & 16.1 & 259.21 & 40 & 1600 & 644 & 1.176 \\
\hline 4.5 & 3.8 & 1.18 & 16.1 & 259.21 & 43.3 & 1874.89 & 697.13 & 1.141 \\
\hline 3.6 & 3.4 & 1.06 & 16.1 & 259.21 & 46.1 & 2125.21 & 742.21 & 1.104 \\
\hline 5.5 & 4.3 & 1.28 & 17.8 & 316.84 & 20 & 400 & 356 & 1.291 \\
\hline 5.5 & 4.2 & 1.31 & 17.8 & 316.84 & 22.8 & 519.84 & 405.84 & 1.299 \\
\hline 5.4 & 4.2 & 1.29 & 17.8 & 316.84 & 25 & 625 & 445 & 1.301 \\
\hline 5.3 & 4.2 & 1.26 & 17.8 & 316.84 & 27.8 & 772.84 & 494.84 & 1.299 \\
\hline 5.3 & 4.2 & 1.26 & 17.8 & 316.84 & 30 & 900 & 534 & 1.294 \\
\hline
\end{tabular}




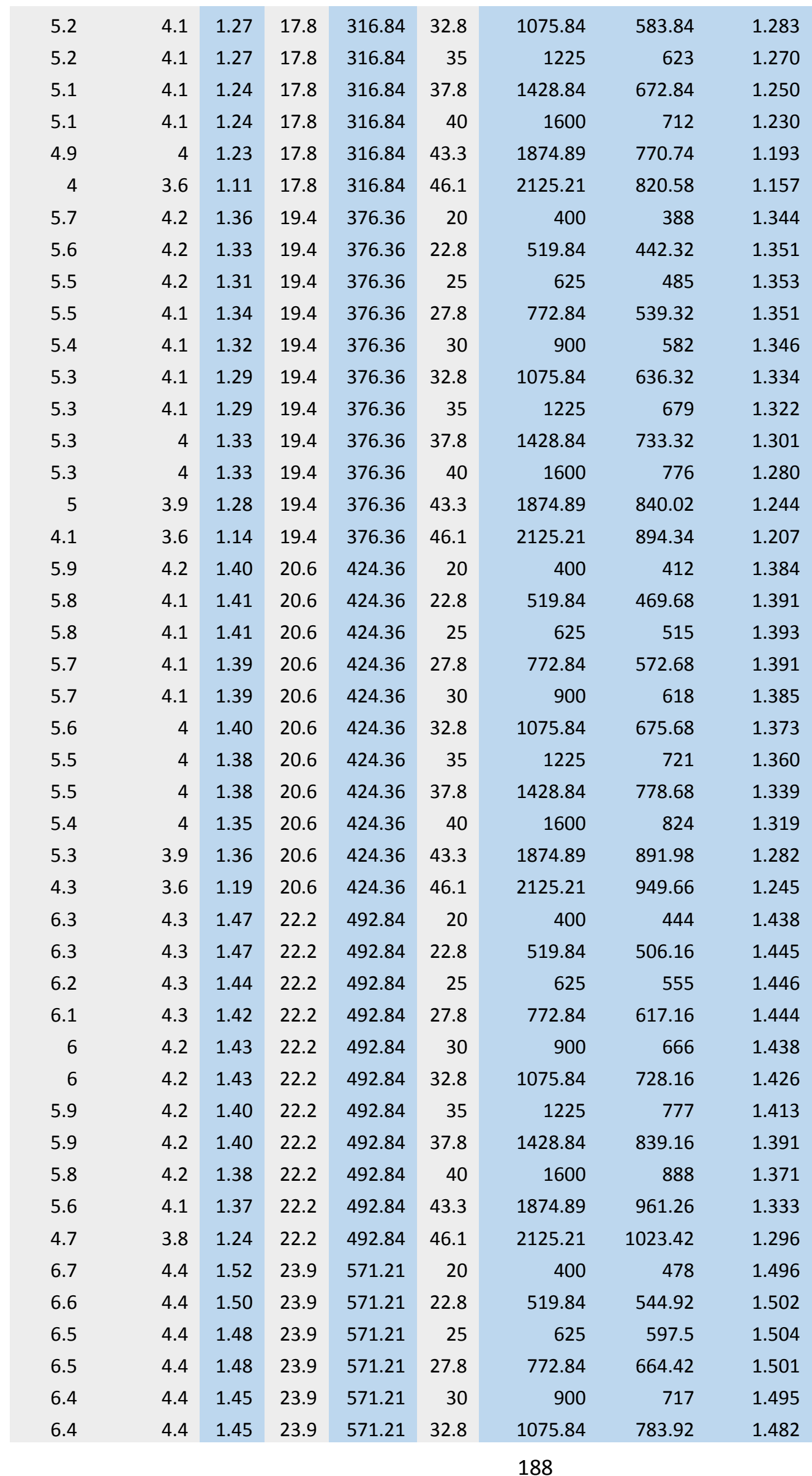




\begin{tabular}{|l|l|l|l|l|r|r|r|r|}
\hline 6.3 & 4.3 & 1.47 & 23.9 & 571.21 & 35 & 1225 & 836.5 & 1.469 \\
\hline 6.3 & 4.3 & 1.47 & 23.9 & 571.21 & 37.8 & 1428.84 & 903.42 & 1.447 \\
\hline 6.2 & 4.3 & 1.44 & 23.9 & 571.21 & 40 & 1600 & 956 & 1.426 \\
6.1 & 4.2 & 1.45 & 23.9 & 571.21 & 43.3 & 1874.89 & 1034.87 & 1.389 \\
\hline 5.1 & 3.9 & 1.31 & 23.9 & 571.21 & 46.1 & 2125.21 & 1101.79 & 1.351 \\
\hline
\end{tabular}

\begin{tabular}{|c|c|c|c|c|c|c|c|c|}
\hline \multicolumn{9}{|c|}{$\begin{array}{l}\text { Cooling Capacity Ratio Modifier Function of Temperature Curve } \\
C A P=a+b^{*} I W B+c^{*} I W^{\wedge} 2+d^{*} O D B+e^{*} O D B^{\wedge} 2+f^{*} I W B^{*} O D B\end{array}$} \\
\hline TOTAL & SENSIBLE & CAP & IWB & $\mathrm{IWB}^{\wedge} 2$ & ODB & $\mathrm{ODB}^{\wedge} 2$ & IWB*ODB & Predicted \\
\hline 6.6 & 5.7 & 1.16 & 15 & 225 & 20 & 400 & 300 & 1.134 \\
\hline 6.5 & 5.7 & 1.14 & 15 & 225 & 22.8 & 519.84 & 342 & 1.146 \\
\hline 6.5 & 5.7 & 1.14 & 15 & 225 & 25 & 625 & 375 & 1.151 \\
\hline 6.4 & 5.6 & 1.14 & 15 & 225 & 27.8 & 772.84 & 417 & 1.150 \\
\hline 6.4 & 5.6 & 1.14 & 15 & 225 & 30 & 900 & 450 & 1.145 \\
\hline 6.3 & 5.6 & 1.13 & 15 & 225 & 32.8 & 1075.84 & 492 & 1.133 \\
\hline 6.2 & 5.5 & 1.13 & 15 & 225 & 35 & 1225 & 525 & 1.119 \\
\hline 6.2 & 5.5 & 1.13 & 15 & 225 & 37.8 & 1428.84 & 567 & 1.094 \\
\hline 6.1 & 5.5 & 1.11 & 15 & 225 & 40 & 1600 & 600 & 1.070 \\
\hline 5.9 & 5.4 & 1.09 & 15 & 225 & 43.3 & 1874.89 & 649.5 & 1.027 \\
\hline 4.7 & 5.7 & 0.82 & 15 & 225 & 46.1 & 2125.21 & 691.5 & 0.982 \\
\hline 6.8 & 5.7 & 1.19 & 16.1 & 259.21 & 20 & 400 & 322 & 1.170 \\
\hline 6.7 & 5.7 & 1.18 & 16.1 & 259.21 & 22.8 & 519.84 & 367.08 & 1.181 \\
\hline 6.7 & 5.6 & 1.20 & 16.1 & 259.21 & 25 & 625 & 402.5 & 1.186 \\
\hline 6.6 & 5.6 & 1.18 & 16.1 & 259.21 & 27.8 & 772.84 & 447.58 & 1.186 \\
\hline 6.5 & 5.6 & 1.16 & 16.1 & 259.21 & 30 & 900 & 483 & 1.181 \\
\hline 6.4 & 5.5 & 1.16 & 16.1 & 259.21 & 32.8 & 1075.84 & 528.08 & 1.169 \\
\hline 6.3 & 5.5 & 1.15 & 16.1 & 259.21 & 35 & 1225 & 563.5 & 1.154 \\
\hline 6.3 & 5.4 & 1.17 & 16.1 & 259.21 & 37.8 & 1428.84 & 608.58 & 1.130 \\
\hline 6.2 & 5.4 & 1.15 & 16.1 & 259.21 & 40 & 1600 & 644 & 1.106 \\
\hline 6 & 5.3 & 1.13 & 16.1 & 259.21 & 43.3 & 1874.89 & 697.13 & 1.063 \\
\hline 4.8 & 4.8 & 1.00 & 16.1 & 259.21 & 46.1 & 2125.21 & 742.21 & 1.018 \\
\hline 7.3 & 5.9 & 1.24 & 17.8 & 316.84 & 20 & 400 & 356 & 1.223 \\
\hline 7.2 & 5.9 & 1.22 & 17.8 & 316.84 & 22.8 & 519.84 & 405.84 & 1.235 \\
\hline 7.1 & 5.9 & 1.20 & 17.8 & 316.84 & 25 & 625 & 445 & 1.240 \\
\hline 7 & 5.8 & 1.21 & 17.8 & 316.84 & 27.8 & 772.84 & 494.84 & 1.240 \\
\hline 7 & 5.8 & 1.21 & 17.8 & 316.84 & 30 & 900 & 534 & 1.235 \\
\hline 6.9 & 5.8 & 1.19 & 17.8 & 316.84 & 32.8 & 1075.84 & 583.84 & 1.223 \\
\hline 6.8 & 5.7 & 1.19 & 17.8 & 316.84 & 35 & 1225 & 623 & 1.208 \\
\hline 6.7 & 5.7 & 1.18 & 17.8 & 316.84 & 37.8 & 1428.84 & 672.84 & 1.184 \\
\hline 6.7 & 5.7 & 1.18 & 17.8 & 316.84 & 40 & 1600 & 712 & 1.160 \\
\hline 6.5 & 5.6 & 1.16 & 17.8 & 316.84 & 43.3 & 1874.89 & 770.74 & 1.117 \\
\hline 5.3 & 5.1 & 1.04 & 17.8 & 316.84 & 46.1 & 2125.21 & 820.58 & 1.073 \\
\hline 7.5 & 5.8 & 1.29 & 19.4 & 376.36 & 20 & 400 & 388 & 1.272 \\
\hline 7.4 & 5.8 & 1.28 & 19.4 & 376.36 & 22.8 & 519.84 & 442.32 & 1.284 \\
\hline
\end{tabular}




\begin{tabular}{|c|c|c|c|c|c|c|c|c|}
\hline 7.3 & 5.8 & 1.26 & 19.4 & 376.36 & 25 & 625 & 485 & 1.289 \\
\hline 7.2 & 5.7 & 1.26 & 19.4 & 376.36 & 27.8 & 772.84 & 539.32 & 1.289 \\
\hline 7.1 & 5.7 & 1.25 & 19.4 & 376.36 & 30 & 900 & 582 & 1.284 \\
\hline 7.1 & 5.7 & 1.25 & 19.4 & 376.36 & 32.8 & 1075.84 & 636.32 & 1.272 \\
\hline 7 & 5.7 & 1.23 & 19.4 & 376.36 & 35 & 1225 & 679 & 1.258 \\
\hline 6.9 & 5.6 & 1.23 & 19.4 & 376.36 & 37.8 & 1428.84 & 733.32 & 1.233 \\
\hline 6.8 & 5.6 & 1.21 & 19.4 & 376.36 & 40 & 1600 & 776 & 1.210 \\
\hline 6.6 & 5.5 & 1.20 & 19.4 & 376.36 & 43.3 & 1874.89 & 840.02 & 1.166 \\
\hline 5.4 & 5 & 1.08 & 19.4 & 376.36 & 46.1 & 2125.21 & 894.34 & 1.122 \\
\hline 7.8 & 5.8 & 1.34 & 20.6 & 424.36 & 20 & 400 & 412 & 1.308 \\
\hline 7.7 & 5.7 & 1.35 & 20.6 & 424.36 & 22.8 & 519.84 & 469.68 & 1.320 \\
\hline 7.6 & 5.7 & 1.33 & 20.6 & 424.36 & 25 & 625 & 515 & 1.325 \\
\hline 7.5 & 5.7 & 1.32 & 20.6 & 424.36 & 27.8 & 772.84 & 572.68 & 1.325 \\
\hline 7.5 & 5.7 & 1.32 & 20.6 & 424.36 & 30 & 900 & 618 & 1.320 \\
\hline 7.4 & 5.6 & 1.32 & 20.6 & 424.36 & 32.8 & 1075.84 & 675.68 & 1.308 \\
\hline 7.3 & 5.6 & 1.30 & 20.6 & 424.36 & 35 & 1225 & 721 & 1.294 \\
\hline 7.2 & 5.6 & 1.29 & 20.6 & 424.36 & 37.8 & 1428.84 & 778.68 & 1.270 \\
\hline 7.2 & 5.5 & 1.31 & 20.6 & 424.36 & 40 & 1600 & 824 & 1.246 \\
\hline 6.9 & 5.5 & 1.25 & 20.6 & 424.36 & 43.3 & 1874.89 & 891.98 & 1.203 \\
\hline 5.7 & 5 & 1.14 & 20.6 & 424.36 & 46.1 & 2125.21 & 949.66 & 1.159 \\
\hline 8.3 & 6 & 1.38 & 22.2 & 492.84 & 20 & 400 & 444 & 1.354 \\
\hline 8.2 & 6 & 1.37 & 22.2 & 492.84 & 22.8 & 519.84 & 506.16 & 1.366 \\
\hline 8.1 & 6 & 1.35 & 22.2 & 492.84 & 25 & 625 & 555 & 1.371 \\
\hline 8.1 & 5.9 & 1.37 & 22.2 & 492.84 & 27.8 & 772.84 & 617.16 & 1.371 \\
\hline 8 & 5.9 & 1.36 & 22.2 & 492.84 & 30 & 900 & 666 & 1.367 \\
\hline 7.9 & 5.9 & 1.34 & 22.2 & 492.84 & 32.8 & 1075.84 & 728.16 & 1.355 \\
\hline 7.8 & 5.9 & 1.32 & 22.2 & 492.84 & 35 & 1225 & 777 & 1.341 \\
\hline 7.7 & 5.8 & 1.33 & 22.2 & 492.84 & 37.8 & 1428.84 & 839.16 & 1.317 \\
\hline 7.7 & 5.8 & 1.33 & 22.2 & 492.84 & 40 & 1600 & 888 & 1.293 \\
\hline 7.4 & 5.7 & 1.30 & 22.2 & 492.84 & 43.3 & 1874.89 & 961.26 & 1.250 \\
\hline 6.2 & 5.3 & 1.17 & 22.2 & 492.84 & 46.1 & 2125.21 & 1023.42 & 1.206 \\
\hline 8.8 & 6.2 & 1.42 & 23.9 & 571.21 & 20 & 400 & 478 & 1.402 \\
\hline 8.7 & 6.2 & 1.40 & 23.9 & 571.21 & 22.8 & 519.84 & 544.92 & 1.414 \\
\hline 8.6 & 6.1 & 1.41 & 23.9 & 571.21 & 25 & 625 & 597.5 & 1.419 \\
\hline 8.6 & 6.1 & 1.41 & 23.9 & 571.21 & 27.8 & 772.84 & 664.42 & 1.419 \\
\hline 8.5 & 6.1 & 1.39 & 23.9 & 571.21 & 30 & 900 & 717 & 1.415 \\
\hline 8.4 & 6.1 & 1.38 & 23.9 & 571.21 & 32.8 & 1075.84 & 783.92 & 1.403 \\
\hline 8.4 & 6 & 1.40 & 23.9 & 571.21 & 35 & 1225 & 836.5 & 1.389 \\
\hline 8.3 & 6 & 1.38 & 23.9 & 571.21 & 37.8 & 1428.84 & 903.42 & 1.365 \\
\hline 8.2 & 6 & 1.37 & 23.9 & 571.21 & 40 & 1600 & 956 & 1.341 \\
\hline 8 & 5.9 & 1.36 & 23.9 & 571.21 & 43.3 & 1874.89 & 1034.87 & 1.298 \\
\hline 6.8 & 5.9 & 1.15 & 23.9 & 571.21 & 46.1 & 2125.21 & 1101.79 & 1.255 \\
\hline
\end{tabular}




\begin{tabular}{|c|c|c|c|c|c|c|c|c|}
\hline \multicolumn{9}{|c|}{$\begin{array}{l}\text { Cooling Capacity Ratio Modifier Function of Temperature Curve } \\
C A P=a+b^{*} I W B+c^{*} I W B^{\wedge} 2+d^{*} O D B+e^{*} O D B^{\wedge} 2+f^{*} I W B^{*} O D B\end{array}$} \\
\hline TOTAL & SENSIBLE & CAP & IWB & $I W^{\wedge} 2$ & ODB & $\mathrm{ODB}^{\wedge} 2$ & IWB*ODB & Predicted \\
\hline 7.5 & 6.1 & 1.23 & 15 & 225 & 20 & 400 & 300 & 1.203 \\
\hline 7.4 & 6.1 & 1.21 & 15 & 225 & 22.8 & 519.84 & 342 & 1.213 \\
\hline 7.3 & 6.1 & 1.20 & 15 & 225 & 25 & 625 & 375 & 1.218 \\
\hline 7.2 & 6 & 1.20 & 15 & 225 & 27.8 & 772.84 & 417 & 1.218 \\
\hline 7.2 & 6 & 1.20 & 15 & 225 & 30 & 900 & 450 & 1.214 \\
\hline 7.1 & 5.9 & 1.20 & 15 & 225 & 32.8 & 1075.84 & 492 & 1.204 \\
\hline 7 & 5.9 & 1.19 & 15 & 225 & 35 & 1225 & 525 & 1.192 \\
\hline 6.9 & 5.9 & 1.17 & 15 & 225 & 37.8 & 1428.84 & 567 & 1.171 \\
\hline 6.9 & 5.8 & 1.19 & 15 & 225 & 40 & 1600 & 600 & 1.150 \\
\hline 6.7 & 5.7 & 1.18 & 15 & 225 & 43.3 & 1874.89 & 649.5 & 1.112 \\
\hline 5.3 & 5.1 & 1.04 & 15 & 225 & 46.1 & 2125.21 & 691.5 & 1.074 \\
\hline 7.7 & 6.1 & 1.26 & 16.1 & 259.21 & 20 & 400 & 322 & 1.238 \\
\hline 7.6 & 6 & 1.27 & 16.1 & 259.21 & 22.8 & 519.84 & 367.08 & 1.249 \\
\hline 7.5 & 6 & 1.25 & 16.1 & 259.21 & 25 & 625 & 402.5 & 1.253 \\
\hline 7.4 & 6 & 1.23 & 16.1 & 259.21 & 27.8 & 772.84 & 447.58 & 1.253 \\
\hline 7.3 & 5.9 & 1.24 & 16.1 & 259.21 & 30 & 900 & 483 & 1.249 \\
\hline 7.2 & 5.9 & 1.22 & 16.1 & 259.21 & 32.8 & 1075.84 & 528.08 & 1.238 \\
\hline 7.2 & 5.8 & 1.24 & 16.1 & 259.21 & 35 & 1225 & 563.5 & 1.226 \\
\hline 7.1 & 5.8 & 1.22 & 16.1 & 259.21 & 37.8 & 1428.84 & 608.58 & 1.205 \\
\hline 7 & 5.8 & 1.21 & 16.1 & 259.21 & 40 & 1600 & 644 & 1.184 \\
\hline 6.7 & 5.7 & 1.18 & 16.1 & 259.21 & 43.3 & 1874.89 & 697.13 & 1.146 \\
\hline 5.4 & 5.1 & 1.06 & 16.1 & 259.21 & 46.1 & 2125.21 & 742.21 & 1.108 \\
\hline 8.2 & 6.3 & 1.30 & 17.8 & 316.84 & 20 & 400 & 356 & 1.293 \\
\hline 8.1 & 6.3 & 1.29 & 17.8 & 316.84 & 22.8 & 519.84 & 405.84 & 1.304 \\
\hline 8.1 & 6.2 & 1.31 & 17.8 & 316.84 & 25 & 625 & 445 & 1.308 \\
\hline 8 & 6.2 & 1.29 & 17.8 & 316.84 & 27.8 & 772.84 & 494.84 & 1.308 \\
\hline 7.9 & 6.2 & 1.27 & 17.8 & 316.84 & 30 & 900 & 534 & 1.303 \\
\hline 7.8 & 6.1 & 1.28 & 17.8 & 316.84 & 32.8 & 1075.84 & 583.84 & 1.292 \\
\hline 7.7 & 6.1 & 1.26 & 17.8 & 316.84 & 35 & 1225 & 623 & 1.280 \\
\hline 7.6 & 6 & 1.27 & 17.8 & 316.84 & 37.8 & 1428.84 & 672.84 & 1.259 \\
\hline 7.5 & 6 & 1.25 & 17.8 & 316.84 & 40 & 1600 & 712 & 1.238 \\
\hline 7.3 & 5.9 & 1.24 & 17.8 & 316.84 & 43.3 & 1874.89 & 770.74 & 1.199 \\
\hline 5.9 & 5.4 & 1.09 & 17.8 & 316.84 & 46.1 & 2125.21 & 820.58 & 1.160 \\
\hline 8.4 & 6.3 & 1.33 & 19.4 & 376.36 & 20 & 400 & 388 & 1.347 \\
\hline 8.3 & 6.3 & 1.32 & 19.4 & 376.36 & 22.8 & 519.84 & 442.32 & 1.357 \\
\hline 8.2 & 6.1 & 1.34 & 19.4 & 376.36 & 25 & 625 & 485 & 1.361 \\
\hline 8.1 & 6.1 & 1.33 & 19.4 & 376.36 & 27.8 & 772.84 & 539.32 & 1.360 \\
\hline 8.1 & 6.1 & 1.33 & 19.4 & 376.36 & 30 & 900 & 582 & 1.356 \\
\hline 8 & 6 & 1.33 & 19.4 & 376.36 & 32.8 & 1075.84 & 636.32 & 1.344 \\
\hline 7.9 & 6 & 1.32 & 19.4 & 376.36 & 35 & 1225 & 679 & 1.332 \\
\hline 7.8 & 6 & 1.30 & 19.4 & 376.36 & 37.8 & 1428.84 & 733.32 & 1.310 \\
\hline 7.7 & 5.9 & 1.31 & 19.4 & 376.36 & 40 & 1600 & 776 & 1.289 \\
\hline
\end{tabular}




\begin{tabular}{|c|c|c|c|c|c|c|c|c|}
\hline 7.4 & 5.8 & 1.28 & 19.4 & 376.36 & 43.3 & 1874.89 & 840.02 & 1.250 \\
\hline 6.1 & 5.3 & 1.15 & 19.4 & 376.36 & 46.1 & 2125.21 & 894.34 & 1.211 \\
\hline 8.8 & 6.1 & 1.44 & 20.6 & 424.36 & 20 & 400 & 412 & 1.387 \\
\hline 8.7 & 6.1 & 1.43 & 20.6 & 424.36 & 22.8 & 519.84 & 469.68 & 1.397 \\
\hline 8.6 & 6.1 & 1.41 & 20.6 & 424.36 & 25 & 625 & 515 & 1.401 \\
\hline 8.5 & 6 & 1.42 & 20.6 & 424.36 & 27.8 & 772.84 & 572.68 & 1.400 \\
\hline 8.4 & 6 & 1.40 & 20.6 & 424.36 & 30 & 900 & 618 & 1.395 \\
\hline 8.3 & 6 & 1.38 & 20.6 & 424.36 & 32.8 & 1075.84 & 675.68 & 1.384 \\
\hline 8.3 & 5.9 & 1.41 & 20.6 & 424.36 & 35 & 1225 & 721 & 1.371 \\
\hline 8.2 & 5.9 & 1.39 & 20.6 & 424.36 & 37.8 & 1428.84 & 778.68 & 1.349 \\
\hline 8.1 & 5.9 & 1.37 & 20.6 & 424.36 & 40 & 1600 & 824 & 1.328 \\
\hline 7.8 & 5.8 & 1.34 & 20.6 & 424.36 & 43.3 & 1874.89 & 891.98 & 1.289 \\
\hline 6.5 & 5.3 & 1.23 & 20.6 & 424.36 & 46.1 & 2125.21 & 949.66 & 1.250 \\
\hline 9.4 & 6.4 & 1.47 & 22.2 & 492.84 & 20 & 400 & 444 & 1.442 \\
\hline 9.3 & 6.4 & 1.45 & 22.2 & 492.84 & 22.8 & 519.84 & 506.16 & 1.452 \\
\hline 9.2 & 6.3 & 1.46 & 22.2 & 492.84 & 25 & 625 & 555 & 1.455 \\
\hline 9.1 & 6.3 & 1.44 & 22.2 & 492.84 & 27.8 & 772.84 & 617.16 & 1.454 \\
\hline 9 & 6.3 & 1.43 & 22.2 & 492.84 & 30 & 900 & 666 & 1.449 \\
\hline 8.9 & 6.2 & 1.44 & 22.2 & 492.84 & 32.8 & 1075.84 & 728.16 & 1.438 \\
\hline 8.8 & 6.2 & 1.42 & 22.2 & 492.84 & 35 & 1225 & 777 & 1.425 \\
\hline 8.7 & 6.2 & 1.40 & 22.2 & 492.84 & 37.8 & 1428.84 & 839.16 & 1.402 \\
\hline 8.6 & 6.1 & 1.41 & 22.2 & 492.84 & 40 & 1600 & 888 & 1.381 \\
\hline 8.4 & 6.1 & 1.38 & 22.2 & 492.84 & 43.3 & 1874.89 & 961.26 & 1.342 \\
\hline 7 & 5.6 & 1.25 & 22.2 & 492.84 & 46.1 & 2125.21 & 1023.42 & 1.302 \\
\hline 9.9 & 6.6 & 1.50 & 23.9 & 571.21 & 20 & 400 & 478 & 1.502 \\
\hline 9.8 & 6.5 & 1.51 & 23.9 & 571.21 & 22.8 & 519.84 & 544.92 & 1.511 \\
\hline 9.8 & 6.5 & 1.51 & 23.9 & 571.21 & 25 & 625 & 597.5 & 1.514 \\
\hline 9.7 & 6.5 & 1.49 & 23.9 & 571.21 & 27.8 & 772.84 & 664.42 & 1.513 \\
\hline 9.6 & 6.5 & 1.48 & 23.9 & 571.21 & 30 & 900 & 717 & 1.508 \\
\hline 9.5 & 6.4 & 1.48 & 23.9 & 571.21 & 32.8 & 1075.84 & 783.92 & 1.496 \\
\hline 9.4 & 6.4 & 1.47 & 23.9 & 571.21 & 35 & 1225 & 836.5 & 1.482 \\
\hline 9.3 & 6.4 & 1.45 & 23.9 & 571.21 & 37.8 & 1428.84 & 903.42 & 1.460 \\
\hline 9.3 & 6.3 & 1.48 & 23.9 & 571.21 & 40 & 1600 & 956 & 1.438 \\
\hline 9 & 6.3 & 1.43 & 23.9 & 571.21 & 43.3 & 1874.89 & 1034.87 & 1.399 \\
\hline 7.7 & 5.8 & 1.33 & 23.9 & 571.21 & 46.1 & 2125.21 & 1101.79 & 1.359 \\
\hline
\end{tabular}

\begin{tabular}{|c|c|c|c|c|c|c|c|c|}
\hline \multicolumn{9}{|c|}{$\begin{array}{l}\text { Cooling Capacity Ratio Modifier Function of Temperature Curve } \\
C A P=a+b^{*} I W B+c^{*} I W^{\wedge} 2+d^{*} O D B+e^{*} O D B^{\wedge} 2+f^{*} I W B^{*} O D B\end{array}$} \\
\hline TOTAL & SENSIBLE & CAP & IWB & $I W B^{\wedge} 2$ & ODB & $\mathrm{ODB}^{\wedge} 2$ & IWB*ODB & Predicted \\
\hline 8.3 & 6.5 & 1.28 & 15 & 225 & 20 & 400 & 300 & 1.262 \\
\hline 8.2 & 6.5 & 1.26 & 15 & 225 & 22.8 & 519.84 & 342 & 1.263 \\
\hline 8.2 & 6.4 & 1.28 & 15 & 225 & 25 & 625 & 375 & 1.262 \\
\hline 8.1 & 6.4 & 1.27 & 15 & 225 & 27.8 & 772.84 & 417 & 1.258 \\
\hline 8 & 6.4 & 1.25 & 15 & 225 & 30 & 900 & 450 & 1.252 \\
\hline
\end{tabular}




\begin{tabular}{|c|c|c|c|c|c|c|c|c|}
\hline 7.9 & 6.3 & 1.25 & 15 & 225 & 32.8 & 1075.84 & 492 & 1.243 \\
\hline 7.8 & 6.3 & 1.24 & 15 & 225 & 35 & 1225 & 525 & 1.233 \\
\hline 7.7 & 6.2 & 1.24 & 15 & 225 & 37.8 & 1428.84 & 567 & 1.218 \\
\hline 7.7 & 6.2 & 1.24 & 15 & 225 & 40 & 1600 & 600 & 1.204 \\
\hline 7.4 & 6.1 & 1.21 & 15 & 225 & 43.3 & 1874.89 & 649.5 & 1.179 \\
\hline 5.9 & 5.4 & 1.09 & 15 & 225 & 46.1 & 2125.21 & 691.5 & 1.154 \\
\hline 8.6 & 6.5 & 1.32 & 16.1 & 259.21 & 20 & 400 & 322 & 1.319 \\
\hline 8.5 & 6.4 & 1.33 & 16.1 & 259.21 & 22.8 & 519.84 & 367.08 & 1.318 \\
\hline 8.4 & 6.4 & 1.31 & 16.1 & 259.21 & 25 & 625 & 402.5 & 1.315 \\
\hline 8.3 & 6.3 & 1.32 & 16.1 & 259.21 & 27.8 & 772.84 & 447.58 & 1.308 \\
\hline 8.2 & 6.3 & 1.30 & 16.1 & 259.21 & 30 & 900 & 483 & 1.300 \\
\hline 8.1 & 6.2 & 1.31 & 16.1 & 259.21 & 32.8 & 1075.84 & 528.08 & 1.288 \\
\hline 8 & 6.2 & 1.29 & 16.1 & 259.21 & 35 & 1225 & 563.5 & 1.276 \\
\hline 7.9 & 6.2 & 1.27 & 16.1 & 259.21 & 37.8 & 1428.84 & 608.58 & 1.258 \\
\hline 7.8 & 6.1 & 1.28 & 16.1 & 259.21 & 40 & 1600 & 644 & 1.242 \\
\hline 7.5 & 6 & 1.25 & 16.1 & 259.21 & 43.3 & 1874.89 & 697.13 & 1.214 \\
\hline 6 & 5.3 & 1.13 & 16.1 & 259.21 & 46.1 & 2125.21 & 742.21 & 1.187 \\
\hline 9.2 & 6.7 & 1.37 & 17.8 & 316.84 & 20 & 400 & 356 & 1.408 \\
\hline 9.1 & 6.7 & 1.36 & 17.8 & 316.84 & 22.8 & 519.84 & 405.84 & 1.402 \\
\hline 9 & 6.6 & 1.36 & 17.8 & 316.84 & 25 & 625 & 445 & 1.396 \\
\hline 8.9 & 6.5 & 1.37 & 17.8 & 316.84 & 27.8 & 772.84 & 494.84 & 1.385 \\
\hline 8.8 & 6.5 & 1.35 & 17.8 & 316.84 & 30 & 900 & 534 & 1.374 \\
\hline 8.7 & 6.5 & 1.34 & 17.8 & 316.84 & 32.8 & 1075.84 & 583.84 & 1.357 \\
\hline 8.6 & 6.4 & 1.34 & 17.8 & 316.84 & 35 & 1225 & 623 & 1.342 \\
\hline 8.5 & 6.4 & 1.33 & 17.8 & 316.84 & 37.8 & 1428.84 & 672.84 & 1.320 \\
\hline 8.4 & 6.4 & 1.31 & 17.8 & 316.84 & 40 & 1600 & 712 & 1.301 \\
\hline 8.1 & 6.3 & 1.29 & 17.8 & 316.84 & 43.3 & 1874.89 & 770.74 & 1.268 \\
\hline 6.6 & 5.6 & 1.18 & 17.8 & 316.84 & 46.1 & 2125.21 & 820.58 & 1.236 \\
\hline 9.4 & 6.6 & 1.42 & 19.4 & 376.36 & 20 & 400 & 388 & 1.490 \\
\hline 9.3 & 6.6 & 1.41 & 19.4 & 376.36 & 22.8 & 519.84 & 442.32 & 1.481 \\
\hline 9.2 & 6.5 & 1.42 & 19.4 & 376.36 & 25 & 625 & 485 & 1.471 \\
\hline 9.1 & 6.5 & 1.40 & 19.4 & 376.36 & 27.8 & 772.84 & 539.32 & 1.456 \\
\hline 9 & 6.4 & 1.41 & 19.4 & 376.36 & 30 & 900 & 582 & 1.443 \\
\hline 8.9 & 6.4 & 1.39 & 19.4 & 376.36 & 32.8 & 1075.84 & 636.32 & 1.422 \\
\hline 8.8 & 6.4 & 1.38 & 19.4 & 376.36 & 35 & 1225 & 679 & 1.404 \\
\hline 8.7 & 6.3 & 1.38 & 19.4 & 376.36 & 37.8 & 1428.84 & 733.32 & 1.378 \\
\hline 8.6 & 6.3 & 1.37 & 19.4 & 376.36 & 40 & 1600 & 776 & 1.355 \\
\hline 8.3 & 6.2 & 1.34 & 19.4 & 376.36 & 43.3 & 1874.89 & 840.02 & 1.318 \\
\hline 6.8 & 5.6 & 1.21 & 19.4 & 376.36 & 46.1 & 2125.21 & 894.34 & 1.282 \\
\hline 9.8 & 6.5 & 1.51 & 20.6 & 424.36 & 20 & 400 & 412 & 1.552 \\
\hline 9.7 & 6.5 & 1.49 & 20.6 & 424.36 & 22.8 & 519.84 & 469.68 & 1.539 \\
\hline 9.6 & 6.5 & 1.48 & 20.6 & 424.36 & 25 & 625 & 515 & 1.528 \\
\hline 9.5 & 6.4 & 1.48 & 20.6 & 424.36 & 27.8 & 772.84 & 572.68 & 1.510 \\
\hline 9.4 & 6.4 & 1.47 & 20.6 & 424.36 & 30 & 900 & 618 & 1.494 \\
\hline 9.3 & 6.3 & 1.48 & 20.6 & 424.36 & 32.8 & 1075.84 & 675.68 & 1.470 \\
\hline
\end{tabular}




\begin{tabular}{|c|c|c|c|c|c|c|c|c|}
\hline 9.2 & 6.3 & 1.46 & 20.6 & 424.36 & 35 & 1225 & 721 & 1.450 \\
\hline 9.1 & 6.3 & 1.44 & 20.6 & 424.36 & 37.8 & 1428.84 & 778.68 & 1.421 \\
\hline 9 & 6.2 & 1.45 & 20.6 & 424.36 & 40 & 1600 & 824 & 1.396 \\
\hline 8.7 & 6.1 & 1.43 & 20.6 & 424.36 & 43.3 & 1874.89 & 891.98 & 1.355 \\
\hline 7.2 & 5.6 & 1.29 & 20.6 & 424.36 & 46.1 & 2125.21 & 949.66 & 1.316 \\
\hline 10.4 & 6.8 & 1.53 & 22.2 & 492.84 & 20 & 400 & 444 & 1.633 \\
\hline 19.3 & 6.8 & 2.84 & 22.2 & 492.84 & 22.8 & 519.84 & 506.16 & 1.617 \\
\hline 10.2 & 6.7 & 1.52 & 22.2 & 492.84 & 25 & 625 & 555 & 1.602 \\
\hline 10.1 & 6.7 & 1.51 & 22.2 & 492.84 & 27.8 & 772.84 & 617.16 & 1.580 \\
\hline 10 & 6.7 & 1.49 & 22.2 & 492.84 & 30 & 900 & 666 & 1.561 \\
\hline 9.9 & 6.6 & 1.50 & 22.2 & 492.84 & 32.8 & 1075.84 & 728.16 & 1.534 \\
\hline 9.8 & 6.6 & 1.48 & 22.2 & 492.84 & 35 & 1225 & 777 & 1.510 \\
\hline 9.7 & 6.5 & 1.49 & 22.2 & 492.84 & 37.8 & 1428.84 & 839.16 & 1.477 \\
\hline 9.6 & 6.5 & 1.48 & 22.2 & 492.84 & 40 & 1600 & 888 & 1.449 \\
\hline 9.3 & 6.4 & 1.45 & 22.2 & 492.84 & 43.3 & 1874.89 & 961.26 & 1.403 \\
\hline 7.8 & 5.9 & 1.32 & 22.2 & 492.84 & 46.1 & 2125.21 & 1023.42 & 1.361 \\
\hline 11.1 & 7 & 1.59 & 23.9 & 571.21 & 20 & 400 & 478 & 1.719 \\
\hline 11 & 6.9 & 1.59 & 23.9 & 571.21 & 22.8 & 519.84 & 544.92 & 1.699 \\
\hline 10.9 & 6.9 & 1.58 & 23.9 & 571.21 & 25 & 625 & 597.5 & 1.681 \\
\hline 10.8 & 6.9 & 1.57 & 23.9 & 571.21 & 27.8 & 772.84 & 664.42 & 1.655 \\
\hline 10.7 & 6.8 & 1.57 & 23.9 & 571.21 & 30 & 900 & 717 & 1.632 \\
\hline 10.6 & 6.8 & 1.56 & 23.9 & 571.21 & 32.8 & 1075.84 & 783.92 & 1.601 \\
\hline 10.5 & 6.8 & 1.54 & 23.9 & 571.21 & 35 & 1225 & 836.5 & 1.574 \\
\hline 10.4 & 6.7 & 1.55 & 23.9 & 571.21 & 37.8 & 1428.84 & 903.42 & 1.537 \\
\hline 10.3 & 6.7 & 1.54 & 23.9 & 571.21 & 40 & 1600 & 956 & 1.505 \\
\hline 10.1 & 6.6 & 1.53 & 23.9 & 571.21 & 43.3 & 1874.89 & 1034.87 & 1.455 \\
\hline 8.5 & 6.1 & 1.39 & 23.9 & 571.21 & 46.1 & 2125.21 & 1101.79 & 1.408 \\
\hline
\end{tabular}

\begin{tabular}{|c|c|c|c|c|c|c|c|c|}
\hline \multicolumn{9}{|c|}{$\begin{array}{l}\text { Cooling Capacity Ratio Modifier Function of Temperature Curve } \\
C A P=a+b^{*} I W B+c^{*} I W^{\wedge} 2+d^{*} O D B+e^{*} O D B^{\wedge} 2+f^{*} I W B^{*} O D B\end{array}$} \\
\hline TOTAL & SENSIBLE & CAP & IWB & $I W^{\wedge} 2$ & ODB & $\mathrm{ODB}^{\wedge} 2$ & IWB*ODB & Predicted \\
\hline 10 & 8.2 & 1.22 & 15 & 225 & 20 & 400 & 300 & 1.202 \\
\hline 9.9 & 8.2 & 1.21 & 15 & 225 & 22.8 & 519.84 & 342 & 1.210 \\
\hline 9.8 & 8.1 & 1.21 & 15 & 225 & 25 & 625 & 375 & 1.213 \\
\hline 9.7 & 8.1 & 1.20 & 15 & 225 & 27.8 & 772.84 & 417 & 1.212 \\
\hline 9.6 & 8 & 1.20 & 15 & 225 & 30 & 900 & 450 & 1.207 \\
\hline 9.5 & 8 & 1.19 & 15 & 225 & 32.8 & 1075.84 & 492 & 1.197 \\
\hline 9.4 & 8 & 1.18 & 15 & 225 & 35 & 1225 & 525 & 1.184 \\
\hline 9.3 & 7.9 & 1.18 & 15 & 225 & 37.8 & 1428.84 & 567 & 1.163 \\
\hline 9.2 & 7.9 & 1.16 & 15 & 225 & 40 & 1600 & 600 & 1.143 \\
\hline 8.9 & 7.7 & 1.16 & 15 & 225 & 43.3 & 1874.89 & 649.5 & 1.107 \\
\hline 7.1 & 6.9 & 1.03 & 15 & 225 & 46.1 & 2125.21 & 691.5 & 1.070 \\
\hline 10.3 & 8.2 & 1.26 & 16.1 & 259.21 & 20 & 400 & 322 & 1.237 \\
\hline 10.2 & 8.1 & 1.26 & 16.1 & 259.21 & 22.8 & 519.84 & 367.08 & 1.246 \\
\hline
\end{tabular}




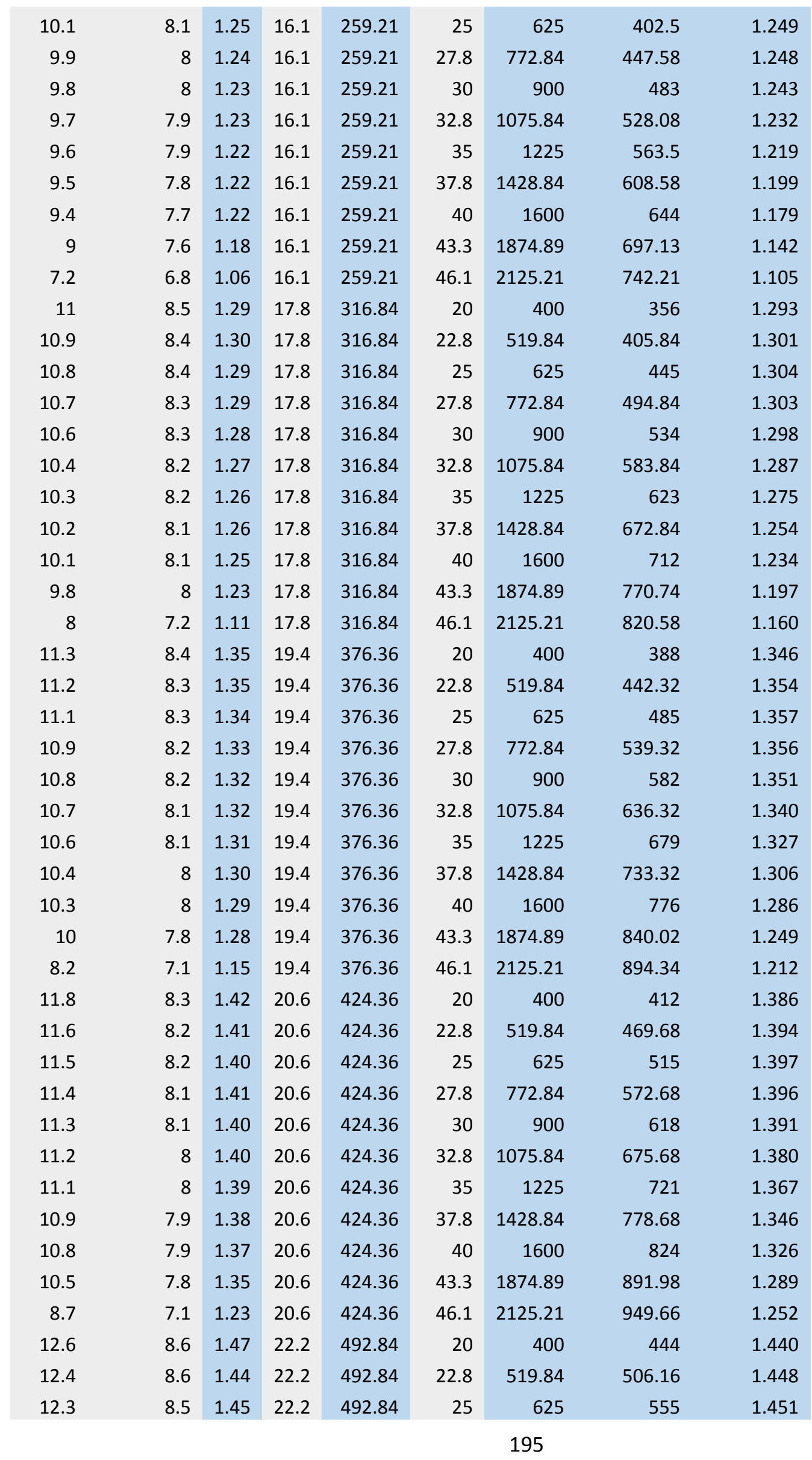




\begin{tabular}{|c|c|c|c|c|c|c|c|c|}
\hline 12.2 & 8.5 & 1.44 & 22.2 & 492.84 & 27.8 & 772.84 & 617.16 & 1.449 \\
\hline 12.1 & 8.4 & 1.44 & 22.2 & 492.84 & 30 & 900 & 666 & 1.444 \\
\hline 12 & 8.4 & 1.43 & 22.2 & 492.84 & 32.8 & 1075.84 & 728.16 & 1.433 \\
\hline 11.8 & 8.4 & 1.40 & 22.2 & 492.84 & 35 & 1225 & 777 & 1.421 \\
\hline 11.7 & 8.3 & 1.41 & 22.2 & 492.84 & 37.8 & 1428.84 & 839.16 & 1.400 \\
\hline 11.6 & 8.3 & 1.40 & 22.2 & 492.84 & 40 & 1600 & 888 & 1.379 \\
\hline 11.3 & 8.1 & 1.40 & 22.2 & 492.84 & 43.3 & 1874.89 & 961.26 & 1.343 \\
\hline 9.4 & 7.5 & 1.25 & 22.2 & 492.84 & 46.1 & 2125.21 & 1023.42 & 1.305 \\
\hline 13.3 & 8.8 & 1.51 & 23.9 & 571.21 & 20 & 400 & 478 & 1.498 \\
\hline 13.2 & 8.8 & 1.50 & 23.9 & 571.21 & 22.8 & 519.84 & 544.92 & 1.506 \\
\hline 13.1 & 8.8 & 1.49 & 23.9 & 571.21 & 25 & 625 & 597.5 & 1.509 \\
\hline 13 & 8.7 & 1.49 & 23.9 & 571.21 & 27.8 & 772.84 & 664.42 & 1.507 \\
\hline 12.9 & 8.7 & 1.48 & 23.9 & 571.21 & 30 & 900 & 717 & 1.502 \\
\hline 12.7 & 8.6 & 1.48 & 23.9 & 571.21 & 32.8 & 1075.84 & 783.92 & 1.491 \\
\hline 12.7 & 8.6 & 1.48 & 23.9 & 571.21 & 35 & 1225 & 836.5 & 1.478 \\
\hline 12.5 & 8.6 & 1.45 & 23.9 & 571.21 & 37.8 & 1428.84 & 903.42 & 1.457 \\
\hline 12.4 & 8.5 & 1.46 & 23.9 & 571.21 & 40 & 1600 & 956 & 1.437 \\
\hline 12.1 & 8.4 & 1.44 & 23.9 & 571.21 & 43.3 & 1874.89 & 1034.87 & 1.400 \\
\hline 10.3 & 7.8 & 1.32 & 23.9 & 571.21 & 46.1 & 2125.21 & 1101.79 & 1.363 \\
\hline
\end{tabular}

\begin{tabular}{|c|c|c|c|c|c|c|c|c|}
\hline \multicolumn{9}{|c|}{$\begin{array}{l}\text { Cooling Capacity Ratio Modifier Function of Temperature Curve } \\
C A P=a+b^{*} I W B+c^{*} I W B^{\wedge} 2+d^{*} O D B+e^{*} O D B^{\wedge} 2+f^{*} I W B^{*} O D B\end{array}$} \\
\hline TOTAL & SENSIBLE & CAP & IWB & $I \mathrm{WB}^{\wedge} 2$ & ODB & $\mathrm{ODB}^{\wedge} 2$ & IWB*ODB & Predicted \\
\hline 13.3 & 10.4 & 1.28 & 15 & 225 & 20 & 400 & 300 & 1.269 \\
\hline 13.2 & 10.3 & 1.28 & 15 & 225 & 22.8 & 519.84 & 342 & 1.278 \\
\hline 13.1 & 10.3 & 1.27 & 15 & 225 & 25 & 625 & 375 & 1.281 \\
\hline 12.9 & 10.2 & 1.26 & 15 & 225 & 27.8 & 772.84 & 417 & 1.280 \\
\hline 12.8 & 10.1 & 1.27 & 15 & 225 & 30 & 900 & 450 & 1.276 \\
\hline 12.7 & 10.1 & 1.26 & 15 & 225 & 32.8 & 1075.84 & 492 & 1.265 \\
\hline 12.5 & 10 & 1.25 & 15 & 225 & 35 & 1225 & 525 & 1.253 \\
\hline 12.4 & 9.9 & 1.25 & 15 & 225 & 37.8 & 1428.84 & 567 & 1.233 \\
\hline 12.3 & 9.9 & 1.24 & 15 & 225 & 40 & 1600 & 600 & 1.214 \\
\hline 11.9 & 9.7 & 1.23 & 15 & 225 & 43.3 & 1874.89 & 649.5 & 1.178 \\
\hline 9.4 & 8.6 & 1.09 & 15 & 225 & 46.1 & 2125.21 & 691.5 & 1.142 \\
\hline 13.7 & 10.3 & 1.33 & 16.1 & 259.21 & 20 & 400 & 322 & 1.308 \\
\hline 13.6 & 10.2 & 1.33 & 16.1 & 259.21 & 22.8 & 519.84 & 367.08 & 1.317 \\
\hline 13.4 & 10.2 & 1.31 & 16.1 & 259.21 & 25 & 625 & 402.5 & 1.320 \\
\hline 13.2 & 10.1 & 1.31 & 16.1 & 259.21 & 27.8 & 772.84 & 447.58 & 1.319 \\
\hline 13.1 & 10 & 1.31 & 16.1 & 259.21 & 30 & 900 & 483 & 1.315 \\
\hline 12.9 & 9.9 & 1.30 & 16.1 & 259.21 & 32.8 & 1075.84 & 528.08 & 1.304 \\
\hline 12.8 & 9.9 & 1.29 & 16.1 & 259.21 & 35 & 1225 & 563.5 & 1.292 \\
\hline 12.6 & 9.8 & 1.29 & 16.1 & 259.21 & 37.8 & 1428.84 & 608.58 & 1.272 \\
\hline 12.5 & 9.7 & 1.29 & 16.1 & 259.21 & 40 & 1600 & 644 & 1.252 \\
\hline 12 & 9.5 & 1.26 & 16.1 & 259.21 & 43.3 & 1874.89 & 697.13 & 1.216 \\
\hline
\end{tabular}




\begin{tabular}{|c|c|c|c|c|c|c|c|c|}
\hline 9.6 & 8.5 & 1.13 & 16.1 & 259.21 & 46.1 & 2125.21 & 742.21 & 1.180 \\
\hline 14.7 & 10.7 & 1.37 & 17.8 & 316.84 & 20 & 400 & 356 & 1.369 \\
\hline 14.5 & 10.6 & 1.37 & 17.8 & 316.84 & 22.8 & 519.84 & 405.84 & 1.378 \\
\hline 14.4 & 10.6 & 1.36 & 17.8 & 316.84 & 25 & 625 & 445 & 1.381 \\
\hline 14.2 & 10.6 & 1.34 & 17.8 & 316.84 & 27.8 & 772.84 & 494.84 & 1.380 \\
\hline 14.1 & 10.4 & 1.36 & 17.8 & 316.84 & 30 & 900 & 534 & 1.375 \\
\hline 13.9 & 10.3 & 1.35 & 17.8 & 316.84 & 32.8 & 1075.84 & 583.84 & 1.364 \\
\hline 13.8 & 10.3 & 1.34 & 17.8 & 316.84 & 35 & 1225 & 623 & 1.352 \\
\hline 13.6 & 10.2 & 1.33 & 17.8 & 316.84 & 37.8 & 1428.84 & 672.84 & 1.332 \\
\hline 13.4 & 10.1 & 1.33 & 17.8 & 316.84 & 40 & 1600 & 712 & 1.312 \\
\hline 13 & 10 & 1.30 & 17.8 & 316.84 & 43.3 & 1874.89 & 770.74 & 1.276 \\
\hline 10.6 & 8.9 & 1.19 & 17.8 & 316.84 & 46.1 & 2125.21 & 820.58 & 1.240 \\
\hline 15.1 & 10.5 & 1.44 & 19.4 & 376.36 & 20 & 400 & 388 & 1.426 \\
\hline 14.9 & 10.4 & 1.43 & 19.4 & 376.36 & 22.8 & 519.84 & 442.32 & 1.435 \\
\hline 14.7 & 10.4 & 1.41 & 19.4 & 376.36 & 25 & 625 & 485 & 1.438 \\
\hline 14.5 & 10.3 & 1.41 & 19.4 & 376.36 & 27.8 & 772.84 & 539.32 & 1.437 \\
\hline 14.4 & 10.3 & 1.40 & 19.4 & 376.36 & 30 & 900 & 582 & 1.432 \\
\hline 14.2 & 10.2 & 1.39 & 19.4 & 376.36 & 32.8 & 1075.84 & 636.32 & 1.421 \\
\hline 14.1 & 10.1 & 1.40 & 19.4 & 376.36 & 35 & 1225 & 679 & 1.409 \\
\hline 13.9 & 10 & 1.39 & 19.4 & 376.36 & 37.8 & 1428.84 & 733.32 & 1.388 \\
\hline 13.7 & 10 & 1.37 & 19.4 & 376.36 & 40 & 1600 & 776 & 1.369 \\
\hline 13.3 & 9.8 & 1.36 & 19.4 & 376.36 & 43.3 & 1874.89 & 840.02 & 1.333 \\
\hline 10.9 & 8.8 & 1.24 & 19.4 & 376.36 & 46.1 & 2125.21 & 894.34 & 1.296 \\
\hline 15.7 & 10.4 & 1.51 & 20.6 & 424.36 & 20 & 400 & 412 & 1.469 \\
\hline 15.5 & 10.3 & 1.50 & 20.6 & 424.36 & 22.8 & 519.84 & 469.68 & 1.478 \\
\hline 15.4 & 10.3 & 1.50 & 20.6 & 424.36 & 25 & 625 & 515 & 1.481 \\
\hline 15.2 & 10.2 & 1.49 & 20.6 & 424.36 & 27.8 & 772.84 & 572.68 & 1.479 \\
\hline 15 & 10.2 & 1.47 & 20.6 & 424.36 & 30 & 900 & 618 & 1.475 \\
\hline 14.9 & 10.1 & 1.48 & 20.6 & 424.36 & 32.8 & 1075.84 & 675.68 & 1.464 \\
\hline 14.7 & 10 & 1.47 & 20.6 & 424.36 & 35 & 1225 & 721 & 1.452 \\
\hline 14.6 & 10 & 1.46 & 20.6 & 424.36 & 37.8 & 1428.84 & 778.68 & 1.431 \\
\hline 14.4 & 9.9 & 1.45 & 20.6 & 424.36 & 40 & 1600 & 824 & 1.411 \\
\hline 14 & 9.7 & 1.44 & 20.6 & 424.36 & 43.3 & 1874.89 & 891.98 & 1.375 \\
\hline 11.6 & 8.8 & 1.32 & 20.6 & 424.36 & 46.1 & 2125.21 & 949.66 & 1.338 \\
\hline 16.7 & 10.8 & 1.55 & 22.2 & 492.84 & 20 & 400 & 444 & 1.527 \\
\hline 16.6 & 10.8 & 1.54 & 22.2 & 492.84 & 22.8 & 519.84 & 506.16 & 1.535 \\
\hline 16.4 & 10.7 & 1.53 & 22.2 & 492.84 & 25 & 625 & 555 & 1.538 \\
\hline 16.2 & 10.6 & 1.53 & 22.2 & 492.84 & 27.8 & 772.84 & 617.16 & 1.537 \\
\hline 16.1 & 10.6 & 1.52 & 22.2 & 492.84 & 30 & 900 & 666 & 1.532 \\
\hline 15.9 & 10.5 & 1.51 & 22.2 & 492.84 & 32.8 & 1075.84 & 728.16 & 1.521 \\
\hline 15.8 & 10.5 & 1.50 & 22.2 & 492.84 & 35 & 1225 & 777 & 1.509 \\
\hline 15.6 & 10.4 & 1.50 & 22.2 & 492.84 & 37.8 & 1428.84 & 839.16 & 1.488 \\
\hline 15.4 & 10.3 & 1.50 & 22.2 & 492.84 & 40 & 1600 & 888 & 1.468 \\
\hline 15 & 10.2 & 1.47 & 22.2 & 492.84 & 43.3 & 1874.89 & 961.26 & 1.432 \\
\hline 12.5 & 9.3 & 1.34 & 22.2 & 492.84 & 46.1 & 2125.21 & 1023.42 & 1.395 \\
\hline
\end{tabular}




\begin{tabular}{|c|c|c|c|c|c|c|c|c|}
\hline 17.7 & 11.1 & 1.59 & 23.9 & 571.21 & 20 & 400 & 478 & 1.589 \\
\hline 17.5 & 11 & 1.59 & 23.9 & 571.21 & 22.8 & 519.84 & 544.92 & 1.597 \\
\hline 17.4 & 11 & 1.58 & 23.9 & 571.21 & 25 & 625 & 597.5 & 1.600 \\
\hline 17.3 & 10.9 & 1.59 & 23.9 & 571.21 & 27.8 & 772.84 & 664.42 & 1.598 \\
\hline 17.1 & 10.9 & 1.57 & 23.9 & 571.21 & 30 & 900 & 717 & 1.593 \\
\hline 17 & 10.8 & 1.57 & 23.9 & 571.21 & 32.8 & 1075.84 & 783.92 & 1.582 \\
\hline 16.8 & 10.8 & 1.56 & 23.9 & 571.21 & 35 & 1225 & 836.5 & 1.570 \\
\hline 16.7 & 10.7 & 1.56 & 23.9 & 571.21 & 37.8 & 1428.84 & 903.42 & 1.549 \\
\hline 16.5 & 10.7 & 1.54 & 23.9 & 571.21 & 40 & 1600 & 956 & 1.529 \\
\hline 16.1 & 10.5 & 1.53 & 23.9 & 571.21 & 43.3 & 1874.89 & 1034.87 & 1.493 \\
\hline 13.7 & 9.7 & 1.41 & 23.9 & 571.21 & 46.1 & 2125.21 & 1101.79 & 1.456 \\
\hline
\end{tabular}




\begin{tabular}{|c|c|c|c|c|c|c|c|c|c|c|}
\hline CCAPFT & $\begin{array}{l}\text { PEFY-P06- } \\
\text { NMAU-E }\end{array}$ & $\begin{array}{l}\text { PEFY-P08- } \\
\text { NMAU-E }\end{array}$ & $\begin{array}{l}\text { PEFY-P12- } \\
\text { NMAU-E }\end{array}$ & $\begin{array}{l}\text { PEFY-P15- } \\
\text { NMAU-E }\end{array}$ & $\begin{array}{l}\text { PEFY-P18- } \\
\text { NMAU-E }\end{array}$ & $\begin{array}{l}\text { PEFY-P24- } \\
\text { NMAU-E }\end{array}$ & $\begin{array}{l}\text { PEFY-P27- } \\
\text { NMAU-E }\end{array}$ & $\begin{array}{l}\text { PEFY-P30- } \\
\text { NMAU-E }\end{array}$ & PEFY-P36-NMAU-E & $\begin{array}{l}\text { PEFY-P48- } \\
\text { NMAU-E }\end{array}$ \\
\hline a & 0.391811 & 0.369649 & 0.649108 & 0.535821 & 0.512648 & 0.312147 & 0.498211 & 0.084483 & 0.522697 & 0.520321 \\
\hline b & 0.030370 & 0.029332 & 0.025262 & 0.027667 & 0.029817 & 0.040169 & 0.027450 & 0.073482 & 0.028688 & 0.034569 \\
\hline $\mathrm{C}$ & 0.000176 & 0.000211 & 0.000251 & 0.000110 & 0.000120 & -0.000270 & 0.000189 & -0.000116 & 0.000125 & 0.000045 \\
\hline d & 0.016075 & 0.024096 & 0.016062 & 0.018279 & 0.018398 & 0.022322 & 0.020978 & 0.022172 & 0.018216 & 0.018252 \\
\hline $\mathrm{e}$ & -0.000119 & -0.000374 & -0.000348 & -0.000361 & -0.000339 & -0.000430 & -0.000378 & -0.000199 & -0.000349 & -0.000345 \\
\hline$f$ & -0.000583 & -0.000242 & 0.000104 & 0.000018 & -0.000065 & 0.000020 & -0.000061 & -0.000877 & -0.000014 & -0.000022 \\
\hline $\mathrm{R}^{2}$ & 0.8292 & 0.8912 & 0.9452 & 0.9295 & 0.8323 & 0.9022 & 0.9424 & 0.4708 & 0.9512 & 0.9540 \\
\hline
\end{tabular}

\begin{tabular}{|l|r|}
\hline $\begin{array}{l}\text { CCAPFFF } \\
\text { HCAPFFF }\end{array}$ & ALL \\
\hline $\mathrm{a}$ & 1 \\
\hline $\mathrm{b}$ & 0 \\
\hline $\mathrm{c}$ & 0 \\
\hline $\mathrm{R}^{2}$ & 1 \\
\hline
\end{tabular}

\begin{tabular}{|l|l|l|}
\hline HCAPFT & PURY & PUHY \\
\hline a & 1 & 1 \\
\hline$b$ & 0 & 0 \\
\hline$c$ & 0 & 0 \\
\hline$d$ & 0 & 0 \\
\hline$e$ & 0 & 0 \\
\hline$f$ & 0 & 0 \\
\hline$R^{2}$ & 1 & 1 \\
\hline
\end{tabular}


APPENDIX H: VRF TERMINAL UNIT FAN INFORMATION 


\begin{tabular}{|c|c|c|c|c|c|c|}
\hline \multirow{2}{*}{ Tag Number } & \multirow{2}{*}{ Model Number } & Speed & Voltage (V) & Current (A) & Power (W) & Power (W) \\
\hline & & Tested & Tested & Tested & Calculated & Simulated \\
\hline FC-1-1 & PEFY-P12NMAUE & High & 209 & 0.55 & 115.0 & 91.3 \\
\hline FC-1-2 & PEFY-P08NMAUE & High & 209 & 0.45 & 94.1 & 91.3 \\
\hline FC-1-3 & PEFY-P18NMAUE & High & 209 & 0.66 & 137.9 & 91.0 \\
\hline FC-1-4 & PEFY-P12NMAUE & Medium & 210 & 0.55 & 115.5 & 91.3 \\
\hline FC-1-5 & PEFY-P27NMAUE & High & 209 & 0.90 & 188.1 & 129.7 \\
\hline FC-1-7A & PEFY-P15NMAUE & High & 210 & 0.56 & 117.6 & 91.3 \\
\hline FC-1-7B & PEFY-P06NMAUE & High & 209 & 0.45 & 94.1 & 91.3 \\
\hline FC-1-8A & PEFY-P24NMAUE & High & 209 & 0.93 & 194.4 & 130.1 \\
\hline FC-1-9 & PEFY-P18NMAUE & High & 209 & 0.66 & 137.9 & 91.0 \\
\hline FC-2-4 & PEFY-12NMAUE & High & 209 & 0.55 & 115.0 & 91.3 \\
\hline FC-2-5 & PEFY-P15NMAUE & High & 210 & 0.56 & 177.6 & 91.3 \\
\hline FC-2-7 & PEFY-P12NMAUE & High & 210 & 0.45 & 94.5 & 91.3 \\
\hline FC-2-8 & PEFY-P27NMAUE & High & 209 & 2.00 & 418.0 & 129.7 \\
\hline FC-2-9 & PEFY-P15NMAUE & High & 209 & 0.56 & 117.0 & 91.3 \\
\hline FC-2-10 & PEFY-P08NMAUE & High & 210 & 0.45 & 94.5 & 91.3 \\
\hline FC-2-11 & PEFY-P15NMAUE & High & 210 & 0.56 & 117.6 & 91.3 \\
\hline FC-2-12 & PEFY-P36NMAUE & High & 210 & 1.39 & 291.9 & 262.2 \\
\hline FC-3-1 & PEFY-P15NMAUE & Low & 210 & 0.56 & 117.6 & 91.3 \\
\hline FC-3-2 & PEFY-P06NMAUE & Medium & 209 & 0.45 & 94.1 & 91.3 \\
\hline FC-3-4 & PEFY-P15NMAUE & Low & 209 & 0.56 & 117.0 & 91.3 \\
\hline FC-3-5 & PEFY-27NMAUE & High & 209 & 0.93 & 194.4 & 129.7 \\
\hline FC-3-7 & PEFY-P15NMAUE & Low & 209 & 0.56 & 117.0 & 91.3 \\
\hline FC-3-8 & PLFY-P18NBMU-E & High & 210 & 0.66 & 138.6 & 53.5 \\
\hline FC-3-9 & PEFY-27NMAUE & High & 209 & 0.93 & 194.4 & 129.7 \\
\hline FC-3-10 & PEFY-P06NMAUE & Low & 210 & 0.45 & 94.5 & 91.3 \\
\hline FC-4-1 & PEFY-12NMAUE & Medium & 210 & 0.55 & 115.5 & 91.3 \\
\hline FC-4-2 & PEFY-27NMAUE & High & 210 & 0.93 & 195.3 & 129.7 \\
\hline FC-4-3 & PEFY-27NMAUE & High & 209 & 0.93 & 194.4 & 129.7 \\
\hline FC-4-5 & PEFY-P06NMAUE & High & 210 & 0.45 & 94.5 & 91.3 \\
\hline FC-4-6 & PEFY-P15NMAUE & High & 209 & 0.56 & 117.0 & 91.3 \\
\hline FC-4-7 & PEFY-P12NMAUE & Low & 210 & 0.55 & 115.5 & 91.3 \\
\hline FC-4-8 & PEFY-P15NMAUE & High & 210 & 0.56 & 117.6 & 91.3 \\
\hline
\end{tabular}


APPENDIX I: SOLARWALL SOLAR COLLECTOR CERTIFICATE 


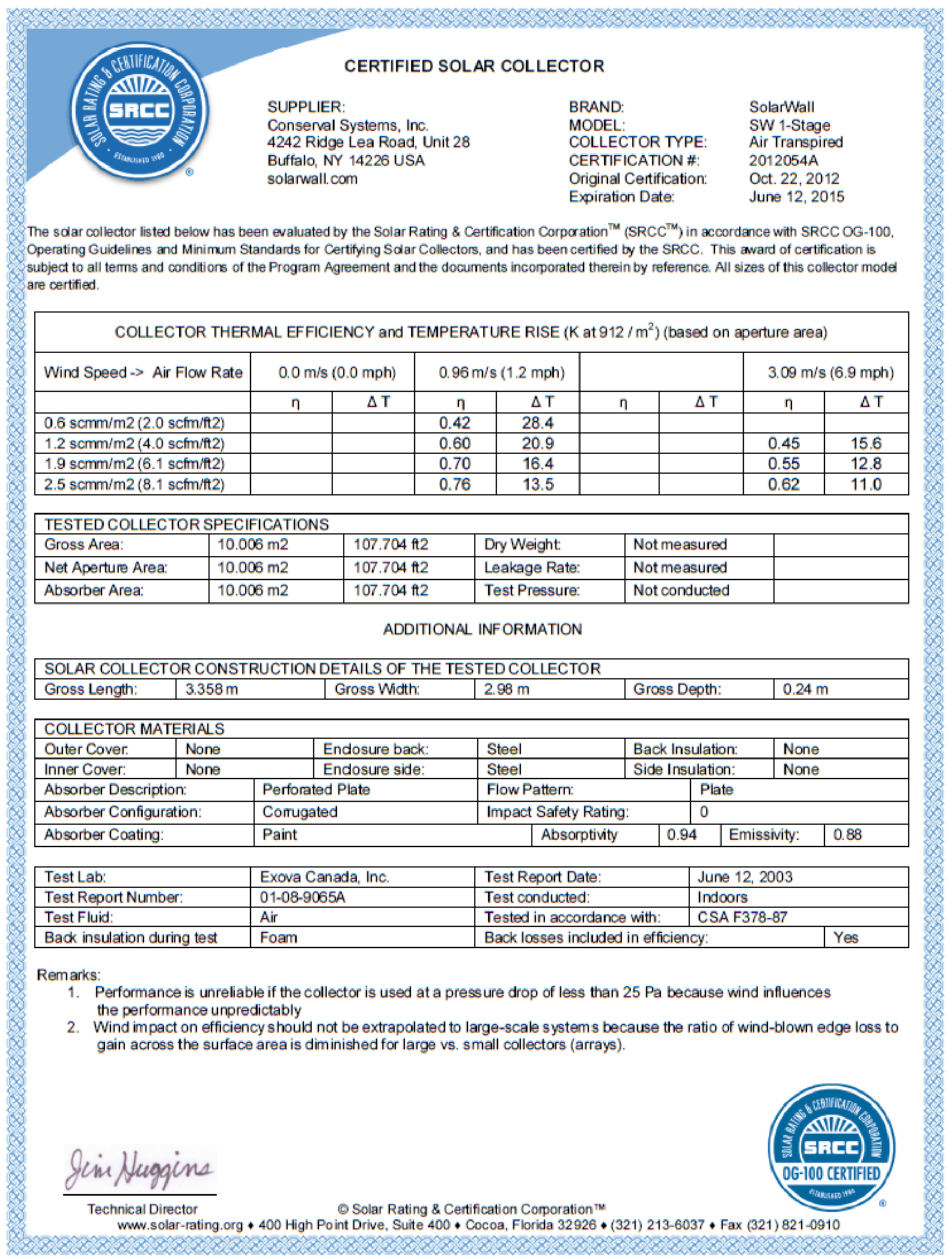

